Universidad Nacional de La Plata

Facultad de Ciencias Exactas

Departamento de Química

Estudio del uso de óxidos de metales de transición obtenidos a partir del reciclado de pilas como fases activas y soportes en la remoción de compuestos orgánicos volátiles y otras aplicaciones

Lic. María Victoria Gallegos 
A Horacio, por estar cerca desde que empecé la Facultad. Gracias por creer que podía, siempre.

A mis directores Jorge y Andrés, por las discusiones sobre este trabajo de Tesis y el apoyo a la hora de escribir.

A mis compañeras/os de grupo por los mates y la compañía, en especial a Cyn y Car por ser mis amigas.

Al Personal de apoyo del CINDECA, por estar a disposición para la realización y análisis de ensayos. Especialmente a Mariela y Pablo, por la alegría.

Al CONICET, por la financiación para la realización de esta Tesis.

A la Dra. Laura Damonte, por la predisposición y el apoyo en este tiempo de trabajo juntas. Gracias por la paciencia.

Al Prof. Guido Busca, Eli y Gaby por el apoyo y la paciencia durante mi estadía en la Universidad de Génova.

Al Dr. Alfredo Juan por abrirme las puertas de su grupo de Física en la Universidad Nacional del Sur. A la Dra. Romina Luna, Romi para mí, por la paciencia y la capacidad de hacer fácil lo difícil. Además de herramientas de Física Teórica, ella me enseñó acerca de la vida, gracias por los mates, las risas y las lágrimas compartidas.

A mis compañeras/os de la Catedra de Química Inorgánica. 
A mis amigas/os, que están, me acompañan y me cuidan. Gracias infinitas y eternas por darme la mano cuando los días fueron oscuros, porque SIEMPRE estuvieron para tomar un mate, una cerveza, secar una lágrima y festejar un logro.

A Lu, que está presente todos los días a pesar de la distancia y tiene la fuerza del viento bahiense.

A las/os amigos que me dio la militancia, el amor a la Patria y a Perón, con los que comparto el sueño de una Patria Justa, Libre y Soberana.

A Belén por regalarme a mi ahijado Simón, que llegó para alegrarme los días.

A mi compañero Santi, porque juntos vamos construyendo desde el amor.

A mi tía, por estar cerca desde que llegue a La Plata.

El agradecimiento más especial es a mi Mamá, mi Papá y mi hermano. Por estar en cada paso que doy, por perdonar los errores y festejar los aciertos. Por ser así, simples y grandes. Por ellos estoy acá, porque su fuerza empuja. 


\section{Estructura de la Tesis}

Este trabajo de tesis estará dividido en seis capítulos:

En el Capítulo 1 se introduce el problema que presentan las pilas agotadas, así como también los distintos métodos de tratamiento.

En el Capítulo 2 se realiza una reseña bibliográfica acerca de la estructura, preparación, caracterización y diferentes usos de los óxidos de manganeso.

En el Capítulo 3 se realiza una reseña bibliográfica acerca de la estructura, preparación, caracterización y diferentes usos de los óxidos de zinc.

En el Capítulo 4 se describe el procedimiento experimental usado tanto para el tratamiento de pilas agotadas como para la síntesis de los sólidos estudiados. En este capítulo también se describen las técnicas de caracterización fisicoquímicas usadas.

En el Capítulo 5 se presentan los resultados de los ensayos de lixiviación realizados y de las caracterizaciones fisicoquímicas. En este capítulo, en la sección 5.3 se presentan los resultados de la actividad catalítica en la degradación de COVs, como moléculas test se usaron etanol y tolueno. Se describe brevemente la importancia de la eliminación de estos compuestos daño ambiental que generan.

El Capítulo 6 está dedicado a una breve introducción al estudio teórico del sistema $\mathrm{ZnO}$ y Mn-O, realizado en colaboración con la UNS.

Por último se presenta un anexo presentando resultados de otras aplicaciones tecnológicas de los sólidos obtenidos.

En la sección final se encuentran las conclusiones generales a las cuales se arribaron luego de los estudios realizados, además se muestran las perspectivas futuras y las publicaciones en revistas y congresos asociadas a este trabajo de Tesis. 


\section{Objetivos}

Las industrias generan gran cantidad de residuos de los cuales muchos son recuperables. Un problema que se plantea es que las técnicas para aprovechar los residuos y hacerlos útiles en algunas ocasiones no son rentables. De todas formas está aumentando la proporción de residuos que se valorizan para usos posteriores.

Esta Tesis plantea como objetivo general el desarrollo de tecnologías a partir de reciclado de residuos, tales como las pilas alcalinas y de $\mathrm{Zn} / \mathrm{C}$ agotadas, con la finalidad primera de disminuir los residuos y segundo generar "nuevos materiales" para procesos de eliminación de contaminantes industriales.

Los objetivos específicos de esta Tesis son obtener y caracterizar óxidos de manganeso y de zinc, a partir del lixiviado de pilas alcalinas y de $\mathrm{Zn} / \mathrm{C}$, para ser utilizados como catalizadores para en diferentes reacciones, tales como oxidación de compuestos orgánicos volátiles o síntesis orgánica. Por otro lado, los óxidos de zinc debido a sus propiedades ópticas y eléctricas podrían ser usados en fotocatálisis en fase acuosa. 


\section{ÍNDICE}

Capítulo 1. El Problema de las Pilas ……………................................................

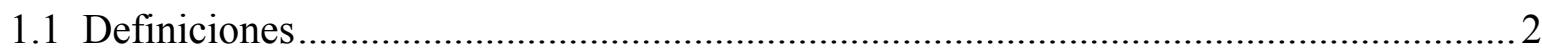

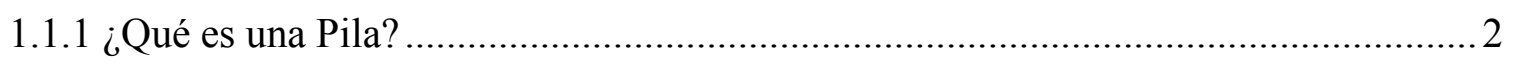

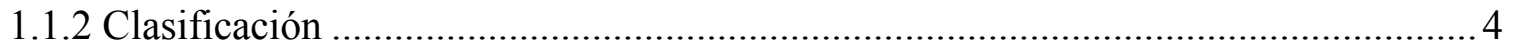

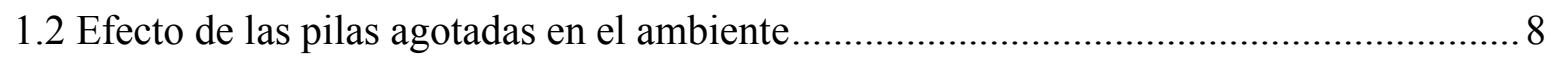

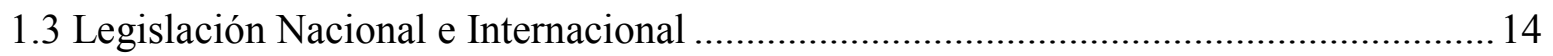

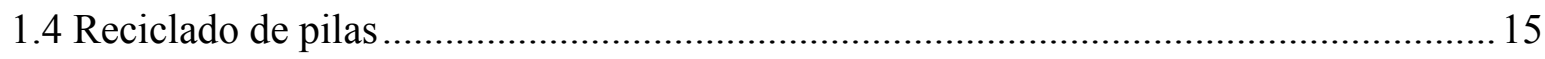

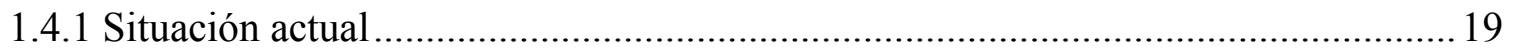

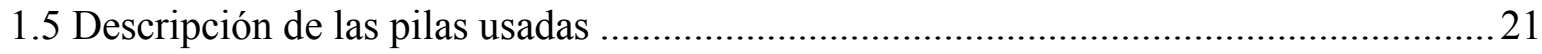

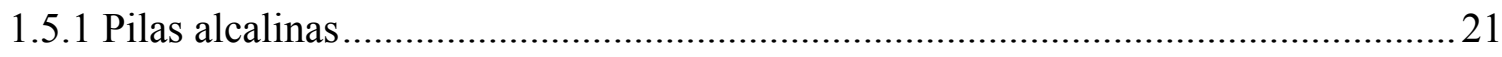

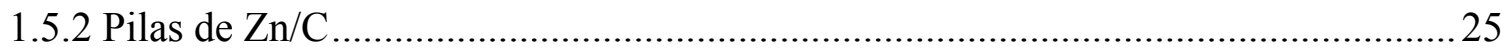

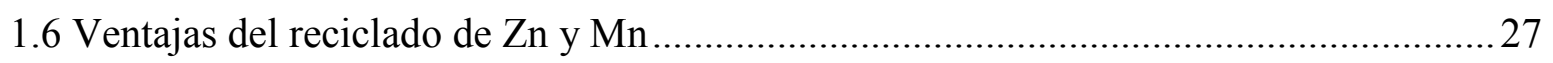

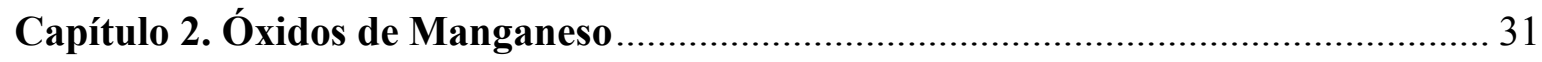

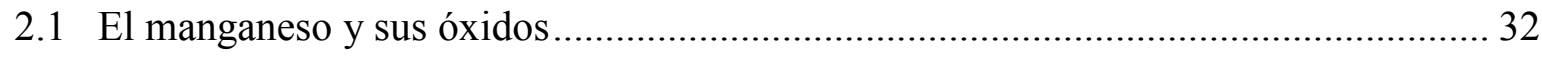

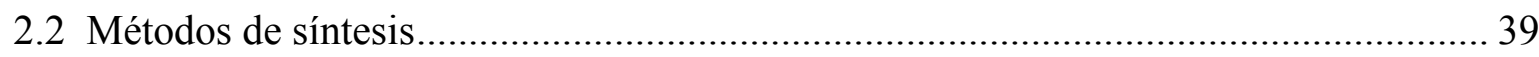

2.2.1 Precipitación, intercambio iónico y rutas hidrotérmicas ........................................... 39

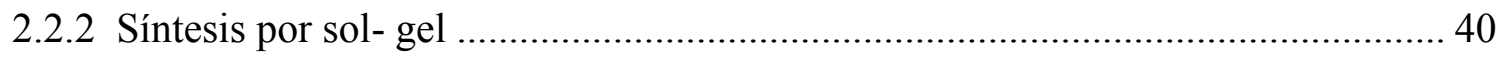

2.2.3 Reacción en estado sólido a alta temperatura ....................................................... 40

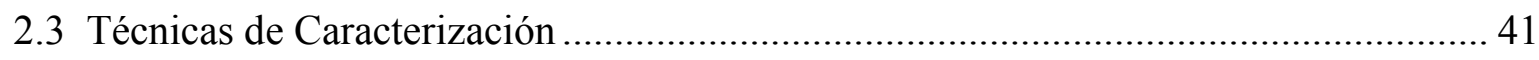

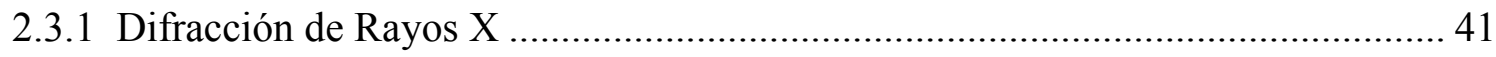

2.3.2 Espectroscopía Fotoelectrónica de Rayos X (XPS) …………………………..... 42

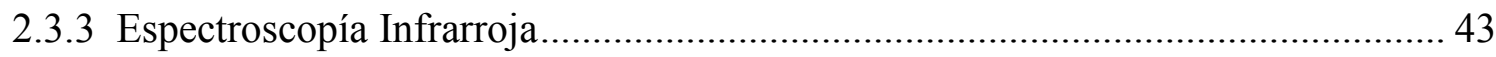




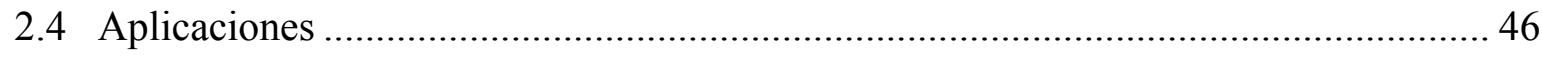

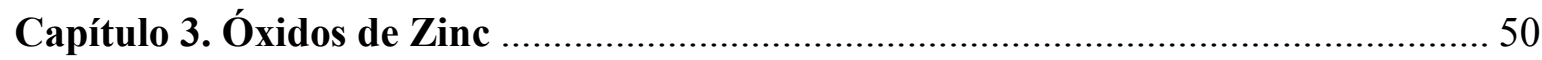

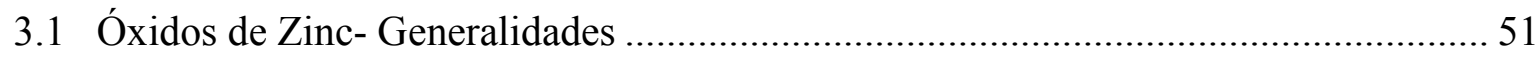

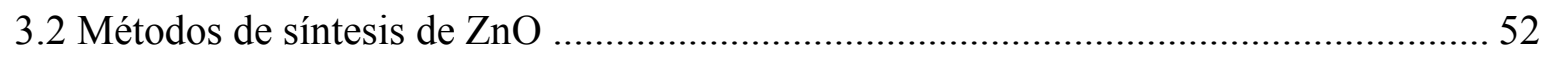

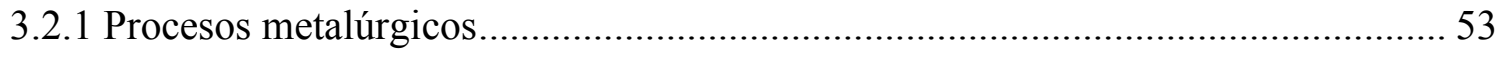

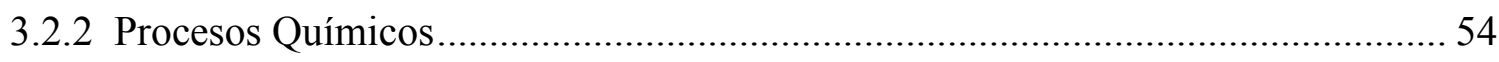

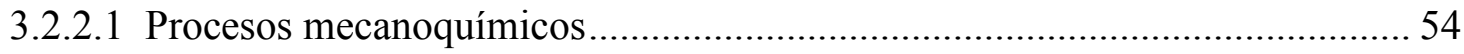

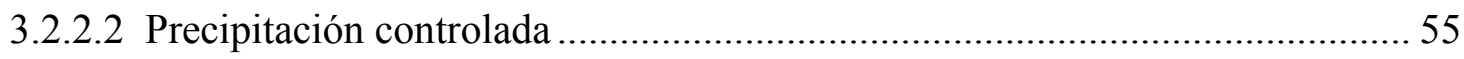

3.2.2.3 Métodos sol- gel ...................................................................................... 57

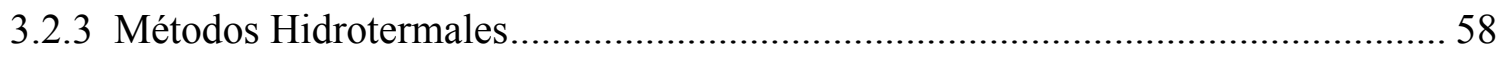

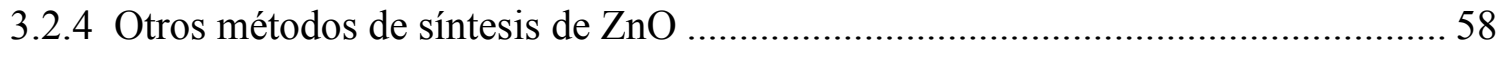

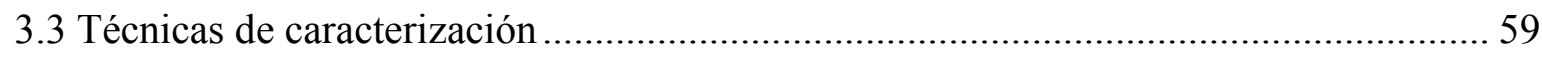

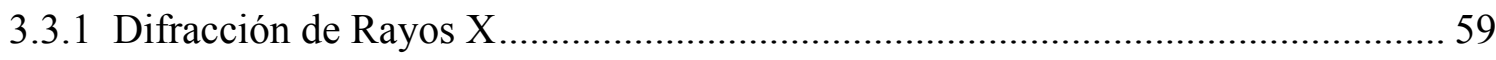

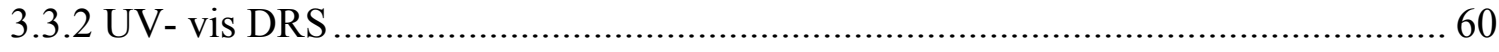

3.3.3 Espectroscopia de aniquilación de positrones (PALS) ………………………….... 61

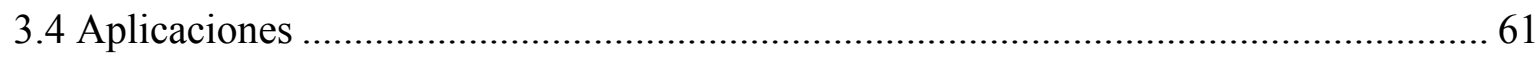

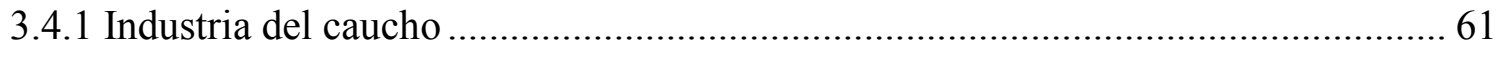

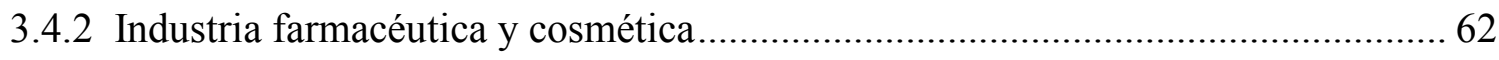

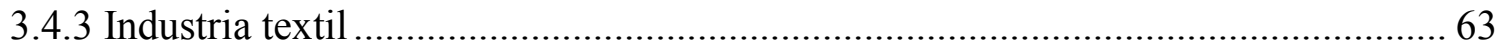

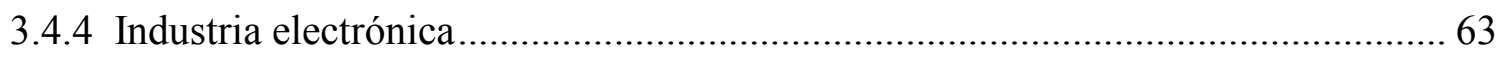

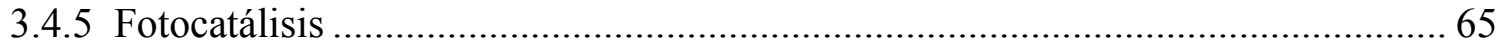

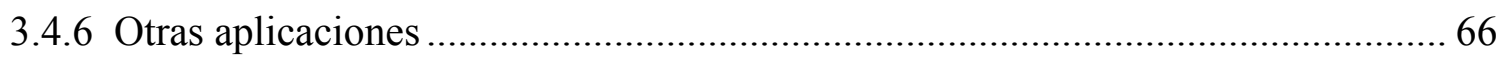

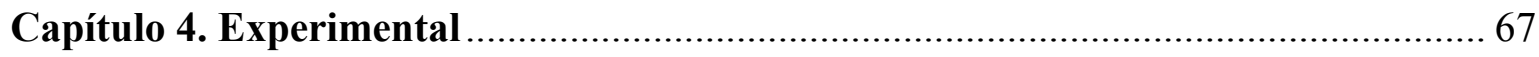




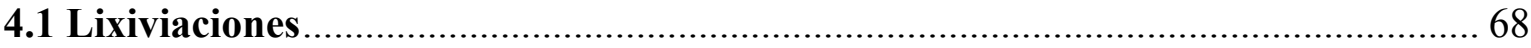

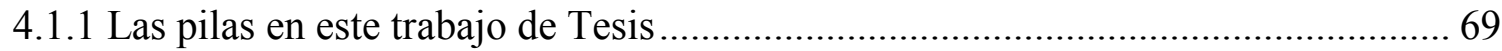

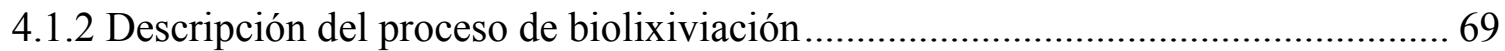

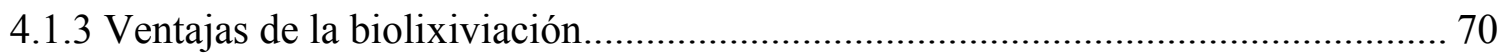

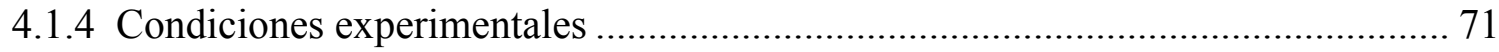

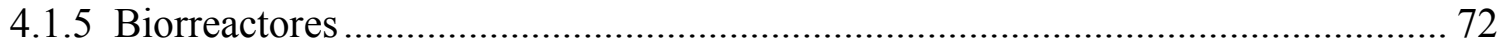

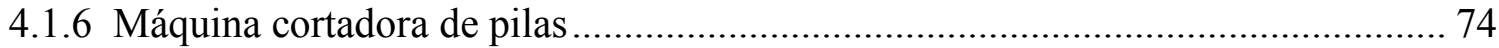

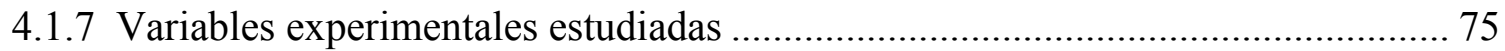

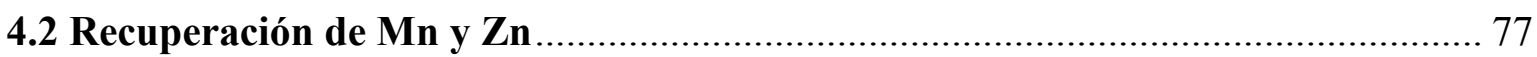

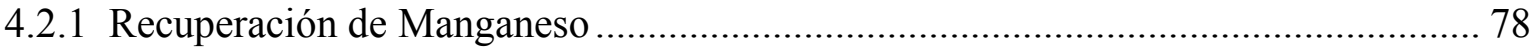

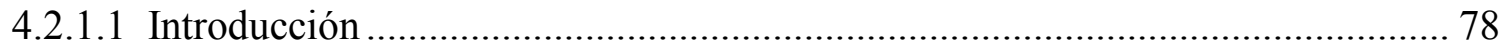

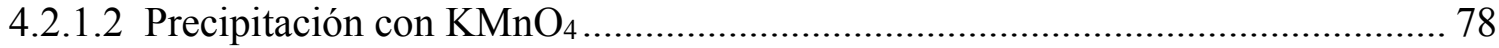

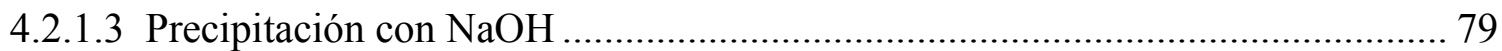

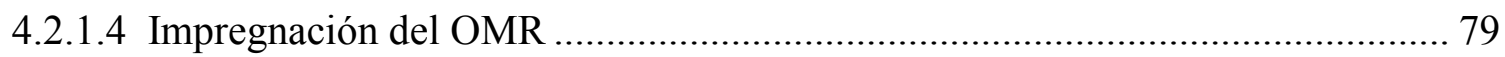

4.2.1.5 Catalizadores soportados sobre estructuras monolíticas .................................. 81

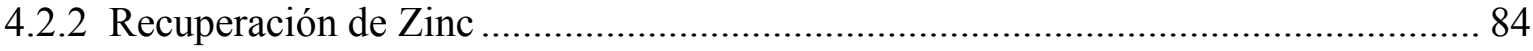

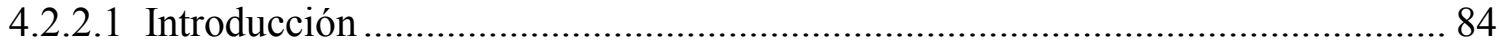

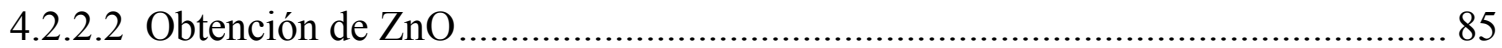

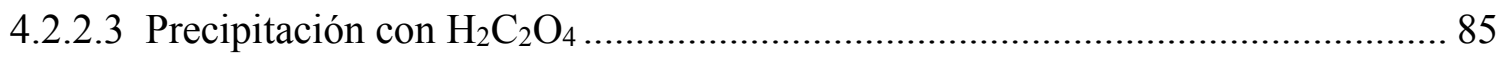

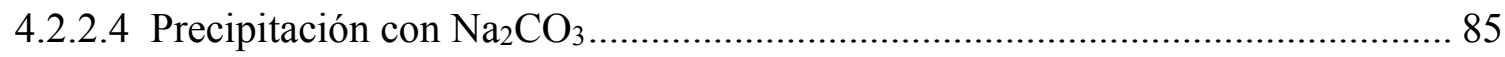

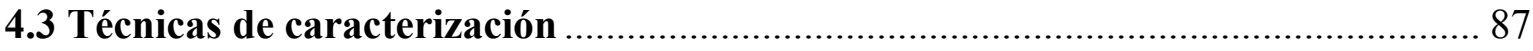

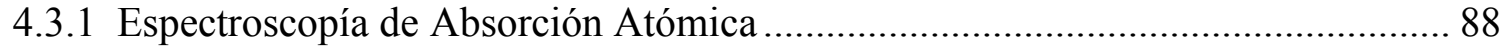

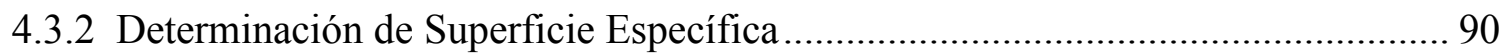

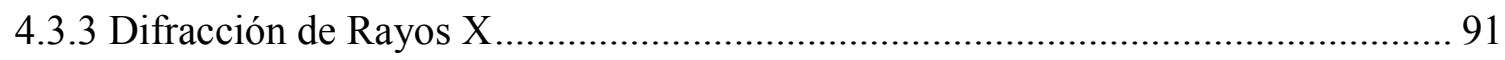

4.3.4 Espectroscopía Infrarroja por Transformada de Fourier..................................... 93 
4.3.5 Espectroscopía fotoelectrónica de rayos X …..................................................... 95

4.3.6 Espectroscopía de absorción de rayos X (XANES y EXAFS) .............................. 97

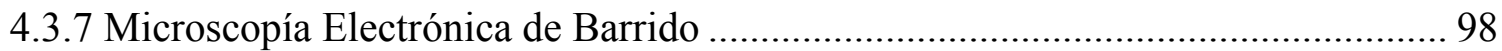

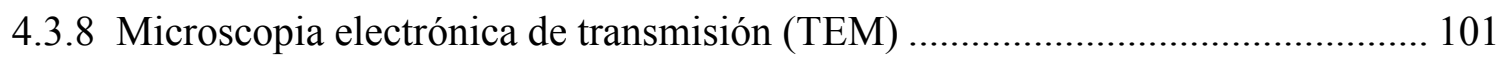

4.3.9 Métodos de Temperatura Programada .................................................................... 104

4.3.10 Espectroscopía de Reflectancia Difusa ............................................................ 104

4.3.11 Espectroscopía UV Visible con Reflectancia Difusa ...................................... 106

4.3.12 Espectroscopía de Aniquilación de Positrones (PALS) ..................................... 107

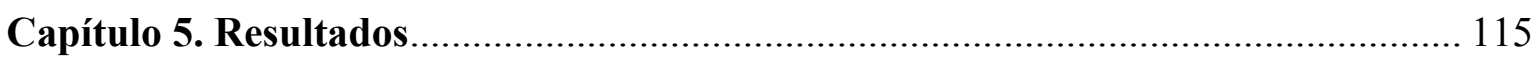

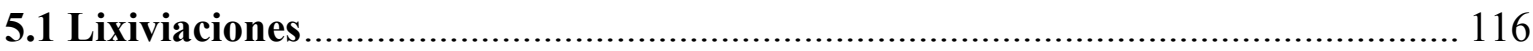

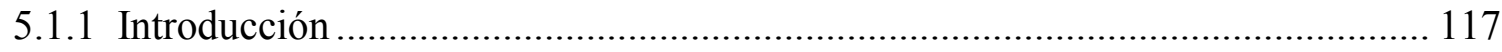

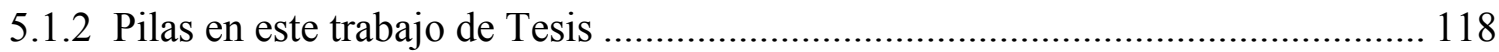

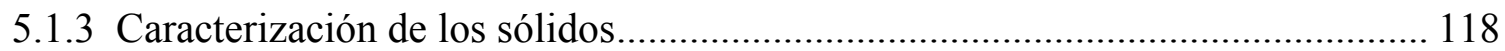

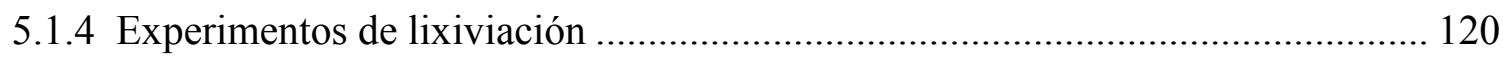

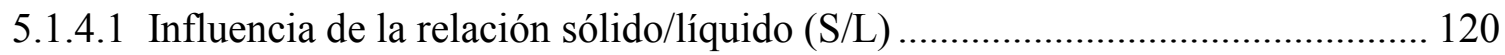

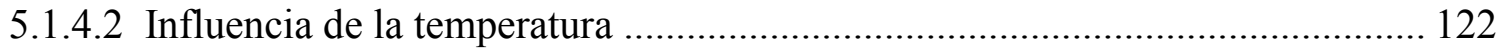

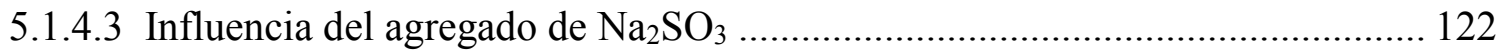

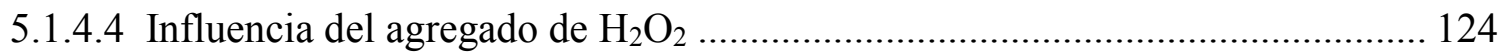

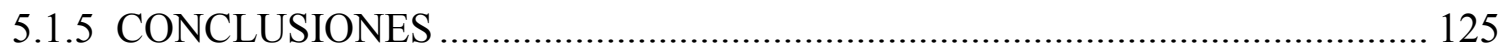

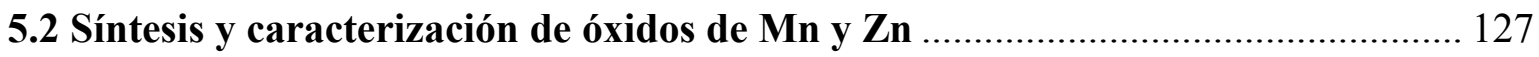

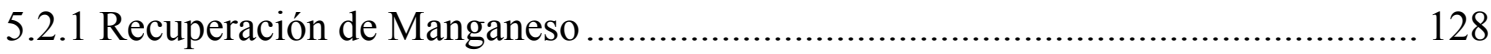

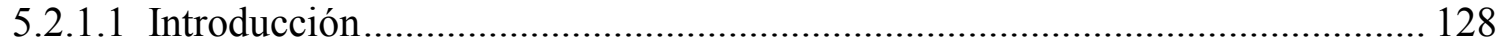

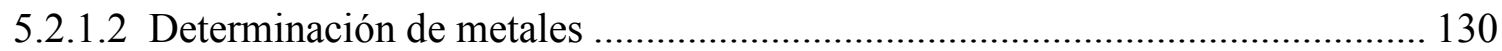

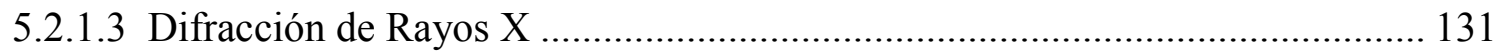

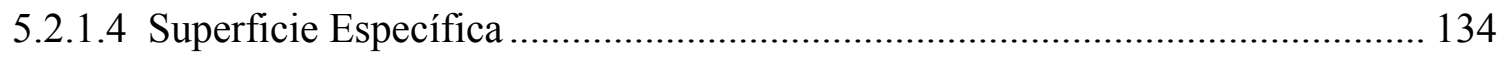


5.2.1.5 Microscopia electrónica de barrido (SEM) y de transmisión (TEM)............... 135

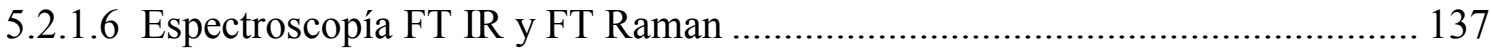

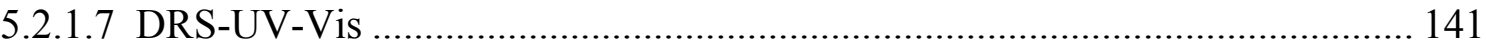

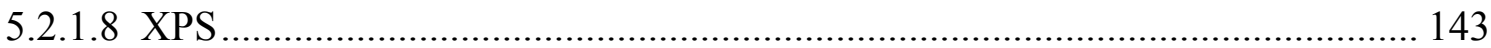

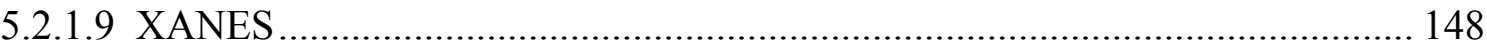

5.2.1.10 Reducción Térmica Programada ................................................................. 156

5.2.1.11 Resumen de las caracterizaciones de óxidos de manganeso recuperados ...... 159

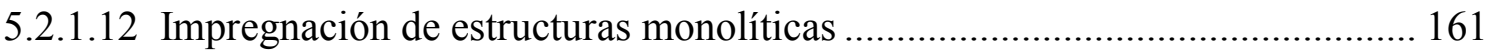

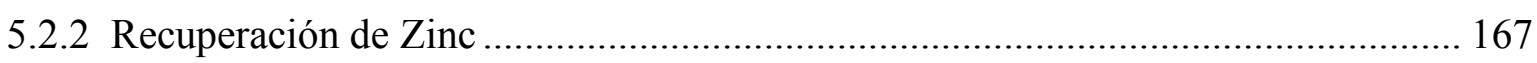

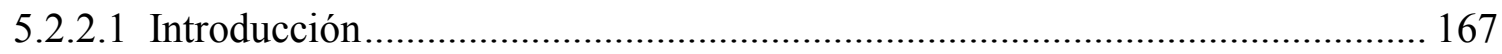

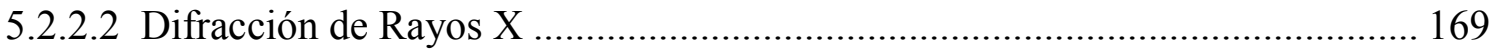

5.2.2.3 Espectroscopía Microelectronica de Barrido (SEM) y de Transmisión (TEM)172

5.2.2.4 Espectroscopía UV Visible con Reflectancia Difusa .................................... 176

5.2.2.5 Espectrocopía de Aniquilación de Positrones (PALS) ................................... 180

5.2.2.7. Resumen de las caracterizaciones de óxidos de zinc recuperados ................... 185

5.3. Uso de los óxidos recuperados como catalizadores. Estudio en reacción de

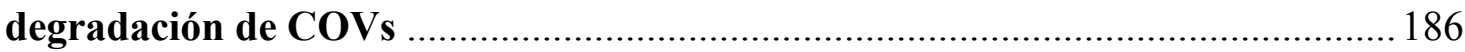

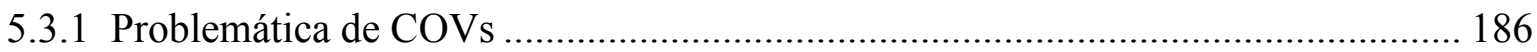

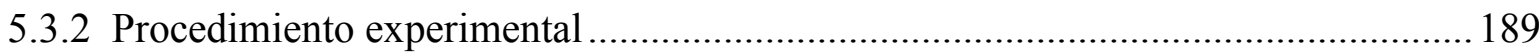

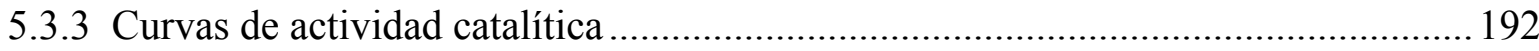

5.3.4 Estudio de especies adsorbidas por Espectroscopía Infrarroja de Transmisión ........ 193

5.3.5 Resultados de la oxidación catalítica de COVs ................................................... 194

5.3.6 Estudio FTIR In Situ de la combustión de Etanol ................................................201

5.3.7 Estudio FTIR In Situ de la combustión Tolueno ................................................211

5.3.8 Oxidación catalítica de COVs sobre estructuras monolíticas................................216 


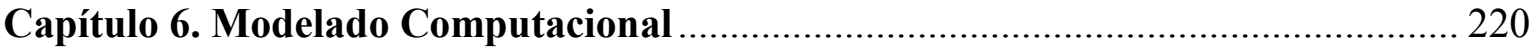

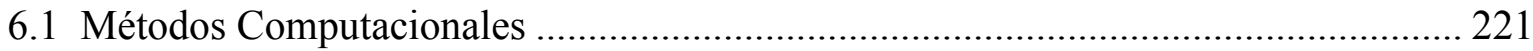

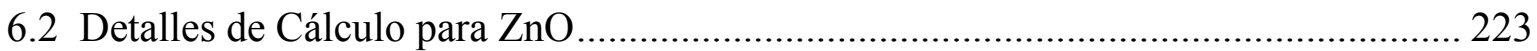

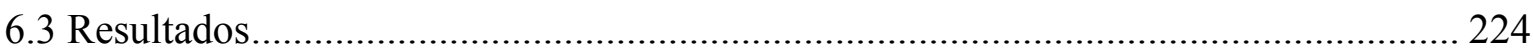

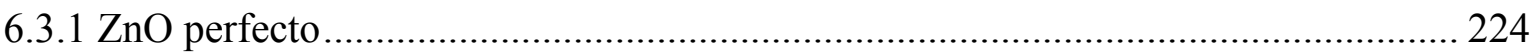

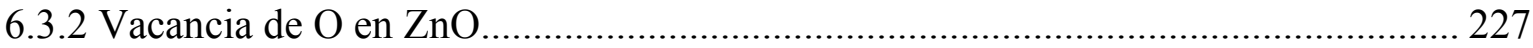

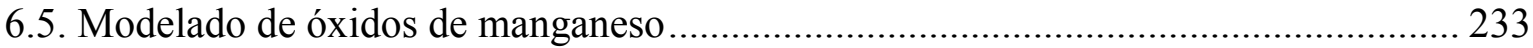

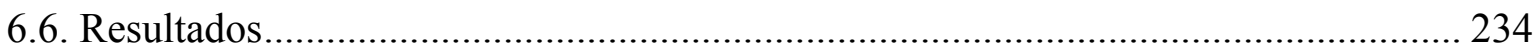

Anexo: Otras aplicaciones de los sólidos recuperados ................................................ 242

A.1 Uso de óxidos de Mn-Zn en la síntesis selectiva de 1,4-dihidropiridina o 2-

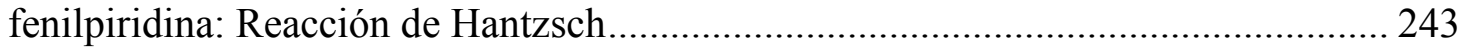

A.2 OMR como adsorbente de metales pesados ......................................................... 248

A.3 Uso de $\mathrm{ZnO}$ recuperados como catalizadores en la glicólisis de PET ........................ 259

A.4 Estudio de la actividad fotocatalítica de $\mathrm{ZnO}$ recuperados. Degradación de azul de

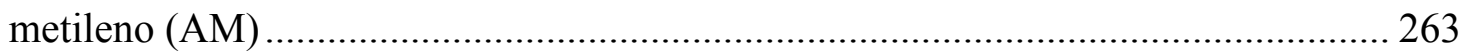

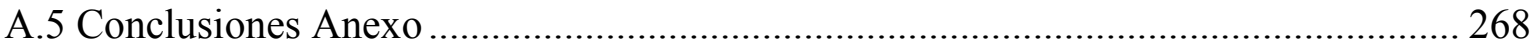

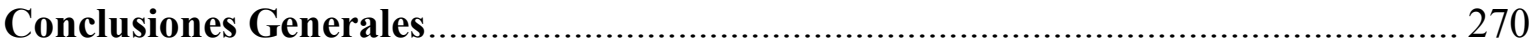

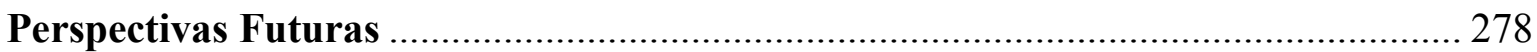

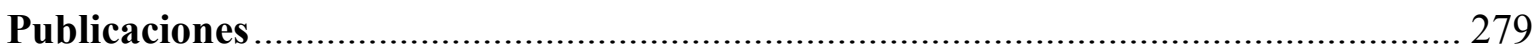

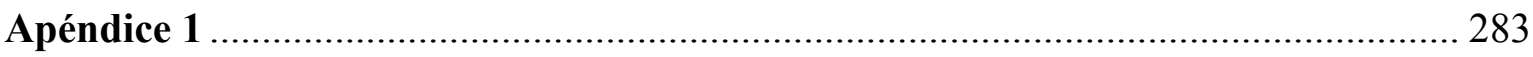

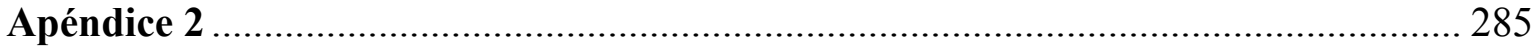




\section{Capítulo 1 \\ El problema de las pilas}




\subsection{Definiciones}

\subsection{1 ¿Qué es una Pila?}

Una pila es un dispositivo capaz de generar electricidad a partir de una reacción química del tipo rédox en forma espontánea. La primera pila fue desarrollada por Volta en el año 1800 y estaba formada por recipientes con una solución salina conectados a través de arcos metálicos, uso pequeños discos redondos de cobre y zinc y otros de paño o cartón en agua acidulada. De esta manera se formaba una serie: cobre, cinc, paño, cobre cinc, paño, etc.; todos ellos apilados formando una columna. Al unir los extremos de la "pila" mediante un hilo conductor, al cerrarse el circuito se obtenía una corriente eléctrica. Desde esa época se han ido desarrollando nuevos tipos de pilas bajo el concepto de ser un dispositivos de portátil usado como fuente de energía eléctrica directa a un voltaje constante.

Las pilas constan de tres componentes principales:

1. El ánodo o electrodo negativo que cede electrones al circuito externo y se oxida durante la reacción electroquímica.

2. El cátodo o electrodo positivo que acepta electrones del circuito externo y se reduce durante la reacción electroquímica.

3. El electrolito, conductor iónico, que proporciona el medio para la transferencia de carga en forma de iones dentro de la celda, entre el ánodo y el cátodo. El electrolito es típicamente un líquido, tal como agua u otros disolventes, con sales acidas o básicas disueltas. Algunas baterías utilizan electrolitos sólidos (drycells o pilas secas), que son conductores iónicos en la temperatura de funcionamiento de la celda. El electrolito debe tener buena conductividad iónica pero no ser electrónicamente conductor, ya que esto podría causar cortocircuitos internos. La mayoría de los electrolitos son soluciones acuosas, pero hay excepciones 
importantes como, por ejemplo, en pilas térmicas y de ánodo de litio, donde se utilizan sales fundidas y otros electrolitos no acuosos para evitar la reacción del ánodo con el electrolito. Físicamente los electrodos de ánodo y cátodo están electrónicamente aislados en la celda para impedir un cortocircuito interno, pero están rodeados por el electrolito.

El material separador aísla los electrodos de ánodo y cátodo mecánicamente, y es permeable al electrolito para mantener la conductividad iónica deseada. También se añade a los electrodos estructuras de rejilla o materiales eléctricamente conductores para reducir la resistencia interna.

Las pilas están selladas, según el tipo, de maneras variadas para prevenir fugas y/o secarse. Algunas están provistas de dispositivos de ventilación u otros medios que permiten a los gases acumulados escapar. Finalmente se colocan en recipientes o carcasas adecuadas para la conexión de terminales y etiquetado, completando la fabricación de la pila y batería. ${ }^{1}$

\subsubsection{Clasificación}

Las pilas pueden clasificarse por su uso o por composición química o por su uso.

La clasificación por aplicaciones surge a partir del desarrollo tecnológico y su versatilidad, lo que llevó a la fabricación de una mayor variedad de las mismas. Se dividen en tres grandes grupos, portátiles, industrial- gubernamental, y vehicular.

Portátiles: electrodomésticos y artículos para el hogar, equipos de audio y comunicación, cámaras y equipo fotográfico, computadoras y calculadoras, audífonos, implantes, equipamiento meteorológico, alarmas, teléfonos, herramientas, juguetes y relojes, entre otros.

${ }^{1}$ T. Reddy, D. Linden, eds., 2011. Linden's Handbook of Batteries. Fourth ed. New York: Mc Graw Hill. 
Industrial - gubernamental: almacenamiento de energía eléctrica, nivelación de carga, municiones y proyectiles, ayudas de navegación, equipo oceanográfico, señalización ferroviaria, los satélites y naves espaciales, vigilancia y detección, entre otros.

Vehicular: baterías de aviones, los vehículos eléctricos, incluyendo los carros de golf, bicicletas, el arranque del motor, equipamiento industrial y comercial, submarinos y propulsión submarina, entre otros. ${ }^{2}$

Desde el punto de vista de su composición química, se pueden clasificar en dos grupos: primarias y secundarias.

Pilas primarias: son aquellas pilas en las que su fuente de energía es una reacción química irreversible. Es decir, sólo pueden utilizarse hasta su descarga completa y luego deben ser descartadas.

Pilas secundarias: Son aquellas pilas que utilizan como fuente de energía una reacción química reversible. Por lo tanto, pueden recargarse y tienen varios ciclos de uso, aunque su vida útil termina luego de varias recargas dependiendo del número de cargas, del tipo de pila y de la tecnología utilizada para su construcción.,

Dentro de estos dos grupos, existe una gran diversidad de pilas, que varían en su composición, geometría y tamaño. Cada una con materiales particulares que determinan su capacidad, su voltaje de salida y su vida útil. Sin embargo, no todos los tipos de baterías tienen un uso extendido. En las Tablas 1.1 y 1.2 se describen los tipos de pilas más comunes

${ }^{2}$ D. Linden, T. Reddy, eds., 2002. Handbook of batteries. Third ed. New York: McGraw-Hill.

3 Ch. Mortimer. Química, Grupo Editorial Iberoamérica, S.A., México, 1983.

${ }^{4}$ R. Chang, W. College. Química, Séptima Edición, Mc. Graw-Gill, México, 2002. 
del mercado, sus componentes y características; tanto de pilas primarias como recargables, respectivamente. 
Tabla 1.1. Tipos de pilas primarias, sus características y componentes.

\begin{tabular}{|c|c|c|c|c|}
\hline Pilas & Características & Ánodo & Cátodo & Electrolito \\
\hline $\begin{array}{l}\text { Zinc/Carbono }(\mathrm{Zn} / \mathrm{C}) \\
\text { o tipo Le Clanché } \\
\text { o pilas secas }\end{array}$ & $\begin{array}{l}\text { Para todo tipo de equipamiento eléctrico y electrónico } \\
\text { sencillo y de bajo consumo. Denominadas "pilas comunes". }\end{array}$ & $\mathrm{Zn}$ & $\mathrm{MnO}_{2}$ & $\mathrm{NH}_{4} \mathrm{Cl}$ y $\mathrm{ZnCl}_{2}$ \\
\hline $\begin{array}{l}\left(\mathrm{Zn} / \mathrm{MnO}_{2}\right) \\
\text { o Alcalinas }\end{array}$ & $\begin{array}{l}\text { Para equipamiento eléctrico y electrónico sencillo y de bajo } \\
\text { consumo, con vida útil hasta } 10 \text { veces mayor a las } \\
\text { "comunes". }\end{array}$ & $\mathrm{Zn}$ & $\mathrm{MnO}_{2}$ & $\mathrm{KOH}$ \\
\hline Óxido Mercúrico & $\begin{array}{l}\text { Uso en audífonos y equipamiento médico. Usualmente de } \\
\text { tipo botón. Contienen alrededor de } 30 \% \text { de mercurio. }\end{array}$ & $\mathrm{Zn}$ & $\mathrm{HgO}$ & $\mathrm{NaOH}$ \\
\hline Zinc/Aire & $\begin{array}{l}\text { Uso en audífonos y equipamiento médico. Presentan } \\
\text { agujeros diminutos en su superficie. Alta capacidad. } \\
\text { Contienen más del } 1 \% \text { de mercurio. }\end{array}$ & $\mathrm{Zn}$ & $\mathrm{O}_{2}$ (aire) & $\mathrm{KOH}$ \\
\hline Óxido de Plata & $\begin{array}{l}\text { Uso en calculadoras, relojes y cámaras fotográficas. } \\
\text { Usualmente de tipo botón pequeñas, pueden contener } \\
\text { alrededor de } 1 \% \text { de mercurio. }\end{array}$ & $\mathrm{Zn}$ & $\mathrm{Ag}_{2} \mathrm{O}$ o $\mathrm{AgO}$ & $\mathrm{KOH}$ o $\mathrm{NaOH}$ \\
\hline Litio & $\begin{array}{l}\text { Uso desde relojes hasta aplicaciones militares e industrias. } \\
\text { Producen tres veces más energía que las alcalinas, } \\
\text { considerando tamaños equivalentes, y posee mayor voltaje } \\
\text { inicial ( } 3 \text { voltios). }\end{array}$ & $\mathrm{Li}$ & $\mathrm{MnO}_{2}$ & $\begin{array}{l}\text { Solvente orgánico, } \\
\text { sales de litio. }\end{array}$ \\
\hline
\end{tabular}


Tabla 1.2.Tipos de pilas Secundarias, sus características y componentes.

\begin{tabular}{|c|c|c|c|c|}
\hline Pilas & Características & Ánodo & Cátodo & Electrolito \\
\hline $\mathrm{Ni} / \mathrm{Cd}$ & $\begin{array}{l}\text { Para todo tipo de equipamiento eléctrico y electrónico } \\
\text { sencillo y de bajo consumo, teléfonos celulares, } \\
\text { computadoras portátiles. Pueden ser recargadas hasta } 1000 \\
\text { veces y alcanzan a durar decenas de años. }\end{array}$ & $\mathrm{Cd}$ & $\mathrm{NiO}(\mathrm{OH})$ & $\mathrm{KOH}$ \\
\hline $\begin{array}{l}\text { Níquel/Hidruro metálico } \\
(\mathrm{Ni} / \mathrm{HM})\end{array}$ & $\begin{array}{l}\text { Mismo uso que Ni/Cd y se sistema similar donde el } \mathrm{Cd} \text { ha } \\
\text { sido reemplazado por una aleación metálica capaz de } \\
\text { almacenar hidrógeno. La densidad de energía producida es } \\
\text { el doble de la producida por } \mathrm{Ni} / \mathrm{Cd} \text {, a voltajes operativos } \\
\text { similares. }\end{array}$ & MH & $\mathrm{NiO}(\mathrm{OH})$ & $\mathrm{KOH}$ \\
\hline Ion- $\mathrm{Li}$ & $\begin{array}{l}\text { Utilizada para telefonía celular, computadoras, cámaras } \\
\text { fotográficas y de video. }\end{array}$ & $\mathrm{C}$ & $\mathrm{LiMO}_{2}$ & $\begin{array}{l}\text { Solvente orgánico, } \\
\text { sales de litio. }\end{array}$ \\
\hline Plomo & Tienen uso automotriz, industrial y doméstico. & $\mathrm{Pb}$ & $\mathrm{PbO}_{2}$ & $\mathrm{H}_{2} \mathrm{SO}_{4}$ \\
\hline
\end{tabular}




\subsection{Efecto de las pilas agotadas en el ambiente}

Las pilas pueden sufrir la corrosión de sus carcazas, las cuales pueden ser afectadas internamente por sus componentes y externamente por la acción climática y/o por el proceso de descomposición de los residuos sólidos urbanos (RSU), en caso que terminen en un vertedero. Cuando se produce un derrame del electrolito contenido en las pilas, éste puede acarrear con él, los metales pesados que conforman la pila. Estos metales pueden lixiviar por los suelos y fluir por cursos de agua superficial y acuíferos, contaminando el ambiente en general. Estas situaciones, tienen mayor probabilidad de ocurrir, y con mayor intensidad, cuanto menos se gestione el destino y tratamiento de estos residuos.

En la Tabla 1.3 se muestran las posibles vías de ingreso y daños al ambiente de los metales presentes en pilas y baterías, mientras que en la Tabla 1.4 se listan las posibles vías de exposición y daños a la salud de los metales presentes en pilas y baterías.

\subsection{Legislación Nacional e Internacional}

Varios gobiernos de la Unión Europea han tratado el problema de las pilas a nivel legal: la Directiva 2006/66/CE prohíbe la comercialización de pilas que contienen algunas sustancias peligrosas, define medidas para establecer esquemas encaminados a un alto nivel de recolección y reciclado, y fija objetivos para estas actividades. Los productores de pilas y acumuladores y los productores de otros productos que los contengan, se les da la 
responsabilidad de la gestión de los residuos de pilas y acumuladores que se comercializan. $^{5}$

En las Argentina las pilas y baterías son enviadas junto con los demás residuos domiciliarios a rellenos sanitarios. Sin embargo, poseen características peligrosas, están incluidas dentro de los denominados residuos peligrosos universales (son aquellos que en virtud de presentar alguna característica de peligrosidad es conveniente su recolección diferenciada de los residuos sólidos urbanos). En este sentido, la Secretaría de Ambiente y Desarrollo Sustentable de la Nación, es Autoridad de Aplicación de las siguientes Leyes y su normativa complementaria:

Ley No 24.051 “Ley de Residuos Peligrosos”, que regula la generación, manipulación, transporte, tratamiento y disposición de residuos peligrosos.

${ }^{5}$ European Comission. [Online] Available at: http://ec.europa.eu/environment/waste/batteries/ 
Tabla 1.3. Metales presentes en baterías, las vías de ingreso y los posibles daños al ambiente [Modificado de Subsecretaria de Control y Fiscalización Ambiental y Prevención de la Contaminación, 2011].

\begin{tabular}{|c|c|c|}
\hline Metal & Daño al ambiente & Vías de ingreso \\
\hline $\mathrm{Hg}$ & $\begin{array}{l}\text { El metilmercurio se acumula en los tejidos de peces (los peces más } \\
\text { grandes y de mayor edad tienden a tener niveles más altos de mercurio). }\end{array}$ & $\begin{array}{l}\text { El mercurio inorgánico (mercurio metálico y compuestos de mercurio } \\
\text { inorgánicos) pasa al aire durante la extracción de depósitos minerales, al } \\
\text { quemar carbón y basura y de plantas industriales. El mercurio pasa al } \\
\text { agua o a la tierra de depósitos naturales, de basurales y de actividad } \\
\text { volcánica. El metilmercurio puede ser formado en el agua y el suelo por } \\
\text { bacterias. }\end{array}$ \\
\hline $\mathrm{Cd}$ & $\begin{array}{l}\text { Las plantas, los peces y otros animales incorporan cadmio del ambiente. } \\
\text { Se bioacumula en todos los niveles de la cadena alimentaria. }\end{array}$ & $\begin{array}{l}\text { Entra al aire de fuentes como la minería, industria, y al quemar carbón y } \\
\text { desechos domésticos. Las partículas pueden viajar largas distancias } \\
\text { antes de depositarse en el suelo o en el agua. El cadmio entra al agua y } \\
\text { al suelo de vertederos y de derrames o escapes en sitios de desechos } \\
\text { peligrosos. }\end{array}$ \\
\hline $\mathrm{Ni}$ & $\begin{array}{l}\text { El níquel no parece acumularse en peces o en otros animales usados } \\
\text { como alimentos. }\end{array}$ & $\begin{array}{l}\text { Es liberado a la atmósfera por industrias que manufacturan o usan } \\
\text { níquel, por plantas que queman petróleo o carbón y por incineradoras de } \\
\text { basura. Se adhiere a partículas de polvo que se depositan en el suelo. El } \\
\text { níquel liberado en desagües industriales termina en el suelo o en el } \\
\text { sedimento, donde se adhiere fuertemente a partículas que contienen } \\
\text { hierro o manganeso. }\end{array}$ \\
\hline
\end{tabular}


Tabla 1.3. (Continuación) Metales presentes en baterías, las vías de ingreso y los posibles daños al ambiente [Modificado de Subsecretaria de Control y Fiscalización Ambiental y Prevención de la Contaminación, 2011].

\section{Metal \\ Daño al ambiente}

$\mathrm{Li}$

$\mathrm{Pb}$

En grandes concentraciones puede afectar flora $y$ fauna de los ecosistemas

$\mathrm{Zn}$

Es poco probable que el zinc se bioconcentre significativamente.

$\mathrm{Mn}$

Tiene potencial de bioconcentrarse, sobre todo en organismos inferiores

de la cadena alimentaria.
Vías de ingreso

El litio puede lixiviar fácilmente a los mantos de acuíferos. No es volátil por lo que puede regresar a la superficie a través de deposición húmeda o seca.

El plomo no se degrada, pero los compuestos de plomo son transformados por la luz natural, el aire y el agua. Cuando se libera al aire, puede movilizarse largas distancias antes de depositarse en el suelo. Generalmente se adhiere a partículas del suelo.

Zinc en la atmósfera es transportado por deposición seca y húmeda. Se adsorbe en partículas en suspensión en el agua, una pequeña porción existirá en la fase acuosa. Es fuertemente adsorbido por el suelo.

El manganeso es liberado a la atmósfera a través de fuentes naturales y antropogénicas. Fuentes industriales importantes son las instalaciones de producción de hierro y acero, plantas de energía y las emisiones de hornos de coque. 
Tabla 1.4. Efectos nocivos de los metales de pilas y baterías agotadas en la salud humana. Dirección de Residuos Peligrosos Dirección Nacional de Control Ambiental. Subsecretaría de Control y Fiscalización Ambiental y Prevención de la Contaminación.

\section{Metal Daño a la salud humana Vías de exposición}

Una alta exposición puede dañar el cerebro, los riñones y al feto, Al respirar aire contaminado, al ingerir agua y alimentos contaminados provocando retraso mental, falta de coordinación, ceguera y con mercurio.

$\mathrm{Hg} \quad$ convulsiones.

La IARC (Agencia Internacional para la Investigación del Cáncer) clasifica al mercurio elemental y sus compuestos inorgánicos en el grupo 3 (no clasificable) y el metilmercurio y sus compuestos grupo 2B (posible carcinógeno)

Respirar altos niveles de cadmio produce lesión a los pulmones e Al respirar aire contaminado, al consumir alimentos o agua ingerirlo produce daños a los riñones. En dosis altas, puede producir la contaminados con cadmio. muerte. El cadmio y sus compuestos son carcinogénicos.

Efectos más comunes del níquel son efectos de la piel, como reacciones $\mathrm{Ni}$ alérgicas. Respirar altas cantidades produce bronquitis crónica y cáncer $\mathrm{Al}$ ingerir alimentos contaminados con níquel y en contacto de la piel de pulmón y de los senos nasales.

Neurotóxico y tóxico para el riñón. Intoxicación por litio produce fallas La sustancia puede ser absorbida por el cuerpo por inhalación y por 
Tabla 1.4. (Continuación) Efectos nocivos de los metales de pilas y baterías agotadas en la salud humana. Dirección de Residuos Peligrosos Dirección Nacional de Control Ambiental. Subsecretaría de Control y Fiscalización Ambiental y Prevención de la Contaminación.

\section{Metal Daño a la salud humana de exposición}

$\mathrm{Pb} \quad$ El plomo puede causar daño al sistema nervioso, los riñones y el sistema reproductivo. La IARC ha determinado que el plomo inorgánico es probablemente cancerígeno para los seres humanos y que no hay

Al respirar aire o polvo, al comer o tomar agua contaminada, especialmente en niños, al ingerir trozos de pintura seca con plomo o información suficiente para determinar si los compuestos orgánicos de plomo causan cáncer en seres humanos. reproductivo. La IARC ha determinado que el plomo inorgánico es probablemente cancerígeno para los seres humanos y que no hay información suficiente para determinar si los compuestos orgánicos de jugar en tierra contaminada plomo causan cáncer en seres humanos. permanente conocido como manganismo con síntomas como temblores, dificultad para caminar, y espasmos musculares faciales. La exposición a altos niveles de polvo de manganeso puede resultar en inflamación pulmonar y la función pulmonar alterada. No hay evidencia de que el manganeso causa cáncer en los seres humanos y hay pocos datos que sugieran que el manganeso inorgánico es cancerígeno en animales.

La ingestión de alimentos, agua potable, aire contaminado, y productos de tabaco.

El zinc es un elemento esencial que el cuerpo necesita en pequeñas cantidades.

Consumo de alimentos y agua, la inhalación de aire, y el contacto dérmico con el aire, el agua, el suelo y los productos de consumo, que contienen manganeso. El manganeso es un nutriente esencial requerido como un cofactor para una variedad de enzimas. La fuente principal de exposición de manganeso para la población general es alimentaria. 
La ley Nacional de Residuos Peligrosos 24.051 fue promulgada en 1992, y reglamentada por el Decreto 831/93 complementado por 6 (seis) Anexos, que regulan la generación, manipulación, transporte, tratamiento y disposición de residuos peligrosos en el ámbito de la Argentina creando además un registro obligatorio de generadores, transportistas y operadores. Es una Ley de Adhesión, a la cual cada provincia puede adherir en su totalidad o en forma parcial o dictar su propia ley.

Ley No 25.916 “Ley de Gestión de Residuos Domiciliarios”, que establece presupuestos mínimos de protección ambiental para la gestión integral de residuos domiciliarios; Disposiciones generales; Autoridades competentes; Generación y Disposición inicial, Recolección y Transporte; Tratamiento, Transferencia y Disposición final; Coordinación interjurisdiccional; Autoridad de aplicación; Infracciones y sanciones; y Disposiciones complementarias. Sancionada: Agosto 4 de 2004. Promulgada parcialmente: Septiembre 3 de 2004.

Las pilas y baterías usadas y agotadas, provenientes mayormente del uso de distintos artefactos: juguetes, electrodomésticos pequeños, equipos de música, relojes, computadoras, etc., forman parte de la generación habitual de residuos domésticos o domiciliarios.

Estos residuos cuya generación no se limita exclusivamente al ámbito industrial o comercial, sino que involucra principalmente el uso hogareño y, que además poseen características peligrosas, están incluidos dentro de los que genéricamente se denominan residuos peligrosos universales (son aquellos que en virtud de presentar alguna característica de peligrosidad es conveniente su recolección diferencia de los residuos sólidos urbanos). 


\subsection{Reciclado de pilas}

Muchos de los procesos de reciclado de pilas ya han sido patentados y están siendo aplicados: BATENUS, proceso hidrometalúrgico para mezcla de todo tipo de baterías; ${ }^{6} P L A C I D$ para la recuperación pirometalúrgica de mercurio de las baterías que lo contienen; RECYTEC, para la recuperación de zinc y manganeso de pilas alcalinas y de zinccarbón; HYDROMETAL SPA para baterías de plomo-ácido; REVABAT/ REVATECH tratamiento hidrometalúrgico para pilas alcalinas y de zinc-carbón, que luego de ser desmanteladas son tratadas con ácido sulfúrico y finalmente se recuperan zinc y manganeso como óxidos o sales; y RECUPYL para la recuperación hidrometalúrgica de zinc y manganeso provenientes de pilas agotadas, como sulfatos, utilizando ácido sulfúrico y agua oxigenada; entre otros. ${ }^{7,8,9}$

La clasificación previa al comienzo del tratamiento es fundamental ya que existen distintos tipos de pilas y baterías que funcionan con diferentes reacciones químicas, como consecuencia de esto los metales presentes varían.

Luego las pilas se abren o trituran con el objetivo de dejar expuestos los metales que se encuentran en su interior, además se busca disminuir el tamaño de partícula para facilitar el contacto entre el barro de las pilas y el reactivo químico usado para tratarlas.

${ }^{6}$ S. Frohlich, D. Sewing. Journal of Power Sources 57 (1995) 27-30.

${ }^{7}$ F. Ferella, G. Furlani, M. Navarra. Hydrometallurgical plant to recycle alkaline and $\mathrm{Zn}-\mathrm{C}$ spent batteries: process and economic analysis, Proceedings of the 2nd International Conference on Engineering for Waste Valorization, Patras, Greece, 2008.

${ }^{8}$ E. Sayilgan, T. Kukrer, G. Civelekoglu, F. Ferella, A. Akcil, F. Veglio, M. Kitis, Hydromettalurgy 97 (2009) 158-166.

${ }^{9}$ C. De Souza, J. Tenório, Journal of Power Sources 136 (2004) 191-196. 
Un segundo paso es la separación magnética, con lo que todas las partes compuestas por materiales ferrosos son separadas físicamente siendo éste el primer producto reciclable que se obtiene de las pilas, el que puede ser enviado a fundición y recuperado.

En ese momento se tiene un barro mezcla de compuestos metálicos que forman cátodo y ánodo, carbón, electrolito: hidróxido de potasio o cloruro de amonio según el tipo de pila, papel y plástico, estos últimos dos fácilmente identificables y separables. Luego se realiza una segunda molienda del barro para homogeneizar el tamaño de partículas. El tratamiento físico de molienda suele ser energéticamente costoso, por lo que se deben estudiar las condiciones de molienda y los tamaños de partícula necesarios para lograr una buena eficiencia de reciclado minimizando los costos de esta etapa del proceso.

Los métodos utilizados hacen uso de procesos tanto piro como hidrometalúrgicos, y en muchos casos introducen técnicas de tipo mineralúrgico para realizar separaciones previas.

Métodos pirometalúrgicos: la pirometalurgia es un método muy usado para el reciclado de baterías. Los métodos pirometalúrgicos consisten básicamente en la volatilización selectiva de los metales a elevadas temperaturas seguida de condensación.

Baronius, ${ }^{10}$ tras romper las pilas, recupera la chatarra mediante separación magnética y a continuación calcina la fracción no magnética en un horno rotatorio, con lo que volatiliza el cinc, para, posteriormente, recuperarlo de los gases de escape. Sugawara ${ }^{11}$ recupera zinc, cadmio y mercurio por volatilización en un horno de diseño especial. Estos metales se separan en los gases de escape del horno. Matsuoka ${ }^{12}$ obtiene zinc, mercurio, y un

\footnotetext{
${ }^{10}$ W. Baronius y col. Pat. de la REA núm. 214365. 1984.

${ }^{11}$ K. Sugawara. Pat. japonesa núm. 60179124. 1985

12 T. Matsouka, S. Kurozu. Pat. japonesa núm. 60255190. 1985.
} 
ferromanganeso por tratamiento de las pilas en un horno con tres zonas, la primera oxidante, la segunda reductora y la tercera de fusión. Heng ${ }^{13}$ lleva a cabo un proceso pirometalúrgico en tres etapas para el tratamiento de las pilas. La primera etapa es una calcinación a $600{ }^{\circ} \mathrm{C}$, con lo que consigue eliminar y recuperar el contenido de mercurio. La segunda etapa se produce tras la molturación del residuo de la calcinación y consiste en una separación magnética con el fin de recuperar el hierro. La tercera etapa es una calcinación reductora a $1.200{ }^{\circ} \mathrm{C}$, con lo que se volatiliza y recupera el zinc y se obtiene una escoria inerte como producto final.

Métodos hidrometalúrgicos: es otra tecnología muy utilizada para el diseño de procesos de reciclado de pilas y baterías. La hidrometalurgia tiene algunas ventajas respecto de la pirometalurgia, como por ejemplo, menos requerimientos para las instalaciones industriales, posible recuperación de los reactivos químicos utilizados para la lixiviación, y menores emisiones de gases y partículas, lo que se traduce en menor contaminación del aire. De todas formas, para mejorar la disolución de los metales es necesario realizar operaciones previas a la lixiviación, como pre-clasificación por tipo de pila y batería, desmantelamiento de las mismas, separación magnética. El procedimiento es largo y se necesita una gran cantidad de reactivos químicos. También se generan efluentes acuosos que deben ser tratados para evitar contaminación secundaria. $^{8,9}$

\footnotetext{
${ }^{13}$ R. Heng y col. Ger. Offen. Pat. de la REA núm. 3609697.1988.
} 
En 1984, Franke y col. patentaron un proceso en el cual las pilas eran tratadas en álcali y luego con ácidos, obteniendo óxidos de zinc y manganeso por electrólisis de las soluciones producto de la lixiviación. $^{14}$

El proceso $B A T E N U S$, usado en la actualidad fue desarrollado para el tratamiento de todo tipo de baterías y pilas, exceptuando las pilas botón de óxido de mercurio. El cobre, níquel y cadmio del lixiviado son separados selectivamente por intercambio iónico, el zinc presente en la fase líquida se separa por extracción líquido-líquido y luego es recuperado por electrodeposición, y el óxido de manganeso es obtenido por electrólisis. Este proceso funciona en Alemania con una capacidad de 7.500 toneladas de pilas por año.

En 2006, Toro y col. ${ }^{15}$ desarrollaron y patentaron en Italia un proceso hidrometalúrgico para el tratamiento de baterías agotadas. Para este proceso usaron una mezcla de ácido sulfúrico con carbohidratos provenientes de aguas residuales como compuestos reductores.

Las únicas alternativas para el tratamiento de este residuo en Argentina son la exportación (Convenio de Basilea) y la disposición en rellenos de seguridad. Un ejemplo de la implementación de esta última alternativa es el municipio de Bahía Blanca en el marco del Programa Integral de Pilas iniciado en 1998 (Dirección Nacional de Control Ambiental, 2010).

\footnotetext{
${ }^{14}$ L. Franke, W. Baronius, A. Bosch, P. Heinze, K. Michael, H. Stahlmann, H. Stiehl, V. Stockmann, A. Weise. DDR Patent No. 210819, 1984.

${ }^{15}$ L. Toro, F. Veglio, F. Beolchini, F. Pagnanelli, Z. Mariachiara, F. Giuliana. Process and plant for the treatment of run-down batteries. European Patent Application, EP Number: 1684 369, 2006.
} 


\subsubsection{Situación actual}

El consumo de las pilas primarias tiende a aumentar año tras año, especialmente por el incremento de la cantidad de aparatos y artefactos que las utilizan (esto incluye también a las baterías aunque la duración de estas últimas es superior ya que soportan entre 200 y 400 cargas). El aumento creciente del consumo y desecho de pilas y baterías -especialmente las primarias- y su gestión última se han vuelto un grave problema para las autoridades. En los últimos años el consumo de pilas ha aumentado notablemente, estas se usan en marcapasos, audífonos, Holters (registro de actividad cardíaca), linternas, relojes, cámaras fotográficas, etc. Las pilas agotadas se consideran residuos peligrosos, esto se debe a la presencia de metales pesados. En particular, las pilas alcalinas y de $\mathrm{Zn} / \mathrm{C}$ contienen $\mathrm{Zn}$ y Mn, dichos elementos son esenciales para las plantas, los animales y los seres humanos, pero a niveles altos resultan nocivos para todos los organismos. La presencia de iones de metales pesados en las aguas residuales municipales e industriales y su potencial impacto en el medio ambiente y la salud humana es un tema de investigación debido a la extrema toxicidad de estos metales, incluso a bajas concentraciones. ${ }^{16}$

En la Tabla 1.5 se muestra el consumo promedio de pilas por persona en diferentes países, de acuerdo a un estudio realizado por el Instituto Nacional de Ecología de México.

En nuestro país a través de normativas y programas de concientización podría reducirse el impacto ambiental. A continuación se listan algunos ejemplos:

- Normativas que regulan los contenidos máximos o prohíben el uso como componente $o$ aditivo de sustancias peligrosas. Esta es una estrategia que se ha comenzado a

\footnotetext{
${ }^{16}$ M. Tavlieva, S. Genieva, V. Georgieva, L. Vlaev, Journal of Molecular Liquids 211 (2015) 938-947.
} 
aplicar a nivel nacional, con la sanción de la Ley Nacional № 26.184 que prohíbe en todo el territorio de la Nación la fabricación, ensamblado e importación de pilas y baterías primarias con las características que se establecen en dicha norma, como así también su comercialización.

Tabla 1.5. Consumo promedio de pilas por persona en diferentes países.

\begin{tabular}{|c|c|c|c|}
\hline País & Año & $\begin{array}{l}\text { Pilas por } \\
\text { persona }\end{array}$ & Referencia \\
\hline Argentina & 2015 & 11 & $\begin{array}{l}\text { http://www.ambiente-ecológico.com/ediciones/068-03- } \\
\text { 2000/068-alfredomarcipar.html }\end{array}$ \\
\hline Chile & 2001 & 7 & http://www.iepe.org/ecoclubes/pages/noticia1.htm \\
\hline Ecuador & 2001 & 10,6 & $\begin{array}{l}\text { http://www.cepis.ops- } \\
\text { oms.org/bvsars/e/fulltext/pilas/pilas.pdf }\end{array}$ \\
\hline España & 2003 & 10 & $\begin{array}{l}\text { http://www.vidasostenible.com/paginas/Canales/PaisajeTo } \\
\text { xicosRuidos/ }\end{array}$ \\
\hline $\begin{array}{l}\text { Estados } \\
\text { Unidos }\end{array}$ & 2003 & 11,5 & http://www.epa.gov/epr/products/batteries.html \\
\hline India & 2000 & 2 & $\begin{array}{l}\text { http://www.blonnet.com/iw/2000/09/17/stories/0517e } 052 . h \\
\text { tm }\end{array}$ \\
\hline Japón & 2000 & 24 & $\begin{array}{l}\text { http://www.blonnet.com/iw/2000/09/17/stories/0517e052.h } \\
\text { tm }\end{array}$ \\
\hline
\end{tabular}

Fuente. Instituto Nacional de Ecología. Gobierno Federal. México. 
- Concientización de los consumidores, para reducir el uso de pilas más peligrosas y minimizar sus riesgos. Fomentar el uso de pilas recargables, de bajo contenido en mercurio (catalogadas como "libre de mercurio"), reducir el consumo de pilas y baterías mediante el uso de equipamiento eléctrico conectado a red, evitar arrojar estos residuos a cloacas o cauces de agua, no quemarlas ni arrojarlas en basurales a cielo abierto.

- Programa de manejo de pilas y baterías usadas (recolección, tratamiento y disposición final) separando las pilas del resto de los residuos domiciliarios.

\subsection{Descripción de las pilas usadas}

\subsubsection{Pilas alcalinas}

Las pilas alcalinas están compuestas por un ánodo de zinc de una gran superficie específica, un cátodo de dióxido de manganeso de alta densidad, y un electrolito de hidróxido de potasio. En la Figura 1 se muestra un esquema de una pila alcalina.

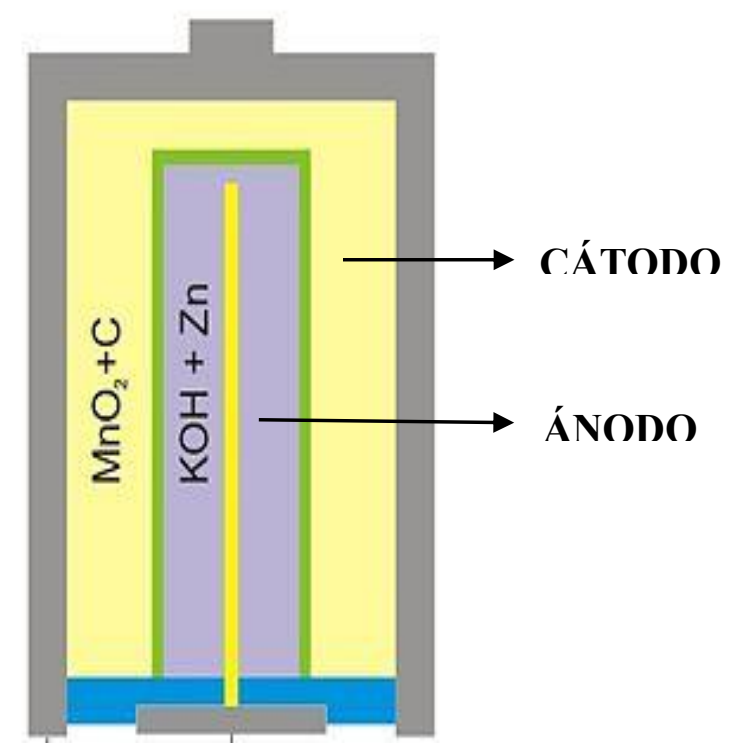

Figura 1.1. Esquema de una pila alcalina. 
El cátodo consiste en una mezcla de dióxido de manganeso electrolítico de alta pureza y carbón conductor y el ánodo, en una mezcla gelatinosa de zinc en polvo y electrolito.

Estas pilas contienen separadores que están compuestos de materiales especiales que previenen la migración de partículas sólidas en la pila.

Carcaza de acero: es el envase que contiene los materiales activos de la pila, y sirve como colector del cátodo.

Colector de latón: es el colector del ánodo.

Terminales positivas y negativas: son las superficies de contacto, están hechas de acero niquelado.

En la Figura 1.2 y en las Tablas 1.6 y 1.7 se muestran los porcentajes de los componentes de las pilas alcalinas y la composición típica del cátodo y el ánodo respectivamente.

Una pila alcalina produce electricidad cuando el cátodo de dióxido de manganeso es reducido y el ánodo de zinc oxidado. La siguiente ecuación muestra la reacción global:

$$
\mathrm{Zn}+2 \mathrm{MnO}_{2}+\mathrm{H}_{2} \mathrm{O} \rightarrow \mathrm{ZnO}+2 \mathrm{MnOOH}
$$

Del análisis de las hemireacciones surge que durante la reacción se consume agua y se produce el ion hidroxilo $\left(\mathrm{OH}^{-}\right)$en el cátodo, mientras que en el ánodo, se consume el ion hidroxilo y se produce agua.

$$
\begin{gathered}
2 \mathrm{MnO}_{2}+2 \mathrm{H}_{2} \mathrm{O}+2 \mathrm{e}^{-} \rightarrow 2 \mathrm{MnOOH}+2 \mathrm{OH}^{-} \\
\mathrm{Zn}+2 \mathrm{OH}-\rightarrow \mathrm{ZnO}+\mathrm{H}_{2} \mathrm{O}+2 \mathrm{e}^{-}
\end{gathered}
$$




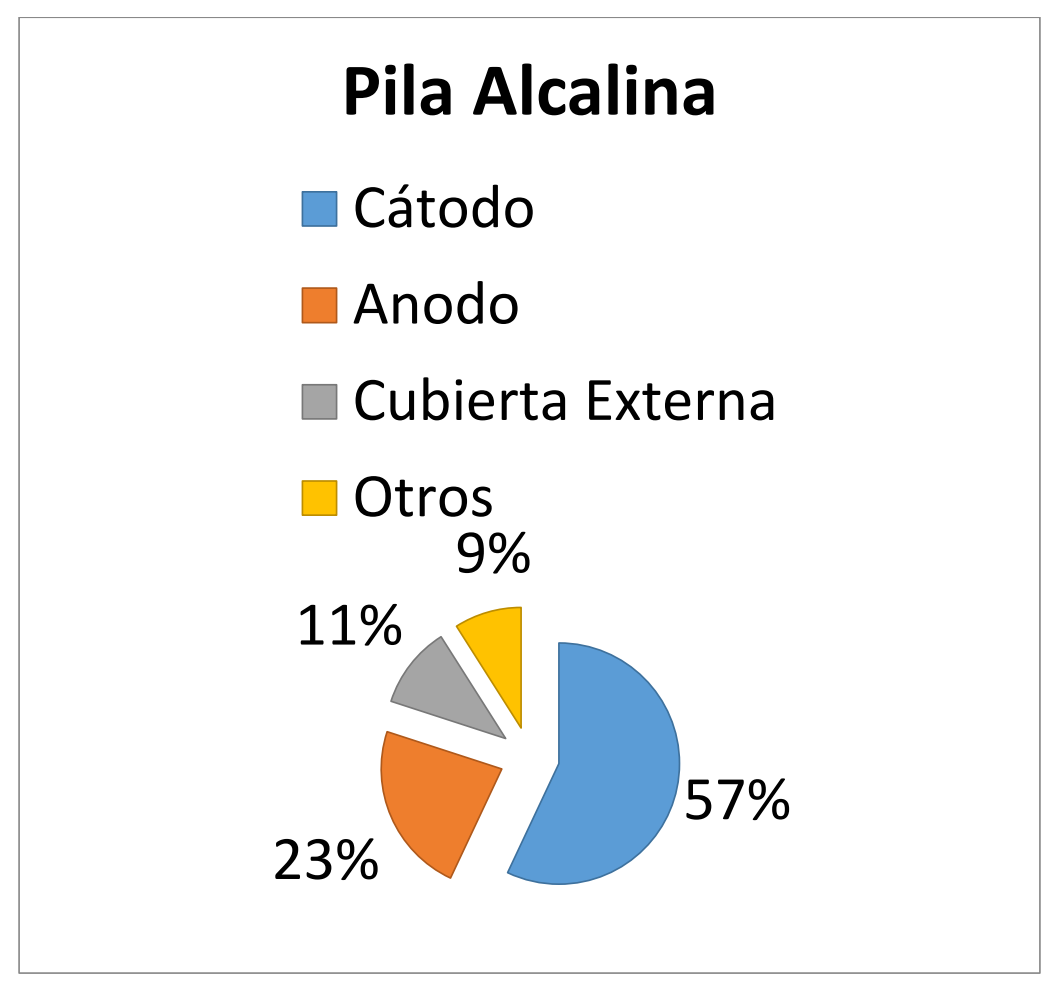

Figura 1.2. Porcentajes de los componentes de una pila alcalina.

Tabla 1.6. Composición típica del cátodo de una pila alcalina.

\begin{tabular}{lcl}
\hline \multicolumn{1}{c}{ Componente } & $\begin{array}{c}\text { Porcentaje en el } \\
\text { cátodo }(\% \mathrm{p} / \mathrm{p})\end{array}$ & \multicolumn{1}{c}{ Función } \\
& $80-90$ & Material activo \\
\hline Dióxido de manganeso & $2-10$ & Conductor electrónico \\
Carbón & $7-10$ & Conductor iónico \\
$\mathrm{KOH}$ & $0-1$ & Mantener la integridad del cátodo \\
Binder & &
\end{tabular}


La velocidad de reacción depende de la calidad de la materia prima y de la disponibilidad de $\mathrm{OH}^{-}$y agua. Cátodo y ánodo se separan para que la reacción no ocurra si no está el circuito cerrado, esto ocurre cuando la pila se conecta a un artefacto y éste se enciende, entonces los electrones comienzan a fluir.

Tabla 1.7. Composición típica del ánodo de una pila alcalina.

\begin{tabular}{lcl}
\hline \multicolumn{1}{c}{ Componente } & $\begin{array}{c}\text { Porcentaje en el } \\
\text { ánodo }(\% \mathrm{p} / \mathrm{p})\end{array}$ & \multicolumn{1}{c}{ Función } \\
\hline Zinc en polvo & $60-70$ & Material activo \\
KOH acuoso & $25-35$ & Conductor iónico \\
Agente gelificante & $0,4-1,0$ & Controla la viscosidad \\
ZnO & $0-2$ & Supresor de gases \\
\hline
\end{tabular}




\subsubsection{Pilas de $\mathrm{Zn} / \mathrm{C}$}

Están divididas en dos grupos: LeClanché o Cloruro de zinc. Ambos sistemas están compuestos por un ánodo de cinc, cátodo de dióxido de manganeso y un electrolito ligeramente ácido. La diferencia entre estos dos tipos de pilas de zinc-carbón es precisamente el electrolito. En el caso de las pilas LeClanché, el electrolito es una mezcla de cloruro de amonio y cloruro de zinc en agua, predominando el primero. Para las pilas de cloruro de zinc, como su nombre lo indica, el electrolito es una solución de cloruro de zinc en agua, aunque puede contener pequeñas cantidades de $\mathrm{NH}_{4} \mathrm{Cl}$ para asegurar una alta performance. Generalmente, algo de óxido de zinc se agrega en el electrolito para prevenir el exceso de corrosión del cinc. En la Figura 1.3 se presenta un esquema y en Tabla 1.8 se muestra un ejemplo de las formulaciones de los electrolitos para las pilas de $\mathrm{Zn} / \mathrm{C}$.

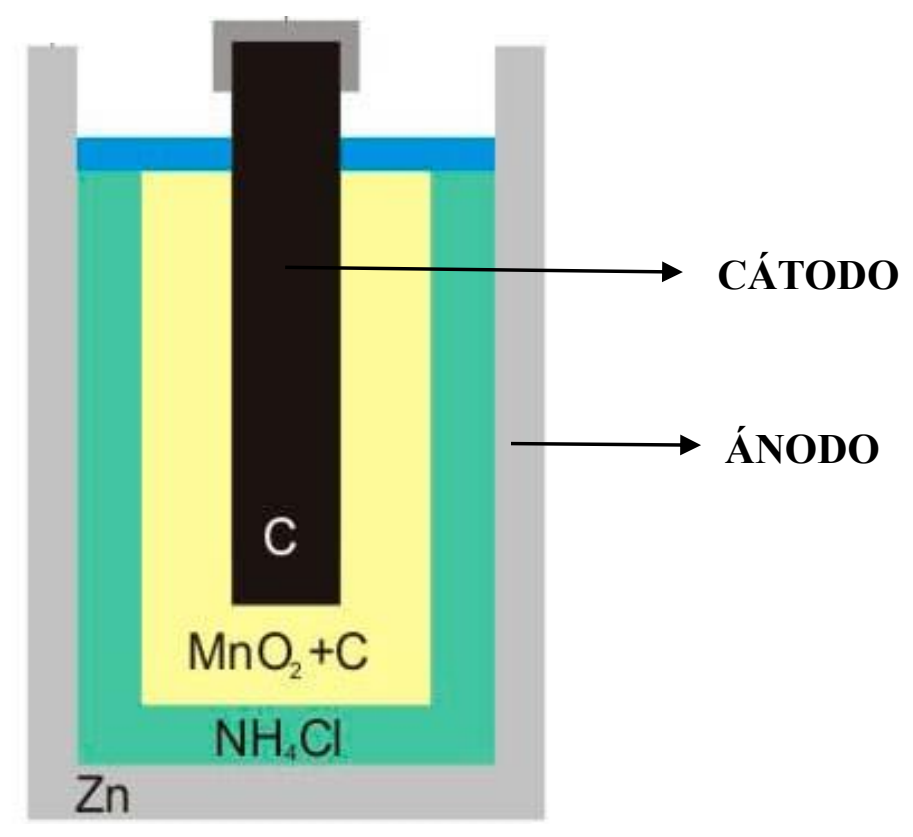

Figura 1.3. Esquema de una pila $\mathrm{Zn} / \mathrm{C}$.

El cátodo consiste en una mezcla de óxido de manganeso y carbón conductor, y electrolito. El ánodo está compuesto por una aleación de zinc de alta pureza, es también el 
envase que encierra los materiales activos de la pila. Poseen un electrodo de carbón que actúa como el colector de la corriente catódica.

Los separadores compuestos por pasta de almidón o papel estucado, previenen la migración de partículas sólidas dentro de la pila. Las terminales son de acero cromado. Tienen una cubierta exterior de nylon o plástico y sellado plástico, para aislar la pila y evitar la pérdida de sus componentes.

Tabla 1.8. Formulación de electrolitos para pilas $\mathrm{Zn} / \mathrm{C}$.

\begin{tabular}{lcc}
\hline Constituyente & \multicolumn{2}{c}{$\% \mathrm{p} / \mathrm{p}$} \\
& Electrolito I & Electrolito II \\
& 26,0 & \\
\hline $\mathrm{NH}_{4} \mathrm{Cl}$ & 8,8 & $15-40$ \\
$\mathrm{ZnCl}_{2}$ & 65,2 & $60-85$ \\
$\mathrm{H}_{2} \mathrm{O}$ & $0,25-1,0$ & $0,02-1,0$ \\
Inhibidor de corrosión & & \\
\hline
\end{tabular}


En la Figura 1.4 se muestran los componentes de las pilas de $\mathrm{Zn} / \mathrm{C}$ y los porcentajes correspondientes.

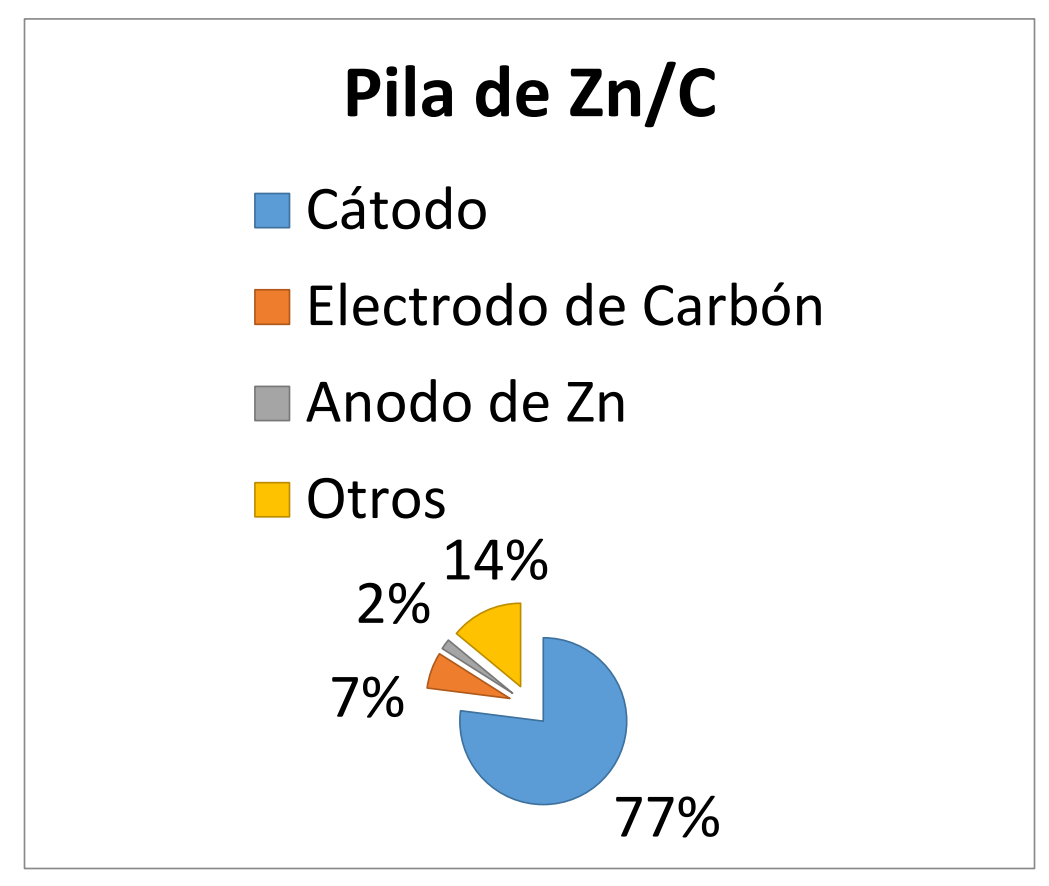

Figura 1.4. Componentes de una pila de $\mathrm{Zn} / \mathrm{C}$ y los porcentajes correspondientes.

Cuando la celda se descarga, ocurre la siguiente reacción global simplificada:

$$
\mathrm{Zn}+2 \mathrm{MnO}_{2} \rightarrow \mathrm{ZnO} \cdot \mathrm{Mn}_{2} \mathrm{O}_{3}
$$

En la práctica, las reacciones que ocurren son más complicadas. Aunque tienen más de 125 años de vida, aún siguen las controversias en cuanto en cuanto a las reacciones de electrodos. ${ }^{17}$

\footnotetext{
${ }^{17}$ D. Glover, A. Kozawa, B. Schum (Eds), Handbook of Manganese Dioxides, Battery Grade, International Battery Material Association (IBA, inc), IC Sample Offic, 1989.
} 


\subsection{Ventajas del reciclado de $\mathrm{Zn}$ y Mn}

El zinc no es muy abundante en la naturaleza $(0,0005-0,02 \%$ de la corteza terrestre), pero se conoce desde hace mucho tiempo debido a la facilidad con que se obtiene de sus minerales y la gran cantidad de posibles aplicaciones. $\mathrm{El} \mathrm{ZnO}$, por ejemplo, podría usarse en paneles solares, sensores de gases, dispositivos electrónicos, esto debido a sus propiedades ópticas y electrónicas. ${ }^{18}$

En la actualidad, aproximadamente un $60 \%$ del zinc consumido en todo el mundo proviene de recursos mineros: el zinc se presenta en varios minerales como óxidos y carbonatos, pero su principal fuente es la esfalerita $\left[(\mathrm{ZnFe}) \mathrm{S}_{2}\right]$, que se encuentra frecuentemente junto con la galena $(\mathrm{PbS})$, y debido a la similaridad del zinc con el cadmio, suele encontrarse este último en casi todos los minerales de zinc por sustitución isomórfica. Existen gran cantidad de métodos de obtención, que implican en la etapa inicial la flotación y la tostación; el zinc y el plomo por lo general se recuperan juntos mediante un método de alto horno. El otro $40 \%$ del zinc proviene del reciclado y del zinc secundario. ${ }^{18}$ Como consecuencia del gran crecimiento en la demanda de este metal y del gradual agotamiento de las reservas naturales no renovables del mismo, se ha comenzado a poner más atención en el estudio de los métodos de recuperación y reciclado del zinc de recursos secundarios. Estos recursos alternativos incluyen: ceniza de cinc, escoria con contenido de cinc, el polvo residual de los hornos de arco eléctrico, fundición de latón, chatarra proveniente del desmantelamiento de automóviles, lodos de la industria del rayón, de la escoria que se produce en la manufactura de chapas de acero galvanizado, de la chatarra generada en la instalación de procesos industriales, etc.Otro importante recurso secundario para la obtención de zinc pueden ser las

\footnotetext{
${ }^{18}$ A. Kołodziejczak-Radzimska, T. Jesionowski, Materials 7 (2014) 2833-2881.
} 
pilas alcalinas, de cinc-carbón y de zinc-aire, una vez que finaliza su vida útil como tales. En 2013, el zinc cotizaba en un promedio de 2.600 U\$S por tonelada (www.metalprices.com).

El manganeso es un elemento relativamente abundante y constituye aproximadamente un 0,085\% de la corteza terrestre. Entre los metales de transición sólo el hierro es más abundante. Aunque se encuentra ampliamente distribuido, se halla en algunos depósitos en formando óxidos, óxidos hidratados o carbonatos. También se encuentra en forma de nódulos en el lecho del océano Pacífico, junto con níquel, cobre y cobalto. El metal se obtiene a partir de sus óxidos por reducción con aluminio. ${ }^{19}$ El manganeso posee varios estados de oxidación entre 0 y VII; sin embargo en la naturaleza los estados de oxidación que tienen importancia biológica son (II), (III) y (IV). De éstos, sólo el Mn (II) es el que puede encontrarse como ion libre en solución acuosa. El Mn (III) puede encontrarse en solución acuosa sólo en forma de complejos. Los iones libres de Mn (III) tienden a desproporcionarse en Mn(II) y Mn (IV). Los óxidos de $\mathrm{Mn}(\mathrm{IV})$ son insolubles en agua, por este motivo, la recuperación hidrometalúrgica de manganeso a partir del $\mathrm{MnO}_{2}$, debe realizarse en condiciones reductoras, este óxido es estable tanto en condiciones reductoras ácidas como alcalinas. La demanda de minerales de manganeso ha crecido considerablemente en los últimos tiempos, este crecimiento es debido principalmente a la industria del acero (que utiliza aproximadamente un 95\% del manganeso extraído) y aún continúa en aumento. Informes de la Manganese Ore India Limited (MOIL), reportaron que la producción de acero fue de 60-70 millones de toneladas en 2009-2010 y se espera una producción de 110 millones de toneladas para el 2021. La consecuencia obvia es la disminución de las reservas naturales de manganeso, las

\footnotetext{
${ }^{19}$ F. Cotton, G. Wilkinson. Química Inorgánica Avanzada, Quinta Edición, Limusa, México, 1996.
} 
que están comenzando a escasear. Según el International Manganese Institute, en la Unión Europea (EU), los recursos naturales de $\mathrm{MnO}_{2}$ hoy en día son escasos, y en general las reservas mundiales de minerales con alto contenido de manganeso están disminuyendo a velocidades alarmantes. Los mayores recursos de estos minerales se encuentran en Australia, Rusia, Gabón, Sud África y en la India. En el año 2012, la tonelada de manganeso se cotizó en alrededor de U\$S 4.000 (www.metalprices.com). Este rápido crecimiento mundial de la demanda de manganeso le ha dado año a año mayor importancia al estudio y desarrollo de tecnologías para el reciclado de este metal a partir de minerales con bajo contenido de manganeso, o bien de residuos que lo contengan. ${ }^{20} \mathrm{La}$ pirometalurgia e hidrometalurgia se aplican al reciclado de manganeso de recursos que contienen bajas concentraciones. La pirometalurgia es una técnica costosa. ${ }^{21}$ Materiales con alto contenido de manganeso como pilas agotadas y electrodos, chatarra de acero, lodos (10\%) y escoria (1-2\%) son recursos secundarios de manganeso. ${ }^{22}$

${ }^{20}$ A. Das, L. Sukla, N. Pradhan, S. Nayak, Bioresource Technology 102 (2011) 7381-7387.

${ }^{21}$ Das, A.P., Sukla, L.B., Pradhan N., Nayak, S., Manganese biomining: A review. Bioresource Technology, 102 (2011), 7381-7387

${ }^{22}$ Zhang, W., Cheng, C.Y., Manganese metallurgy, recovery and control. A literature review, Part I: Manganese Metallurgy CSIRO Minerals, Australia, DMR-2809 (2006). 
〜 Capítulo 2

Óxidos de Manganeso

Generalidades, obtención y

aplicaciones 


\subsection{El manganeso y sus óxidos}

El manganeso es un metal de transición perteneciente al grupo VII B, y es el décimo elemento más abundante en la corteza terrestre y el segundo después del hierro entre los metales pesados.

Este metal se halla ampliamente distribuido, se encuentra en los depósitos principalmente como óxidos, siendo los más importantes por su contenido de manganeso la pirolusita, la bixbyita y la hausmanita. ${ }^{1}$ Geoquímicamente el Mn se comporta como $\mathrm{Mg}, \mathrm{Fe}, \mathrm{Ni}, \mathrm{Co}$ y tiende a repartirse en minerales que se forman en las primeras etapas de cristalización magmática. Cerca de la superficie de la Tierra, Mn se oxida fácilmente, dando lugar a más de 30 formas de óxidos e hidróxidos. Estos óxidos constituyen las principales fuentes de Mn a nivel industrial. Los óxidos de manganeso se encuentran en una amplia variedad de entornos geológicos y es casi omnipresente en suelos y sedimentos. Se producen como agregados de grano fino, nódulos marinos, costras, dendritas, y los recubrimientos de otras partículas minerales y rocas.

Los óxidos de manganeso están presentes en suelos y sedimentos, participan de una gran cantidad de reacciones químicas que afectan aguas subterráneas y la composición del suelo. Se encuentran en forma de mezclas de finos granos, esto dificulta el estudio de la estructura cristalina y composición química. Sin embargo, en los últimos años a partir de investigaciones usando microscopia de transmisión electrónica, difracción de rayos X y difracción de neutrones se obtuvo información acerca de la estructura y las propiedades de estos materiales.

\footnotetext{
${ }^{1}$ A. Angiolani. Introducción a la química industrial: fundamentos químicos y tecnológicos, Ed. Andrés Bello, 1960, Santiago, Chile.
} 
Los óxidos de manganeso cristalizan en una amplia variedad de estructuras, dentro de una gama de fases multivalentes que están relacionadas con tres estados de oxidación del manganeso $2+, 3+$ y $4+$.

Sus estructuras cristalinas están constituidas por túneles y capas, que constituyen una gran familia de materiales porosos (desde ultramicroporosos hasta mesoporosos).
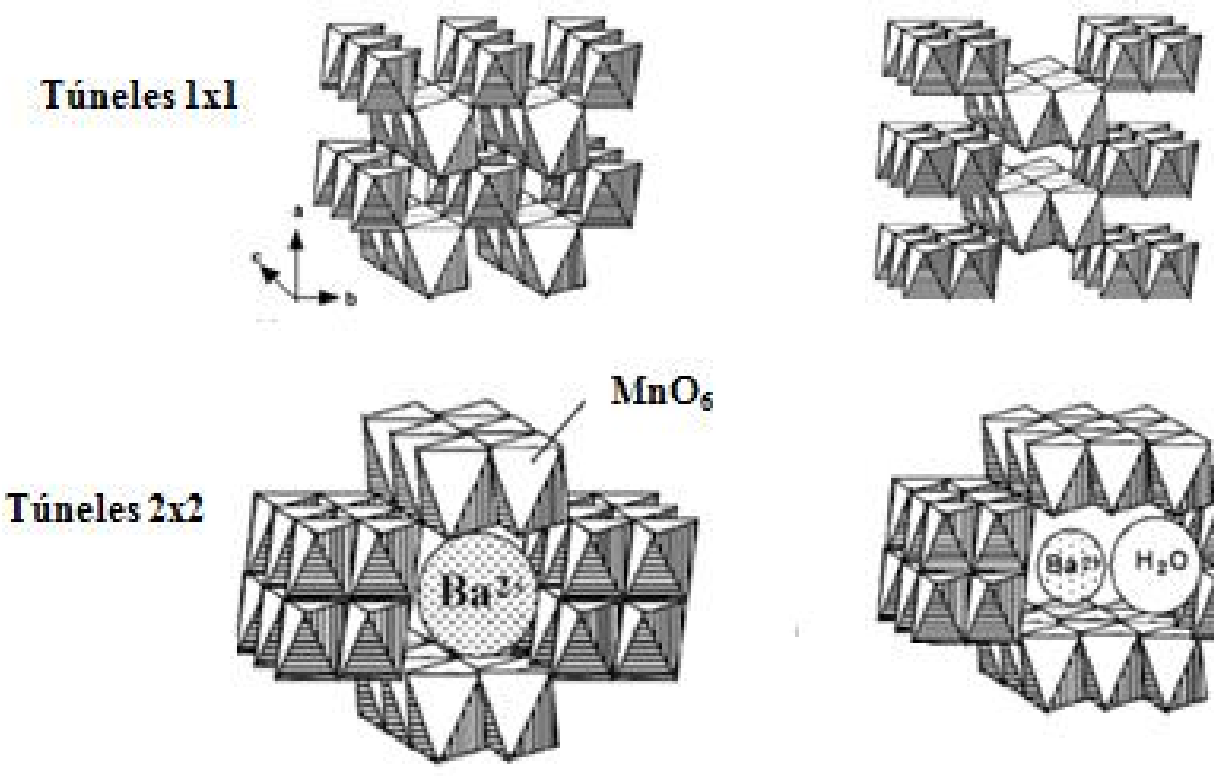

Túneles 2xl

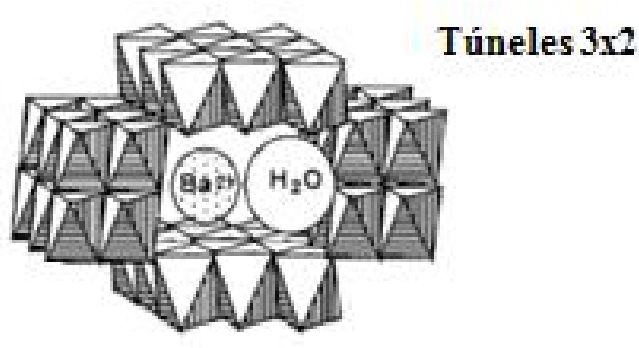

Figura 2.1. Tamaño de túneles de varios OMS.

Todas las estructuras de $\mathrm{MnO}_{2}$ se pueden describir como una distribución de cationes $\mathrm{Mn}^{4+}$ en los huecos de una forma más o menos compacta de una red de átomos de oxígeno, su complejidad resulta del hecho de que existen varias formas de arreglos catiónicos y a la química redox de los óxidos de manganeso que da lugar a una gran variedad descomposiciones estrechamente relacionados con cantidades variables de $\mathrm{Mn}^{4+}, \mathrm{Mn}^{3+} \mathrm{y}$ $\mathrm{Mn}^{2+}$. El octaedro $\mathrm{MnO}_{6}$ es la estructura básica de la mayoría de estos óxidos. Los octaedros pueden estar unidos compartiendo los vértices y/o aristas que dan lugar a una variedad de estructuras, las cuales pueden ser en cadenas, túneles y laminares. La unión 
de los octaedros $\mathrm{MnO}_{6}$ es representada por el símbolo $\mathrm{T}(\mathrm{m}, \mathrm{n})$ donde $\mathrm{m}$ y $\mathrm{n}$ son la cantidad de octaedros por capa que se unen para formar el túnel.

Las estructuras de tipo pirolusita, ramsdelita, holandita, romanchita y todorokita están formadas por túneles con las siguientes dimensiones (1x1), (1x2), (2x2), (2x3), y (3x3) (Figura 2.1).

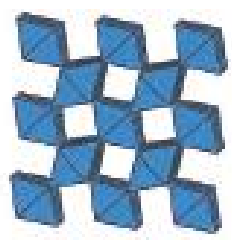

A

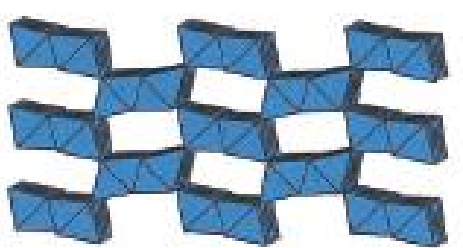

B

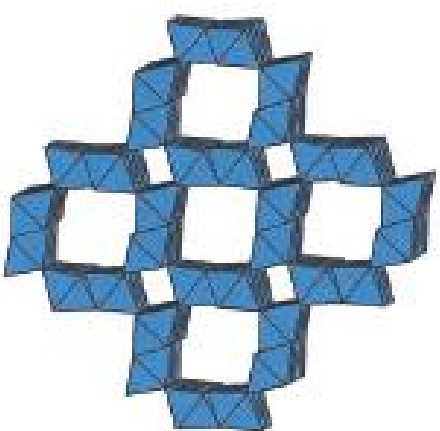

C

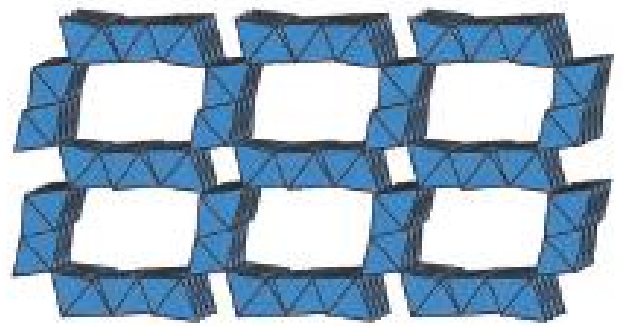

D

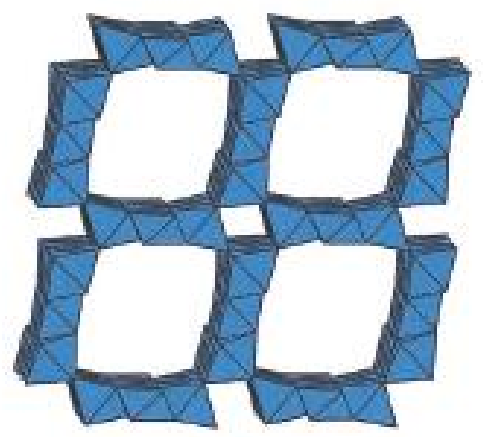

$\mathrm{F}$

Figura 2.2. Representación poliédrica de las estructuras cristalinas de (A) pirolusita, (B) Ramsdelita, (C) Holandita, (D) Romancita y (E) Todorokita. 
Pirolusita ( $\left.\boldsymbol{\beta} \mathbf{M n O}_{2}\right)$. Es el polimorfo del $\mathrm{MnO}_{2}$ más estable y abundante. Esta estructura posee túneles muy pequeños como para acomodar a otras especies químicas. ${ }^{2}$ Se representa como $\mathrm{T}(1,1)$ debido a que un octaedro de una capa se une por los vértices a los octaedros de otras capas, generando túneles de dimensión (1x1). Se obtiene por descomposición térmica de $\mathrm{Mn}\left(\mathrm{NO}_{3}\right)_{2}$ a $180{ }^{\circ} \mathrm{C}$ durante $48 \mathrm{~h} .{ }^{3}$

Ramsdelita, R-MnO2. Los octaedros se hallan unidos de a dos por los lados y estos unidos a otros dos por el vértice, lo que se simboliza como $T(1,2)$. Esta estructura posee dos tipos de oxígenos, uno planar y otro piramidal. El oxígeno planar se encuentra ubicado en el centro de un triángulo casi equilátero de cationes $\mathrm{Mn}^{4+}$, con una hibridación $\mathrm{sp}^{2}$ con distancias de enlace Mn-O de 1,86 (dos veces) y de $1,91 \AA$.

El oxígeno piramidal está en la cúspide de una pirámide trigonal de cationes con una hibridación $\mathrm{sp}^{3}$, con distancias de enlace Mn-O de 1,92 (dos veces) y de 1,89 ̊́.

Los túneles generalmente se encuentran vacíos pero en algunas ocasiones pueden contener pequeñas cantidades de moléculas de $\mathrm{H}_{2} \mathrm{O}$.

Puede ser preparada por hidrolisis acida a $90{ }^{\circ} \mathrm{C}$ de espinelas de $\mathrm{LiMn}_{2} \mathrm{O}_{4}$ y $\mathrm{Li}_{2} \mathrm{Mn}_{4} \mathrm{O}_{9}$ obteniéndose impurificada con pirolusita. ${ }^{4}$

Nsutita $\boldsymbol{\gamma}-\mathbf{M n O}_{2}$. Tiene una estructura formada por una matriz de ramsdelita donde hay distribuidas estadísticamente unidades de pirolusita. Se representa como $\mathrm{T}(1,1)-$ $\mathrm{T}(1,2)$. Posee defectos estructurales como defectos de Wolf y defectos puntuales. Los primeros hacen referencia a la cantidad de unidades de pirolusita en la matriz de ramsdelita y los segundos a las vacancias de $\mathrm{Mn}^{4+}$, el reemplazo de $\mathrm{Mn}^{4+}$ por $\mathrm{Mn}^{3+}$ y el reemplazo de $\mathrm{O}^{2-}$ por $\mathrm{OH}^{-}$. La nsutita contiene considerables cantidades de agua e hidroxilos en su estructura, presentes en tres formas diferentes: (a) oxidrilos compensando

\footnotetext{
${ }^{2}$ W. Baur, Acta Crystallographica B 32 (1976) 2200.

3 J. Fernandez, B. Desai, K. Dalal, Journal of Power Sources 15 (1985) 209.

${ }^{4}$ M. Thackeray, M. Rossouw, R. Gummow, D. Liles, K. Pearce, A. De Kock, W. David, S. Hull, Electrochimica Acta 38 (1993) 1259.
} 
las vacancias de $\mathrm{Mn}^{4+}$ (se asume que cuatro átomos de oxígeno de un octaedro rodeando una vacancia de $\mathrm{Mn}^{4+}$ son convertidos en oxidrilos), (b) oxidrilos compensando cada catión $\mathrm{Mn}^{3+} \mathrm{y}(\mathrm{c})$ agua molecular adsorbida.

Por lo tanto, la composición global de nsutita puede ser representada como:

$$
\mathrm{Mn}_{1-\mathrm{x}-\mathrm{y}}{ }^{4+} \mathrm{Mn}_{\mathrm{y}}{ }^{3+} \mathrm{O}^{2-}{ }_{4 \mathrm{x}-\mathrm{y}}(\mathrm{OH})_{4 \mathrm{x}+\mathrm{y}} \cdot \mathrm{z} \mathrm{H}_{2} \mathrm{O}
$$

Industrialmente este óxido es preparado por electrólisis de soluciones ácidas de $\mathrm{MnSO}_{4}{ }^{4}$ En el laboratorio se puede preparar a partir de la descomposición térmica de $\mathrm{MnCO}_{3}$ en flujo de gases $\left(\mathrm{H}_{2} \mathrm{O}\right.$, aire y $\left.\mathrm{O}_{2}\right),{ }^{5}$ por oxidación de $\mathrm{MnSO}_{4}$ con distintos oxidantes como: flujo de $\mathrm{O}_{2},{ }^{6}\left(\mathrm{NH}_{4}\right)_{2} \mathrm{~S}_{2} \mathrm{O}_{8}$ o $\mathrm{KMnO}_{4}$ en presencia de $\mathrm{KNO}_{3}{ }^{7}$

Espinela $\lambda \mathrm{MnO}_{2}$. Se obtiene extrayendo $\mathrm{Li}^{+}$de la espinela $\mathrm{LiMn}_{2} \mathrm{O}_{4}$. Retiene la estructura del precursor y presenta un empaquetamiento cubico compacto de aniones oxigeno donde el Mn(IV) ocupa sitios octaédricos.

Hollanditas. La holandita propiamente dicha $\left(\alpha \mathrm{MnO}_{2}\right)$ y los criptomelanos, pertenecen a este grupo de óxidos con estructuras con túneles y presentan una composición general $\mathrm{A}_{\mathrm{x}}\left(\mathrm{Mn}^{4+}, \mathrm{Mn}^{3+}\right)_{8}(\mathrm{O}, \mathrm{OH})_{16}$ donde $\mathrm{A}$ es $\mathrm{Ba}^{2+}$ (hollandita) o $\mathrm{K}^{+}$ (criptomelanos), y su concentración depende de la cantidad de $\mathrm{Mn}^{3+}$. Presentan una estructura formada por dobles cadenas de octaedros de $\mathrm{MnO}_{6}$ unidas por los vértices formando túneles de [2 2 2 2], con un tamaño de 4,7 $\AA$ x 4,7 $\AA$. Esta estructura es simbolizada como T $(2,2)$. Los túneles se encuentran parcialmente ocupados por grandes cationes mono y divalentes, y en algunas ocasiones por moléculas de agua.

Estos óxidos son comúnmente denominados tamices moleculares octaédricos u OMS2 (de octahedral molecular sieves en inglés). Los criptomelanos pueden ser sintetizados

\footnotetext{
${ }^{5}$ F. Kapteijn, L. Singoredjo, A. Moulijn, Applied Catalysis B 3 (1994) 173-189.

${ }^{6}$ S. Netto, R. Hypolito, J. Valarelli, R. Giovanoli, R. Shultz-Gutler, Anais da Academia Brasileira de Ciências 70 (1998) 563.

${ }^{7}$ Z. Wang, S. Tezuka, H. Kanoh, Chemistry of Materials 13 (2001) 530-537.
} 
mediante la reducción de $\mathrm{KMnO}_{4}$ con $\mathrm{HCl}$ y luego la digestión con $\mathrm{HNO}_{3}$; mediante técnicas de sol-gel a partir de $\mathrm{KMnO}_{4}$ glicerol y agua; a partir de oxidación de nitratos de $\mathrm{Mn}^{2+}$ y K $\mathrm{K}^{+}$con ácido cítrico; por oxidación de sales de $\mathrm{Mn}^{2+}$ con $\mathrm{KMnO}_{4} \mathrm{O}$ a partir de reacción hidrotérmica de $\mathrm{Li}_{2} \mathrm{MnO}_{3}$ con solución de $\mathrm{H}_{2} \mathrm{SO}_{4}{ }^{7}$

Todorokita. Posee una estructura de tipo túnel T(3,3) construida por triples cadenas de octaedros $\mathrm{MnO}_{6}$ unidos por los vértices. En estos túneles se hallan cationes $\left(\mathrm{Na}^{+}, \mathrm{K}^{+}\right.$, $\mathrm{Ca}^{2+}$ ) y moléculas de agua. Puede ser preparado por oxidación de $\mathrm{MnCl}_{2}$ con $\mathrm{KMnO}_{4}$ en medio básico. Esta fase se denomina OMS-1.

Filomanganatos. Son óxidos con estructura en capas. Poseen una estructura laminar construida a partir de láminas de octaedros de $\mathrm{MnO}_{6}$, las cuales son separados por moléculas de agua u hidroxilos.

Estos compuestos se pueden clasificar en dos grupos según el espaciado entre las láminas sea de $7 \AA$ Á, grupo de las Birnessitas y con espaciado de $10 \AA$, grupo de las Buseritas, que son hidratos del grupo anterior. Estas estructuras se pueden simbolizar como $\mathrm{T}(1, \infty)$ sin tener en cuenta las moléculas de agua y los cationes presentes.

Oxihidróxidos de Manganeso. Existen tres polimorfos naturales de $\mathrm{MnOOH}$; manganita, grutita y feitknequita. Siendo la manganita la más estable y abundante en la naturaleza. La Manganita $(\gamma-\mathrm{MnOOH})$ posee una estructura cristalina similar a la pirolusita, pero en este caso todos los cationes de manganeso se encuentran en el estado trivalente, y la mitad y medio de los aniones oxígeno son reemplazos por especies $\mathrm{OH}^{-}$. El octaedro de $\mathrm{Mn}^{3+}$ está bastante distorsionado debido al efecto Jahn-Teller. La Grutita $(\alpha-\mathrm{MnOOH})$ es isoestructural con la ramsdellita, pero, como en la manganita, todos los cationes $\mathrm{Mn}^{4+}$ son sustituidos por $\mathrm{Mn}^{3+}$, y la mitad y media de los aniones oxígeno son sustituidos por aniones $\mathrm{OH}^{-}$. Por último, la Feitknequita $(\beta-\mathrm{MnOOH})$ es un oxihidróxido 
de manganeso que posee un diagrama de difracción de rayos $\mathrm{X}$ similar al óxido $\mathrm{Mn}_{3} \mathrm{O}_{4}$. $\mathrm{Su}$ estructura cristalina no ha sido muy bien determinada.

Nódulos oceánicos de manganeso. Los depósitos naturales más extensos de óxidos de manganeso se encuentran en los mares como nódulos. Los óxidos de manganeso predominantes en estos nódulos son todorokita y birnesita. ${ }^{8}$ Además de manganeso estos nódulos contienen grandes cantidades de óxido de Fe, Si y Al, y óxidos de $\mathrm{Cu}$, Ni y Co en menor proporción. ${ }^{9}$

Pirocrita $\left[\mathbf{M n}(\mathbf{O H})_{2}\right]$. Consiste en láminas de octaedros de $\mathrm{Mn}^{2+}(\mathrm{OH})_{6}$ compartiendo aristas. Su estructura es topológicamente idéntica a los filomanganatos.

Manganosita. Cristaliza en la red del $\mathrm{NaCl}$, derivada del empaquetamiento cúbico compacto, donde los aniones $\mathrm{O}^{2-}$ forman el empaquetamiento, los cationes $\mathrm{Mn}^{2+}$ ocupan todos los huecos octaédricos y los huecos tetraédricos se encuentran vacíos. ${ }^{10}$

Bixbyta, $\mathrm{Mn}_{2} \mathrm{O}_{3}$. Cristaliza en una red cúbica aproximadamente compacta, donde los átomos de $\mathrm{Mn}^{3+}$ se encuentran en sitios octaédricos diferentes con cuatro uniones $\mathrm{Mn}-\mathrm{O}$ cortos y dos más largas.

Hausmannita, Mn33 $\mathrm{O}_{4}$. Presenta una estructura de espinela normal $\mathrm{Mn}^{\mathrm{II}} \mathrm{Mn}^{\mathrm{III}}{ }_{2} \mathrm{O}_{4}$ donde los $\mathrm{Mn}^{2+}$ ocupan 1/8 de los sitios tetraédricos y los $\mathrm{Mn}^{3+}$ ocupan la 1/2 de los sitios octaédricos. A altas temperaturas cambia a la forma cubica de espinela.

$\mathrm{Mn}_{2} \mathrm{O}_{5}$ y $\mathbf{M n}_{2} \mathrm{O}_{7}$. Estos óxidos son poco frecuentes y han sido poco estudiados.

Óxidos mixtos de Manganeso. El Manganeso puede formar óxidos mixtos del tipo $\mathrm{AMnO}_{3}$ denominados perovskitas. En estas estructuras, A es un catión grande (lantano o

\footnotetext{
8 J. Post, Proceedings of the National Academy of Sciences 96 (1999) 3447-3454.

9 K. Parida, P. Satapathy, N. Das, A. Sahoo, Journal of Colloid Interface Science 173 (1995) 112-118.

${ }^{10}$ N. Greenwood, A. Earnshaw, 1970. Chemistry of the Elements, Second Edition.
} 
alcalino terreo) y el Manganeso se encuentra coordinado octaédricamente por 6 oxígenos.

El catión ocupa las cavidades generadas por los octaedros $\mathrm{MnO}_{6}$.

\subsection{Métodos de síntesis}

\subsubsection{Precipitación, intercambio iónico y rutas hidrotérmicas}

Las técnicas de precipitación involucran reacciones redox usando sales de $\mathrm{MnO}_{4}^{-}$y/o $\mathrm{Mn}^{2+}$ para obtener óxidos de manganeso. Los materiales típicos formados a partir de esta ruta son óxidos de manganeso con estructura de capas (birnesita) y óxidos de fase condesada como $\mathrm{Mn}_{3} \mathrm{O}_{4}$. Las estructuras de tipo birnesita pueden incorporar cationes entre sus capas (iones de metales alcalinos y alcalinos térreos), estas reacciones son de intercambio iónico y se producen con el objetivo de aumentar la estabilidad de los sólidos.

El tratamiento hidrotérmico de esta estructura conduce a una variedad de estructuras con túneles como pirolusita, todorokita, etc. Algunos estudios recientes muestran avances en cuanto al estudio de las propiedades de la birnesita. ${ }^{11}$

\subsubsection{Síntesis por sol- gel}

Es posible la síntesis de óxidos de manganeso por reducción de $\mathrm{KMnO}_{4}$ usando agentes reductores orgánicos, estas rutas conducen a la formación de un sol o gel. Desde 1990 que el estudio de estos métodos de síntesis está en auge, se han investigado dos grandes grupos de agentes reductores orgánicos: ácidos carboxílicos multifuncionales (tales como maleico y fumárico ${ }^{12}$ y polioles. $^{13}$

Las investigaciones incluyen el efecto de los cationes $(\mathrm{K}, \mathrm{Na})$, la relación agente reductor/ $\mathrm{KMnO}_{4}$, temperatura de calcinación y pH en la estructura del sólido generado.

\footnotetext{
${ }^{11}$ J. Luo, S. Suib, The Journal of Physical Chemistry 101 (1997) 10403-10413.

12 S. Ching, J. Roark, N. Duan, S. Suib, Chemistry of Materials 9 (1997) 750-754.

${ }^{13}$ S. Ching, D. Petrovay, M. Jorgensen, S. Suib, Inorganic Chemistry 36 (1997) 883-890.
} 
Esta ruta de síntesis permite obtener materiales con propiedades únicas no encontradas en los materiales sintetizados por precipitación o tratamientos hidrotérmicos. La morfología observada es diferente las placas y agujas observadas normalmente en la birnesita o criptomelano.

La síntesis de hollandita usando microondas también ha sido investigada, ${ }^{14}$ debido al éxito en la obtención rápida y selectiva. Se cree que la influencia de las microondas se debe a la constante dieléctrica alta presentada por los $\mathrm{MnO}_{2}$.

\subsubsection{Reacción en estado sólido a alta temperatura}

Generalmente los sólidos microporosos se obtienen por reacciones a baja temperatura, debido a que son más estables en estas condiciones. Sin embargo, a altas temperaturas también es posible la obtención de fases porosas. Recientemente se han reportado de un sólido del tipo manganita $\mathrm{Ba}_{6} \mathrm{Mn}_{24} \mathrm{O}_{48},{ }^{15}$ obtenida por molienda mecánica y posterior tratamiento a alta temperatura.

Los autores observaron que este material presentaba un ordenamiento de largo alcance, además no hay incorporación de $\mathrm{H}_{2} \mathrm{O}$ en la estructura debido al tratamiento a alta temperatura. Esta síntesis debe optimizarse, debido a que se obtuvieron otros materiales como subproductos.

${ }^{14}$ Q. Zhang, J. Luo, E. Vileno, S. Suib, Chemistry of Materials 9 (1997) 2090-2095.

${ }^{15}$ P. Boullay, M. Hervieu, B. Raveau, Journal of Solid State Chemistry 132 (1997) 239-248. 


\subsection{Técnicas de Caracterización}

Los óxidos de manganeso poseen cierto desorden estructural, por esta razón la identificación de las diferentes estructuras cristalinas no es una tarea sencilla.

\subsubsection{Difracción de Rayos $\mathrm{X}$}

En general, la técnica de difracción de rayos X (XRD) en polvo es un buen diagnóstico para identificar fases bien cristalizadas. Desafortunadamente, la estructura cristalina, y por ende, los diagramas de difracción de rayos X son similares para muchos de los óxidos de manganeso (además en muchas ocasiones los óxidos preparados presentan una baja cristalinidad, lo cual hace mucho más dificultoso la identificación a partir de los diagramas de XRD). Por lo tanto, es necesario el uso de otras técnicas de caracterización, como la espectroscopía infrarroja (IR), espectroscopia fotoelectrónica de Rayos X (XPS), absorción de Rayos X Cercana al Borde de Absorción (XANES), espectroscopia de absorción de rayos $\mathrm{X}$ en la región extendida (EXAFS) y técnicas como reducción térmica programada (TPR) y análisis termogravimétrico (ATG).

En la Tabla 2.1 se presentan los ángulos de los principales picos y su intensidad relativa en $\mathrm{XRD}$ de las fases cristalinas de algunos de los más importantes óxidos de manganeso obtenidos de la base de datos $\operatorname{JCPDS}^{16}$ utilizando anticátodo de $\mathrm{Cu}$.

\footnotetext{
${ }^{16}$ Join Committee on Powder Diffraction Standard, JCPDS Files, International Centre of Diffraction Data,
} 2000. 
Tabla 2.1. Principales picos en XRD para algunos óxidos de manganeso.

\begin{tabular}{lllllllll}
\hline Fase & Ref. & \multicolumn{7}{c}{ Ángulos ( $)$} \\
Pirolusita & $24-0735$ & 28,7 & 37,4 & 42,8 & 56,7 & & & \\
Ramsdelita & $44-0142$ & 22,0 & 35,0 & 36,9 & 42,1 & 55,8 & 68,4 & \\
Nsutita & $17-0510$ & 22,9 & 37,1 & 38,6 & 42,4 & 56,3 & 68,7 & \\
Criptomelano & $29-1020$ & 28,7 & 37,6 & 42,0 & 49,9 & 56,2 & & \\
$\boldsymbol{\alpha M n O}_{2}$ & $44-0141$ & 28,8 & 36,7 & 37,5 & 42,0 & 49,9 & 56,4 & 60,3 \\
$\boldsymbol{\alpha M n}_{2} \mathbf{O}_{3}$ & $41-1442$ & 23,1 & 33,0 & 55,2 & 65,8 & & & \\
$\mathbf{M n}_{3} \mathbf{O}_{4}$ & $24-0734$ & 18,0 & 28,9 & 32,3 & 36,1 & 59,8 & & \\
$\mathbf{M n O}$ & $07-0230$ & 34,9 & 40,5 & 58,7 & & & & \\
\hline
\end{tabular}

\subsubsection{Espectroscopía Fotoelectrónica de Rayos X (XPS)}

Esta técnica es usada para investigar la composición química de los óxidos. La habilidad de esta técnica radica en su capacidad para generar información acerca de las propiedades electrónicas de estos materiales.

La región Mn $2 p$, caracterizada por una diferencia de energía entre los niveles $2 \mathrm{p}_{3 / 2}$ $2 \mathrm{p}_{1 / 2}$ de 11,4 - 11,6 eV con relación de intensidad de 2:1, es ensanchada debido a múltiples splitting y a estructuras satélites. $\mathrm{El} \mathrm{MnO}$ presenta picos a una distancia de aproximadamente $5 \mathrm{eV}$ de los dos picos Mn 2p. Por otro lado, tanto los espectros del $\mathrm{Mn}_{2} \mathrm{O}_{3}$ como del $\mathrm{MnO}_{2}$ muestran claramente la presencia de satélites asociados al pico $2 \mathrm{p}_{1 / 2}$. Los compuestos que no tienen electrones desapareados, como el $\mathrm{KMnO}_{4}$, dan picos simétricos. En la Tabla 2.2 se presentan las posiciones de los picos correspondientes a los niveles de energía del Mn 2p, 3p y 3s y del oxígeno 1s de algunos de los más importantes óxidos de manganeso. 
Tabla 2.2. Posiciones características en espectros de algunos óxidos de manganeso.

\begin{tabular}{llllll}
\hline & Mn2p1/2 & Mn2p $3 / 2$ & Mn3s & Mn3p & O 1s \\
\hline $\mathbf{K M n O}_{4}$ & 657,21 & 646,07 & 88,91 & 53,34 & 529,89 \\
$\mathbf{K}_{2} \mathbf{M n O}_{4}$ & 654,22 & 642,39 & 83,34 & 49,92 & 530,80 \\
$\mathbf{M n O}_{2}$ & 653,54 & 641,76 & 84,10 & 49,53 & 529,14 \\
$\mathbf{M n}_{2} \mathbf{O}_{3}$ & 653,01 & 641,32 & 83,17 & 48,65 & 529,55 \\
$\mathbf{M n}_{3} \mathbf{O}_{4}$ & 653,15 & 641,38 & 83,19 & 49,08 & 529,56 \\
$\mathbf{M n O}$ & 653,28 & 641,60 & 83,42 & 48,65 & 530,00 \\
$\mathbf{M n}$ & 649,62 & 638,41 & 82,57 & 47,17 & \\
\hline
\end{tabular}

El pico correspondiente a $\mathrm{Mn} 2 \mathrm{p}_{3 / 2}$ generalmente es ancho y asimétrico, por lo que algunos autores para la identificación de los diferentes estados de oxidación utilizan el método de la deconvolución del pico. ${ }^{17,18,19}$ Cuando se realiza esto se encuentran tres componentes, una debido a $\mathrm{Mn}^{4+}$, otra a $\mathrm{Mn}^{3+}$ y la tercera se atribuye a un pico satélite. Algunos autores utilizan el splitting del Mn 3s como método para obtener el estado de oxidación del manganeso. ${ }^{20}$

\footnotetext{
${ }^{17}$ Y. Zhang-Steenwinkel, J. Beckers, Applied Catalysis A 235 (2002) 79-92.

${ }^{18}$ Y. Lee, R. Lago, J. Fierro, V. Cortés, F. Sapiňa, E. Martinez, Applied Catalysis A 207 (2001) 17-24.

${ }^{19}$ S. Ponce, M. Peña, J. Fierro, Applied Catalysis B 24 (2000) 193-205.

${ }^{20}$ M. Chigane, M. Ishikawa, Journal of the Electrochemical Society 147 (2000) 2246-2251.
} 


\subsubsection{Espectroscopía Infrarroja}

La espectroscopia infrarroja, especialmente en la región entre 400 y $1000 \mathrm{~cm}^{-1}$, es sensible a la polimerización de los octaedros de $\mathrm{MnO}_{6}{ }^{21} \mathrm{Se}$ observan tres zonas, entre 200-450,450-600, y 600-750 $\mathrm{cm}^{-1}$ correspondientes a los movimientos de wagging, bending y stretching, respectivamente.

En las Tablas 2.3 y 2.4 se presentan las frecuencias de vibración características correspondientes a las fases cristalinas de algunos de los más importantes minerales y óxidos de manganeso

La espectroscopia vibracional Raman también es usada en la caracterización de materiales amorfos, como los óxidos de manganeso. Esta técnica proporciona información confiable y completa acerca, ya que permite un análisis cercano a los oxígenos coordinados a cationes manganeso o metales alcalinos presentes en los materiales $(\mathrm{Na}, \mathrm{K}, \mathrm{Ba})$. Según Julien y col. ${ }^{22}$ existen discrepancias sobre los datos de frecuencias de vibración publicados, debido al hecho de la baja sensibilidad de los óxidos de manganeso a la luz láser, ya que cuando son expuestos a esta radiación rápidamente se reducen.

Los modos activos Raman característicos de las fases cristalinas de algunos de los más importantes minerales y óxidos de manganeso se presentan en las Tablas 2.5 y 2.6.

${ }^{21}$ R. Potter, G. Rosmann, American Mineralogist 64 (1979) 1199-1226.

${ }^{22}$ C. Julien, M. Massot, C. Poinsignon, Spectrochimica Acta A 60 (2004) 689-700. 
Tabla 2.3. Frecuencias IR $\left(\mathrm{cm}^{-1}\right)$ de algunos óxidos de manganeso minerales.

\begin{tabular}{lccccccccc}
\hline Compuesto & $\boldsymbol{v 1}$ & $\boldsymbol{v 2}$ & $\boldsymbol{v 3}$ & $\boldsymbol{v 4}$ & $\boldsymbol{v 4}$ & $\boldsymbol{v 5}$ & $\boldsymbol{v 6}$ & $\boldsymbol{v 7}$ & $\boldsymbol{v} \boldsymbol{8}$ \\
\hline Nsutita & 228 & 330 & & 380 & 472 & 533 & 567 & 690 & \\
Hollandita & & 314 & & 392 & 463 & 530 & 579 & 710 & \\
Coronadita & 310 & & & 482 & 520 & 571 & 709 & \\
Romanequita & 275 & 319 & 400 & 432 & 461 & 520 & 577 & 719 & 748 \\
Todorokita & 231 & & 419 & & 493 & 530 & 620 & & 748 \\
Birnesita & & & 423 & & 477 & 513 & 583 & 635 & \\
\hline
\end{tabular}

Tabla 2.4. Frecuencias IR $\left(\mathrm{cm}^{-1}\right)$ de varios óxidos de manganeso.

\begin{tabular}{|c|c|c|c|c|c|c|c|c|c|}
\hline Compuesto & $v 1$ & $v 2$ & $v 3$ & $v 4$ & $v 5$ & $v 6$ & $v 7$ & 18 & 29 \\
\hline$\beta_{M_{n} O_{2}}$ & & 329 & 387 & & & 545 & 618 & 626 & \\
\hline$\gamma \mathrm{MnO}_{2}$ & & & 374 & 480 & 530 & 564 & & 705 & \\
\hline $\mathrm{RMnO}_{2}$ & 263 & & 366 & 471 & 515 & 589 & & 687 & 740 \\
\hline$\alpha \mathrm{Mn}_{2} \mathrm{O}_{3}$ & & 300 & 408 & 453 & 533 & 576 & 602 & 672 & \\
\hline$\gamma \mathbf{M n}_{2} \mathrm{O}_{3}$ & 217 & 295 & 390 & 446 & 484 & 523 & 591 & 666 & \\
\hline $\mathrm{Mn}_{3} \mathrm{O}_{4}$ & 122 & 164 & 241 & 291 & 356 & 475 & 527 & 594 & 655 \\
\hline MnO & 258 & 329 & & 473 & & & & & \\
\hline
\end{tabular}

Tabla 2.5. Modos activos en Raman $\left(\mathrm{cm}^{-1}\right)$ de algunos óxidos de manganeso minerales.

\begin{tabular}{lccccccc}
\hline Compuesto & $\boldsymbol{v 1}$ & $\boldsymbol{v 2}$ & $\boldsymbol{v 3}$ & $\boldsymbol{v 4}$ & $\boldsymbol{v 5}$ & $\boldsymbol{v 6}$ & $\boldsymbol{v} \mathbf{7}$ \\
\hline Nsutita & 280 & 382 & 458 & 515 & 572 & 634 & 732 \\
Hollandita & 259 & & 410 & 507 & 586 & 628 & \\
Coronadita & & 332 & 388 & 495 & 585 & 626 & \\
Romanequita & 284 & & 372 & 515 & 578 & 643 & 721 \\
Todorokita & 263 & & 358 & & 590 & 641 & \\
Birnesita & 296 & \multirow{2}{*}{303} & & 506 & 575 & 656 & 730 \\
\hline
\end{tabular}


Tabla 2.6. Modos activos en Raman $\left(\mathrm{cm}^{-1}\right)$ de algunos óxidos de manganeso.

\begin{tabular}{|c|c|c|c|c|c|c|c|c|c|}
\hline Compuesto & $v 1$ & $v 2$ & $v 3$ & $v 4$ & $v 5$ & $v 6$ & $v 7$ & 18 & $v 9$ \\
\hline$\beta_{\mathrm{MnO}_{2}}$ & & 319 & 377 & 486 & 538 & & 665 & & 750 \\
\hline$\gamma \mathrm{MnO}_{2}$ & 264 & 337 & 379 & 491 & 520 & 572 & 631 & 670 & 738 \\
\hline $\mathrm{RMnO}_{2}$ & 275 & & 387 & 490 & 522 & 575 & 630 & 648 & 742 \\
\hline$\alpha \mathrm{Mn}_{2} \mathrm{O}_{3}$ & 192 & 314 & 404 & 481 & & 592 & 645 & 698 & \\
\hline$\gamma \mathbf{M n}_{2} \mathrm{O}_{3}$ & 263 & 308 & & & 512 & & 631 & 670 & \\
\hline $\mathrm{Mn}_{3} \mathrm{O}_{4}$ & & 310 & 357 & 485 & & 579 & & 653 & \\
\hline MnO & 250 & & & 531 & 591 & & 654 & & \\
\hline
\end{tabular}




\subsection{Aplicaciones}

Los óxidos de manganeso se han explotado desde la antigüedad. La pirolusita se ha usado como pigmento y en la eliminación del tinte verde impartido por el hierro en el vidrio.

Desde mediados del Siglo XIX, el Mn es esencial en el proceso de fabricación del acero. En la actualidad el $80-90 \%$ de la producción mundial de manganeso es destinada a la industria metalúrgica. En promedio el acero contiene el 6\% de su peso en Mn, pero este porcentaje puede variar dependiendo de la dureza del mismo.

Otros usos incluyen: fabricación de agentes purificadores y baterías, fertilizantes, colorantes de ladrillos, etc. ${ }^{9}$

Los óxidos de manganeso son usados como catalizadores reemplazando a metales de transición como $\mathrm{Pt}, \mathrm{Pd}, \mathrm{Au}$, etc. debido a su menor costo y por su resistencia al envenenamiento, como desventaja presentan una actividad menor. ${ }^{23,24,25}$

En trabajos anteriores se demostró que existe una clara relación entre las propiedades fisicoquímicas de los $\mathrm{MnO}_{\mathrm{x}}$ (estructura amorfa, vacancias de iones, formación de $\mathrm{OH}$, presencia del par redox $\mathrm{Mn}^{3+} / \mathrm{Mn}^{4+}$ ) y su performance catalítica. ${ }^{26,27}$ Una de las primeras reacciones en las cuales fueron y aún siguen siendo empleados los óxidos de manganeso son la descomposición de $\mathrm{H}_{2} \mathrm{O}_{2}{ }^{28,29}$ y la oxidación de CO. ${ }^{30}$ Sobre óxidos de manganeso del tipo de criptomelanos, todorokita y birnesitase han estudiado la oxidación de benceno. Los primeros, también llamados OMS-2, presentaron mejor actividad que los otros dos.

\footnotetext{
${ }^{23}$ C. Lahousse, A. Bernier, P. Grange, B. Delmon, P. Papaeftiens, T. Ionnas, X. Verkyos, Journal of Catalysis 178 (1998) 214-225.

${ }^{24}$ O. Lebedeva, A. Sarmurzina, Applied Catalysis B 26 (2000) L1-L3

${ }^{25}$ V. Bentrup, A. Bruickner, M. Ritcher, R. Fricke, Applied catalysis B 32 (2001) 229-241.

${ }^{26}$ M. Peluso, J. Sambeth, H. Thomas, Reaction, Kinetics and Catalysis Letters 80 (2003) 241-248.

27 S. Figueroa, M. Peluso, E. Lede, L. Lamaita, J. Sambeth, F. Requejo, Catalysis Today 107-108 (2005) 849-855.

${ }^{28}$ S. Kanungo, Journal of Catalysis 58 (1979) 419-435.

${ }^{29}$ J. Carnö, M. Ferrandom, E. Bjornbom, S. Jarás, Applied Catalysis A 155 (1997) 265-281.

${ }^{30}$ A. Cimino, V. Indovina, Journal of Catalysis 33 (1974) 493-496.
} 
La eliminación de compuestos orgánicos volátiles tales como aldehídos y cetonas fue ampliamente estudiada por distintos autores como Sekine, ${ }^{31}$ Gandía y col. ${ }^{32}$ y Gil y col., ${ }^{33}$ empleando diferentes fases de $\mathrm{MnO}_{\mathrm{x}} \mathrm{u}$ óxidos mixtos. En todos los casos los catalizadores de mayor actividad catalítica son aquellos donde es detectada la presencia del par $\mathrm{Mn}^{3+} / \mathrm{Mn}^{4+}$.

Estos óxidos también son usados como catalizadores para la reacción de la reducción selectiva de $\mathrm{NO}_{\mathrm{x}}{ }^{34,35}$ y la oxidación de compuestos aromáticos clorados. ${ }^{36}$

Debido a su alta capacidad de adsorción, los óxidos de manganeso se usan como controles primarios de metales pesados y otros oligoelementos en suelos y sedimentos acuáticos ${ }^{37}$. Además, estos solidos pueden actuar como adsorbentes importantes del fosfato en aguas naturales y sedimentos superficiales. ${ }^{9}$

En la actualidad muchos de los catalizadores se usan soportados sobre pellets de $\mathrm{Al}_{2} \mathrm{O}_{3}$, $\mathrm{TiO}_{2}$ o $\mathrm{ZrO}_{2}$, en procesos de gran caudal.

Funcionan como soporte de materiales de alta superficie donde luego se depositará la fase catalíticamente activa. Los monolitos más usados son cerámicos, aunque presentan algunas limitaciones relacionadas con el espesor de la pared y la baja conductividad térmica. Los monolitos metálicos, a pesar de tener un costo mayor poseen mayor resistencia mecánica y conductividad térmica. La principal desventaja que presentan es la baja adhesión del recubrimiento que actuara como soporte de la fase activa. Este hecho puede mejorarse mediante tratamientos químicos para formar una capa de óxido.

\footnotetext{
${ }^{31}$ Y. Sekine, Atmospheric Environment 36 (2002) 5543-5547.

${ }^{32}$ L. Gandía, M. Vicente, A. Gil, Applied Catalysis B 38 (2002) 295-307.

${ }_{33}$ A. Gil, L. Gandía, S. Korili, Applied Catalysis A 274 (2004) 229-235.

${ }^{34}$ G. Qi, R. Yang, R. Chang, Applied Catalysis B 51 (2004) 93-106.

${ }^{35}$ G. Qy, R. Yang, Journal of Catalysis 217 (2003) 434-441.

${ }^{36}$ Y. Liu, Z. Wei, Z. Feng, M. Luo, P. Ying, C. Li, Journal of Catalysis 202 (2001) 200-204.

${ }^{37}$ O. Kenta, M. Yoshitaka, K. Shunsaku K, Recovery Science and Technology 21(1986) 755-786.
} 
En la fabricación de monolitos se usan aleaciones ferríticas que contienen aluminio, estas soportan tratamiento a altas temperaturas y poseen superficies aptas para luego ser recubiertas por el catalizador. ${ }^{38}$

${ }^{38}$ F. Aguero, A. Scian, B. Barbero, L. Cadús, Catalysis Today 133-135 (2008) 493-501. 
Capítulo 3

Óxidos de Zinc.

Generalidades, obtención y

aplicaciones 


\section{1 Óxidos de Zinc - Generalidades}

El Óxido de Zinc es un compuesto semiconductor del grupo II - VI, la ionicidad de este compuesto reside en la frontera entre los semiconductores covalentes e iónicos.

Este oxido cristaliza en forma cúbica (blenda de zinc o sal de roca) o hexagonal (wurtzita) donde cada anión está rodeado por cuatro cationes en las esquinas de un tetraedro, y viceversa, como se esquematiza en la Figura 3.1.

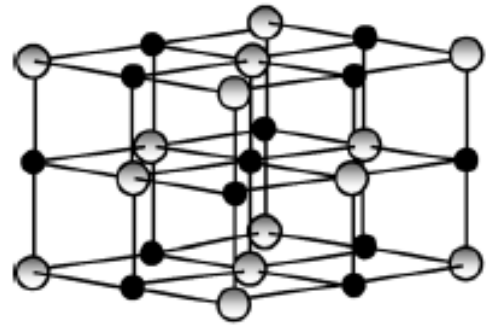

a

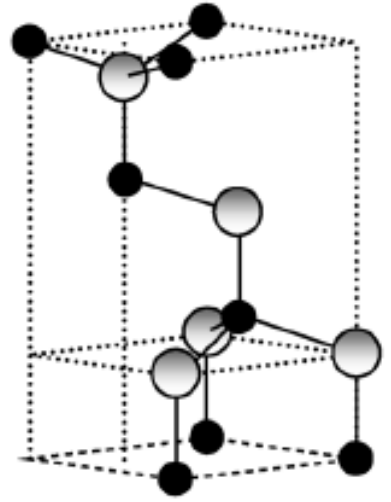

b

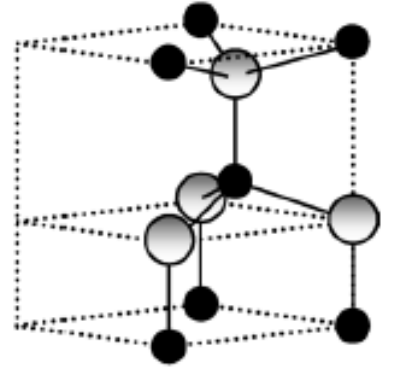

C

Figura 3.1. Representación de las estructuras cristalinas de ZnO. (a) Sal de Roca, (b)

Blenda de Zinc y (c) wurtzita.

Como en cualquier semiconductor, los defectos puntuales afectan las propiedades eléctricas y ópticas de $\mathrm{ZnO}$. Los óxidos de zinc reciben especial atención desde aproximadamente 1960 debido a sus posibles aplicaciones como sensores de gases, transductores y catalizadores.

En las últimas décadas el interés en obtener este material a escala manométrica aumentó notablemente, pudiéndose obtener nanopartículas en forma de flores, anillos, hélices, cintas, agujas y cajas, tal como se muestran en la Figura 3.2. 

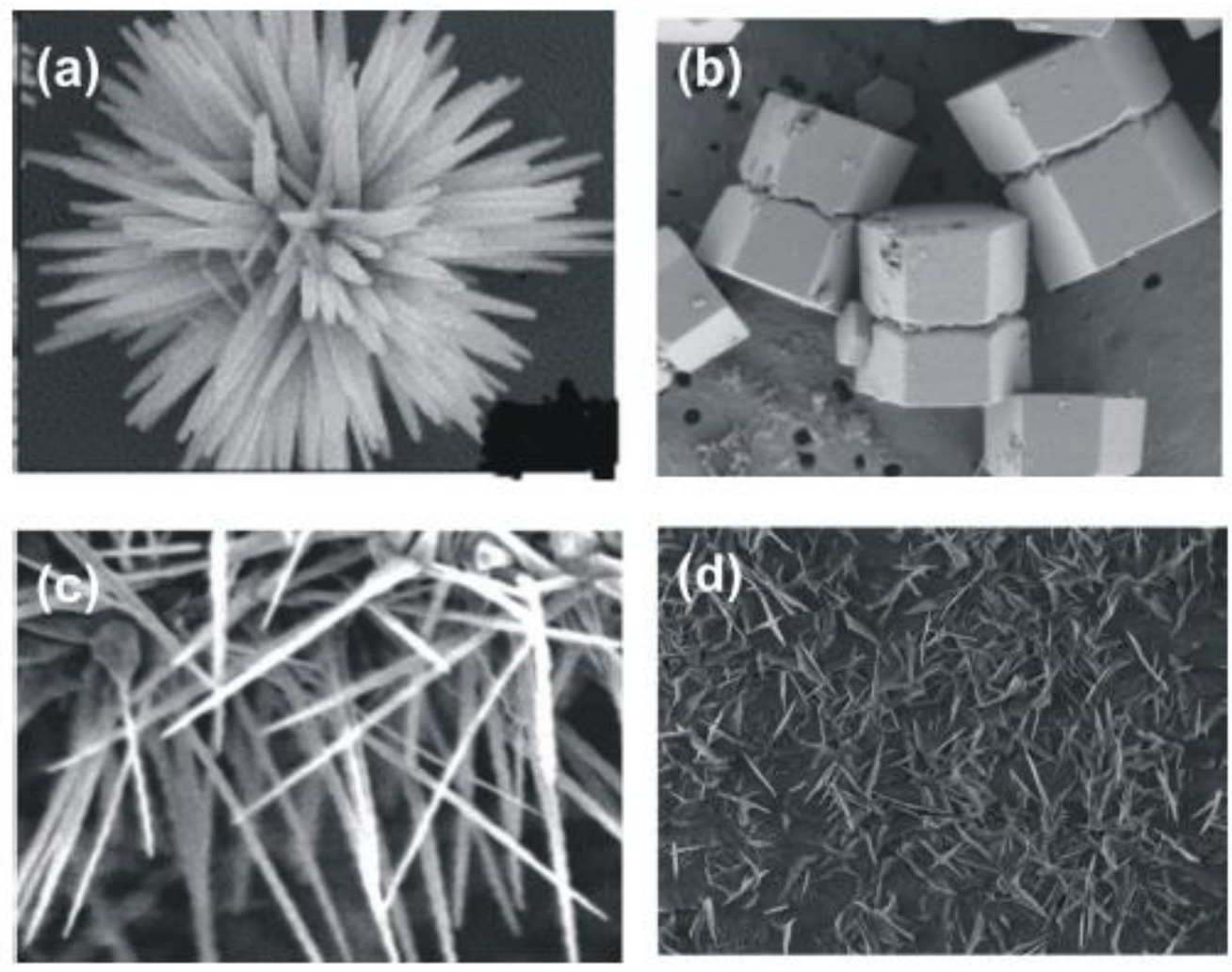

Figura 3.2. Nanopartículas de $\mathrm{ZnO}$ en forma de: (a) flores; (b) barras; (c,d) agujas. ${ }^{1}$

\subsection{Métodos de síntesis de $\mathrm{ZnO}$}

Las estructuras de $\mathrm{ZnO}$ pueden crecer por diferentes métodos, desde aquellos que involucran técnicas de vacío hasta otros donde se usan bajas temperaturas y por lo tanto el costo es menor.

Se ha observado una relación clara entre la concentración de defectos y las propiedades ópticas y eléctricas del óxido de zinc. No sucede esto con la relación entre los mecanismos de crecimiento y las propiedades observadas, por esta razón este tema está siendo estudiado con especial interés.

\footnotetext{
${ }^{1}$ A. Kolodziejczak-Radzimska, T. Jesionowski, Materials 7 (2014) 2833-2881.
} 
Un problema crítico, aun no resuelto, en el crecimiento de nanoestructuras de $\mathrm{ZnO}$ es el control del tamaño y la posición de estas estructuras sobre el sustrato.

\subsubsection{Procesos metalúrgicos}

Este proceso se basa en la calcinación del zinc mineral. De acuerdo con la norma ISO $9298,{ }^{2}$ el óxido de zinc se clasifica como tipo A, obtenido por un proceso directo (el proceso americano); y tipo $\mathrm{B}$, obtenido por un proceso indirecto (el proceso francés).

El proceso directo (americano) implica la reducción del mineral de zinc mediante calentamiento con carbón (Antracita), seguido por la oxidación del vapor de zinc en el mismo reactor, en un único ciclo de producción.

Este proceso fue desarrollado por Samuel Wetherill, y tiene lugar en un horno en el que la primera capa consiste en un lecho de carbón, iluminado por el calor restante de la carga anterior. Sobre este lecho hay una segunda capa en forma de mineral de zinc mezclado con carbón. El aire de soplado se alimenta desde abajo, para suministrar calor a ambas capas y llevar monóxido de carbono para la reducción del zinc. El óxido de zinc resultante (de tipo A) contiene impurezas de otros metales y las partículas tienen forma de aguja mayoritariamente. Para obtener un producto de color blanco, los óxidos de plomo, hierro y cadmio que están presentes como impurezas se convierten en sulfatos. La presencia de color en el sólido obtenido índica un aumento en el contenido de sustancias solubles en agua y por lo tanto un aumento en la acidez. La acidez es deseable en el caso de la tecnología de procesamiento de caucho ya que alarga el tiempo de prevulcanización. ${ }^{3}$

\footnotetext{
2 International Organization for Standardization (ISO). Rubber Compounding Ingredients-Zinc Oxide-Test Methods; ISO 9298:1995. ISO: Geneva, Switzerland, 2010.

${ }^{3}$ L. Pyskło, W. Parasiewicz, P. Pawłowski, K. Niciński. Zinc Oxide in Rubber Compounds; Instytut Przemyslu Gumowego: Piastow, Poland, 2007.
} 
En el proceso indirecto (francés), el zinc metálico se funde en un horno y se vaporiza a aproximadamente $910^{\circ} \mathrm{C}$. La reacción inmediata del vapor de zinc con el oxígeno del aire produce $\mathrm{ZnO}$. Las partículas de óxido de zinc son transportadas a través de un conducto de enfriamiento y se recogen en una estación de filtro de bolsas. Este proceso fue popularizado por LeClaire en 1844, y desde entonces se ha conocido como el proceso francés. El producto consiste en aglomerados con un tamaño medio de partícula que varía de $0,1 \mu \mathrm{m}$ a unos pocos micrometros. ${ }^{4}$ Las partículas de $\mathrm{ZnO}$ son principalmente de forma esferoidal. El proceso francés se lleva a cabo en hornos verticales, con una carga vertical original, columna de refino vertical, vaporizador con arco y cámara de combustión rotativa. ${ }^{5}$ El óxido de zinc tipo B tiene un grado de pureza superior al del tipo A.

\subsubsection{Procesos Químicos}

\subsubsection{Procesos mecanoquímicos}

Este proceso se utiliza para obtener nanopartículas de forma sencilla y económica. EL método implica una molienda en seco de alta energía, en un molino de bolas, a baja temperatura. Como diluyente se usa $\mathrm{NaCl}$ que actúa separando las partículas formadas.

Una dificultad fundamental en este método es la molienda uniforme del polvo y la reducción de los granos al tamaño requerido, las cuales pueden modificarse aumentando el tiempo y la energía de molienda, pero esto conduce a un aumento en las impurezas. Las ventajas de este método son los bajos costos de producción, una estructura cristalina similar y morfología homegenea.

\footnotetext{
${ }^{4}$ S. Mahmud, M. Abdullah, G. Putrus, J. Chong, A. Mohamad, Synthesis and Reactivity in Inorganic, MetalOrganic, and Nano-Metal Chemistry 36 (2003) 155-159.

5 T. Tsuzukim, P. McCormick, Journal of Materials Science 39 (2004) 5143-5146.
} 
Los materiales de partida usados generalmente son $\mathrm{ZnCl}_{2}$ y $\mathrm{Na}_{2} \mathrm{CO}_{3}$, como medio de reacción se usa $\mathrm{NaCl}$. Este proceso involucra dos etapas:

$$
\mathrm{ZnCl}_{2}+\mathrm{Na}_{2} \mathrm{CO}_{3} \rightarrow \mathrm{ZnCO}_{3}+2 \mathrm{NaCl}
$$

La segunda etapa consiste en la descomposición térmica del $\mathrm{ZnCO}_{3}$ a temperaturas entre 400 y $800^{\circ} \mathrm{C}$

$$
\mathrm{ZnCO}_{3} \rightarrow \mathrm{ZnO}+\mathrm{CO}_{2}
$$

El proceso mecano - químico fue estudiado por varios autores con el objetivo de obtener $\mathrm{ZnO}$ con diferentes tamaños de partículas. ${ }^{6}$ Los resultados obtenidos mostraron que el tamaño depende del tiempo de molienda y de la temperatura de calcinación, cuando aumenta el tiempo de molienda de 2 a 6 hs el tamaño cristalino disminuye.

Por otro lado, Tsuzuki y Mc Cormick ${ }^{7}$ encontraron que un tiempo de molienda de 4 hs era suficiente para obtener el $\mathrm{ZnCO}_{3}$, este se calcinó a $400{ }^{\circ} \mathrm{C}$ y se obtuvieron partículas con un tamaño cristalino de $26 \mathrm{~nm}$. Estos autores mostraron que la molienda en ausencia de diluyentes conduce a la formación de agregados de entre $100 \mathrm{~nm}$ y $1 \mu \mathrm{m}$, confirmando así el rol fundamental del $\mathrm{ZnCl}_{2}$ en la prevención de formación de aglomerados.

\subsubsection{Precipitación controlada}

Para obtener un producto con propiedades reproducibles se utiliza el método de precipitación controlada. Este proceso implica una reducción rápida y espontánea de una solución de sal de zinc utilizando un agente reductor, para limitar el crecimiento de partículas con dimensiones especificadas, seguido por la precipitación de un precursor de $\mathrm{ZnO}$ de la solución. En la etapa siguiente, este precursor se somete a tratamiento térmico,

\footnotetext{
${ }^{6}$ W. Ao, J. Li, H. Yang, X. Zeng, X. M, Powder Technology 168 (2006) 128-151.
}

${ }^{7}$ T. Tsuzuki, P. McCormick, Scripta Materialia 44 (2001) 1731-1734. 
seguido de molienda para eliminar las impurezas. Es muy difícil de romper los aglomerados que se forman, de manera que los polvos calcinados tienen un alto nivel de aglomeración de partículas. El proceso de precipitación es controlado por parámetros tales como $\mathrm{pH}$, temperatura y tiempo de precipitación.

A partir de soluciones de $\mathrm{ZnCl}_{2}$ o $\mathrm{Zn}\left(\mathrm{CH}_{3} \mathrm{COO}\right)_{2}$ se han obtenido $\mathrm{ZnO}$, en estos casos los parámetros que controlan las propiedades son: concentración de reactivos, velocidad de adición de sustratos y temperatura de reacción.

Varios autores estudiaron este proceso usando diferentes precursores, por ejemplo, Wang y col., ${ }^{8}$ quienes sintetizaron $\mathrm{ZnO}$ a partir de una solución acuosa de $\mathrm{NH}_{4} \mathrm{HCO}_{3}$ y $\mathrm{ZnSO}_{4} .7 \mathrm{H}_{2} \mathrm{O}$, según las siguientes reacciones:

$$
\begin{gathered}
5 \mathrm{ZnSO}_{4}+10 \mathrm{NH}_{4} \mathrm{HCO}_{3} \rightarrow \mathrm{Zn}_{5}\left(\mathrm{CO}_{3}\right)_{2}(\mathrm{OH})_{6}+5\left(\mathrm{NH}_{4}\right)_{2} \mathrm{SO}_{4}+8 \mathrm{CO}_{2}+2 \mathrm{H}_{2} \mathrm{O} \\
\mathrm{Zn}_{5}\left(\mathrm{CO}_{3}\right)_{2}(\mathrm{OH})_{6} \rightarrow 5 \mathrm{ZnO}+2 \mathrm{CO}_{2}+3 \mathrm{H}_{2} \mathrm{O}
\end{gathered}
$$

Este proceso se llevó a cabo en un reactor de membrana formado por dos placas de politetrafluoroetileno (PTFE). El ZnO obtenido por este método tenía un rango de tamaños de partículas de 9 a $20 \mathrm{~nm}$. Se encontró que el tamaño de partícula se ve afectado por la temperatura, tiempo de calcinación, concentración y velocidad de agregado del agente precipitante.

En los procesos de síntesis de nanopartículas basados en la precipitación, es cada vez más frecuente el uso de tensioactivos con el objetivo de controlar el crecimiento de las mismas. La presencia de estos compuestos afecta no sólo la nucleación y el crecimiento de

\footnotetext{
${ }^{8}$ Y. Wang, C. Zhang, S. Bi, G. Luo, Powder Technology 202 (2010) 30-136.
} 
partículas, sino también la coagulación y la floculación. El método tensioactivo implica la quelación de los cationes metálicos del precursor por tensioactivos en un medio acuoso. Wang y col. ${ }^{9}$ obtuvieron óxido de zinc nanométrico a partir de $\mathrm{ZnCl}_{2}$ y $\mathrm{NH}_{4} \mathrm{OH}$ en presencia del tensioactivo catiónico $\mathrm{CTAB}$ (bromuro de cetiltrimetilamonio). El procedimiento se llevó a cabo a temperatura ambiente y el sólido resultante se calcinó a 500 ${ }^{\circ} \mathrm{C}$ para eliminar los residuos del tensioactivo. El producto fue altamente cristalino con una estructura wurtzita y nanopartículas esféricas pequeñas $(50 \mathrm{~nm})$. Se encontró que CTAB afecta el proceso de nucleación y crecimiento de cristales durante la síntesis, y también evita la formación de aglomerados.

\subsubsection{Métodos sol- gel}

La obtención de $\mathrm{ZnO}$ por este método es de gran interés, debido a la simplicidad, bajo costo, reproducibilidad y condiciones suaves de síntesis. Las propiedades ópticas favorables de los sólidos obtenidos por este método lo hacen interesante.

Diferentes autores ${ }^{10,11}$ han estudiado este método, usando $\mathrm{Zn}\left(\mathrm{CH}_{3} \mathrm{COO}\right)_{2} \cdot 2 \mathrm{H}_{2} \mathrm{O}$ como sal precursora y 2- metoxietanol o dietilen glicol como solventes, con el objetivo de mejorar las propiedades de los sólidos obtenidos. Encontrándose diferencias en los parámetros de red y en la morfología de los sólidos obtenidos.

\footnotetext{
${ }^{9}$ Y. Wang, C. Ma, X. Sun, H. Li. Inorganic Chemistry Communications 5 (2002) 751-755.

${ }^{10}$ J. Lee, K. Ko, B. Park. Journal of Crystal Growth 247 (2003) 119-125.

11 K. Lin, H. Cheng, H. Hsu, L. Lin, W. Hsieh. Chemical Physics Letters 409 (2005) 208-211.
} 


\subsubsection{Métodos Hidrotermales}

Este método no requiere el uso de solventes orgánicos ni procesos adicionales, como molienda y calcinación. De esta forma el producto obtenido es amigable con el ambiente. La síntesis tiene lugar en una autoclave, aquí los reactivos se mezclan y se calientan de forma gradual a una temperatura entre 100 y $300{ }^{\circ} \mathrm{C}$, dejándose varios días. Se forman núcleos cristalinos, que luego crecen, como consecuencia del calentamiento y posterior enfriamiento. Este método tiene varias ventajas: la posibilidad de realizar la síntesis a bajas temperaturas, la diversidad de tamaños y formas de partículas que pueden obtenerse como resultado de la composición de la mezcla de partida y de la temperatura de calentamiento, el alto grado de cristalinidad y la pureza del material obtenido. ${ }^{12,13}$

\subsubsection{Otros métodos de síntesis de $\mathrm{ZnO}$}

Existen otros métodos de síntesis de $\mathrm{ZnO}$, entre ellos se encuentran crecimiento a partir de vapor, métodos sonoquímicos, síntesis usando microondas, etc.

Todos estos métodos fueron estudiados por diferentes autores con el objetivo de mejorar las propiedades de los sólidos obtenidos. Como se verá más adelante, las propiedades están relacionadas con el tamaño de partícula y el número de vacancias presentes.

\footnotetext{
${ }^{12}$ A. Djurišcić, X. Chen, Y. Lung, Recent Patents on Nanotechnology 6 (2012) 124-134.

${ }^{13}$ T. Tsuzuki, H. Dawkins, J. Dunlop, G. Trotter, M. Nearn, P. McCormick, Cosmet. Aeorosol Toilet. Aust. 15 (2005) 10-24.
} 


\subsection{Técnicas de caracterización}

\subsubsection{Difracción de Rayos X}

Las estructuras cristalinas adoptadas por el $\mathrm{ZnO}$ son wurtzita, blenda y sal de roca. En condiciones normales, la fase termodinámicamente estable es la wurtzita, mientras que la fase blenda de zinc solo se estabiliza por crecimiento en sustratos cúbicos. La sal de roca se obtiene bajo condiciones de síntesis con alta presión.

La estructura wurtzita tiene una celda unidad hexagonal con dos parámetros de red $a$ y $c$, con relación de $c / a=1.633$. Pertenece al grupo espacial C46v en la notación de Schoenflies y P63mc en la notación de Hermann-Mauguin.

Los parámetros de red del $\mathrm{ZnO}$ se ven afectados por defectos tales como de vacancias e impurezas, los cuales pueden modificarse usando diferentes precursores y temperaturas de trabajo. $^{14}$

La relación c/a depende de la diferencia de electronegatividades entre los átomos presentes en el sólido. Cuando los componentes presentan grandes diferencias, mayor es la desviación respecto de la relación $c / a$ ideal. ${ }^{15}$

La estructura de la blenda de zinc es metaestable y solo puede estabilizarse mediante el crecimiento en sustratos cúbicos como $\mathrm{ZnS}, \mathrm{GaAs} / \mathrm{ZnS}$ y $\mathrm{Pt} / \mathrm{Ti} / \mathrm{SiO}_{2} / \mathrm{Si}$, reflejando así la tendencia intrínseca a formar la fase wurtzita. Hay cuatro átomos por cada celda unidad, y cada uno de ellos se coordina tetraédricamente con cuatro átomos de otro tipo y viceversa.

\footnotetext{
${ }^{14}$ M. Leszczynski, T. Suski, P. Perlin, H. Teisseyre, I. Grzegory, M. Bockowski, J. Jun, S. Porowski, K. Pakula, J. Baranowski, C. Foxon, T. Cheng, Applied Physics Letters 69 (1996) 73.

${ }^{15}$ E. Kisi, M. Elcombe, Acta Crystallographica C. Crystal Structure Communications 45 (1989) 1867.
} 
En ambas estructuras la coordinación es tetraédrica, de esta forma los cuatro primeros vecinos y los doce de la segunda esfera de coordinación presentan las mismas distancias de enlace.

Al igual que otros semiconductores del grupo II- IV, la wurtzita puede convertirse en sal de roca a presiones relativamente moderadas.

\subsubsection{UV- vis DRS}

El $\mathrm{ZnO}$ tiene una banda de energía prohibida o band gap, Egap, de 3,37 eV y una alta energía de enlace excitónica de $60 \mathrm{MeV}$. Debido a estas propiedades, el ZnO es un material promisorio como emisor de luz ultravioleta (UV) y como posible dispositivo utilizando efectos excitónicos, inclusive a temperatura ambiente. Es un semiconductor transparente atractivo para posibles aplicaciones novedosas en circuitos integrados de electrónica transparente, tecnología que se espera pueda reemplazar a las existentes.

Otras propiedades interesantes del $\mathrm{ZnO}$ son: la energía de los fonones ópticos longitudinales tiene un valor de $72 \mathrm{MeV}$, su permitividad dieléctrica a baja frecuencia es $\varepsilon_{0}$ $=8,75(\|)$ y $7,8(\perp)$, y frecuencia alta es $\varepsilon_{\infty}=3,75(\|)$ y $3,70(\perp)$.

A altas presiones, se forma una estructura cúbica (red de $\mathrm{NaCl}$ ); $\mathrm{El} \mathrm{ZnO}$ cúbico es un semiconductor con un ancho de banda de $\mathrm{E}_{g a p}=2,7 \mathrm{eV}$.

Algunas de estas propiedades (en especial su alto band gap a temperatura ambiente) convierten a este óxido metálico en un excelente candidato para aplicaciones como dispositivos optoelectrónicos, transductores acústicos, varistores, sensores de gas, electrodos transparentes, ventanas ópticas en paneles solares, dispositivos emisores de campo y conductores transparentes. 
El $\mathrm{ZnO}$ puede doparse con ciertos elementos como Ga, In, Mg. Experimentalmente se observó que esto conduce a un aumento en el valor de $\mathrm{E}_{g a p}$, así como un crecimiento en el valor de Energía de Activación de los centros donantes y su estabilidad.

\subsubsection{Espectroscopía de aniquilación de positrones (PALS)}

La espectroscopia de aniquilación de positrones es una técnica de caracterización no destructiva, ya que solo se estudia la radiación electromagnética producida por la aniquilación electrón- positrón y es, sobre todo, muy utilizada para estudiar la estructura electrónica e identificar defectos en sólidos. Esto último se debe, principalmente, al hecho de que esta técnica es sensible a la densidad electrónica en la red.

La espectroscopía de aniquilación de positrones permite relacionar los parámetros de aniquilación con las técnicas de síntesis usadas. ${ }^{16,17}$

\subsection{Aplicaciones}

Debido a sus propiedades químicas y físicas, el $\mathrm{ZnO}$ es usado en diversas áreas. Desempeña un papel importante en una amplia gama de aplicaciones tales como: carga de neumáticos, industria farmacéutica, agricultura, cerámicos, pinturas, etc.

\subsubsection{Industria del caucho}

Gran parte de la producción de $\mathrm{ZnO}$ es usada en la industria del caucho. ${ }^{18}$ El objetivo del agregado de $\mathrm{ZnO}$ al caucho es provocar un aumento en la conductividad térmica. Las

\footnotetext{
${ }^{16}$ A. Zubiaga, F. Plazaola, J. Garcia, F. Tuomisto, V. Munoz-Sanjose, R. Tena-Zaera, Physical Review B 76 (2007)

${ }^{17}$ L. Damonte, L. Mendoza Zelis, B. Marı Soucase, M. Hernandez Fenollosa, Powder Technology 148 (2004) 15- 19 .
} 
nanopartículas de $\mathrm{ZnO}$ tienden a aglomerarse formando partículas de mayor tamaño en la matriz polimérica, debido a la baja interacción entre la superficie de las nanopartículas y el polímero.

Con el objetivo de solucionar este problema se están estudiando técnicas de modificación de la superficie, para mejorar la interacción entre las nanopartículas y el polímero.

\subsubsection{Industria farmacéutica y cosmética}

Debido a sus propiedades antibacteriales, desinfectantes y deshidratantes ${ }^{19,20}$ el $\mathrm{ZnO}$ es ampliamente utilizado en la producción de diversos tipos de medicamentos. En la actualidad se aplica localmente, usualmente en forma de pomadas y cremas debido a la capacidad para acelerar la cicatrización de heridas. En concentraciones más altas tiene un efecto de descamado de la piel. Además, se utiliza en odontología, principalmente como componente de pastas dentales, y también para rellenos temporales. El ZnO también se utiliza en varios tipos de productos nutricionales y suplementos dietéticos. ${ }^{21}$

Debido a su capacidad para absorber la radiación UVA y UVB, el ZnO se utiliza en protectores solares. Una nueva formulación contiene una combinación de $\mathrm{ZnO}$ y $\mathrm{TiO}_{2}$, siendo más transparente, menos adhesiva y se frota mucho más fácilmente en la piel. ${ }^{22}$

\footnotetext{
${ }^{18}$ A. Das, D. Wang, A. Leuteritz, K. Subramaniam, H. Greenwell, U. Wagenknecht, G. Heinrich, Journal of Materials Chemistry 21 (2011) 7194-7200.

19 H. Liu, D. Yang, H. Yang, H. Zhang, W. Zhang, Y. Fang, Z. Liu, L. Tian, B. Lin, J. Yan, Journal of Hazardous Materials 248 (2013) 478-486.

${ }^{20}$ M. Mirhosseini, F. Firouzabadi, International Journal of Dairy Technology 65 (2012) 1-5.

${ }^{21}$ P. Mason. Physiological and medicinal zinc, The Pharmaceutical Journal 276 (2006) 271-274.

${ }^{22}$ M. Newman, M. Stotland, J. Ellis, Journal of the American Academy of Dermatology 61 (2009) 685-692.
} 


\subsubsection{Industria textil}

La industria textil ofrece un gran potencial para la aplicación de materiales nanoestructurados. Los tejidos autolimpiantes son muy requeridos para aplicaciones militares. El ZnO es biológicamente compatible, permeable al aire y eficiente bloqueador de los rayos UV, por esta razón se ha vuelto atractivo para la industria textil. ${ }^{23}$ Se han descrito diferentes métodos para la producción de tejidos que protegen los rayos ultravioletas utilizando nanoestructuras de $\mathrm{ZnO}$. Por ejemplo, las nanopartículas de $\mathrm{ZnO}$ cultivadas de forma hidrotérmica en tela de algodón recubierta con $\mathrm{SiO}_{2}$ mostraron excelentes propiedades de bloqueo de UV. ${ }^{24}$ La síntesis de nanopartículas de ZnO en otras partes a través de una reacción de fase homogénea a altas temperaturas, seguida de su deposición en tejidos de algodón y lana, produjo una mejora significativa en la actividad de absorción de UV. ${ }^{25}$

\subsubsection{Industria electrónica}

El ZnO tiene una gama de aplicaciones en electrónica y electrotecnia. ${ }^{26,27} \mathrm{Su}$ amplitud de banda de energía $(3,37 \mathrm{eV})$ y alta energía de enlace $(60 \mathrm{MeV})^{28}$ a temperatura ambiente hacen que el $\mathrm{ZnO}$ pueda ser utilizado en equipos fotoelectrónicos ${ }^{29} \mathrm{y}$ electrónicos, ${ }^{30}$ en

23 A. Yadav, V. Prasad, A. Kathe, S. Raj, D. Yadav, C. Sundaramoorthy, N. Vigneshwaran, Bulletin of Materials Science 29 (2006) 641-645.

${ }^{24}$ Z. Mao, Q. Shi, L. Zhang, H. Cao, Thin Solid Films 517 (2009) 2681-2686.

${ }^{25}$ A. Becheri, D. Maximilian, P. Lo Nostro, P. Baglioni, Journal of Nanoparticle Research 10 (2008) 679689.

26 Y. Liu, J. Zhou, A. Larbot, M. Persin, Journal of Materials Processing Technology 189 (2007) 379-383.

27 K. Gunaratne, C. Berkdemir, C. Harmon, A. Castelman, The Journal of Physical Chemistry A 116 (2012) $12429-12437$.

28 Y. Kong, D. Yu, B. Zhang, W. Fang, S. Feng, Applied Physics Letters 78 (2001) 407-409.

${ }^{29}$ M. Purica, E. Budianu, E. Rusu, Thin Solid Films 383 (2001) 284-286.

30 T. Aoki, Y. Hatannaka, D. Look, Applied Physics Letters 76 (2000) 3257-3258. 
dispositivos que emiten una onda acústica superficial en los emisores de campo, ${ }^{31}$ sensores, ${ }^{32,33}$ láseres $^{34}$ y células solares. ${ }^{35}$ Este óxido también exhibe el fenómeno de la luminiscencia (principalmente la fotoluminiscencia de la emisión de luz bajo la exposición a la radiación electromagnética). Debido a esta propiedad se utiliza televisores. Es superior a los materiales convencionales, azufre y fósforo (compuestos que exhiben fosforescencia), ya que es más resistente a los rayos UV, y también tiene mayor conductividad eléctrica. Las propiedades fotoluminiscentes del óxido de zinc dependen del tamaño de los cristales del compuesto, defectos en la estructura cristalina y también de la temperatura. ${ }^{36,37}$

Debido a su alta conductividad y excelente permeabilidad para rayos visibles puede utilizarse para la producción de electrodos permeables a la luz en baterías solares. También tiene usos potenciales como electrodos transparentes en equipos fotovoltaicos y electroluminiscentes, y es un material prometedor para dispositivos emisores de UV..$^{38}$

El $\mathrm{ZnO}$ también se utiliza en sensores de gas. Es un material estable cuya selectividad es débil con respecto a gases particulares se puede mejorar añadiendo otros elementos. La temperatura de trabajo de $\mathrm{ZnO}$ es relativamente alta $\left(400-500{ }^{\circ} \mathrm{C}\right)$, pero cuando se utilizan partículas nanométricas esto se puede reducir a alrededor de $300{ }^{\circ} \mathrm{C}$. La sensibilidad de tales dispositivos depende de la porosidad y del tamaño de grano del material, la sensibilidad aumenta a medida que disminuye el tamaño de las partículas de óxido de zinc.

31 S. Jo, J. Lao, Z. Ren, R. Farrer, T. Baldacchini, J. Fourkas, Applied Physics Letters 83 (2003) 4821-4823.

${ }_{32}$ M. Arnold, P. Avouris, Z. Pan, Z. Wang, The Journal of Physical Chemistry B 107 (2003) 659-663.

33 J. Muller, K. Weissenrieder, Journal of Analytical Chemistry 349 (1994) 380-384.

${ }^{34}$ H. Yan, R. He, J. Johnson, M. Law, R. Saykally, P. Yang, Journal of the American Chemical Society 125 (2003) 4728-4729.

${ }^{35}$ N. Senoussaoui, M. Krause, J. Müller, E. Bunte, T. Brammer, H. Stiebig, Thin Solid Films 397 (2004) 451452.

36 S. Lima, F. Sigoli, M. Jafelicci, M. Davolo, International Journal of Inorganic Materials. 3 (2001) 749754.

37 J. Soares, J. Whitten, D. Oblas, D. Steeves, Langmuir 24 (2008) 371-374.

38 M. Wang, X. Wang, Solar Energy Materials and Solar Cells 92 (2008) 357-362. 
Es más comúnmente usado para detectar $\mathrm{CO}$ y $\mathrm{CO}_{2}$ (en minas y en equipos de alarma), pero también puede ser usado para la detección de otros gases $\left(\mathrm{H}_{2}, \mathrm{SF}_{6}, \mathrm{C}_{4} \mathrm{H}_{10}, \mathrm{C}_{2} \mathrm{H}_{5} \mathrm{OH}\right)$. El óxido de zinc utilizado en la producción de tales equipos se obtiene mediante una variedad de métodos (deposición química en fase vapor, pirólisis en aerosol u oxidación de zinc metálico), siendo importante controlar la temperatura del proceso, ya que esto determina las propiedades del producto. ${ }^{39}$

\subsubsection{Fotocatálisis}

El auge de la fotocatálisis como proceso de degradación de contaminantes se observó durante los últimos años. En este proceso, la luz irradiada genera un par electrón- hueco en el sólido debido a reacciones redox que se producen la superficie del mismo.

En presencia de un fotocatalizador un contaminante orgánico puede oxidarse directamente en un hueco fotogenerado o indirectamente a través de una reacción con grupos reactivos característicos (ROS), por ejemplo, el radical $\mathrm{OH}$, generado en solución. Los catalizadores más comúnmente usados son $\mathrm{TiO}_{2}$ y $\mathrm{ZnO}$. El $\mathrm{TiO}_{2}$ exhibe actividad fotocatalítica en longitudes de onda correspondientes al espectro $\mathrm{UV} \cdot{ }^{40} \mathrm{El} \mathrm{ZnO}$ proporciona una actividad similar o superior a la del $\mathrm{TiO}_{2}$, pero es menos estable y menos sensible a la fotocorrosión. ${ }^{41}$ Los óxidos con dimensiones nanométricas ofrecen mejor cristalinidad y defectos más pequeños, ${ }^{42}$ dando lugar a un aumento en la actividad. La actividad fotocatalítica de $\mathrm{ZnO}$ puede mejorarse dopándolo con otros metales.

\footnotetext{
${ }^{39}$ S. Roy, S. Basu, Bulletin of Materials Science 25 (2002) 513-515.

${ }^{40}$ T. Kuo, C. Lin, C. Kuo, M. Huang, Chemistry of Materials 19 (2007) 5143-5147.

${ }^{41}$ C. Hariharan, Applied Catalysis A 304 (2006) 55-61.

42 Q. Xiao, L. Ouyang, Journal of Alloys and Compounds 479 (2009) L4-L7.
} 
Varios autores ${ }^{43}$ han estudiado las propiedades del $\mathrm{ZnO}$, haciendo posible su uso en la degradación de diversos contaminantes.

\subsubsection{Otras aplicaciones}

Además de las aplicaciones mencionadas anteriormente, el $\mathrm{ZnO}$ también puede ser utilizado en otras ramas de la industria, incluyendo por ejemplo la producción de hormigón. La adición de este material mejora el tiempo de proceso y la resistencia del hormigón a la acción del agua. Además, el agregado de $\mathrm{ZnO}$ al cemento Portland ralentiza el endurecimiento y enfriamiento (reduce la evolución gradual del calor), y mejora la blancura y la resistencia final. El zinc se agrega en forma de silicatos a pinturas, ya que funcionan como ligantes. El metanol, el tercer producto químico más importante de la industria química, se produce utilizando un catalizador de $\mathrm{Cu} / \mathrm{ZnO} / \mathrm{Al}_{2} \mathrm{O}_{3}$, con pequeñas partículas de $\mathrm{Cu}$ promovidas por su interacción con el sustrato de $\mathrm{ZnO}$ como componente activo. ${ }^{44} \mathrm{El}$ ZnO también se utiliza para la producción de tintas tipográficas y debido a su alta fluidez, la cual le otorga buenas propiedades de impresión. Este óxido también se utiliza en los pigmentos para producir brillo. Debido a sus propiedades químicas y antifúngicas especiales, el $\mathrm{ZnO}$ y sus derivados también se utilizan en el proceso de producción y envasado de productos cárnicos (por ejemplo, carne y pescado) y productos vegetales (maíz, garbanzos y lentejas). ${ }^{45}$

\footnotetext{
${ }^{43}$ J. Xie, Y. Li, W. Zhao, L. Bian, Y. Wei, Powder Technology 207 (2011)140-144.

${ }^{44}$ C. Wöll, Progress in Surface Science 82 (2007) 55-120.

45 P. Espitia, N. Soares, J. Coimbra, N. de Andrade, R. Cruz, E. Medeiros, Food and Bioprocess Technology 5 (2012) 1447-1464.
} 


\section{$\sim$ Capítulo 4}

\section{Experimental}




\subsection{Lixiviaciones}

Tipos de pilas usadas, ventajas de la

biolixiviación y condiciones

experimentales estudiadas 


\subsubsection{Las pilas en este trabajo de Tesis}

En este trabajo de Tesis se evaluará el reciclado de pilas alcalinas y de $\mathrm{Zn} / \mathrm{C}$ y posibles aplicaciones tecnológicas de los metales recuperados.

Como se describió en el Capítulo 1, las pilas alcalinas están compuestas por un ánodo de zinc, un cátodo de dióxido de manganeso de alta densidad, y un electrolito de hidróxido de potasio.

Las pilas de $\mathrm{Zn} / \mathrm{C}$ están divididas en dos grupos: LeClanché o cloruro de zinc. Ambos sistemas están compuestos por un ánodo de zinc, cátodo de dióxido de manganeso y un electrolito ligeramente ácido. Las pilas LeClanché contienen una mezcla de cloruro de amonio y cloruro de zinc en agua como electrolito, mientras que en las pilas de cloruro de zinc, el electrolito es una solución de cloruro de zinc en agua.

\subsubsection{Descripción del proceso de biolixiviación}

El proceso de biolixiviación se produce por la catálisis que ciertos microorganismos ejercen durante la disolución de algunas menas minerales. El microorganismo utiliza el mineral como fuente de energía, generalmente minerales sulfurados o con contenido de Fe (II). Los sulfuros insolubles son transformados en sulfatos solubles, sin la necesidad de aplicar una fuente externa de energía. ${ }^{1}$ A partir del cultivo de bacterias Acidithiobacillus thiooxidans $(A t)$ en un biorreactor relleno con azufre elemental, estas bacterias forman un biofilm sobre el azufre generando ácido sulfúrico y compuestos reductores (politionatos). Estos últimos luego son usados en el proceso de disolución de minerales no sulfurados. ${ }^{2,3}$

\footnotetext{
${ }^{1}$ Y. Rodríguez, M. Blázquez, A. Ballester, F. González, J. Muñoz, Revista de Metalurgia Madrid 37 (2001) 616-627.

${ }^{2}$ G. Curutchet, E. Donati, C. Pogliani, C. Oliver, M. Viera, Methods in Enzymology 337 (2001) 171-186.
} 
En esta tesis se usó este método para la recuperación de metales de pilas alcalinas y de $\mathrm{Zn} / \mathrm{C}$, modificando algunas variables (temperatura, agregado de agentes reductores, relación sólido/líquido) con el objetivo de optimizar el proceso de lixiviación.

Tanto las pilas alcalinas como las de $\mathrm{Zn} / \mathrm{C}$ tienen como componentes principales zinc y manganeso, las ecuaciones generales de disolución de estos metales al reaccionar con el medio ácido reductor generado por las bacterias del tipo At se muestran a continuación: ${ }^{4,5}$

$$
\begin{aligned}
& \mathrm{Zn}+\mathrm{H}_{2} \mathrm{SO}_{4} \rightarrow \mathrm{Zn}^{2+}+\mathrm{SO}_{4}{ }^{2-}+\mathrm{H}_{2} \\
& \mathrm{MnO}+\mathrm{H}_{2} \mathrm{SO}_{4} \rightarrow \mathrm{Mn}^{2+}+\mathrm{SO}_{4}{ }^{2-}+\mathrm{H}_{2} \mathrm{O} \\
& \mathrm{MnO}_{2}+\mathrm{S}_{\mathrm{n}}\left(\mathrm{SO}_{3}\right)_{2}{ }^{2-} \rightarrow \mathrm{Mn}^{2+}+\mathrm{m} \mathrm{SO}_{4}{ }^{2-}
\end{aligned}
$$

\subsubsection{Ventajas de la biolixiviación}

Los procesos biohidrometalúrgicos presentan numerosas ventajas que los hacen atractivos para su utilización en la industria.

Entre estas ventajas se encuentran: los bajos costos de producción, energía; equipamiento básico, de fácil instalación y operación; recuperación de metales de minerales de baja ley; de residuos, bajos costos ambientales. ${ }^{6,7}$ Algunos procesos biohidrometalúrgicos para operaciones industriales y remediación tienen menor demanda

${ }^{3}$ C. Pogliani, G. Curutchet, E. Donati, Bioleaching of a sulfide ore by combined attack of two species of Thiobacilli, Proceedings of 3rd Sourthen Hemisphere Meeting of Mineral Technology, Bs. As., 1997.

${ }^{4}$ Y. Li, G. Xi, Journal of Hazardous Materials 127 B (2005) 244-248.

5 I. De Michelis, F. Ferella, E. Karakaya, F. Beolchini, F. Veglio, Journal of Power Sources 172 (2007) 975983.

${ }^{6} \mathrm{H}$. Watling, Hydrometallurgy 84 (2006) 81-108.

${ }^{7}$ J. Brierley, Hydrometallurgy 94 (2008) 2-7. 
de energía que las tecnologías alternativas y pueden reducir potencialmente los costos de la industria.

Los costos del ácido sulfúrico pueden ser variables dependiendo de la demanda y la ubicación. La biolixiviación puede ser utilizada para producción in situ de ácido sulfúrico y de esta manera eliminar o reducir los costos de la producción tradicional de ácido.

La explotación de depósitos de minerales de baja ley por procesos convencionales es, entre otras cosas, difícil de aprovechar. Un ejemplo de esto es la explotación de depósitos secundarios de sulfuros de cobre, los que pueden ser demasiado pequeños o de muy difícil acceso como para ser rentables realizando una flotación de concentrado tanto para despachar como para fundir in situ. Otro ejemplo es el procesado de sulfuros refractarios de oro que se encuentran en regiones donde las tecnologías de biooxidación son más factibles por costos y razones de fuerza laboral. Un tercer ejemplo son los depósitos de minerales cuya mineralogía es compleja. Estos depósitos son difíciles de tratar y la biohidrometalurgia puede ser una alternativa viable.

Los trámites para obtener los permisos ambientales para la explotación de minas pueden ser largos y dificultosos. El uso de la biohidrometalurgia tanto para el procesado de minerales como para el tratamiento de efluentes puede ofrecer algunas ventajas ambientales en comparación con las tecnologías convencionales. En algunos casos, los bioprocesos son vistos como "tecnologías verdes". 


\subsubsection{Condiciones experimentales}

En su Tesis Doctoral L. Falco ${ }^{8}$ ha demostrado que el proceso biohidrometalúrgico para la recuperación de metales de pilas alcalinas y de zinc-carbón agotadas, es una alternativa viable y amigable con el medio ambiente para el tratamiento y revalorización de este residuo.

A partir de la información obtenida en esa Tesis, se construyó en la Planta Piloto Multipropóstio (PlaPiMu-LaSeISiC, CICPBA) una planta de producción de medio ácido reductor que consta de 15 biorreactores air-lift de $40 \mathrm{~L}$ de capacidad (una vez rellenados con el lecho de azufre) un sistema de almacenamiento de este medio ácido y dos reactores tipo tanque agitado de $100 \mathrm{~L}$ de capacidad destinados a los procesos de lixiviación y recuperación de los metales.

En este capítulo se estudiarán distintos factores que podrían mejorar el rendimiento de la lixiviación, por esta razón los ensayos se harán a escala de laboratorio.

\subsubsection{Biorreactores}

Se usaron quince biorreactores del tipo air-lift de circulación interna que fueron estudiados en una tesis previa del grupo. ${ }^{8}$ Los reactores funcionan con tres fases: sólida, el lecho compacto de azufre; líquido, el medio de cultivo y las bacterias en suspensión; gaseoso, el aire inyectado por la parte inferior del reactor. El diseño de circulación interna con inyección de gas en el tubo central tiene como objetivo utilizar la zona del downcomer para formar el lecho compacto de azufre, aprovechando el hecho que en esta zona la

\footnotetext{
8 L. Falco, Tesis Doctoral: Optimización de un proceso biohidrometalurgico de recuperación de metales de
} pilas alcalinas y de cinc- carbón agotadas. UNLP- 2013 
contribución a la transferencia de masa es despreciable. ${ }^{9}$ El downcomer se rellenó con un lecho de azufre molido a una granulometría determinada. Los reactores se inocularon con una cepa de bacterias en medio de cultivo. En la Figura 4.1 se muestra un esquema de un biorreactor.

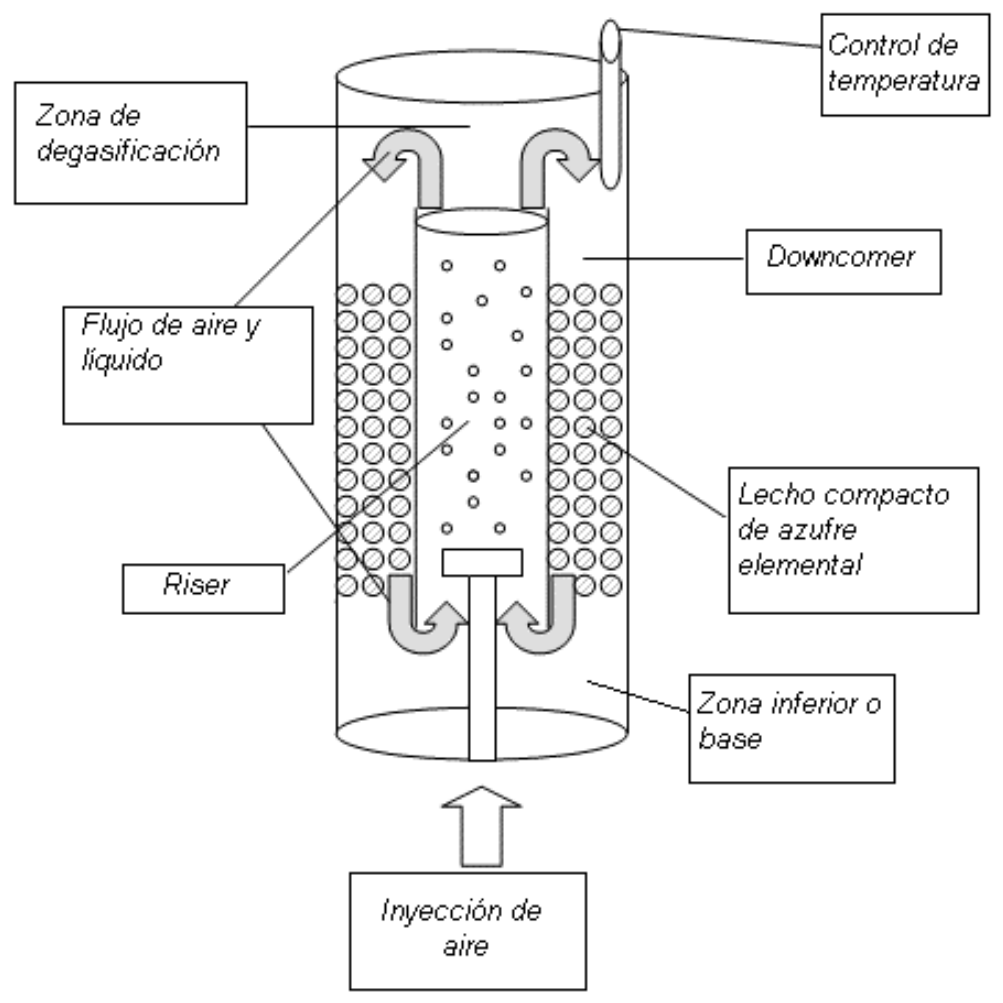

Figura 4.1. Esquema del biorreactor.

Las bacterias utilizadas fueron Acidithiobacillus thiooxidans DSM 11478 aislada originalmente en Morro Velho (Minas Gerais, Brasil). El medio de cultivo utilizado es el denominado $0 \mathrm{~K}^{10}$ y tiene la siguiente composición: sulfato de amonio (Cicarelli) $3 \mathrm{~g} \mathrm{~L}^{-1}$, sulfato de magnesio (Anedra) 0,5 $\mathrm{g} \mathrm{L}^{-1}$, fosfato di-ácido de potasio (Cicarelli) 0,5 $\mathrm{g} \mathrm{L}^{-1}$,

\footnotetext{
9 J. Merchunk, F. Garcia Camacho, Biorreactors. Air-lift reactors, Wiley Encyclopedia of Industrial Biotechnology (2007)

${ }_{10}$ M. Silverman, D. Lundgren, Journal of Bacteriology 77 (1959) 642-647.
} 
cloruro de potasio (Cicarelli) 0,1 $\mathrm{g} \mathrm{L}^{-1}$, nitrato de calcio (Cicarelli) $0,01 \mathrm{~g} \mathrm{~L}^{-1}$, ácido sulfúrico (Anedra) $1 \mathrm{M}$ gotas hasta llegar a $\mathrm{pH}=2,5$.

Para los biorreactores se utilizó este mismo medio reducido en nitrógeno $\left(1 \mathrm{~g} \mathrm{~L}^{-1}\right.$ de sulfato de amonio), estos funcionan en batch. Se utilizó agua corriente para preparar el medio de cultivo $0 \mathrm{~K}$. Debido a que el $\mathrm{pH}$ no era similar en todos los reactores el sistema fue modificado con el objetivo de lograr un caudal homogéneo de aire, realizándose esta mejora con un PICT start up 2012. El caudal de aire se mantuvo a $300 \mathrm{~L} \mathrm{~h}^{-1}$, controlado por válvulas agujas y rotámetros instalados en la entrada de aire.

\subsubsection{Máquina cortadora de pilas}

El equipo usado para cortar las pilas consiste en dos discos de corte de acero de $115 \mathrm{~mm}$ de diámetro externo y $0,8 \mathrm{~mm}$ de espesor, girando a elevada velocidad (entre $12.000 \mathrm{y}$ $15.000 \mathrm{rpm}$ ) en sentidos opuestos. Sus bordes asoman dentro de una guía de acero a través de la cual se hace bajar la pila forzándola con una varilla de madera. En la parte inferior de esta guía se encuentra un recipiente que recoge las pilas con sus dos cortes longitudinales. Los discos se accionan mediante dos amoladoras puestas en oposición, instaladas en un gabinete estanco con extractor incluido para eliminar el polvo y los vapores originados por el corte de las pilas. Esta máquina es útil para esta escala de trabajo, pero al pensar en una planta industrial se deberían usar molinos especiales o trituradores. En la Figura 4.2 se muestra un esquema de la maquina usada para cortar pilas. 


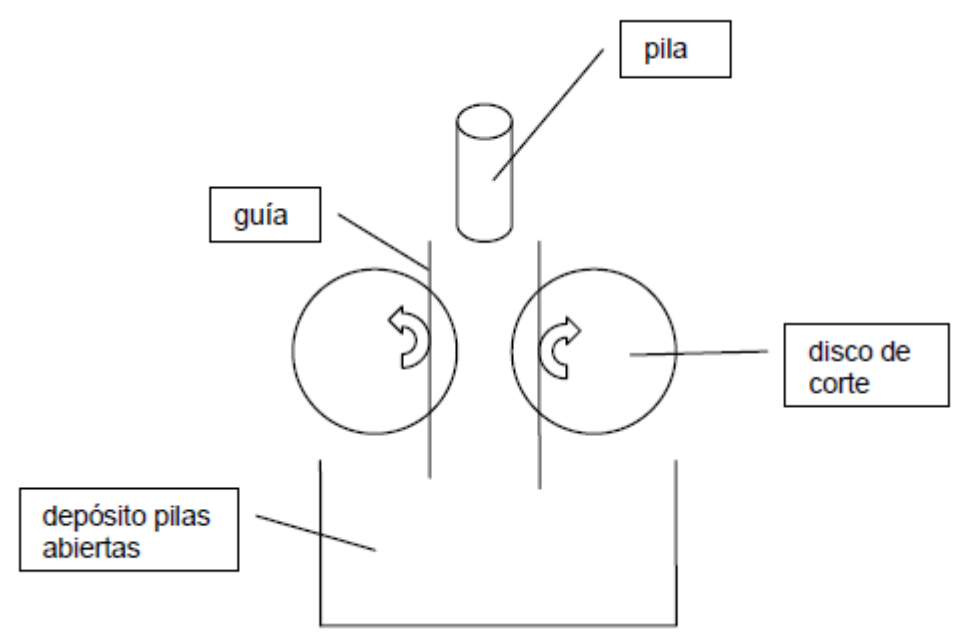

Figura 4.2. Esquema de la maquina usada para cortar las pilas.

\subsubsection{Variables experimentales estudiadas}

En bibliografía se encontró ${ }^{11,12}$ que la variación de la temperatura, la relación sólido/líquido usada, el pH, el agregado de agentes reductores, etc. afectan al proceso de lixiviación. Por esta razón el objetivo de la primera parte de esta Tesis fue optimizar las condiciones de recuperación de manganeso y zinc de pilas agotadas.

En las experiencias realizadas se estudió en primer término, la influencia de la relación sólido/líquido. Con este fin se utilizaron diferentes tipos de muestras de barros de pilas: (i) barro crudo (secado a $120{ }^{\circ} \mathrm{C}$ ), (ii) barro lavado con agua neutra y secado a $120{ }^{\circ} \mathrm{C}$ y (iii) barro lavado con agua neutra, secado a $120{ }^{\circ} \mathrm{C}$ y calcinado a $700{ }^{\circ} \mathrm{C}$ en aire durante 4 horas. Las variables estudiadas en las experiencias de lixiviación fueron: relación sólido/líquido, el efecto de la temperatura y el agregado de agentes reductores. Las lixiviaciones se

${ }^{11}$ E. Sayilgan, T. Kukrer, G. Civelekoglu, F. Ferella, A. Akcil, F. Veglio, M. Kitis, Hydrometallurgy 97 (2009) 158-166.

12 R. Biswas, M. Habib, A. Karmakar, S. Tanzin, Waste Management 51 (2016) 149-156. 
realizaron poniendo en contacto el barro con el medio ácido reductor biogenerado en un erlenmeyer con agitador magnético. Se tomaron alícuotas de $1 \mathrm{~mL}$ cada 30 min para determinar la concentración de metales por espectrofotometría de absorción atómica. El pH fue monitoreado usando un electrodo de vidrio en el erlenmeyer.

Variables estudiadas:

$\checkmark$ Relación barro/ácido, entre 0,01 y $0,05 \mathrm{~g} \mathrm{~mL}^{-1}$.

$\checkmark$ Temperatura, entre 30 y $70{ }^{\circ} \mathrm{C}$.

$\checkmark$ Agentes reductores, $\mathrm{H}_{2} \mathrm{O}_{2}$ (Anal Quim 100 vol) y $\mathrm{Na}_{2} \mathrm{SO}_{3}$ (Cicarelli Anhidro PA), concentraciones de $1 ; 2,5$ y $5 \mathrm{p} / \mathrm{v} \%$. 


\subsection{Recuperación de Mn y Zn}




\subsubsection{Recuperación de Manganeso}

\subsubsection{Introducción}

Como se describió en el Capítulo 2, los óxidos de manganeso pueden usarse como catalizadores en diferentes reacciones de oxidación parcial de alcoholes, tales como butanol, ciclohexanol, alcohol bencílico y fenoles ${ }^{1}$, a sus respectivas cetonas y quinonas; reacción de hidrogenación de etileno ${ }^{2}$, reacciones de deshidrogenación oxidativa como conversión de etilbenceno a estireno ${ }^{3}$,1-buteno a 1-3-butadieno ${ }^{4}$, etc. El amplio uso de los óxidos de manganeso como catalizadores se debe a que poseen iones $\mathrm{Mn}$ en más de un estado de oxidación, estructuras amorfas o poco cristalinas y vacancias.

La solución obtenida de a partir de la lixiviación del barro de pilas alcalinas y de $\mathrm{Zn} / \mathrm{C}$ agotadas, en las mejores condiciones operativas (ver Capitulo 5, sección 1) fue utilizada para preparar una serie de sólidos. A continuación, se describe la preparación de cada una de ellos, como así también las técnicas empleadas para su caracterización.

\subsubsection{Precipitación con $\mathrm{KMnO}_{4}$}

De acuerdo con antecedentes previos ${ }^{5}$ se pueden obtener óxidos de manganeso por reacción directa entre iones $\mathrm{Mn}^{2+}$ y $\mathrm{MnO}_{4}^{-}$, de acuerdo a la siguiente ecuación:

$$
2 \mathrm{MnO}_{4}^{-}+3 \mathrm{Mn}^{2+} \rightarrow 5 \mathrm{MnO}_{2}
$$

\footnotetext{
${ }^{1}$ S. Kanungo, S. Parida, Electrochimica Acta 26(8) (1981) 1147.

2 M. Baltanas, A. Stiles, R. Katzer, Applied Catalysis 28 (1986) 13.

${ }^{3}$ R. Cracium, N. Dulamita, Industrial and Engneering Chemistry Research 38 (1999)1357.

${ }^{4}$ V. Krishnan, S. Suib, Journal of Catalysis 184 (1999) 305.

5 A. Peluso, L. Gambaro, E. Pronsato, D. Gazzoli, H. Thomas, J. Sambeth. Catalysis Today 133-135 (2008) 487492.
} 
Sobre $100 \mathrm{~mL}$ de la solución lixiviada se adicionó $\mathrm{KMnO}_{4}$ (Anhedra RA), con agitación magnética durante 1 hs, obteniéndose un sólido oscuro. El precipitado fue filtrado, lavado y finalmente secado a $100{ }^{\circ} \mathrm{C}(12 \mathrm{hs})$, y calcinado a $50{ }^{\circ} \mathrm{C}$ ( 2 hs). Este solido se denominó OMR.

\subsubsection{Precipitación con $\mathrm{NaOH}$}

Sobre $100 \mathrm{~mL}$ de la solución lixiviada se agregaron granallas de $\mathrm{NaOH}$ comercial (Merck pa) hasta $\mathrm{pH}=8$ con agitación constante durante 60 minutos, a temperatura ambiente. El precipitado fue tratado en las mismas condiciones anteriores. Este sólido se denominó ZnMnR.

\subsubsection{Impregnación del OMR}

El sólido denominado OMR, fue impregnado posteriormente con la solución de iones $\mathrm{Zn}^{2+}$ proveniente de la lixiviación del cátodo de pilas de $\mathrm{Zn} / \mathrm{C}(\mathrm{pH}$ 4) usando dos métodos diferentes, impregnación a humedad incipiente y en exceso de solución.

Al sólido obtenido por impregnación a humedad incipiente se lo denomino OMRA.

El método de impregnación a humedad incipiente consiste en poner en contacto un soporte seco con un volumen de solución impregnante igual al volumen de poros del soporte. Por efecto de las fuerzas capilares la solución impregnante ingresa en los poros del soporte y se distribuye en su interior en un breve período de tiempo. En ocasiones el llenado de los poros con la solución impregnante puede ser demorado por la presencia de aire en los mismos. Este método se emplea para preparar catalizadores donde la fase activa se encuentra altamente dispersa sobre la superficie del soporte. Se pusieron en contacto $5 \mathrm{~g}$ de sólido con $0.8 \mathrm{~mL}$ solución. El sólido se secó y calcinó durante 2 horas a $500{ }^{\circ} \mathrm{C}$. 
El sólido obtenido por la técnica de impregnación con exceso de solución, se denominó

\section{OMRB}

El soporte se contacta con solución en exceso, pero durante el tiempo necesario para llenar los poros, también se está efectuando una impregnación a volumen de poro, por lo que el tiempo de contacto es una variable importante. En el caso de tener exceso de solución, existe la posibilidad de entrada de soluto por mecanismo difusivo. Mediante este método $5 \mathrm{~g}$ del sólido OMR se impregnaron con $50 \mathrm{ml}$ de solución, con agitación constante durante 60 minutos. El sólido obtenido se secó y posteriormente calcinó durante 2 horas a $500{ }^{\circ} \mathrm{C}$

En Tabla 4.1 se indica la nomenclatura de los sólidos obtenidos junto con un resumen de su preparación.

Tabla 4.1. Resumen de la preparación y nomenclatura de los óxidos de manganeso.

\begin{tabular}{lcc}
\hline Nombre & $\begin{array}{c}\text { Método de } \\
\text { preparación }\end{array}$ & $\begin{array}{c}\text { Temperatura de } \\
\text { calcinación }\left({ }^{\mathbf{O} C)}\right.\end{array}$ \\
\hline OMR & $\begin{array}{c}\text { Precipitación con } \\
\mathrm{KMnO}_{4} .\end{array}$ & 500 \\
ZnMnR & $\begin{array}{c}\text { Precipitación con } \\
\text { NaOH a pH 8 }\end{array}$ & 500 \\
OMRA & $\begin{array}{c}\text { Impregnación a } \\
\text { humedad incipiente }\end{array}$ & 500 \\
OMRB & $\begin{array}{c}\text { Impregnación con } \\
\text { exceso de solución }\end{array}$ & 500 \\
\hline
\end{tabular}




\subsubsection{Catalizadores soportados sobre estructuras monolíticas}

Los catalizadores utilizados para la eliminación de COVs operan generalmente en condiciones preestablecidas (presión, temperatura, velocidad espacial, etc.) impuestas por el funcionamiento del sistema de la planta de producción. Asimismo, la pérdida de carga producida en el conjunto, debe ser lo menor posible, para evitar un posible taponamiento de la salida, efecto que aumentaría notoriamente el costo de producción. Por este motivo, es necesario soportar los catalizadores sobre estructuras monolíticas con el fin de mejorar la ecuación eficiencia - ahorro de energía.

La preparación de los soportes monolíticos empleados se realizó en base al trabajo de Tesis Doctoral de A. Peluso ${ }^{6}$. Se utilizaron monolitos de aluminio para depositar la fase activa de interés, en este caso el sólido OMR por el método de washcoating. Otro monolito se impregnó a partir de las sales precursoras comerciales, con el objetivo de comparar la actividad catalítica.

Las condiciones de impregnación se eligieron realizando ensayos previos sobre placas de aluminio anodizadas.

\section{Electrólisis de placas de aluminio.}

Se realizó la electrólisis de dos placas de $\mathrm{Al}$ con el objetivo de formar una capa de $\mathrm{Al}_{2} \mathrm{O}_{3}$ sobre la superficie y de esta manera soportar los óxidos de manganeso. Se prepararon dos placas de aluminio de $22 \mathrm{~cm} \times 3 \mathrm{~cm}$. Las placas se lavaron con agua y detergente, luego con acetona y se secaron para eliminar las impurezas de la superficie.

Antes del proceso de electrólisis, una de las placas se corruga utilizando un dispositivo mecánico diseñado para tal fin. Para la electrólisis se empleó una fuente Digital DC Power Supply TES 6210.

${ }^{6}$ M. A. Peluso, Tesis Doctoral: Desarrollo de Catalizadores para la eliminación de Compuestos Orgánicos Volátiles de Alta Reactividad (ROCs). UNLP, 2006. 
En todos los ensayos se empleó como cuba electrolítica un vaso de precipitado con 200 $\mathrm{ml}$ de solución, con las siguientes condiciones:

Electrolito: ácido sulfúrico 2,55 molar.

Temperatura: $30^{\circ} \mathrm{C}$.

Tiempo: 90 minutos.

Densidad de corriente: $2 \mathrm{~A} \mathrm{dm}^{-2}$.

Burbujeo continuo con aire

Luego del anodizado, las placas se lavaron con agua, se secaron con aire comprimido y fueron calcinadas a $500{ }^{\circ} \mathrm{C}$ por 2 horas.

A partir de las placas de aluminio anodizadas se construye el monolito a usando una placa lisa y una corrugada. Para ello se colocan ambas placas entre dos varillas de acero unidas en uno de los lados y se enrolla la placa corrugada alrededor de la placa lisa, y para sujetar se utiliza un alambre hilo Kantal.

En la Figura 4.3 se muestra una imagen del monolito antes de ser impregnado.

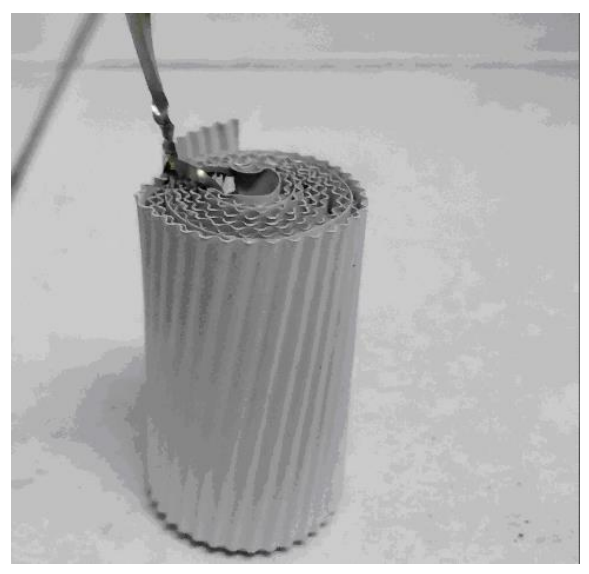

Figura 4.3. Monolito de aluminio anodizado. 


\section{Determinación de cantidad de alúmina}

La cantidad de alúmina generada durante la anodización se determinó por gravimetría. Se calculó a partir de la diferencia de peso en una lámina de aluminio anodizado antes y después de un tratamiento químico que disuelve selectivamente la capa de alúmina. La solución usada contenía $35 \mathrm{~mL}$ de ácido fosfórico y $20 \mathrm{~g}$ de ácido crómico disueltos en $1 \mathrm{~L}$ de agua destilada. El proceso de disolución se lleva a cabo durante $10 \min$ a $80^{\circ} \mathrm{C}$.

\section{Impregnación de Monolitos}

El sólido OMR fue depositado sobre el soporte por la técnica el washcoating. El monolito seco se sumergió en una suspensión del sólido, después de 30 segundos se retiró, se centrifugo para retirar el exceso de suspensión y finalmente se calcinó a $500^{\circ} \mathrm{C}$ con el objetivo lograr una mejor adherencia del catalizador sobre el soporte. El comportamiento de la suspensión usada debe ser del tipo pseudoplástico, por este motivo se agregó un dispersante (carboximetilcelulosa).

Para el estudio de la concentración de sólido, se prepararon suspensiones con 20, 30 y 40 \% p/p del sólido OMR, usando $0.5 \%$ p/p de dispersante. Este monolito se denominó OMRW.

Se comparó la actividad catalítica del monolito OMRW con uno preparado a partir de las sales precursoras, tal como realizó Peluso ${ }^{6}$ en su tesis doctoral.

El monolito seco fue sumergido en una solución de $\mathrm{Mn}\left(\mathrm{NO}_{3}\right)_{2}$, se sometió a agitación orbital durante 30 minutos y se secó en estufa a $100{ }^{\circ} \mathrm{C}$. Luego fue sumergido en una solución de $\mathrm{KMnO}_{4}$, se agito durante 30 minutos y se secó nuevamente. Finalmente se calcinó a $500{ }^{\circ} \mathrm{C}$ durante 2hs. El monolito obtenido se denominó MK. 


\section{Test de adherencia}

Los monolitos colocados en viales con tapa se sumergieron en $5 \mathrm{~mL}$ de éter de petróleo, luego de ser secados a $105{ }^{\circ} \mathrm{C}$ durante $3 \mathrm{hs}$ antes de pesarlos para realizar el ensayo. Se colocaron en un baño de ultrasonido (TESTLAB TB10, Potencia $=400$ Watts, frecuencia $=40$ $\mathrm{kHz}$ ) durante 30 minutos. Luego se dejó escurrir el éter de petróleo de cada monolito en papel y se secaron en estufa a $105^{\circ} \mathrm{C}$ durante 3 horas antes de pesarlos nuevamente.

\subsubsection{Recuperación de Zinc}

\subsubsection{Introducción}

Como se muestra en el Capítulo 3, se pueden preparar $\mathrm{ZnO}$ con diferentes estructuras usando métodos físicos y químicos. Algunos métodos físicos usados son: evaporación, deposición laser de pulso, pulverización catódica, etc. Estas técnicas son costosas y consumen grandes cantidades de energía, porque se necesitan condiciones de alto vacío, alta temperatura y el uso de catalizadores para potenciar el crecimiento de las nanoestructuras. ${ }^{7}$

Los métodos químicos presentan varias ventajas en la síntesis de nanopartículas debido a la posibilidad de producción en masa y su reproducibilidad. Se han usado en los últimos años algunas técnicas químicas para preparar $\mathrm{ZnO}$ nano o microestructurado entre las cuales se encuentran: precipitación, hidrolisis, pirolisis, técnicas de sol gel, etc. éstas permiten controlar el tamaño y la morfología de los cristales si se optimizan ciertos parámetros como por ejemplo: $\mathrm{pH}$, temperatura de calcinación, medio de reacción, contraiones presentes.

La técnica de precipitación comparada con otros métodos químicos proporciona una manera fácil de producción a gran escala de manera reproducible.

\footnotetext{
${ }^{7}$ A. Kołodziejczak-Radzimska, T.Jesionowski, Materials 7 (2014) 2833-2881.
} 


\subsubsection{Obtención de ZnO}

Las pilas alcalinas fueron separadas en cátodo y ánodo. El ánodo de zinc se trató con ácido sulfúrico biogenerado, en una relación sólido/líquido $0.04 \mathrm{~g} \mathrm{~mL}^{-1}$; durante $120 \mathrm{~min}$.

Como resultad se obtuvo una solución $0.4 \mathrm{M}$ de $\mathrm{Zn}^{2+}$ y un sólido remanente que no reaccionó, compuesto por impurezas de carbón en el ánodo de zinc.

Como se vio anteriormente la técnica de precipitación es un método químico fácil, de bajo costo y con ventajas a la hora de la producción en masa y control en la morfología y tamaño de cristales. Ya se mencionó que el objetivo de esta tesis es obtener sólidos a partir de pilas agotadas mediante procesos que impliquen bajos costos y energía y su posterior aplicación en procesos amigables con el ambiente.

Así a partir de la solución de $\mathrm{Zn}^{2+}$ se sintetizaron diferentes sólidos usando la técnica de precipitación con diferentes agentes precipitantes con el objetivo de comparar las propiedades estructurales, ópticas y electrónicas de los óxidos de zinc.

\subsubsection{Precipitación con $\mathrm{H}_{2} \mathrm{C}_{2} \mathrm{O}_{4}$}

Para la obtención del sólido llamado $\boldsymbol{O Z n \boldsymbol { O }}$ se colocaron en un erlenmeyer $100 \mathrm{~mL}$ de solución lixiviada obtenida en el paso anterior. Se agregó luego $\mathrm{H}_{2} \mathrm{C}_{2} \mathrm{O}_{4} .2 \mathrm{H}_{2} \mathrm{O}$ (Anedra RA) sólido en cantidades estequiométricas (0.04 moles). El producto sólido fue filtrado, lavado y secado en estufa a $100^{\circ} \mathrm{C}$ hasta peso constante. Posteriormente se calcinó durante 2 hs a $500{ }^{\circ} \mathrm{C}$.

\subsubsection{Precipitación con $\mathrm{Na}_{2} \mathrm{CO}_{3}$}

Para la obtención del solido llamado $\boldsymbol{C Z n \boldsymbol { O }}$ se colocaron en un erlenmeyer $100 \mathrm{~mL}$ de solución lixiviada. Se agregó $\mathrm{Na}_{2} \mathrm{CO}_{3} \cdot 10 \mathrm{H}_{2} \mathrm{O}$ (Anal Quim) en cantidades estequiométricas 
(0.04moles). El sólido obtenido fue filtrado, lavado y posteriormente secado en estufa a $100{ }^{\circ} \mathrm{C}$ hasta peso constante. Finalmente se calcinó durante 2 hs a $500{ }^{\circ} \mathrm{C}$.

Los sólidos CZnO y OZnO fueron comparados con un óxido de zinc comercial $(99,99 \%$, Alfa Aesar, Johnson Matthey Co), al cual se denominó ZnOc.

Las muestras fueron caracterizadas usando las siguientes técnicas fisicoquímicas: Superficie Especifica BET, Difracción de Rayos X (DRX), espectroscopia Infrarroja, microscopia electrónica de barrido (SEM) y de transmisión (TEM). Además en el caso de los óxidos de zinc se usaron otras técnicas como: UV de Reflectancia Difusa y espectroscopia de Aniquilación de Positrones, con el objetivo de estudiar las propiedades ópticas y estructurales. 


\subsection{Técnicas de caracterización}

Fundamentos y arreglo experimental 
A continuación se detallan las diferentes técnicas de caracterización utilizadas a lo largo de este trabajo de Tesis.

\subsubsection{Espectroscopía de Absorción Atómica}

La técnica hace uso de la espectrometría de absorción para evaluar la concentración de un analito en una muestra. Se basa en la ley de Beer-Lambert. Los electrones de los átomos en el atomizador pueden ser promovidos a orbitales más altos por un instante mediante la absorción de una cantidad de energía (es decir, luz de una determinada longitud de onda). Esta cantidad de energía (o longitud de onda) se refiere específicamente a una transición de electrones en un elemento particular, y en general, cada longitud de onda corresponde a un solo elemento.

Un espectrofotómetro de absorción atómica consta de los siguientes elementos, que se muestran en la Figura 4.4:

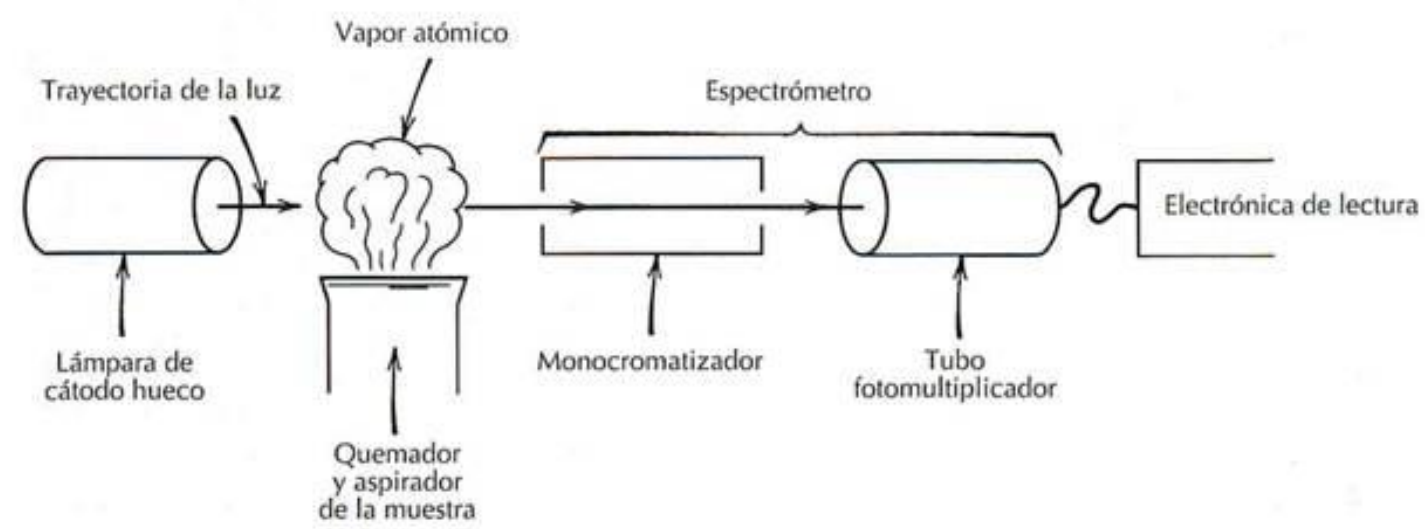

Figura 4.4. Esquema de funcionamiento de un equipo de absorción atómica.

Fuente: se emplean lámparas de cátodo hueco de un sólo elemento o de múltiples elementos. Consta de un ánodo de wolframio y un cátodo cilíndrico, soldados en un tubo de vidrio que 
contiene un gas inerte como argón, a una presión de 1 a 5 torr. El cátodo se fabrica o con el mismo metal del analito o con un soporte recubierto de ese metal. Aplicando un potencial de 300 V a través de los electrodos se provoca la ionización del argón y se genera una corriente de 5 a 19 mA por migración de los cationes de argón hacia el cátodo y de los electrones hacia el ánodo. Si el potencial es suficientemente alto, los cationes del argón chocan contra el cátodo con una energía suficientemente alto, los cationes de argón chocan contra el cátodo con una energía suficiente para arrancar átomos de metal produciendo así una nube atómica. Algunos de estos átomos metálicos llegan a excitarse y emiten radiación a longitudes de onda característicos cuando vuelven al estado fundamental.

Mechero premezcla: el combustible, el oxidante y la muestra se mezclan antes de introducirlos en la llama. Dentro del mechero ocurre la nebulización de la muestra, de manera que se crea un aerosol, una suspensión de partículas líquidas o sólidas en un gas. Este aerosol es el que llega a la llama.

Monocromador: selecciona una línea de emisión de la lámpara de cátodo hueco y elimina la mayor parte de emisión posible procedente de la llama.

Detector: produce una señal eléctrica cuando incide en él un haz de fotones.

Amplificador: aumenta la señal eléctrica proveniente del detector para que pueda ser leída por el dispositivo de lectura.

Cuando se hace pasar por la solución el haz de radiación proveniente de la lámpara de cátodo hueco y se mide la fracción de energía absorbida por la muestra, se calcula la Transmitancia (T), a partir de la cual se calcula el otro término usado en las medidas espectrométricas, la Absorbancia (A), la cual se define como: $A=-\log (T)$

Finalmente la Ley de Beer relaciona la absorbancia y la concentración del analito: 


$$
\mathrm{A}=\varepsilon \mathrm{bC}
$$

donde $\mathrm{b}=$ Camino óptico a través del medio, $\mathrm{C}=$ Concentración del analito y $\varepsilon=$ Coeficiente de absorptividad molar.

Las unidades del coeficiente de absortividad molar dependen de las usadas para b y para C. Es muy común que el valor de b se exprese en $\mathrm{cm}$ y la concentración en $\mathrm{g} \mathrm{L}^{-1}$; en este caso las unidades de $\varepsilon$ son $\mathrm{L} \mathrm{g}^{-1} \mathrm{~cm}^{-1}$.

\section{Procedimiento Experimental}

El contenido metálico de todas las muestras analizadas se determinó usando un espectrofotómetro Varian AA 240 con llama aire-acetileno. Las muestras sólidas fueron primeramente digeridas usando $\mathrm{HNO}_{3}-\mathrm{HCl}$.

\subsubsection{Determinación de Superficie Específica}

El método más común para la medición de áreas superficiales se basa en la adsorción física de un gas sobre la superficie sólida. Para poder determinar el área es necesario identificar la cantidad adsorbida que corresponde a una monocapa. Este es el principio del método Brunauer Emmett - Teller (B. E. T.). ${ }^{1}$ El método clásico para determinar áreas superficiales se basa en admitir cantidades crecientes de un gas, generalmente nitrógeno, que se adsorbe sobre el material sólido que ha sido previamente secado, pesado y librado de gases y vapores adsorbidos por calentamiento haciendo vacío, midiendo el volumen de $\mathrm{N}_{2}$ adsorbido y la presión de equilibrio. El equipo opera a presiones que pueden variarse desde $10^{-3}$ torr hasta la presión atmosférica. La

\footnotetext{
${ }^{1}$ J. Thomas, W. Thomas, Principles and Practice of Heterogeneous Catalysis, VCH, Alemania, (1997).
} 
temperatura de operación es del orden de magnitud del punto de ebullición normal del nitrógeno (77 K). Los datos obtenidos son volúmenes de gas a una serie de presiones de equilibrio en la cámara de adsorción. Graficando volúmenes vs. presión se obtiene la isoterma de adsorción. Aplicando la ecuación BET a dicha isoterma se obtiene la cantidad de moléculas de gas adsorbido en la monocapa. Conociendo la superficie efectiva por molécula (nm) en la monocapa, se calcula la superficie específica multiplicando la cantidad de moléculas adsorbidas por nm.

\section{Procedimiento experimental}

Las superficies específicas de los sólidos obtenidos fueron determinadas a partir de la isoterma de adsorción de nitrógeno a $77 \mathrm{~K}$ por el método BET. Las medidas se llevaron a cabo en un sortómetro Micromeritics Accussorb 2100 D. Los gases empleados fueron $\mathrm{N}_{2}$ y He.

\subsubsection{Difracción de Rayos $X$}

Muchas veces los catalizadores utilizados son sólidos cristalinos, aunque puede ocurrir que en ocasiones esa estructura cristalina sea pobre, especialmente cuando los métodos de preparación producen sólidos formados por partículas pequeñas. Sin embargo, la técnica de difracción de rayos $\mathrm{X}(\mathrm{DRX})$ es un método estándar para la caracterización de catalizadores y es generalmente utilizada para determinar las fases cristalinas presentes en un sólido, así como también como una medida del tamaño de partícula. También es posible seguir los cambios estructurales que ocurren en un sólido al ser calentado, mediante DRX “in situ”. 


\section{Teoría}

La difracción de rayos X (DRX) se refiere a la dispersión de los rayos X por las unidades de un sólido cristalino. Los diagramas de difracción se utilizan para deducir el arreglo de las partículas en el retículo de un sólido. Los rayos $\mathrm{X}$ son radiaciones electromagnéticas con longitudes de onda comparables con la magnitud de las distancias interatómicas en un cristal, por lo que una red cristalina es capaz de difractar los rayos X. Un patrón de difracción de rayos X es consecuencia de las interferencias en las ondas asociadas a los rayos $\mathrm{X}$. Cuando rayos $\mathrm{X}$ inciden sobre dos planos paralelos, cada plano dispersa ondas (Figura 4.5).

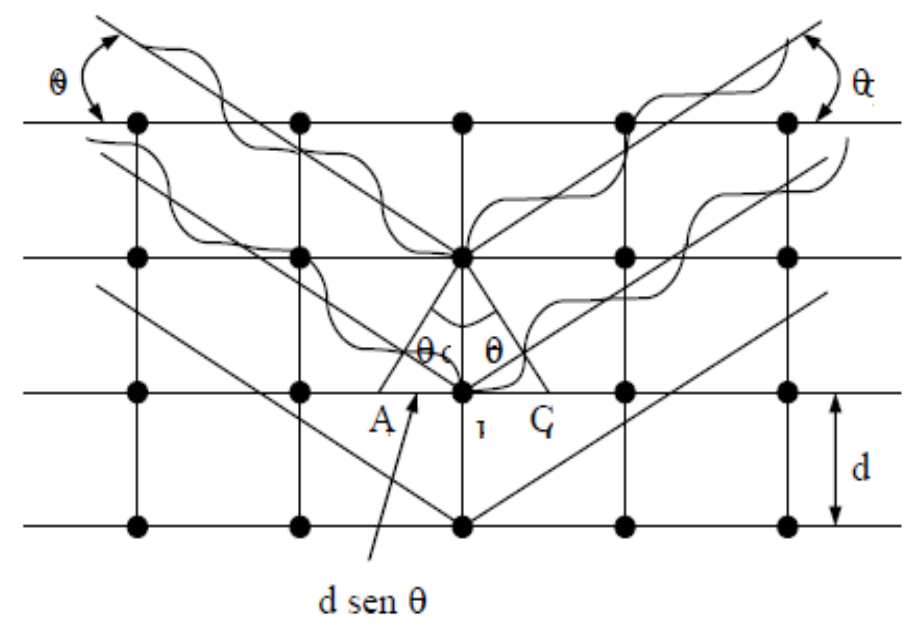

Figura 4.5. Ondas incidiendo entre planos paralelos.

La onda superior es dispersada por un átomo del primer plano, mientras que la onda inferior es dispersada por un átomo del segundo plano. Para que estos dos rayos vuelvan a entrar en fase después de la difracción, o sea, que ocurra un máximo en el patrón de difracción a cualquier ángulo de incidencia $\theta$ (respecto a los planos cristalinos $h k l$ ) debe de satisfacerse la siguiente ecuación: 


$$
\mathrm{n} \lambda=2 \mathrm{~d}_{h k l} \operatorname{sen} \theta_{h k l}
$$

$\mathrm{d}_{h k l}=$ distancia entre los planos $(h k l)$

$\mathrm{n}=$ orden de la difracción

$\lambda=$ longitud de onda de los rayos $\mathrm{X}$ incidentes

Mediante la difracción de rayos $\mathrm{X}$ es posible identificar fases cristalinos tales como $\beta-\mathrm{Mn}_{2} \mathrm{O}_{3}$, $\alpha-\mathrm{Mn}_{2} \mathrm{O}_{3}, \mathrm{Mn}_{3} \mathrm{O}_{4}$ y $\mathrm{MnO}$. Sin embargo, esta técnica no es apta para detectar fases amorfas, ni aquellas fases que se encuentren en forma microcristalina (cristales menores a $40 \AA$ ).

\section{Procedimiento experimental}

El análisis de difracción de rayos X se realizó en un equipo Philips PW 1390, utilizando radiación $\mathrm{CuK} \alpha(\lambda=1.540589 \AA$ A $)$ con filtro de níquel. Se realizó un barrido de difracción en el intervalo de ángulos $2 \theta$ entre $5^{\circ}$ y $70^{\circ}$ con incrementos de $2^{\circ} \mathrm{min}^{-1}$.

Las fases cristalinas fueron identificadas con referencia a los datos estándares de difracción de polvos JCPDS - ICDD empleando un software específico provisto con el difractómetro.

\subsubsection{Espectroscopia Infrarroja por Transformada de Fourier}

\section{Teoría}

La técnica consiste en hacer incidir un haz de luz infrarroja sobre el sólido cuyas propiedades se desean determinar, siendo condición necesaria que la energía de la radiación incidente coincida con la energía de la vibración y que la Integral del momento dipolar de la transición sea no nula. La transición entre dos estados caracterizados por dos funciones de onda se calcula 
mediante la expresión $\mu=\int \psi \mu \psi \delta \tau$ y si el momento dipolar se expande en serie de Taylor $\mu \mu 0$ $+(\mathrm{d} \mu / \mathrm{dq})_{0} \mathrm{q}+\ldots \mu$ momento dipolar permanente, se obtiene la siguiente expresión $\mu=(\mathrm{d} \mu / \mathrm{dq})$ $\int \psi \mathrm{q} \psi \mathrm{d} \tau$, lo que significa que ambos términos deben ser no nulos para que la vibración sea activa al IR. Es decir, se debe producir un cambio neto en el momento dipolar y la transición se debe producir entre estados de distinta paridad, $\Delta v= \pm 1$.

Esta espectroscopía se basa en la excitación de los modos de vibración y rotación de los enlaces entre los átomos al ser irradiados con un haz de luz infrarroja para que se produzca una transición permitida por las reglas de selección. En el espectro infrarrojo de un sólido la rotación está muy restringida, generando picos vibracionales algo ensanchado.

\section{Procedimiento Experimental}

Los análisis por espectroscopía infrarroja por transformada de Fourier (FTIR) se realizaron en un espectrómetro infrarrojo Vertex 70. La radiación IR procedente de la fuente se enfoca hacia el interferómetro, luego incide sobre la muestra y se dirige finalmente hacia el detector. La fuente es una barra de carburo de silicio que se calienta eléctricamente, la desventaja de este sistema es la variación de la intensidad de la radiación con la longitud de onda y la respuesta térmica del material. El interferómetro de Michelson consiste en dos espejos planos, uno de ellos fijo y el otro móvil y un separador de haces. El haz de radiación IR se divide en dos al pasar por el separador uno se refleja en el espejo fijo y el otro en el espejo móvil y recorre así una distancia extra, una vez reflejados se superponen e inciden sobre la muestra. La intensidad del haz transmitido fluctúa según la interferencia sea constructiva o destructiva y la curva resultante de intensidades en función del tiempo (distancia extra/ velocidad del espejo) es el interferograma. 
El detector utilizado para las medidas de transmisión es un DLaTGS (deuterated Lalanine doped triglycene sulphate) el cual es un material piroeléctrico, mantiene una fuerte polarización dependiente de la temperatura después de eliminar el campo eléctrico aplicado.

Se coloca el cristal piroeléctrico entre dos electrodos, uno transparente a la radiación IR y al cambiar la temperatura por irradiación se genera una corriente eléctrica medible.

Las muestras se prepararon diluyendo el sólido en bromuro de potasio (transparente a la radiación infrarroja). Se tomaron espectros en el rango de 400-4000 $\mathrm{cm}^{-1}$ con una resolución de 4 $\mathrm{cm}^{-1}$, por acumulación de 200 scans.

\subsubsection{Espectroscopía fotoelectrónica de rayos $\mathrm{X}$}

La espectroscopía fotoelectrónica de rayos X o XPS (de X-Ray Photoelectron Spectrocopy) es ampliamente usada para la caracterización de superficies de catalizadores. Esta técnica permite obtener información acerca de las energías de enlace, el estado de oxidación de los elementos y la composición de las capas superficiales de espesor del orden de 1-3 nm.

\section{Teoría}

Cuando una especie A es irradiada con rayos X monocromáticos, se produce una emisión de electrones, en un proceso denominado fotoemisión, el cual puede ser representado mediante la siguiente ecuación:

$$
\mathrm{A}+\mathrm{h} v=\mathrm{A}^{+*}+\mathrm{e}^{-}
$$

donde una especie $\mathrm{A}$ es ionizada a una especie excitada $\mathrm{A}^{+*}$ por medio de un fotón de energía $h v$. 


$$
\mathrm{Ek}=\mathrm{h} v-\mathrm{Eb}
$$

En XPS, las emisiones de electrones son de los niveles electrónicos internos del sólido. La radiación incidente es producida por una fuente de rayos $\mathrm{X}$ que tiene generalmente un anticátodo de $\mathrm{Al} \mathrm{K} \alpha(\mathrm{h} v=1486,6 \mathrm{eV})$ o $\mathrm{Mg} \mathrm{K} \alpha(\mathrm{h} v=1253,6 \mathrm{eV})$. La vacancia generada en un nivel interno luego de una fotoemisión puede ser reocupada por uno o dos procesos distintos: por una reorganización, en donde cuando un electrón "cae" desde un nivel mayor para ocupar esa vacancia hay una concomitante emisión de radiación que puede expulsar un electrón de un nivel más externo; o alternativamente, un fotón de rayos $\mathrm{X}$ es emitido cuando un electrón desciende desde el nivel de mayor energía para ocupar la vacancia. El primer evento es el proceso Auger y el segundo la fluorescencia de rayos X.

\section{Procedimiento Experimental}

Los espectros XPS se obtuvieron utilizando un sistema multitechnique (SPECS) equipado con un doble fuente de rayos X, $\mathrm{Al}(1486,6 \mathrm{eV})$ y $\mathrm{Mg}(1253,6 \mathrm{eV})$ y un analizador 150 hemisférico PHOIBOS operando en modo de analizador de transmisión (FAT), equipamiento perteneciente al INCAPE (CCT CONICET Santa Fe). Las energías de enlace fueron referidas al C 1s $=284,6 \mathrm{eV}$ $\mathrm{y}$ medidas con un error de $\pm 0,1 \mathrm{eV}$.

Los análisis de datos incluyeron remoción de las señales de rayos X satélites, substracción del fondo y deconvolución usando una función mixta Gaussiana-Lorentziana. La descomposición de la forma del espectro por deconvolución fue realizada manteniendo fijos parámetros espectroscópicos, la posición, la intensidad y siendo el valor FWHMH optimizado por la computadora, utilizando el programa CasaXPS (Casa Software Ltd., UK). 


\subsubsection{Espectroscopía de absorción de rayos X (XANES y EXAFS)}

Estas dos técnicas conllevan principios físicos y tratamientos matemáticos distintos y brindan información diferente.

El XANES se refiere a la estructura fina cercana al borde de absorción, y su teoría no es aun totalmente general y requiere de diferentes consideraciones físicas, análisis diferenciados y específicos para cada tipo de átomo absorbente y región de energía incidente.

Los picos en el borde de absorción son indicadores del tipo de estructura y del estado electrónico. Para los metales de transición son generalmente picos débiles pero poseen características distinguibles justo en el principio de la absorción (por ejemplo en el borde K- o L). Estas características han sido atribuidas a transiciones electrónicas desde el estado $1 s$ a estados vacíos del tipo $d$-, $s$ - y $p$ - (dipolo permitido). La naturaleza del pre-pico en el borde de absorción es bastante diferente para coordinación octaédrica que para tetraédrica.

\section{Procedimiento Experimental}

Los experimentos XAFS en el borde $\mathrm{K}$ de Mn se llevaron a cabo en un Espectrómetro de Absorción de Rayos-X Rigaku "RXAS" en INIFTA. Los experimentos XAFS en el borde K de Zn fueron realizados en las líneas XAFS-2 del LNLS. Esta línea se encuentra instalada en un dipolo con una orientación tal que le provee fotones en el rango de energías entre 2,3 y $25 \mathrm{keV}$. Cuenta con un monocromador de Si cortado por el plano (111) que en el rango de medida provee una resolución aproximada de 0,2 eV. El sistema de monocromadores se encuentra en una cámara con una presión del orden de $10^{-8}$ torr y está aislado del resto de la línea mediante ventanas de Be. Las Medidas XAFS fueron realizadas en el modo transmisión: la geometría de este modo de detección consta fundamentalmente de un tándem de dos cámaras de ionización. 


\subsubsection{Microscopía Electrónica de Barrido}

El microscopio electrónico de barrido o SEM (de Scanning Electron Microscopy) es un instrumento de gran utilidad para examinar y analizar características morfológicas de muestras sólidas. Las razones de esta utilidad son la alta resolución, la gran profundidad de foco que le da apariencia tridimensional y la fácil preparación de las muestras e interpretación de los resultados. La información que se obtiene corresponde a una profundidad de hasta 1-3 micrones.

\section{Teoría}

Cuando un haz de electrones focalizados incide sobre una muestra se producen distintos fenómenos, siendo los más comunes las dispersiones elásticas. Si la interacción es elástica con los electrones más externos del material analizado, estos electrones pueden ser eyectados fuera de la muestra como "electrones secundarios". Debido a su baja energía estos electrones escapan de zonas poco profundas, lo que los hace sensibles a la topografía de la muestra. Si la interacción se produce cerca del núcleo la dirección del haz de electrones sufre una gran deflexión. La fracción de electrones que salen en la dirección contraria a la de incidencia se conoce como "electrones retrodispersados", y depende del número atómico de la muestra.

Cuando la interacción es inelástica con los núcleos, ésta provoca en el electrón incidente un cambio en su dirección inicial, y en algunos casos se emiten fotones de rayos X, perdiendo el electrón una cantidad equivalente de energía. Esto da lugar al "espectro continuo de rayos X”.

Si la interacción es inelástica con los electrones de las capas más internas del átomo de la muestra se produce el "espectro de rayos X de líneas características" de los elementos de las muestras. Esto se origina cuando electrones de una capa interna son arrancados, dejando una vacancia, la cual es llenada por otro electrón de otra capa más externa y así sucesivamente. Cada 
transición implica una pérdida de energía que aparece como un fotón característico o fluorescente.

Algunas veces la energía disponible de una transición es utilizada para eyectar otro electrón en lugar de emitir un fotón fluorescente. Este efecto se denomina "efecto Auger", y también puede ser utilizado para el análisis espectrométrico, debido a que la energía de los mismos depende de los niveles de energía del átomo en cuestión.

En la Figura 4.6 se esquematiza el principio del funcionamiento del SEM.

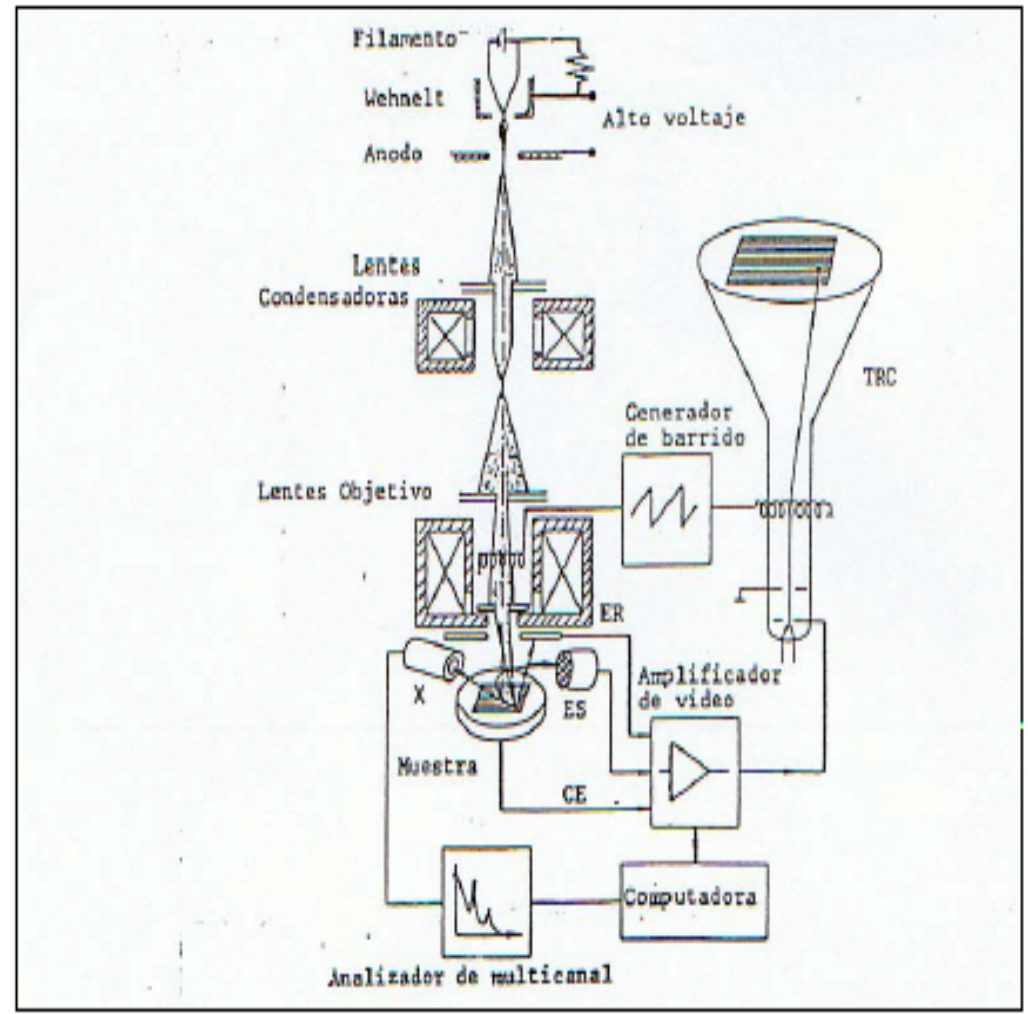

Figura 4.6. Diagrama esquemático del funcionamiento de un microscopio electrónico de barrido combinado con un microanalizador por sonda de electrones. ER=electrones retrodispersados (backscatter), $\mathrm{ES}=$ electrones secundarios, $\mathrm{CE}=$ corriente de espécimen, $\mathrm{X}=$ rayos $\mathrm{X}, \mathrm{TRC}=$ tubo de rayos catódicos. 
Como fuente de electrones o cátodo se utiliza un filamento de tungsteno de $100 \mu \mathrm{m}$ de diámetro, en forma de V, el cual es calentado en vacío por medio de una corriente eléctrica. Este haz de electrones se acelera a través de un potencial de hasta $30 \mathrm{kV}$ entre el cátodo y el ánodo. Simultáneamente un cilindro polarizado negativamente respecto al cátodo obliga al haz a converger en una sección eficaz de 10-50 $\mu \mathrm{m}$ de diámetro. Un sistema de lentes demagnifican esta sección eficaz para obtener una sonda de electrones cuyo diámetro puede variarse entre 10 y $500 \mu \mathrm{m}$.

La señal más comúnmente utilizada es la provocada por los electrones secundarios debido a su alta resolución espacial. El detector utilizado para estos electrones es el de centelleofotomultiplicador, el cual contiene un material centellador que emite luz al ser alcanzado por electrones de alta energía. Estos fotones son llevados hasta la ventana de un fotomultiplicador a través de una guía. Allí se produce una cascada de electrones que luego generan una señal eléctrica en el sistema de video que posibilita la formación de la imagen. El sistema de visualización de imágenes del microscopio cuenta con dos tubos de rayos catódicos, uno destinado a la observación directa de la imagen y el otro al registro fotográfico.

\section{Procedimiento Experimental}

El equipo utilizado es un Microscopio Philips SEM 505. Las muestras en polvo antes de ser utilizadas se las cubre con una capa muy delgada de un material conductor, en nuestro caso de oro. Esto se realiza para evitar una distorsión de la imagen, debido a que cuando un haz de electrones incide sobre un material aislante, se produce una acumulación de electrones en la superficie de la muestra generando una región de carga que puede deflectar el haz incidente en los reiterados barridos. Para el estudio de la capa de óxido de manganeso depositada sobre la 
alúmina en los monolitos metálicos, se procedió a desarmar un monolito y analizar una pequeña parte del mismo, de un tamaño acorde al portamuestra.

\subsubsection{Microscopia electrónica de transmisión (TEM)}

\section{Teoría}

El microscopio electrónico más sencillo es muy similar al microscopio óptico. Ambos tienen lentes y condensadores para concentrar la iluminación sobre la muestra. En la Figura 4.7 se esquematiza el principio del funcionamiento del TEM.

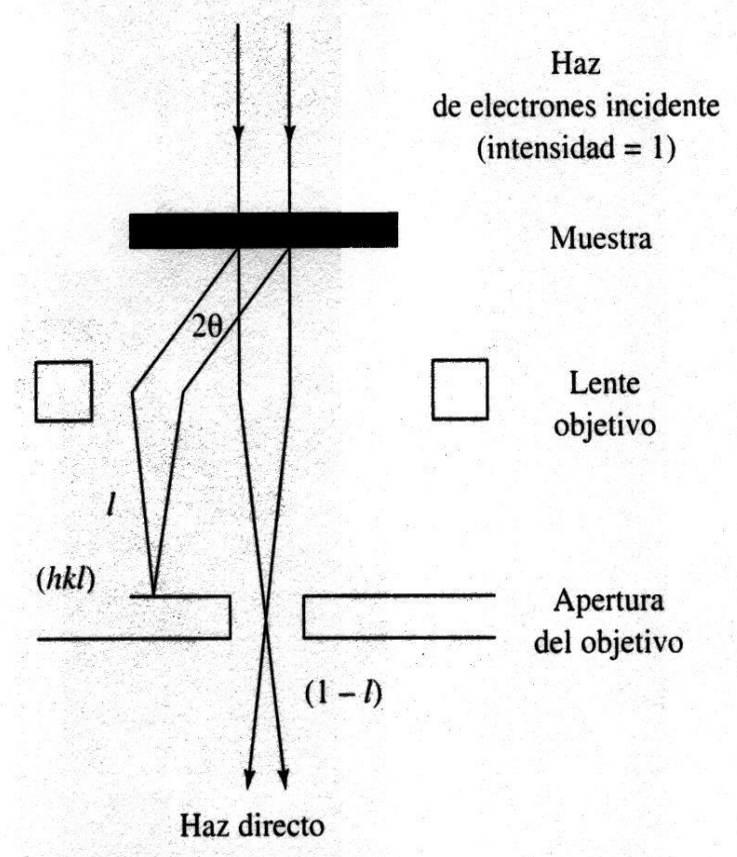

Figura 4.7. Esquema del Microscopio Electrónico de Transmisión.

Para que los electrones puedan ser acelerados hasta la velocidad prefijada, debe trabajarse en condiciones de alto vacío. El sistema central del microscopio electrónico incluyendo la pantalla fluorescente y el equipo fotográfico, lo constituye un tubo hueco. El equipo eléctrico que 
suministra la corriente necesaria se halla generalmente situado a una cierta distancia para evitar la interferencia de los campos magnéticos dispersados.

La mayoría de los microscopios están equipados con dispositivos de seguridad que no permiten conectar el filamento de alto voltaje hasta que no se ha conseguido el vacío apropiado. Las lentes magnéticas del microscopio electrónico están formadas por imanes en forma de herradura. El imán puede ser permanente o de tipo dectromagnético. Variando la potencia de la corriente a la lente se consigue el efecto de variar la distancia focal de la lente continuamente, lo cual es muy similar al sistema de "zoom". Sin embargo, normalmente se preselecciona la corriente deseada.

Un Microscopio Electrónico de Transmisión consta de los siguientes elementos:

Cañón electrónico: El tipo más usado de cañón electrónico consiste de un filamento de alambre de tungsteno (10) doblado en forma de V. El electrodo de control se denomina cilindro de Wehndt, y tiene una apertura circular de 1 a $3 \mathrm{~mm}$ de diámetro centrada en el ápice del filamento. La superficie cóncava hace las funciones de ánodo, y utilizando una superficie convexa la imagen de la fuente electrónica puede reducirse en tamaño respecto al electrodo cóncavo. La intensidad total de haz de cátodo a ánodo puede ser de 10 a 400 microamperios, pero solamente una pequeña fracción de este llega hasta la muestra.

Condensadores: Los dos condensadores son capaces de dar una amplia gama de intensidad ajustando el cañón electrónico. Esto reduce el área iluminada en la muestra. Sin embargo, otras partes de la muestra también sufren los efectos del haz electrónico. El primer condensador reduce la imagen de la fuente mientras que el segundo condensador obtiene la intensidad adecuada de iluminación 
Plataforma para la colocación de la muestra: está situada en frente del objetivo. Se introduce la muestra en la columna del microscopio a través de una abertura.

Objetivo: es la lente más importante en el microscopio electrónico. La distancia foca1 de esta lente está comprendida entre 1 y 5 milímetros, siendo $1,1 \mathrm{~mm}$ la más frecuente. Cuanto menor es la distancia focal, mayor es la resolución. Debido a que el haz de imagen tiene la máxima apertura angular en el primer objetivo, esta lente controla la calidad de la imagen producida.

Lente intermedia: puede aumentar o disminuir la imagen. Se puede conseguir esto aumentando o disminuyendo la potencia de la corriente a esta lente.

Lente de proyección: corresponde al ocular del microscopio óptico. Su función es la de proyectar la imagen real sobre la pantalla fluorescente, y permite una amplia gama de aumentos. Se puede variar la ampliación de $100 \mathrm{X}$ hasta $300.000 \mathrm{X}$ usando lentes intermedias y de proyección.

Cámara de observación: junto con la pantalla fluorescente están situadas en el fondo de la columna. La imagen se enfoca sobre un punto marcado y el enfoque fino se consigue con unos binoculares de 6 y $20 \mathrm{X}$. El diámetro del punto de enfoque es de 100 pm, por lo tanto la imagen debe ser mayor que este diámetro para ser resuelta. La cámara de observación está protegida por un vidrio grueso de plomo para evitar la emisión de rayos $\mathrm{X}$.

Cámara fotográfica: está situada debajo de la pantalla fluorescente. La pantalla fluorescente está sujetada por m lado, y al quitar el paso del haz electrónico la imagen se centra sobre la película fotográfica. Se pueden usar varios tipos de películas y placas de vidrio.

\section{Procedimiento Experimental}

Las micrografías TEM se realizaron usando un microscopio JEOL CXII operando a $100 \mathrm{kV}$. 


\subsubsection{Métodos de Temperatura Programada}

La técnica de Reducción Térmica Programada (RTP) es muy usada para la caracterización de sólidos. En este experimento se hace pasar una corriente continua de un gas reductor (generalmente hidrógeno) sobre el lecho catalítico a medida que la temperatura se incrementa.

En la técnica de RTP se monitorea la señal que produce la corriente de salida al pasar por un detector de conductividad térmica (DCT), en función de la temperatura. Al reducirse parte de la muestra, disminuye la cantidad de $\mathrm{H}_{2}$ en la corriente de salida, y se genera un pico en el registro de la señal. El área bajo el pico de reducción es proporcional a la cantidad de materia reducida. Sin embargo, la reducibilidad de las sustancias es función del compuesto a analizar y en cada caso factores como el tamaño de partícula, la superficie específica, la cristalinidad, etc., pueden modificar uno de los parámetros fundamentales de esta técnica que es la temperatura de reducción. Finalmente, mediante reducción térmica programada es posible obtener una medida cuantitativa de especies de Mn en óxidos que poseen manganeso en más de un estado de oxidación.

\subsubsection{Espectroscopía de Reflectancia Difusa}

El fenómeno óptico conocido como reflectancia difusa es comúnmente utilizado en las regiones UV-Vis e infrarrojo del espectro para obtener información espectroscópica molecular. Es usual su empleo para obtener espectros de muestras en polvo con una mínima preparación previa de las mismas. El espectro de reflectancia es obtenido colectando y analizando radiación electromagnética reflejada por una superficie como función de la frecuencia ( $v$, generalmente como número de onda, $\left.\mathrm{cm}^{-1}\right)$ o longitudes de onda ( $\lambda$, generalmente en nanómetros, $\mathrm{nm}$ ). 


\section{Teoría}

Cuando un haz de radiación electromagnética incide sobre una superficie, éste puede ser reflejado de dos maneras: como reflexión regular o especular, tal como ocurre con la reflexión de superficies lisas como espejos, y como reflexión difusa asociada a la reflexión sobre superficies mate como la de polvos.

La reflexión especular se caracteriza por tener el ángulo de reflexión de la radiación electromagnética igual al ángulo de incidencia. Contrariamente, en la reflexión difusa la radiación incidente es reflejada a distintos ángulos independientes del ángulo de incidencia. La reflexión especular puede ser rigurosamente estudiada teóricamente utilizando la ecuación de Fresnel, ${ }^{2}$ la cual relaciona la reflectancia con el índice de refracción de la muestra bajo estudio. Por otro lado, los fenómenos ópticos resultantes de la reflexión difusa son varios y muy complejos, por lo que a continuación se explicarán brevemente los conceptos fundamentales de esta técnica.

En la Figura 4.8 se esquematizan algunos fenómenos ópticos que ocurren en un experimento de reflectancia difusa. Consideremos a la muestra como constituida por partículas distribuidas al azar. Estas partículas individuales pueden provocar la reflectancia especular de la radiación incidente. Para el tratamiento teórico se asume que la reflectancia difusa ocurre por reflexiones especulares producidas por espejos elementales de la muestra con planos estadísticamente distribuidos a diferentes ángulos.

\footnotetext{
${ }^{2}$ J. Blitz, Diffuse Reflectance Spectroscopy en Modern Technique in Applied Molecular Spectrocopy, J. Wiley \& Sons, Inc. (1998).
} 


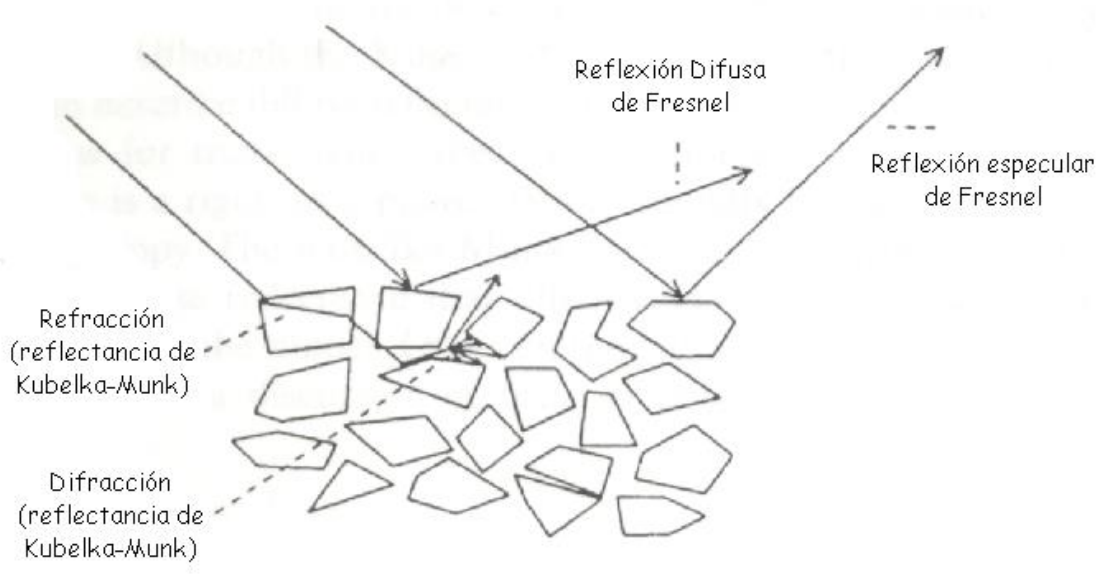

Figura 4.8. Tipos de reflectancia que ocurren en una muestra sólida.

\subsubsection{Espectroscopía UV Visible con Reflectancia Difusa}

Cuando la reflectancia difusa es colectada usando como haz incidente radiación en la región UV-Visible del espectro, se utiliza un accesorio óptico denominado esfera integradora, la cual es un dispositivo hueco con paredes construidas por un material que refleja todas las longitudes de onda de interés con una gran poder de reflexión (generalmente $\mathrm{BaSO}_{4}$ o $\mathrm{MgCO}_{3}$ ). Un dispositivo comúnmente usado se muestra en la Figura 4.9.

La radiación monocromática entra en la esfera desde una fuente externa. Primero se coloca un material de referencia y la radiación es medida en un detector. Luego se reemplaza el estándar por la muestra y se repite el procedimiento. 


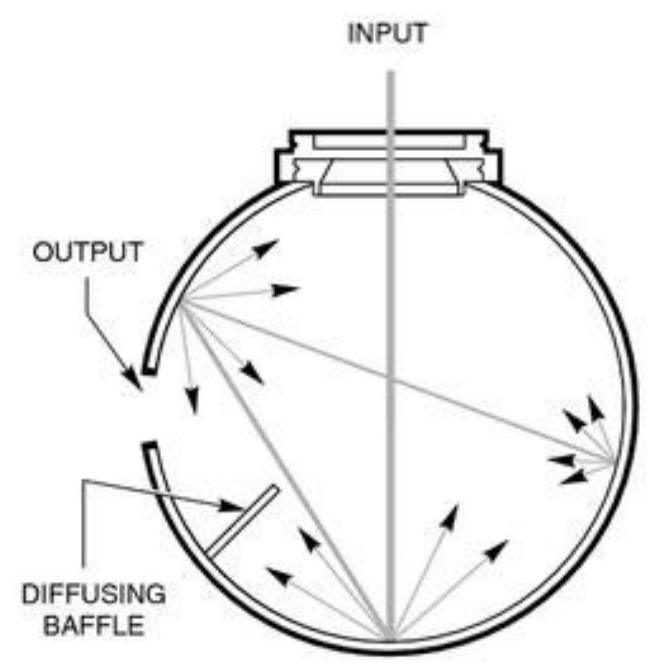

Figura 4.9. Esquema de esfera integradora.

\section{Procedimiento Experimental}

Las medidas se realizaron en un equipo Perkin Elmer Lambda 35, en un intervalo de 200-800 $\mathrm{nm}$ usando una esfera integradora y Spectralon como reflectancia estándar.

\subsubsection{Espectroscopía de Aniquilación de Positrones (PALS)}

La espectroscopia de aniquilación de positrones es una técnica de caracterización no destructiva, ya que solo se estudia la radiación electromagnética producida por la aniquilación electrón- positrón y es, sobre todo, muy utilizada para estudiar la estructura electrónica e identificar defectos en sólidos. Esto último se debe, principalmente, al hecho de que esta técnica es sensible a la densidad electrónica en la red.

\section{Fundamentos teóricos}


El positrón, la antipartícula del electrón, fue predicha en 1928 por Dirac ${ }^{3}$ y detectada por Anderson en $1932 .^{4}$

Una de las formas más comunes para obtener positrones en el laboratorio es usando isótopos radioactivos que presentan decaimiento $\beta^{+}\left(\mathrm{p} \rightarrow \mathrm{n}+\mathrm{e}^{+}+\mathrm{v}\right)$, como por ejemplo, el ${ }^{22} \mathrm{Na}$. Cuando un positrón energético penetra en un sólido, sufre el proceso de termalización, en el que su energía cinética disminuye hasta valores térmicos del orden de $\mathrm{kT}$, en un tiempo que oscila entre 1 a 10 ps. Su rango de penetración es de entre 10 y $1000 \mu \mathrm{m}$, dependiendo de la densidad electrónica del material y la energía cinética inicial del positrón. Una vez termalizado, el positrón puede permanecer en equilibrio térmico con el medio, difundiendo en el material (hasta unos $100 \mathrm{~nm}$ ) hasta su aniquilación con un electrón. Los procesos o mecanismos de aniquilación electrón- positrón, varían con la cantidad de fotones que se emiten al aniquilarse, siempre garantizando las leyes de conservación del momento y la energía. Se tiene:

$$
\mathrm{e}^{+}+\mathrm{e}^{-}+\mathrm{M} \rightarrow \mathrm{n} \gamma+\mathrm{M}
$$

El proceso más probable es aquel en el cual se aniquila un positrón térmico y un electrón libre, emitiendo dos rayos gamma de $0,511 \mathrm{MeV}$ (masa en reposo del electrón). El tiempo de vida media de los positrones depende del material y varía desde los 100 a los 500 ps (para metales, semiconductores y aisladores). La vida media puede extenderse hasta algunos nanosegundos en el caso de la formación de positronio (esto suele encontrarse en polímeros y materiales porosos).

\footnotetext{
${ }^{3}$ P. Dirac, Proceeding of the Royal Society A 117 (1928) 610-624.

${ }^{4}$ C. Anderson, The Physical Review 43 (1933) 491-494.
} 
En la Figura 4.10 se muestra un esquema de los posibles procesos que sufre un positrón desde que es emitido hasta que se aniquila.

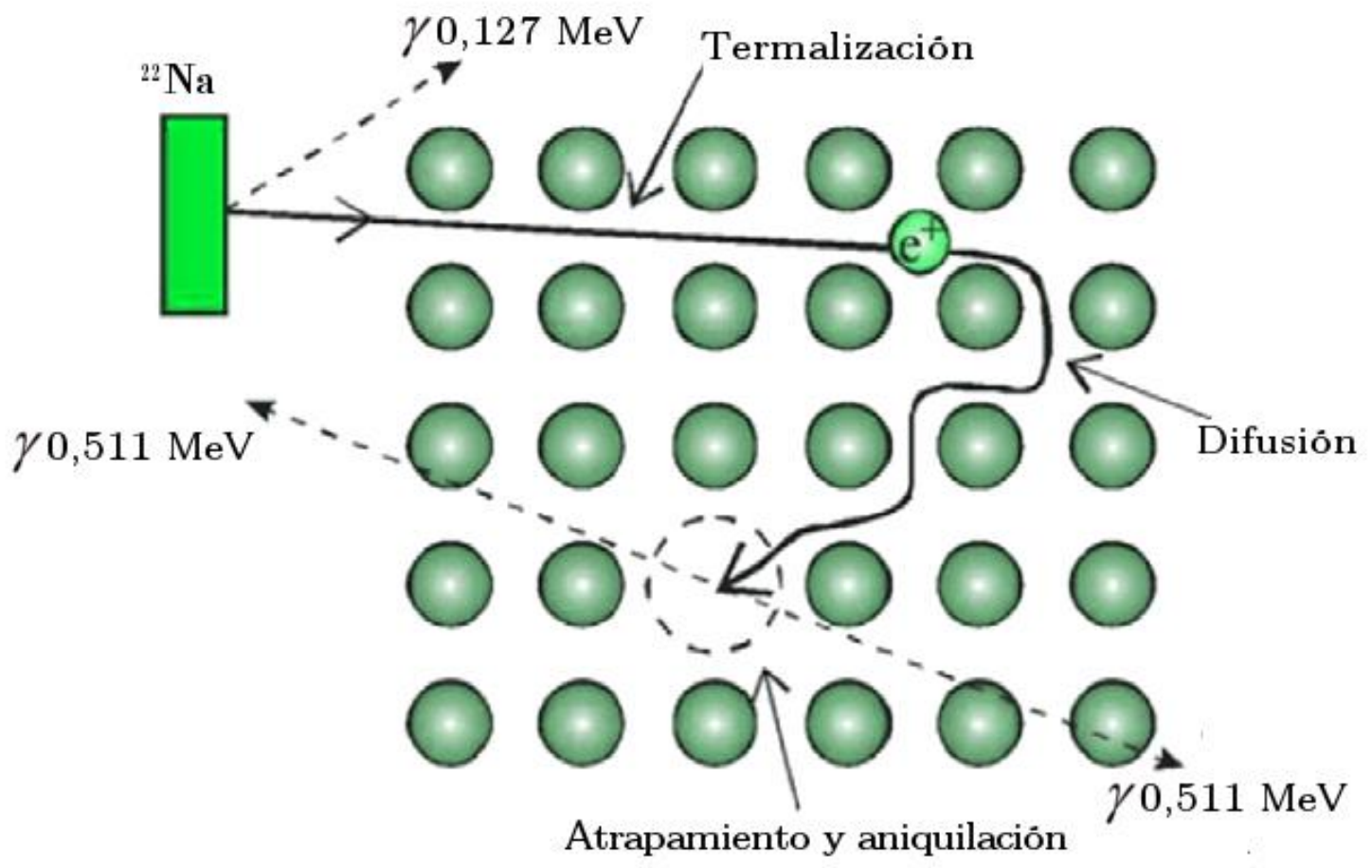

Figura 4.10. Esquema de los posibles procesos que sufre un positrón desde que es emitido por la fuente hasta que se aniquila.

En los semiconductores, los positrones pueden quedar atrapados en defectos tipo vacancias, que tienen energías de ligadura del orden de algunos eV, con lo que una vez atrapado, el positrón no puede escapar y se aniquila en el defecto. El positrón atrapado en un defecto se encuentra con una densidad electrónica menor que en la región intersticial de la red y, por ende, su vida media aumenta. El modelo para describir el fenómeno de atrapamiento es comúnmente llamado "Modelo de atrapamiento" o "Modelo de trampas". ${ }^{5}$ La cantidad de defectos que puede tener un

\footnotetext{
${ }^{5}$ R. West, Positron studies of lattice defects in metals, en Positrons in Solids, P. Hautojärvi (Ed), (1979).
} 
cristal es grande y la probabilidad de escape de estos no siempre es nula pero, para poder tratar nuestro sistema y tener un modelo simple y realizable, se considera el caso en que se tiene un solo tipo de defecto y el positrón no puede escapar. Este modelo es uno de los más empleados y suele llamarse modelo de dos estados.

El número de positrones que se encuentran deslocalizados en la red $(n b)$ o atrapados en los defectos $(n d)$ en el instante $\mathrm{t}$ viene dado por las ecuaciones:

$$
d n b / d t=-\lambda n b-\kappa n b
$$

$\mathrm{y}$

$$
d n d / d t=\kappa \mathrm{nb}-\lambda \mathrm{nb}
$$

donde $\lambda \mathrm{b}$ y $\lambda \mathrm{d}$ son las tasas de aniquilación en la red $\mathrm{y}$ en los defectos, $\mathrm{y} \kappa$ es la tasa de atrapamiento de los positrones en el defecto. Se considera que es solo proporcional a la concentración de defectos (cd): $\kappa=\mu_{\mathrm{d}} \mathrm{c}_{\mathrm{d}}$, donde $\mu$ es la tasa de atrapamiento característica de cada tipo de defecto.

Suponiendo que las condiciones iniciales son $n b(0)=1$ y $n d(0)=0$, es decir, que cuando el positrón ingresa al material se encuentra en un estado libre. Por lo tanto, las soluciones a las ecuaciones diferenciales anteriores son:

$$
n b(\mathrm{t})=\exp [-(\lambda \mathrm{b}+\kappa) \mathrm{t}]
$$

y

$$
n d(\mathrm{t})=(\mathrm{k} / \lambda \mathrm{b}-\lambda \mathrm{d}+\kappa)\left[\exp \left(-\lambda_{\mathrm{d}} \mathrm{t}\right)-\exp (-\lambda+\kappa) \mathrm{t}\right]
$$




\section{Procedimiento Experimental}

A continuación se detalla el equipo experimental, la fuente emisora de positrones y el análisis de los datos realizados.

En el presente trabajo se ha utilizado una fuente de positrones de ${ }^{22} \mathrm{Na}$, que es una de las más usadas en los estudios de vidas medias de positrones. Esta fuente tiene la ventaja que, además de emitir positrones, emite un fotón (ambas emisiones prácticamente en simultáneo) con el que se puede realizar una detección en coincidencia, característica imprescindible para esta técnica, como se verá más adelante.

El esquema de decaimiento del isótopo ${ }^{22} \mathrm{Na}$ se muestra en la Figura 4.13. Se puede ver que se desintegra por emisión $\beta^{+}$(en un $90,2 \%$ y el resto es por captura electrónica), con una vida media de 2,6 años. El proceso de emisión $\beta^{+}$es:

$$
\mathrm{p}^{+} \rightarrow \mathrm{n}+\mathrm{e}^{+}+\mathrm{v}
$$

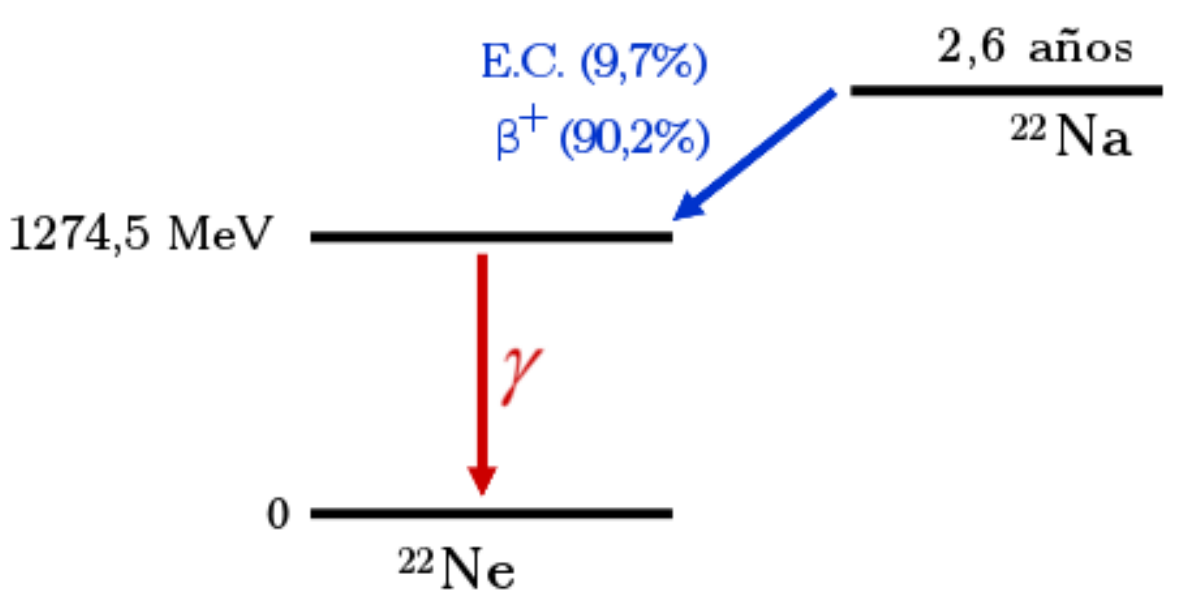

Figura 4.13. Decaimiento del isotopo del ${ }^{22} \mathrm{Na}$. 
Este positrón emitido, puede tener energía de hasta $0,545 \mathrm{MeV}$, siendo su valor más probable cercano a los 0,200 MeV. Luego de la emisión del positrón (del orden de los 3 ps), la fuente emite un rayo gamma de 1,274 MeV. Por lo tanto, la detección de este fotón estaría indicando la emisión del positrón.

La fuente utilizada se preparó evaporando una solución de ${ }^{22} \mathrm{NaCl}$ del orden de $10 \mu \mathrm{Ci}$ entre dos láminas de kapton delgadas del mismo tamaño (densidad 1,42 $\mathrm{g} \mathrm{cm}^{-3}$ ), que fueron selladas superpuestas con pegamento. Este contenedor es uno de los que permiten el mayor escape de positrones de la fuente hacia la muestra a analizar, cercano al $95 \%$. De todas formas, es bien conocido que existirán aniquilaciones tanto en el kapton como en el pegamento, con lo que debe tenerse en cuenta una componente adicional de corrección de fuente en los espectros de aniquilación.

Al utilizar una fuente de ${ }^{22} \mathrm{Na}$ se puede conocer el momento de emisión del positrón, gracias al rayo gamma característico de su decaimiento $(1,27 \mathrm{MeV})$. Por lo tanto, al detectar la diferencia temporal entre ambas radiaciones, se está en condiciones de determinar la vida media del positrón dentro del material bajo estudio.

Particularmente en este trabajo se utilizó un espectrómetro convencional rápido-rápido para medidas de vidas medias con dos detectores centelleadores, uno plástico BURLE y otro con cristal de $\mathrm{BaF}_{2}$, acoplado a un fotomultiplicador XP2020Q (Photonis) y electrónica especifica asociada. Un esquema de este espectrómetro puede verse en la Figura 4.14. 


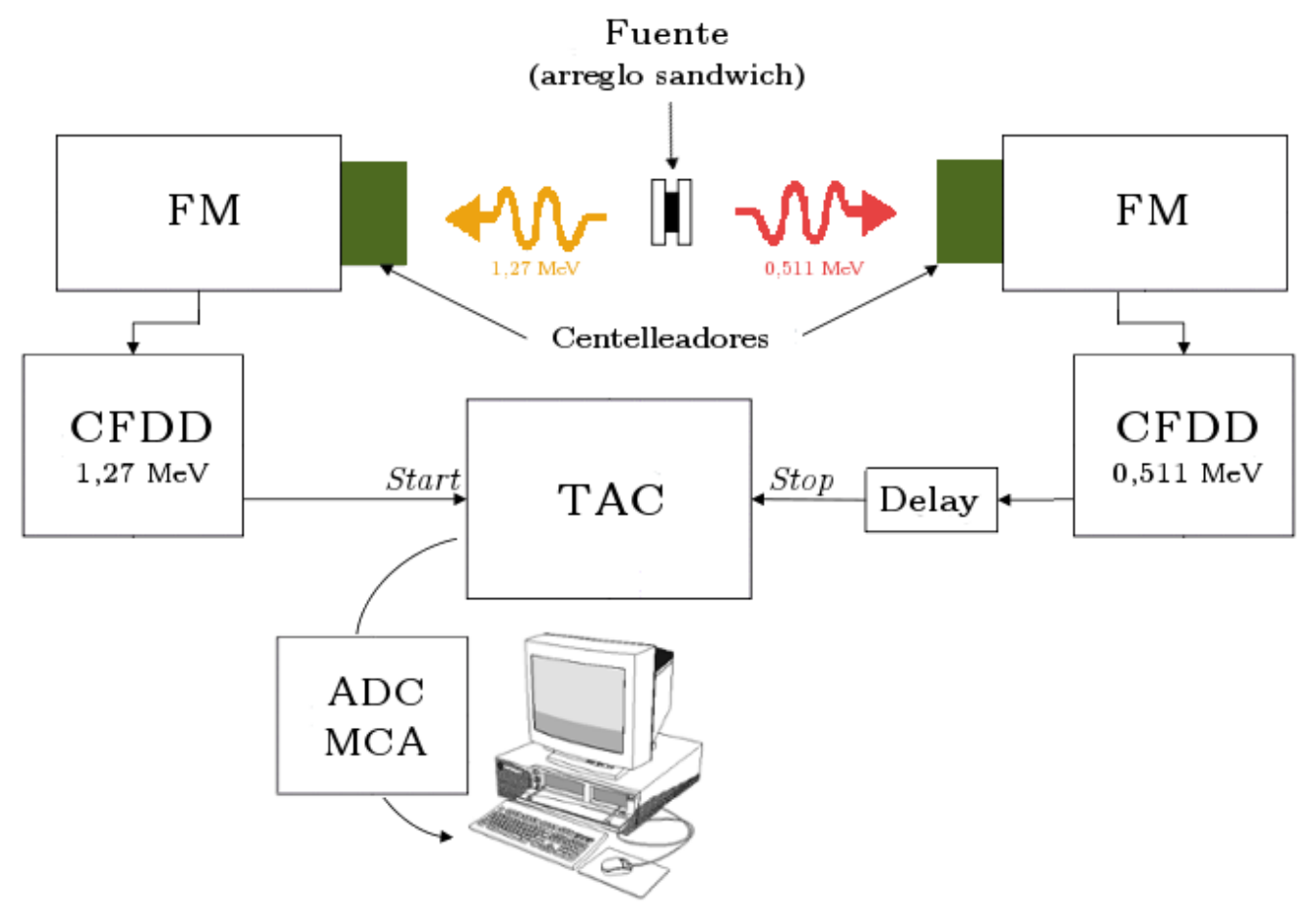

Figura 4.14. Esquema del espectrómetro convencional rápido-rápido para medidas de vidas medias con dos detectores centelladores, utilizado en este trabajo.

El arreglo que se ha utilizado para la fuente y la muestra es el llamado "arreglo sandwich", en el cual la fuente (en el soporte de kapton) es colocada entre dos discos de la muestra a analizar, de un espesor suficientemente grande para que ningún positrón pueda escapar, en este caso aproximadamente $1 \mathrm{~mm}$. Los detectores centelleadores, colocados sobre una misma línea y enfrentados, con el arreglo fuente-muestras entre ellos, convierten la radiación gamma en un numero de fotones con energías del rango visible o UV. Estos se encuentran acoplados al fotomultiplicador, consistente en un arreglo de dinodos conectados a diferencias de potenciales crecientes, que convierte esta luz en dos señales eléctricas, la de dinodo y la de ánodo, siendo ambas proporcionales a la energía del rayo gamma incidente. En el arreglo experimental disponible se utiliza solo la señal rápida de ánodo, que es la entrada a los módulos 
discriminadores diferenciales a fracción constante (CFDD). Estos módulos cumplen la función de seleccionar la energía de interés. Por un lado, la de la señal de nacimiento del positrón, el rayo gamma de 1,274 MeV, que se utilizara como señal start en el módulo TAC. Por otro, la energía correspondiente a la aniquilación del positrón, 0,511 MeV, señal de stop. Las señales lógicas de ambos discriminadores ingresan a un módulo convertidor de tiempo en amplitud (TAC), el cual produce un pulso analógico cuya altura es proporcional al tiempo transcurrido entre las llegadas de las señales start y stop, es decir, a la vida media del positrón en el material. 


\title{
$\sim$ Capítulo 5
}

\author{
Resultados
}




\title{
5.1 Lixiviaciones
}

\author{
Resultados
}




\subsubsection{Introducción}

Las bacterias del género Acidithiobacillus thiooxidans son quimioautótrofas y acidófilas extremas, obteniendo su energía de la oxidación de compuestos reducidos de azufre. Producto de este metabolismo se forman especies químicas oxidantes, reductoras y ácidas:

$$
\begin{aligned}
& \mathrm{mS}+\mathrm{O}_{2}+\mathrm{H}_{2} \mathrm{O} \rightarrow \mathrm{S}_{\mathrm{n}}\left(\mathrm{SO}_{3}\right)_{2}{ }^{2-}+2 \mathrm{H}^{+} \\
& \mathrm{S}_{\mathrm{n}}\left(\mathrm{SO}_{3}\right)_{2}{ }^{2-}+\mathrm{O}_{2}+\mathrm{H}_{2} \mathrm{O} \rightarrow \mathrm{mSO}_{4}{ }^{2-}+2 \mathrm{H}^{+}
\end{aligned}
$$

Estas especies son capaces de reaccionar con los compuestos presentes en pilas agotadas estabilizando los cationes en solución acuosa $\left(\mathrm{Mn}^{2+}, \mathrm{Zn}^{2+}\right)$ de donde es factible recuperarlos.

$$
\begin{aligned}
& \mathrm{Zn}+\mathrm{H}_{2} \mathrm{SO}_{4} \rightarrow \mathrm{ZnSO}_{4}+\mathrm{H}_{2} \\
& \mathrm{ZnO}+\mathrm{H}_{2} \mathrm{SO}_{4} \rightarrow \mathrm{ZnSO}_{4}+\mathrm{H}_{2} \mathrm{O} \\
& \mathrm{Mn}_{2} \mathrm{O}_{3}+\mathrm{H}_{2} \mathrm{SO}_{4} \rightarrow \mathrm{MnO}_{2}+\mathrm{MnSO}_{4}+\mathrm{H}_{2} \mathrm{O} \\
& \mathrm{Mn}_{3} \mathrm{O}_{4}+2 \mathrm{H}_{2} \mathrm{SO}_{4} \rightarrow \mathrm{MnO}_{2}+2 \mathrm{MnSO}_{4}+2 \mathrm{H}_{2} \mathrm{O} \\
& \mathrm{MnO}_{2}+\mathrm{S}_{\mathrm{n}}(\mathrm{SO} 3)_{2}{ }^{2-} \rightarrow \mathrm{Mn}^{2+}+\mathrm{mSO}_{4}{ }^{2-}
\end{aligned}
$$

Una vez recolectadas las pilas en PlaPiMu, los dos tipos de pilas agotadas se mezclaron entre sí para simular la alimentación de un proceso industrial; de hecho, su separación sólo sería factible mediante inspección visual y no a mayor escala. 


\subsubsection{Pilas en este trabajo de Tesis}

El barro original y el barro lavado y calcinado se disolvieron en agua regia, con el objetivo de determinar el contenido metálico presente. En la Tabla 5.1 se muestra el contenido de Zn y Mn de los sólidos usados en esta Tesis.

Tabla 5.1. Porcentaje de metales en los barros estudiados.

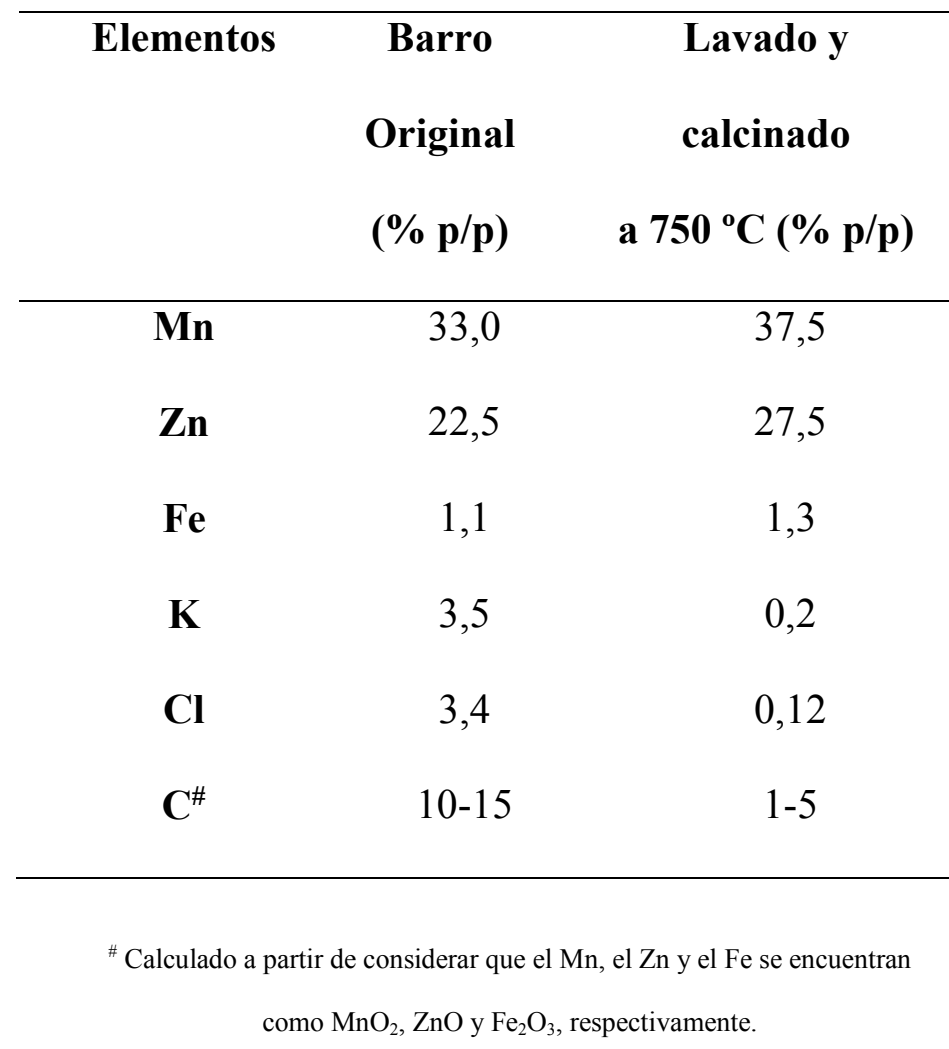

\subsubsection{Caracterización de los sólidos}

Los resultados del análisis químico del barro de pilas agotadas sin tratamiento y después de ser lavado y calcinado en aire a $750{ }^{\circ} \mathrm{C}$ se muestran en la Tabla 5.1. Los elementos mayoritarios son $\mathrm{Mn}$ y $\mathrm{Zn}$. K y Cl son derivados del electrolito; en las pilas alcalinas se usa $\mathrm{KOH}$, mientras que en las de $\mathrm{Zn} / \mathrm{C}$ se encuentra $\mathrm{NH}_{4} \mathrm{Cl}$. Los datos correspondientes al barro 
sin tratar están de acuerdo con los encontrados en bibliografía, los cuales señalan la presencia de $\operatorname{Mn}(30-40 \% \mathrm{p} / \mathrm{p})$ y Zn $(20-25 \% \mathrm{p} / \mathrm{p}){ }^{1,2}$

El incremento del porcentaje de $\mathrm{Zn}$ y Mn en las muestras lavadas y calcinadas se debe a la remoción de $\mathrm{K}$ y $\mathrm{Cl}$ durante el lavado y la eliminación de $\mathrm{C}$ como consecuencia del proceso de calcinación.

En la Figura 5.1 se presentan los diagramas de difracción de rayos $\mathrm{X}$ de los barros estudiados.

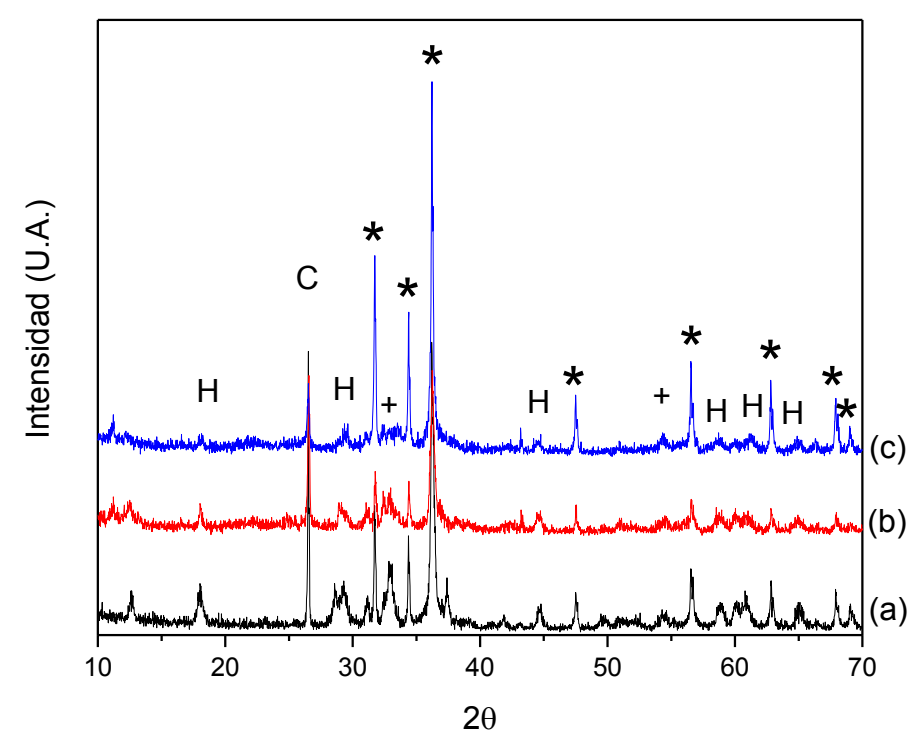

Figura 5.1. Diagramas de difracción de rayos $\mathrm{X}$ : (a) barro original secado a $120^{\circ} \mathrm{C}$; (b) barro lavado y secado y (c) barro lavado, secado y calcinado a $750^{\circ} \mathrm{C}$. (C) Grafito; (*) $\mathrm{ZnO} ;(+) \mathrm{ZnMn}_{2} \mathrm{O}_{4} ;(\mathrm{H}) \mathrm{Mn}_{3} \mathrm{O}_{4}$.

1 G. Belardi, P. Balliranob, M. Ferrinic, R. Lavecchiac, F. Medicic, L. Pigac, A. Scoppettuolo, Thermochimica Acta 526 (2011) 169-177.

${ }^{2}$ B. Xin, W. Jiang, H. Aslam, K. Zhang, C. Liu, R. Wang, Y. Wang, Bioresourse Technology 106 (2012) $147-153$. 
El espectro correspondiente al barro original presenta líneas de difracción correspondientes al carbono grafito, $\mathrm{ZnO}$ (wurzita), $\mathrm{ZnMn}_{2} \mathrm{O}_{4}$ (hetaerolita) y $\mathrm{Mn}_{3} \mathrm{O}_{4}$ (hausmanita), en concordancia con lo reportado con Sayilgan y col. ${ }^{3}$

$\mathrm{El} \mathrm{ZnO}$ en forma de wurzita está presente en el ánodo de las pilas alcalinas como el producto de la descarga de la batería. ${ }^{4}$ Mientras que en el cátodo se encuentran $\mathrm{Mn}_{3} \mathrm{O}_{4}$, $\mathrm{Mn}_{2} \mathrm{O}_{3}$ y $\mathrm{C}$ grafito. Krekeler ${ }^{5}$ también informa la presencia de pirocrita $\mathrm{Mn}(\mathrm{OH})_{2}$, siendo $2+$ el estado de oxidación de manganeso. Vatistas y col. ${ }^{6}$ han estudiado la migración de zinc del ánodo al cátodo en la batería alcalina durante la descarga, pero no se menciona la fase que se forma.

El diagrama de difracción correspondiente al barro lavado y calcinado presenta picos correspondientes a las fases asignadas al barro original, observándose una disminución de la intensidad del pico correspondiente al Carbono como consecuencia del proceso de calcinación.

\subsubsection{Experimentos de lixiviación}

\subsubsection{Influencia de la relación sólido/líquido (S/L)}

Para el estudio de la relación sólido/líquido se mantuvieron fijas la temperatura y el tiempo de lixiviación. Veloso y col. ${ }^{7}$ señalan que entre 20 y 120 minutos no se modifica la

${ }^{3}$ E.Sayilgan, T. Kukrer, G. Civelekoglu, F. Ferella, A. Akcil, F. Veglio, M. Kitis, Hydrometallurgy 97 (2009)158-166.

${ }^{4}$ G. Belardi, P. Ballirano, M. Ferrini, R. Lavecchia, F. Medici, L.Piga, A. Scoppettuolo, Thermochimica Acta 526 (2011) 169-177.

${ }^{5}$ M. Krekeler, Waste Management 28 (2008) 2061-2069.

${ }^{6}$ N. Vatistas, M. Bartolozzi, S. Arras, Journal of Power Sources 101 (2001) 182-187.

${ }^{7}$ L. Veloso,L. Rodrigues, D. Ferreira, F. Magalhanes, M. Mansur, Journal of Power Sources 152 (2005) 295-302. 
concentración de Mn y Zn en solución acida. Por su parte, Buzatu y col. ${ }^{8}$ han mostrado que un tiempo de lixiviación superior a 60 minutos no mejora la extracción de los metales de interés.

En la Figura 5.2 se muestra la influencia de la relación sólido/líquido $(S / L)$ en la eficiencia de lixiviación de zinc y manganeso, utilizando ácido biogenerado como agente lixiviante, a $30{ }^{\circ} \mathrm{C}$ durante $120 \mathrm{~min}$. Esta relación fue estudiada en el barro lavado y calcinado, ya que después del tratamiento térmico el sólido se enriquece en los metales de interés.

Se puede observar que la extracción de ambos metales, Zn y Mn, es máxima para una $S / L$ de $0,04 \mathrm{~g} \mathrm{~mL}^{-1}$, disminuyendo progresivamente a medida que aumenta el valor de $S / L$. Esto puede ser debido a la disminución de reactivos en solución.

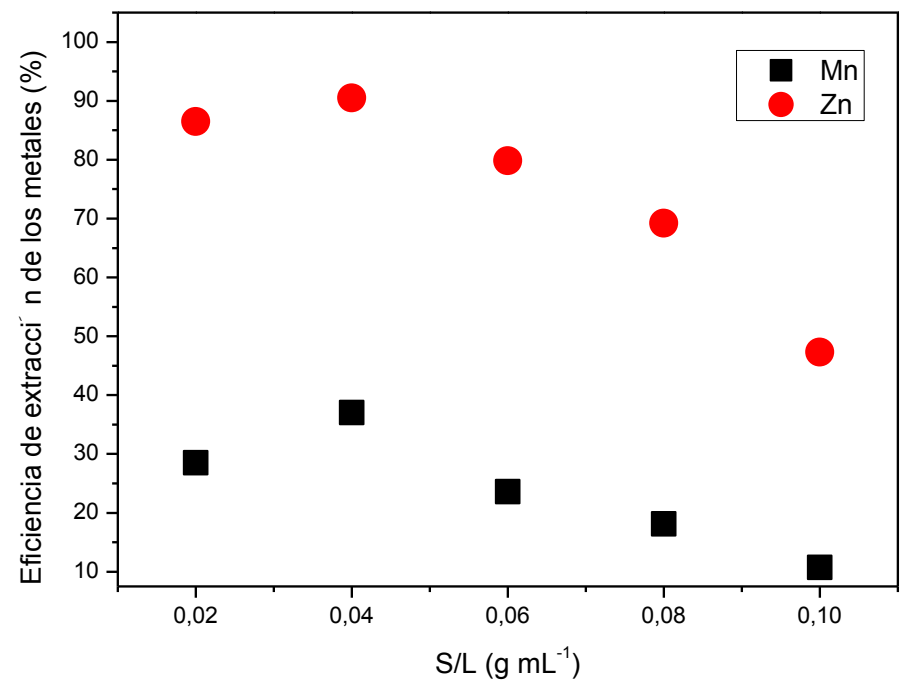

Figura 5.2. Porcentaje de extracción de $\mathrm{Zn}$ y Mn en función de la relación $S / L$ (120 min, 30 ${ }^{\circ} \mathrm{C}$ ).

${ }^{8}$ T. Buzatu, G. Popescu, I. Birloaga, S. Saceanu, Waste Management 33 (2013) 699-705. 
Por lo tanto, en este trabajo de tesis se eligió usar una relación $S / L$ de $0,04 \mathrm{~g} \mathrm{~mL}^{-1}$, usando el barro calcinado, ya que como se ve la extracción mejora notablemente.

\subsubsection{Influencia de la temperatura}

En la Figura 5.3 se muestra la influencia de la temperatura en los experimentos de lixiviación, utilizándose una relación sólido/líquido de $0,04 \mathrm{~g} \mathrm{~mL}^{-1}$ y durante $120 \mathrm{~min}$.

Puede observarse en la Figura 5.3 que con el aumento de la temperatura la eficiencia de la lixiviación aumenta, siendo siempre más alto el porcentaje de extracción de zinc que de manganeso.

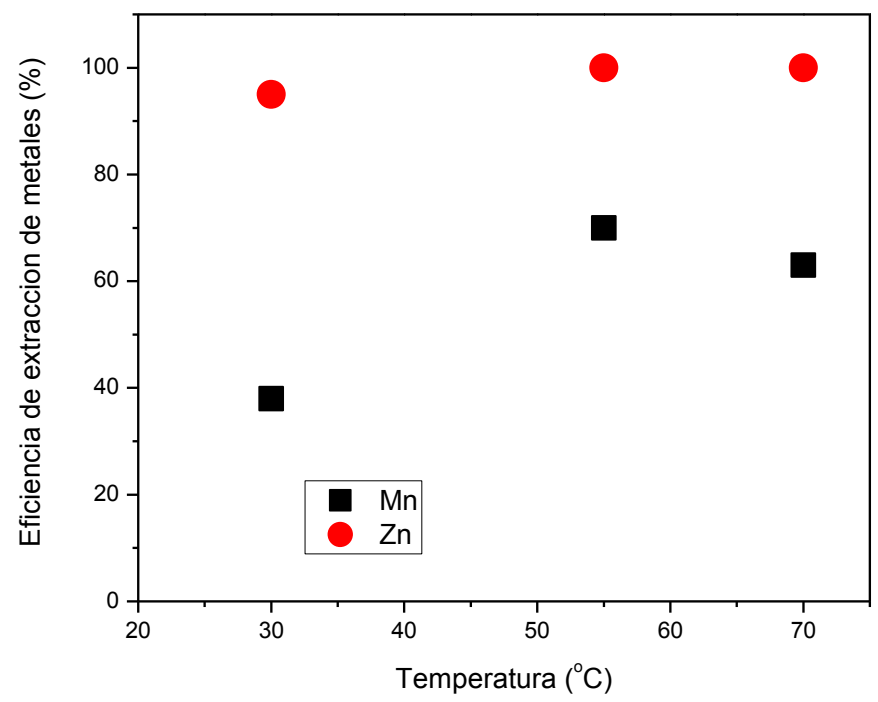

Figura 5.3. Influencia de la temperatura en el proceso de lixiviación.

\subsubsection{Influencia del agregado de $\mathrm{Na}_{2} \mathrm{SO}_{3}$}

En la Figura 5.4 se muestra la eficiencia de la extracción en función de la cantidad de $\mathrm{Na}_{2} \mathrm{SO}_{3}$ agregada. Al agregar un $1 \% \mathrm{p} / \mathrm{v}$ de sulfito de sodio, se produce un notorio aumento 
en la eficiencia de extracción de manganeso, lo cual podría estar asociado a la facilidad de reducción del $\mathrm{MnO}_{2}$ en presencia de sulfito de sodio:

$$
2 \mathrm{MnO}_{2}+\mathrm{Na}_{2} \mathrm{SO}_{3}+\mathrm{H}_{2} \mathrm{SO}_{4} \rightarrow 2 \mathrm{MnSO}_{4}+5 \mathrm{Na}_{2} \mathrm{SO}_{4}+\mathrm{H}_{2} \mathrm{O}
$$

En el caso del Zn, la eficiencia de extracción aumenta de 90 hasta casi el $100 \%$.

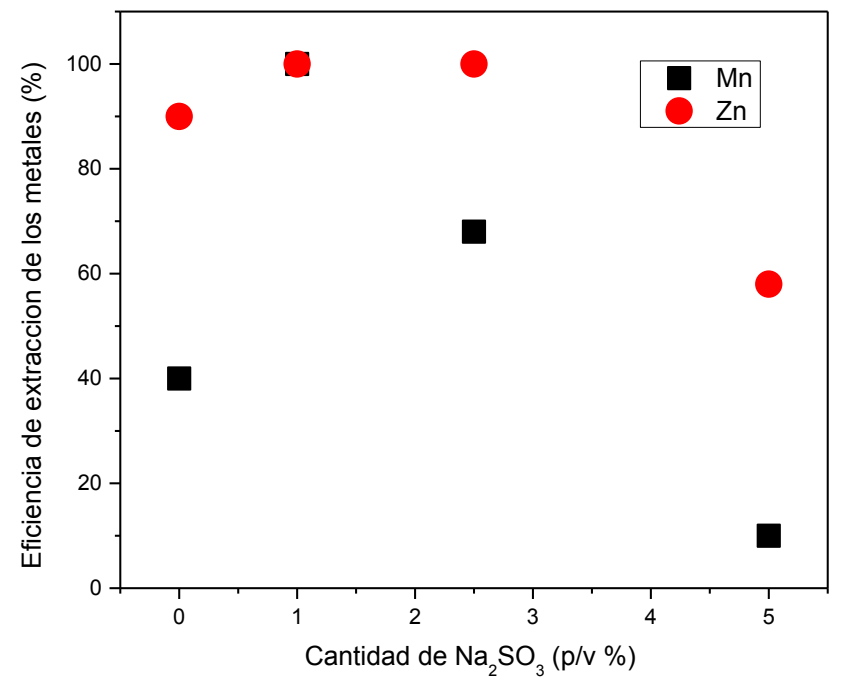

Figura 5.4. Porcentaje de extracción de $\mathrm{Zn}$ y $\mathrm{Mn}$ en función de la cantidad de $\mathrm{Na}_{2} \mathrm{SO}_{3}$

$$
\left(S / L=0,04 \mathrm{~g} \mathrm{~mL}^{-1}, 120 \mathrm{~min}, 30^{\circ} \mathrm{C}\right) .
$$

Sin embargo, con un aumento de la cantidad de sulfito de sodio agregada, se produce una disminución en la eficiencia de extracción de manganeso. Este hecho está asociado al aumento de $\mathrm{pH}$ que ocasiona el agregado del sulfito de sodio, lo cual ocasiona una menor eficiencia de la lixiviación. En la Tabla 5.2 se muestra la variación de $\mathrm{pH}$ frente al agregado de diferentes cantidades de $\mathrm{Na}_{2} \mathrm{SO}_{3}$. 
Tabla 5.2. Variación del pH con el agregado de $\mathrm{Na}_{2} \mathrm{SO}_{3}$.

\begin{tabular}{cc}
\hline Cantidad de & $\mathbf{p H}$ \\
$\mathrm{Na}_{2} \mathrm{SO}_{3}(\% \mathbf{p} / \mathbf{v})$ & \\
\hline 1 & 1 \\
2,5 & 1,48 \\
5 & 5 \\
\hline
\end{tabular}

\subsubsection{Influencia del agregado de $\mathrm{H}_{2} \mathrm{O}_{2}$}

En función de los resultados obtenidos y con el objetivo de aumentar las especies reductoras se analizó el efecto del agregado de $\mathrm{H}_{2} \mathrm{O}_{2}$ a las solución de $\mathrm{H}_{2} \mathrm{SO}_{4}$ biogenerado. El uso de $\mathrm{H}_{2} \mathrm{O}_{2}$ facilita la solubilización del $\mathrm{MnO}_{2}$ de acuerdo a la siguiente ecuación:

$$
\mathrm{MnO}_{2}+\mathrm{H}_{2} \mathrm{O}_{2}+\mathrm{H}_{2} \mathrm{SO}_{4} \rightarrow \mathrm{MnSO}_{4}+2 \mathrm{H}_{2} \mathrm{O}+\mathrm{O}_{2}
$$

En la Figura 5.5 se muestra el efecto de usar $\mathrm{H}_{2} \mathrm{O}_{2}$ durante el proceso de lixiviación. Con el agregado de un $1 \% \mathrm{v} / \mathrm{v}$ de $\mathrm{H}_{2} \mathrm{O}_{2}$, la eficiencia de extracción de zinc aumenta de 90 hasta casi el $100 \%$. En el caso de la extracción del manganeso, el agregado de $1 \% \mathrm{v} / \mathrm{v}$ de $\mathrm{H}_{2} \mathrm{O}_{2}$ mejora la extracción del 40 al 60 \%. Sin embargo, al aumentar la concentración de $\mathrm{H}_{2} \mathrm{O}_{2}$ la eficiencia de extracción aumenta hasta alcanzar aproximadamente el 100\% con una concentración de $5 \% \mathrm{v} / \mathrm{v}$ de $\mathrm{H}_{2} \mathrm{O}_{2}$. 


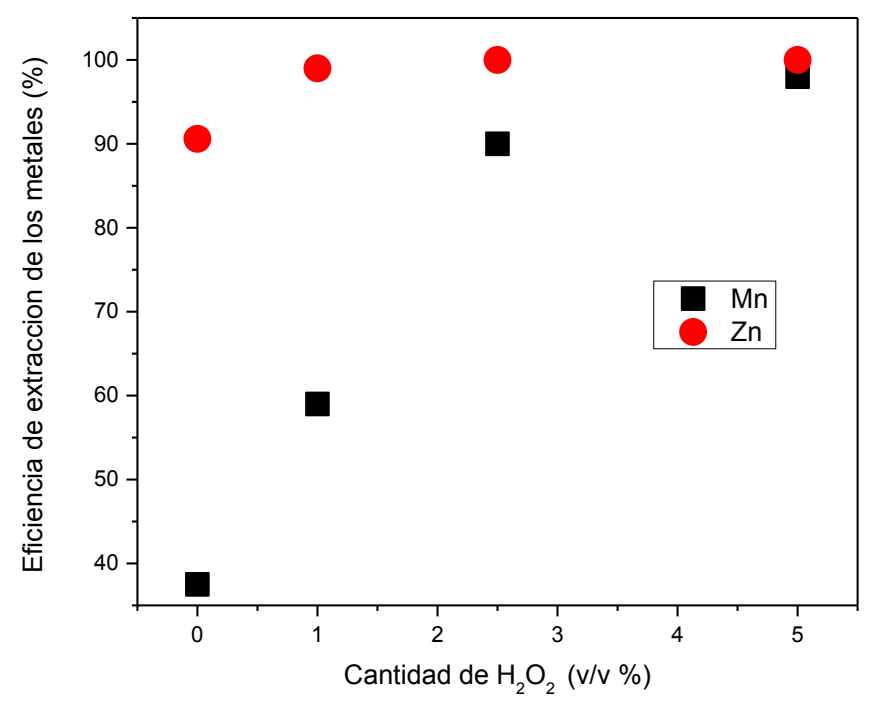

Figura 5.5. Porcentaje de extracción de $\mathrm{Zn}$ y Mn en función de la cantidad de $\mathrm{H}_{2} \mathrm{O}_{2}(S / L=$

$$
\left.0,04 \mathrm{~g} \mathrm{~mL}^{-1}, 120 \mathrm{~min}, 30^{\circ} \mathrm{C}\right) \text {. }
$$

Los resultados indican que el agregado de $\mathrm{H}_{2} \mathrm{O}_{2}$ al ácido biogenerado mejora la lixiviación de manganeso debido a una mayor presencia de agentes reductores.

\subsubsection{CONCLUSIONES}

Los resultados señalan que $50^{\circ} \mathrm{C}$ es la temperatura óptima de lixiviación sin agregado de agentes reductores. Por otro lado, el agregado de $1 \% \mathrm{p} / \mathrm{v}$ de $\mathrm{Na}_{2} \mathrm{SO}_{3}$ permite una recuperación del $100 \%$ de los metales a $30{ }^{\circ} \mathrm{C}$, el mismo resultado se observó luego del agregado de $5 \%$ de $\mathrm{H}_{2} \mathrm{O}_{2}$.

Teniendo en cuenta que el objetivo es lograr un proceso amigable con el ambiente se decidió usar las siguientes condiciones de lixiviación: 
$\checkmark \quad 0,04 \mathrm{~g} \mathrm{~mL}^{-1}$ de relación sólido/ líquido.

$\checkmark \quad \mathrm{T}=30^{\circ} \mathrm{C}$.

$\checkmark 5 \% \mathrm{H}_{2} \mathrm{O}_{2}$, como agente reductor.

$\checkmark \quad 120$ min de reacción.

Desde el punto de vista de la Química Verde se logra: i)ahorrar energía, debido a que la reacción se lleva a cabo a $30^{\circ}$, ii) disminuir las emisiones de $\mathrm{CO}_{2}$ y iii) obtener como producto de reacción $\mathrm{H}_{2} \mathrm{O}$, siendo inocua para el ambiente, iv) siendo el $\mathrm{H}_{2} \mathrm{O}_{2}$ más económica que el sulfito. 


\title{
5.2 Síntesis y caracterización de
}

\author{
óxidos de Mn y Zn
}




\subsubsection{Recuperación de Manganeso}

\subsubsection{Introducción}

En este trabajo se han empleado varias técnicas de caracterización con el objetivo de dilucidar las propiedades estructurales, morfológicas y estados de oxidación de los sólidos recuperados.

Los óxidos de manganeso presentan propiedades interesantes desde el punto de vista catalítico, en este caso la reacción estudiada fue la oxidación de COVs (etanol y tolueno), los resultados se muestran en el Capítulo 5, sección 3. En el Capítulo 5, sección 1 se mostraron los pasos del tratamiento de las pilas y se analizaron diferentes condiciones de lixiviación, esto se hizo con el objetivo de optimizar la recuperación de Mn y Zn de pilas agotadas.

En la Figura 5.7 se representa una breve descripción de la metodología de recuperación de metales de pilas agotadas, en esta sección se describirá la síntesis y caracterización de los sólidos. Los pasos resaltados en el esquema corresponden a los mencionados anteriormente. 


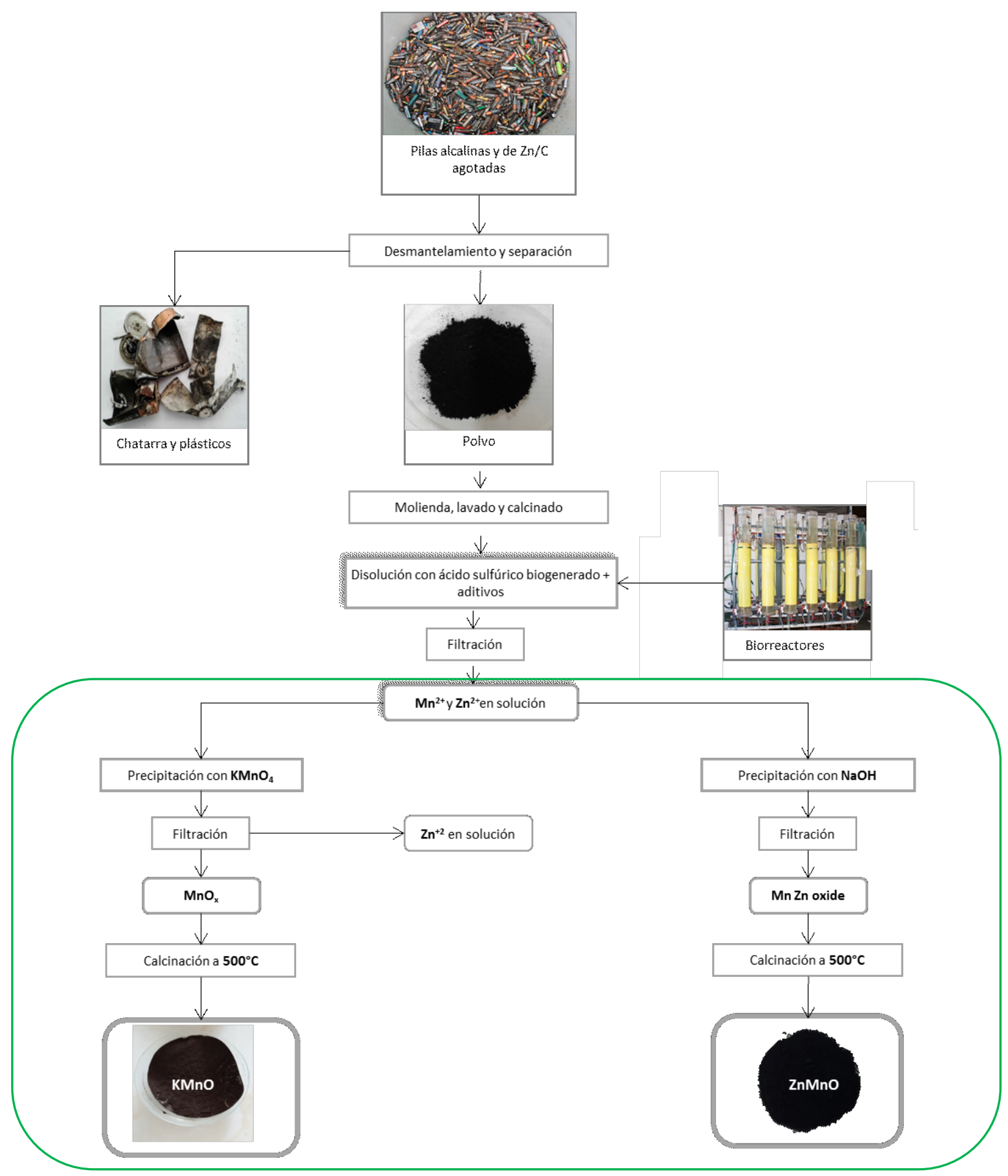

Figura 5.7. Esquema de obtención de óxidos de manganeso a partir de pilas alcalinas y de $\mathrm{Zn} / \mathrm{C}$ agotadas. 


\subsubsection{Determinación de metales}

Como se mencionó en el Capítulo 4, sección 2, a partir de la solución lixiviada se prepararon diferentes sólidos. El contenido total de Mn y Zn en las muestras se determinó por AbsorciónAtómica (A.A.), mientras que por EDS se analizó la composición de las primeras capas de los sólidos. En la Figura 5.8 se muestra la relación $\mathrm{Mn} / \mathrm{Zn}$ determinada por las técnicas mencionadas.

De los resultados de EDS puede suponerse que en los sólidos OMR, OMRB y ZnMnR tienen una composición superficial homogénea, a pesar de presentar distintas cantidades totales de $\mathrm{Zn}$ y Mn, de acuerdo a los datos de A.A. En cambio en el sólido OMRA ocurre lo contrario, el contenido de Mn es mayor en las primeras capas superficiales de acuerdo al análisis por EDS.

Los resultados observados en el análisis EDS de los sólidos OMR, OMRA y OMRB podrían estar relacionados con una posible lixivicion de manganeso producto del traamiento con la solución acida de iones $\mathrm{Zn}^{2+}$. Esto estaría relacionado con los cambios estructurales y formación de distintas fases. 


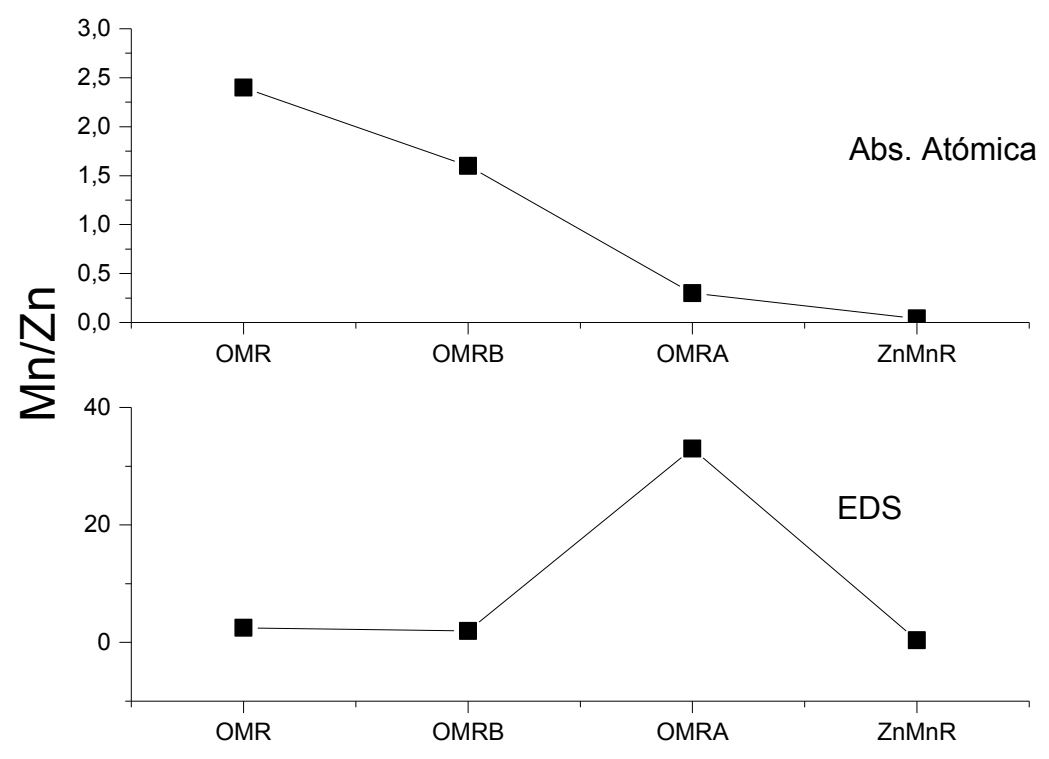

Figura 5.8. Relación $\mathrm{Mn} / \mathrm{Zn}$ en los sólidos recuperados medida por diferentes técnicas.

\subsubsection{Difracción de Rayos $X$}

En la Figura 5.9.a se muestran los patrones de Difracción de Rayos X de los sólidos OMR y ZnMnR, mientras que en la Figura 5.9.b se presentan los difractogramas de OMR junto con OMRA y OMRB. Se dividieron de esta manera de acuerdo al método de síntesis.

El patrón de difracción de rayos $\mathrm{X}$ de OMR presenta picos asignados a la fase $\alpha \mathrm{MnO}_{2}$ (JCPDS 44-138), adicionalmente aparecen algunas líneas de difracción de menor intensidad correspondientes a $\mathrm{Mn}_{2} \mathrm{O}_{3}$ (Bixbyita JCPDS 89-4836). La fase $\alpha \mathrm{MnO}_{2}$ es una estructura de tipo holandita, en este tipo de estructura los iones $\mathrm{K}$ presentes se encuentran ubicando los túneles formados por octaedros del tipo $\mathrm{MnO}_{6}$, como se describió en el Capítulo 2. A pesar 
de la presencia de $\mathrm{Zn}$ en la estructura del sólido OMR no se observaron líneas correspondientes a $\mathrm{ZnO}$, sin embargo no se descarta la presencia de la fase $\mathrm{ZnMn}_{2} \mathrm{O}_{4}$. El difractograma del sólido $\mathrm{ZnMnR}$ presenta líneas de difracción correspondientes a la fase ZnO wurtzita (JCPDF 36-1451). Además presenta líneas de difracción de baja intensidad correspondientes a $\mathrm{ZnMn}_{2} \mathrm{O}_{4}$ (JCPDF 71-2499), y un óxido de manganeso. Como consecuencia de las técnicas de preparación se observa la segregación de la fase $\mathrm{ZnO}$ y alguna fase mixta Mn-Zn. Estos resultadps permiten suponer que en el sólido OMR el Zn ocuparía sitios intersticiales o túneles presentes en la estructura $\mathrm{MnO}_{2}$, sin formación de fase $\mathrm{ZnO}$.

En los difractogramas correspondientes a los sólidos OMRA y OMRB, se observan las mismas líneas de difracción que en el sólido inicial OMR. Estas líneas corresponden a un óxido de manganeso de tipo holandita. Asimismo se observan picos que corresponden a la fase cristalina $\mathrm{ZnMn}_{2} \mathrm{O}_{4}$, mas destacados en el sólido OMRB. El difractograma correspondiente al sólido OMRA presenta un cambio notorio en el pico ubicado en $2 \theta=$ $36^{\circ}$ con respecto a OMR, esto podría relacionarse con un aumento en la cantidad de $\mathrm{Zn}^{2+}$ en ambos sólidos. 
(a)

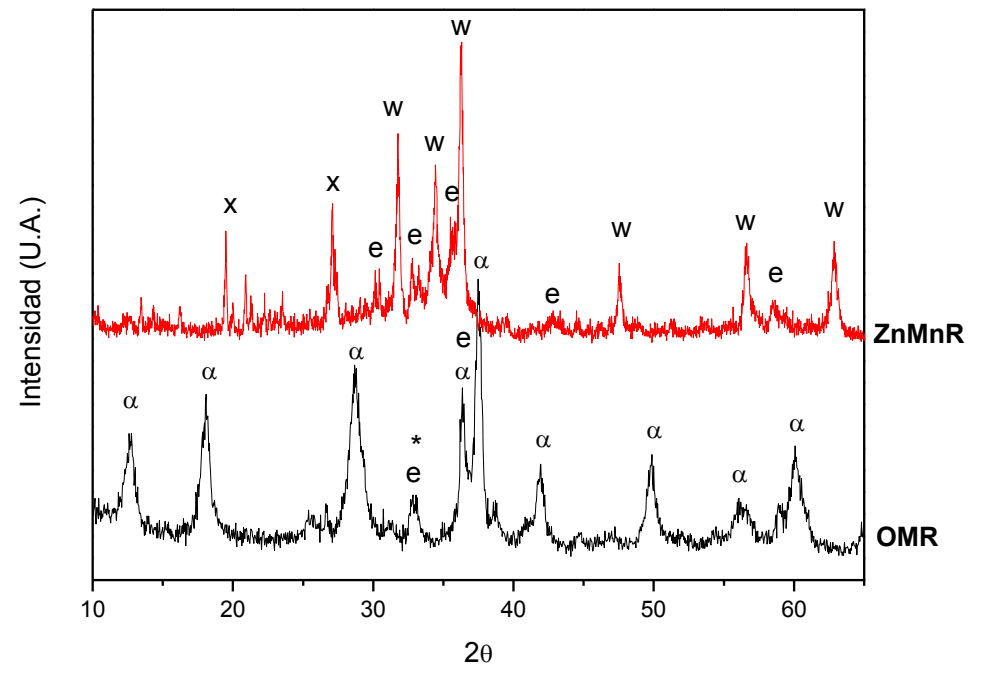

(b)

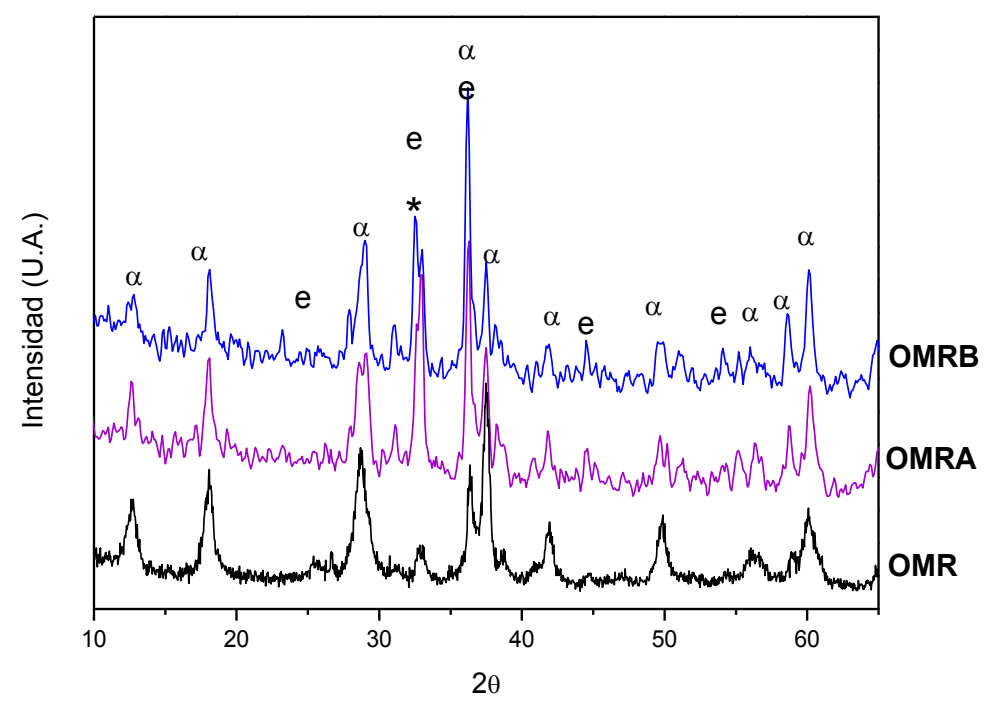

Figura 5.9. Diagramas de difracción de rayos $X$ de los sólidos: (a) ZnMnR y OMR y (b) OMR, OMRA y OMRB. (o) $\mathrm{ZnO} ;(\alpha) \alpha \mathrm{MnO}_{2} ;(*) \mathrm{Mn}_{2} \mathrm{O}_{3}$ y (e) $\mathrm{ZnMn}_{2} \mathrm{O}_{4}$ 


\subsubsection{Superficie Específica}

En la Tabla 5.3 se presentan los resultados de las medidas de Superficie Específica por el método BET, para los sólidos recuperados.Se observa que el valor de $\mathrm{S}_{\mathrm{BET}}$ y Dp varían en las diferentes muestras. Este hecho se atribuye a la formación de diferentes fases cristalinas.

El sólido OMR presenta un valor de Superficie Específica ligeramente superior a los demás sólidos, posiblemente debido a la fase cristalina $\alpha \mathrm{MnO}_{2}$. En el sólido OMRB se produce una disminución del $35 \%$ con respecto a OMR, lo cual podría estar relacionado con la técnica de impregnación usada.

Tabla 5.3. Propiedades texturales de los sólidos recuperados.

\begin{tabular}{|c|c|c|c|}
\hline Muestra & $\operatorname{S}_{\text {Bet }}\left(\mathrm{m}^{2} \mathrm{gr}^{-1}\right)$ & $V_{P}\left(\mathrm{~cm}^{3} \mathrm{gr}^{-1}\right)$ & $D_{P}(\dot{A})$ \\
\hline $\mathrm{ZnMnR}$ & 33 & 0,15 & 166 \\
\hline OMR & 37 & 0,16 & 169 \\
\hline OMRA & 32 & 0,12 & 150 \\
\hline OMRB & 24 & 0,12 & 185 \\
\hline
\end{tabular}




\subsubsection{Microscopia electrónica de barrido (SEM) y de transmisión (TEM)}

Mediante microscopía electrónica de barrido (SEM) y de transmisión (TEM) se ha obtenido información acerca de la morfología de los sólidos obtenidos. En la Figura 5.10 se presentan las micrografías TEM (50000X) de las muestras y en el interior de cada una de ellas se presenta la imagen SEM (1000X) correspondiente. En la Figura 5.10.a, la microgafia TEM muestra partículas globulares características de óxidos de manganeso obtenidos por precipitación con $\mathrm{KMnO}_{4}{ }^{1} \mathrm{King}^{\prime}$ ondu y col. ${ }^{2}$ mostraron la existencia de tres niveles de estructuras en los oxidos de manganeso: primaria, correspondiente a túneles; secundaria, morfología de tipo aguja y por último, la estructura terciaria que comprende esferas ensambladas. En este caso se puede apreciar la estructura terciaria. En las Figuras 5.10 b y c, el análisis TEM permite observar además de las partículas globulares, partículas fibrosas lo cual podría relacionarse con el aumento de la cantidad de zinc en los sólido. Los autores mencionados anteriormente reportaron la aparición de esta morfología de tipo aguja luego de la incorporación de distintos metales en óxidos de manganeso del tipo OMS-2 en medio ácido. Esta variación en la morfología podría estar relacionada con un cambio estructural producto de la sustitución de iones $\mathrm{Mn}$ en los octaedros por $\mathrm{Zn}$.

\footnotetext{
${ }^{1}$ R. Jothiramalingam, B. Viswanathan, T.K. Varadarajan, Applied Catalysis B 59 (2005) 91-98

${ }^{2}$ C. King' ondu, N.Opembe, C. Chen, K. Ngala, H. Huang, A. Iyer, H. Garces, S. Suib, Advanced Functional Materials 21 (2011) 312-323
} 


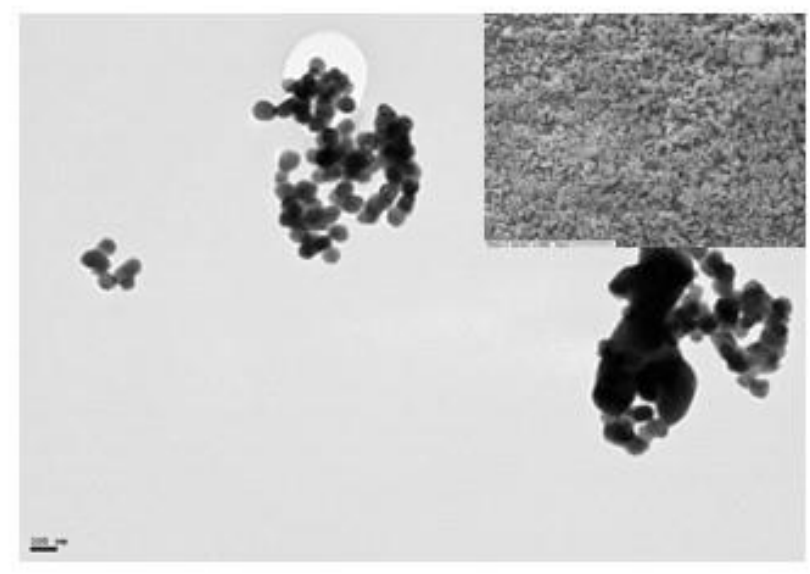

(a)

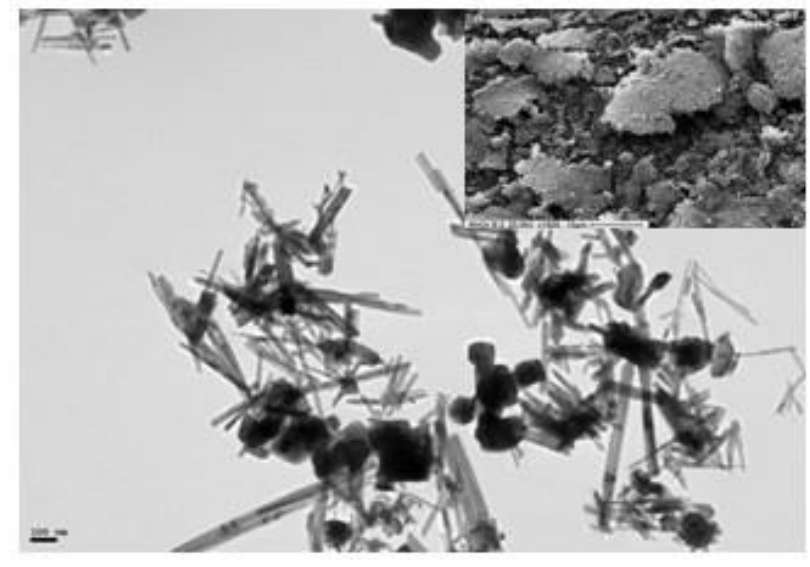

(c)

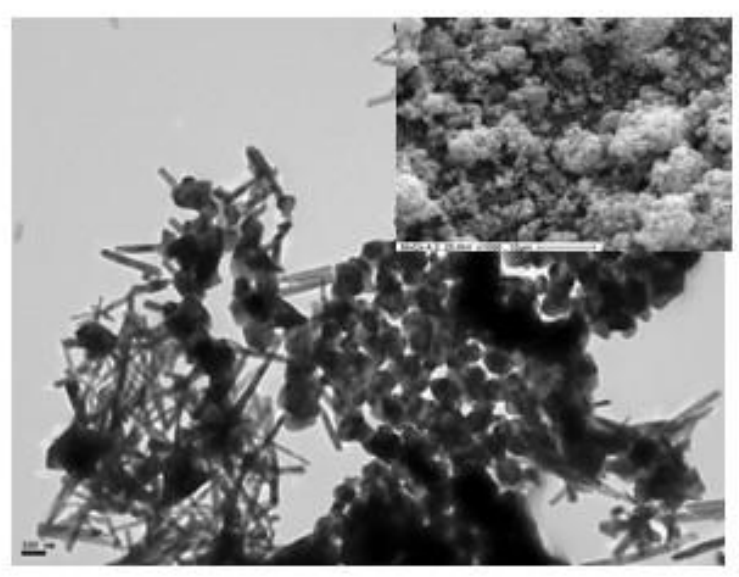

(b)

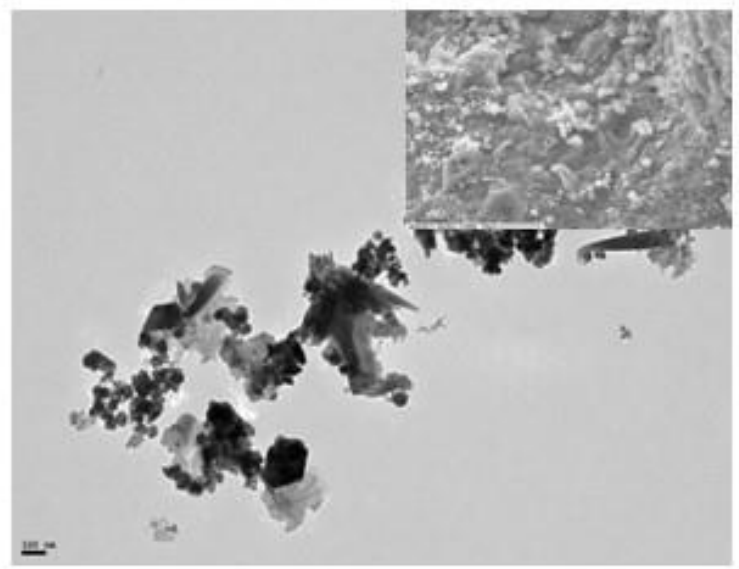

(d)

Figura 5.10. Micrografías TEM (50000X) y SEM (1000X) de los sólidos: (a) OMR, (b) OMRA, (c) OMRB y (d) ZnMnR. 
Por otro lado, en las imágenes TEM mostradas en las Figuras 5.10 c y d, se observan partículas hexagonales que podrían atribuirse a la presencia de la espinela $\mathrm{ZnMn}_{2} \mathrm{O}_{4}$, tal como reportan Xiang y col. ${ }^{3}$ Estos autores sintetizaron la fase $\mathrm{ZnMn}_{2} \mathrm{O}_{4}$ a partir de una solución de $\mathrm{ZnSO}_{4}$ en medio ácido.

El análisis SEM del sólido OMR muestra partículas con forma globular, característica de los óxidos de manganeso. En el caso de OMRA y OMRB se mantiene la forma de las partículas, produciéndose además una aglomeración de las partículas.

Por último el sólido ZnMnR, presenta partículas con forma hexagonal, lo cual confirma la presencia de la espinela $\mathrm{ZnMn}_{2} \mathrm{O}_{4}$.

\subsubsection{Espectroscopía FT IR y FT Raman}

La espectroscopía infrarroja provee información acerca de los enlaces M-O. En este apartado se estudiarán las frecuencias de los enlaces Mn-O y las modificaciones que sufren como consecuencia de la presencia de Zn en la estructura.

En la Figura 5.11a se muestran los espectros FT IR correspondientes a los óxidos OMR y ZnMnR, mientras que los sólidos OMRA y OMRB se presentan en la Figura 5.11 b. Nuevamente se muestran separados con el objetivo de hacer más notables las diferencias entre ellos teniendo en cuenta el método de síntesis.

\footnotetext{
${ }^{3}$ Z. Xiang-Dong, W. Zhong-Shuai, Z. Jian, L. Da, Z. Zhi-Dong, Journal of Physics and Chemistry of Solids 68 (2007) 1583-1590.
} 

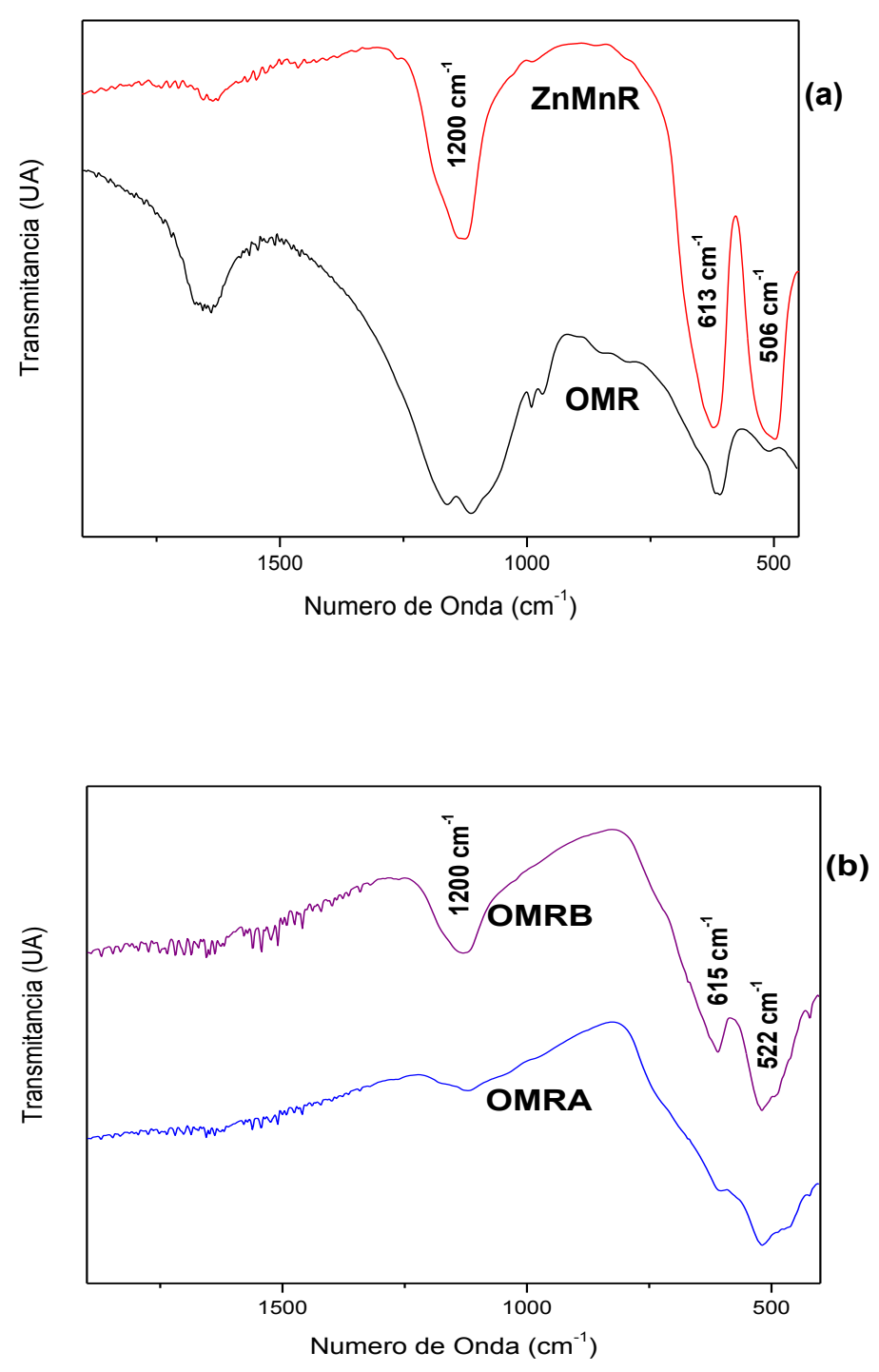

Figura 5.11. Espectros FT IR correspondientes a los sólidos: (a) ZnMnR y OMR y (b) OMRA y OMRB. 
Entre 400 y $1000 \mathrm{~cm}^{-1}$ es donde más se diferencian los espectros de los óxidos de manganeso, ya que esta región da información acerca de la disposición de los octaedros de $\mathrm{MnO}_{6}$. La banda observada a $1200 \mathrm{~cm}^{-1}$ corresponde a estiramientos $\mathrm{S}=\mathrm{O}$ de especies $\mathrm{SO}_{4}{ }^{2-}$ superficiales, ${ }^{4}$ los cuales están presentes en la solución madre a partir de la cual se sintetizaron los sólidos estudiados.

El sólido ZnMnR presenta bandas a 506 y $613 \mathrm{~cm}^{-1}$, asignadas a los estiramientos Mn$\mathrm{O}^{5}$ y Mn-O-Zn, ${ }^{6}$ respectivamente.

En los espectros correspondientes a OMR, OMRA y OMRB aparece una banda centrada alrededor de $522 \mathrm{~cm}^{-1}$. Russel y col. ${ }^{7}$ sugieren que esta banda corresponde a la fase criptomelano, la cual se ubica dentro del grupo de las Holanditas.

Se ha demostrado que la espectroscopía Raman resulta útil en la identificación de fases cristalinas. Julien y col. ${ }^{5}$ mencionan las discrepancias que existen en cuanto a la asignación de las bandas a las diferentes fases. Sugieren que esto se debe a la pobre caracterización estructural que existe sobre estos óxidos, producto de la inestabilidad de los mismos y su tendencia a la formación de la fase $\mathrm{Mn}_{2} \mathrm{O}_{3}$ como consecuencia de la reducción. En la Figura 5.12 se presentan los espectros de los sólidos recuperados.

\footnotetext{
${ }^{4}$ X. Guo, C. Bartholomew, W.Hecker, L.L. Baxter, Applied Catalysis B: Environmental 92 (2009) 30-40.

${ }^{5}$ C. Julien, M. Massot, C. Poinsignon, Spectrochimica Acta Part A. 60 (2004) 689-700.

${ }^{6}$ P. Zhang, X. Li, Q. Zhao, S. Liu, Nanoscale Research Letters 6 (2011) 1-6.

${ }^{7}$ R. M. Poter, G.A. Rossman, American Mineralogist 64 (1979)1199-1218.
} 

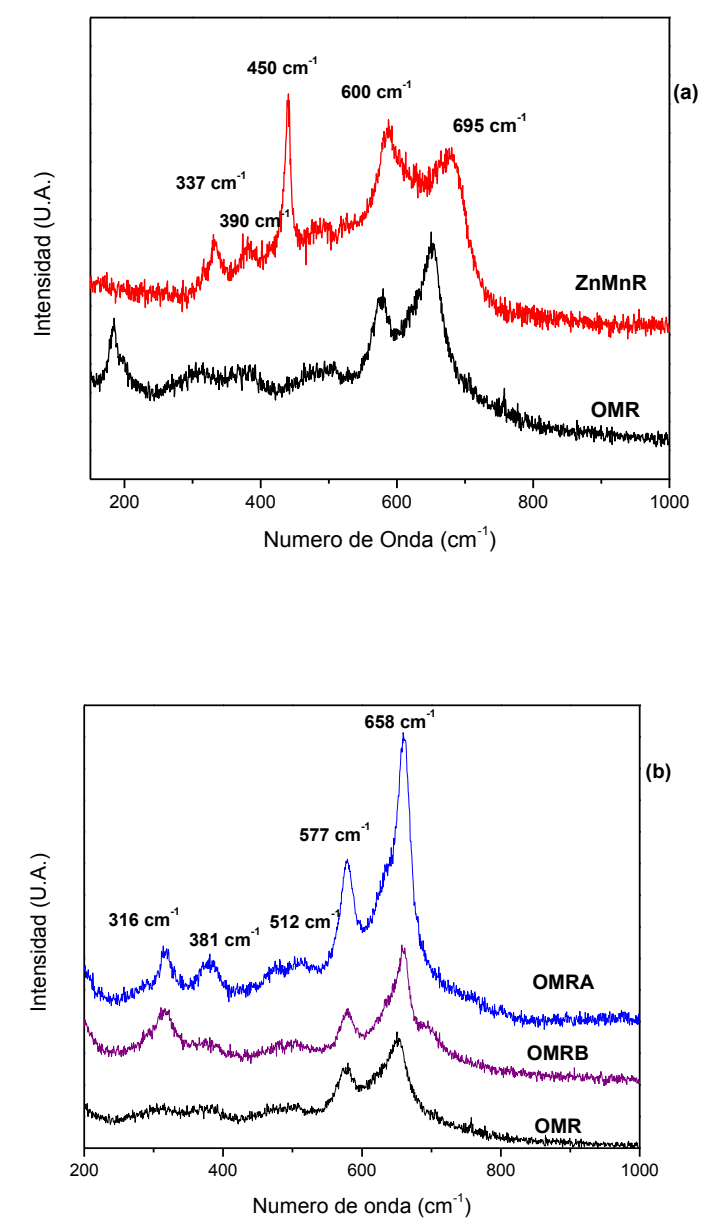

Figura 5.12. Espectros Raman de los sólidos recuperados: (a) OMR y ZnMnR, (b) OMR, OMRA y OMRB.

El espectro correspondiente al sólido ZnMnR presenta bandas características de la fase $\mathrm{ZnO}$ ubicadas a 337, 390, 450, y $600 \mathrm{~cm}^{-1}$, coincidiendo con lo establecido por Damen y 
col. ${ }^{8}$ Se observa además una banda a $695 \mathrm{~cm}^{-1}$, la cual fue asignada por Cong y col. ${ }^{9}$ a alguna fase mixta de zinc y manganeso. Este resultado coincide con lo publicado por Malavasi y col. ${ }^{10}$ que atribuyen este modo a la fase $\mathrm{ZnMn}_{2} \mathrm{O}_{4}$.

Los óxidos OMR, OMRA y OMRB presentan bandas a 316, 381, 503, 577 y $658 \mathrm{~cm}^{-1}$. De acuerdo con Julien y col..$^{5}$ la primera banda podría ser asignada a modos vibracionales presentes en $\mathrm{Mn}_{2} \mathrm{O}_{3}$, mientras que los restantes se atribuyen a la fase holandita. Estos resultados coindicen con lo observado por difracción de rayos $\mathrm{X}$, donde los picos encontrados podrían asignarse a la familia de holanditas.

\subsubsection{DRS-UV-Vis}

Mediante la técnica de DRS-UV-VIS es posible determinar la presencia de los diferentes iones de $\mathrm{Mn}(2+, 3+, 4+, 7+)$. El análisis de DRS-UV-Vis fue realizado en el intervalo de medida de 200 hasta $2000 \mathrm{~nm}$, cubriendo la región ultravioleta y visible del espectro. En la Figura 5.13 se muestran los espectros para las muestras OMR, OMRA y ZnMnR.

Se observa que la muestra ZnMnR presenta una banda con un máximo entre 300-500 $\mathrm{nm}$, coincidiendo con el valor reportado en bibliografía para una espinela del tipo $\mathrm{ZnMn}_{2} \mathrm{O}_{4}{ }^{11}$

\footnotetext{
${ }^{8}$ T. Damen, S. Porto, B. Tell, Physics Review 142 (1966) 570

${ }^{9}$ C. Cong, L. Liao, C.Li, L.Fan, K. Zhang, Nanotechnology 16 (2005) 981-984.

${ }^{10}$ L. Malavasi, P. Galinetto, M. Mozzati, C.Azzoni, G. Flor, Physical Chemistry Chemical Physics 4 (2002) 3876-3880.

${ }^{11}$ P. Zhang, X. Li, Q. Zhao, S. Liu, Nanoscale Research Letters 6 (2011) 323.
} 


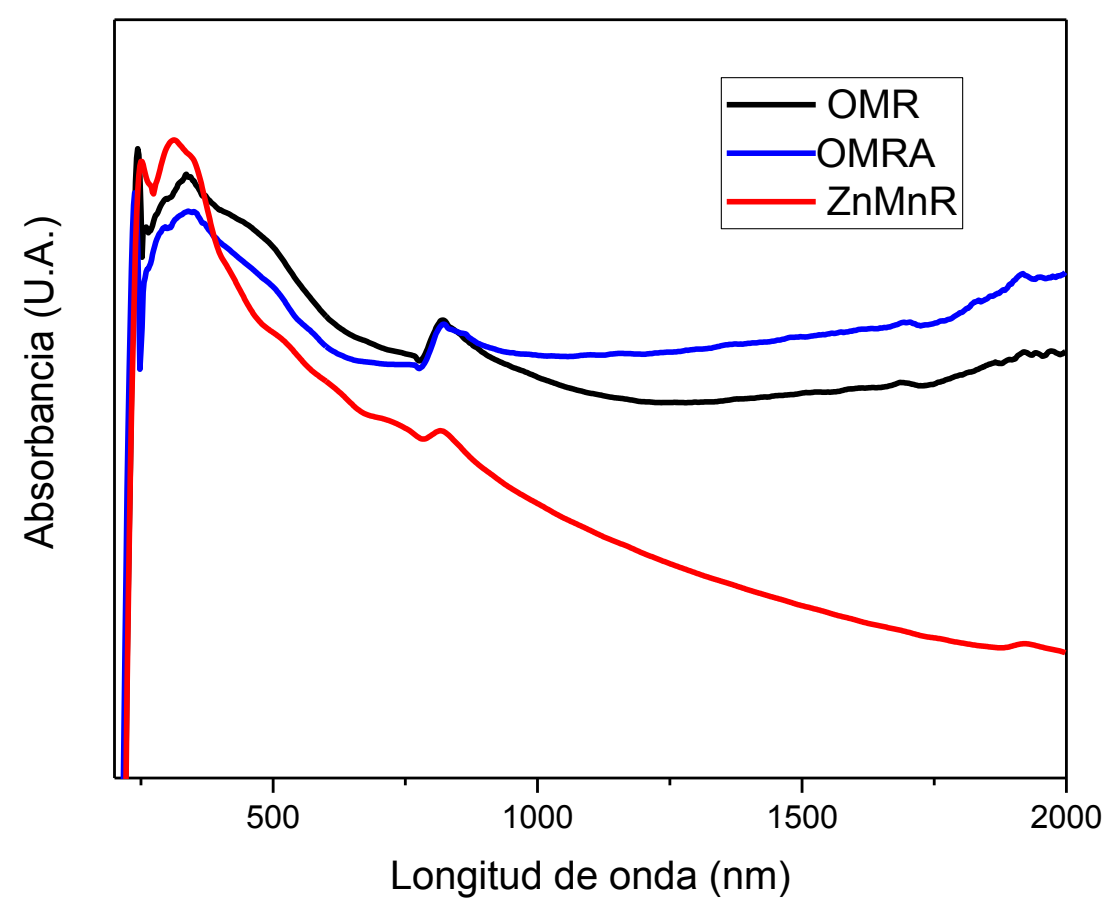

Figura 5.13. Diagramas de DRS-UV-Vis de las muestras OMR, OMRA y ZnMnR.

Por otro lado, los espectros de las muestras OMR y OMRA presentan una banda ancha con un máximo en la zona alrededor de $320 \mathrm{~nm}$, que indica la presencia de especies $\mathrm{Mn}^{3+}$. En el caso de la muestra OMRA, se observa una disminución de la intensidad con respecto a la muestra OMR, lo cual podría relacionarse con un aumento en la concentración de iones $\mathrm{Zn}^{2+}$. Fernández López y col. ${ }^{12}$ reportaron resultados similares para óxidos mixtos de MnZr. La banda entre 450 y $550 \mathrm{~nm}$ podría atribuirse al ion $\mathrm{Mn}^{3+}$ ocupando posiciones

\footnotetext{
${ }^{12}$ E. FernándezLópez, V. Sánchez Escribano, C. Resini, J.M. Gallardo-Amores,G. Busca, Applied Catalysis B 29 (2001) 251-261.
} 
octaédricas, y la transición d-d permitida por el spin es esperada en $500 \mathrm{~nm}$, tal cual ocurre en la especie $\left[\mathrm{Mn}\left(\mathrm{H}_{2} \mathrm{O}\right)_{6}\right]^{3+}$. Sin embargo, la distorsión de la coordinación octaédrica en el $\mathrm{Mn}_{2} \mathrm{O}_{3}$, permite suponer que la transición es debida a transferencias de carga $\mathrm{O}^{2-} \rightarrow \mathrm{Mn}^{3+}$.

\subsubsection{XPS}

Para la caracterización de las especies superficiales se realizó un estudio mediante XPS. En las Figuras 5.14, 5.15 y 5.16 se muestran los espectros correspondientes a $\mathrm{Mn} 2 \mathrm{p}_{3 / 2}$, O 1s y $\mathrm{Zn} 2 \mathrm{p}_{3 / 2}$, respectivamente.

Para la identificación de las diferentes especies de manganeso se utilizó el método de deconvolución del pico de $\mathrm{Mn} 2 \mathrm{p}_{3 / 2}$ descrito por Ponce y col. ${ }^{13}$ En todos los sólidos obtenidos el nivel del pico Mn 2p p3/2 está centrado cerca de $642 \mathrm{eV}$, y fue deconvolucionado en dos componentes, que podrían asociarse a $\mathrm{Mn}^{3+}(641,9 \mathrm{eV})$ y $\mathrm{Mn}^{4+}(642,8 \mathrm{eV})$. Aunque el nivel de Mn 3s se suele utilizar para determinar el estado de oxidación Mn, esta región energética aparece superpuesta con un pico fuerte de Zn 3p, por esta razón se analizaron las líneas de Mn 2p únicamente.

Con respecto al pico debido al O 1s, cuando éste es deconvolucionado se observan tres componentes a energías cercanas a 530, 531 y 533 eV los cuales son asignados a especies $\mathrm{O}^{2-}(\mathrm{OI})$, grupos $\mathrm{OH}^{-}$o vacancias (OII) y $\mathrm{H}_{2} \mathrm{O}$ molecular adsorbida(OIII), respectivamente.

En la Tabla 5.4 se muestran los porcentajes de las especies de $\mathrm{Mn}$ y O presentes en los sólidos. Se observa que la relación $\mathrm{Mn}^{4+} / \mathrm{Mn}^{3+}$ varía de acuerdo al método de síntesis. En el

${ }^{13}$ S. Ponce, M. Peña, J. Fierro, Applied Catalysis B 24 (2000) 193-205. 
sólido $\mathrm{ZnMnR}$ la relación $\mathrm{Mn}^{4+} / \mathrm{Mn}^{3+}$ es cercana a 1; mientras que en los impregnados esta relación es menor que en el sólido de partida indicando la reducción de iones Mn debido a la incorporación de $\mathrm{Zn}^{2+}$ en la estructura.

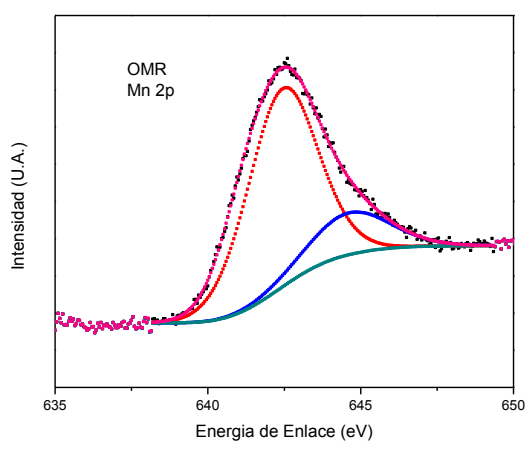

(a)

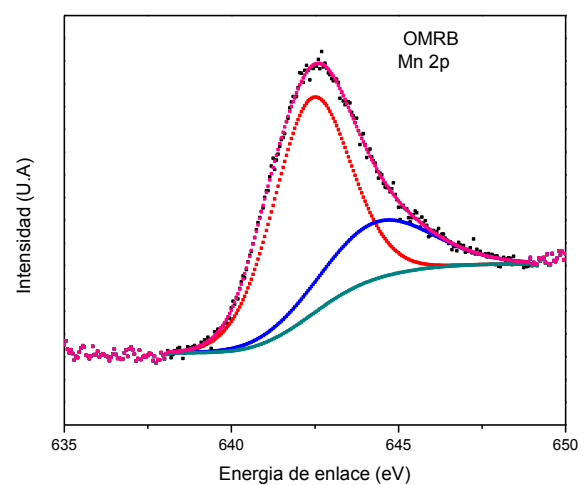

(c)

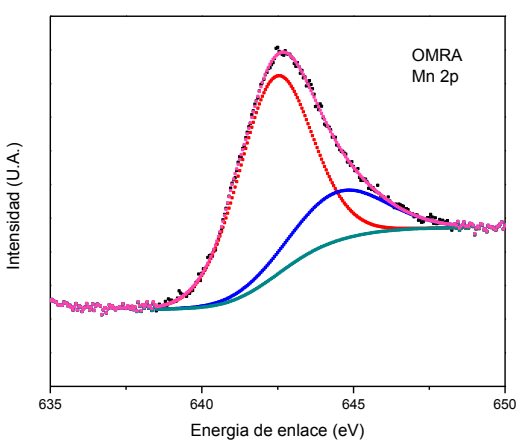

(b)

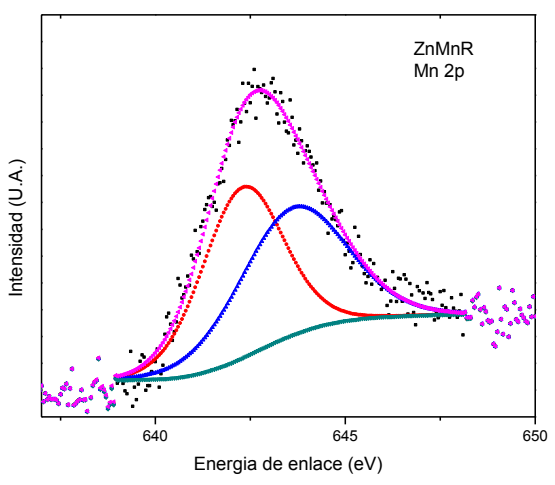

(d)

Figura 5.14. Espectros Mn 2p de los sólidos estudiados: (a) OMR, (b) OMRA, (c) OMRB y (d) $\mathrm{ZnMnR}$. 
Por otro lado, analizando las diferentes especies de oxígeno, se observa una variación en la relación OII/OI. En el sólido $\mathrm{ZnMnR}(0,42)$ este valor es menor que en el sólido OMR $(0,67)$. Asimismo, este valor aumenta luego de la impregnación de OMR con Zn $(0,84$ en OMRA y 0,88 en OMRB), posiblemente debido a la disminución de la relación $\mathrm{Mn}^{4+} / \mathrm{Mn}^{3+}$.

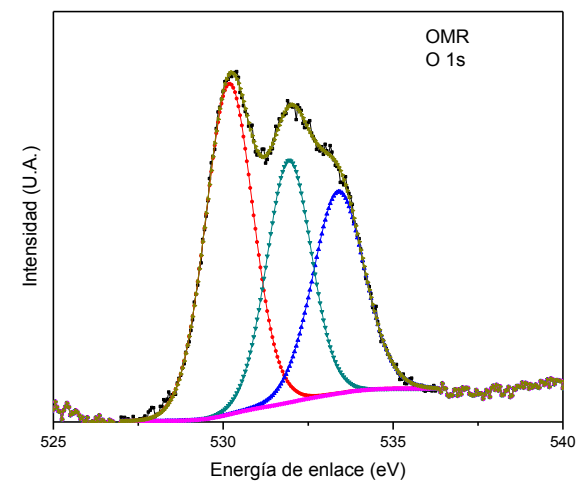

(a)

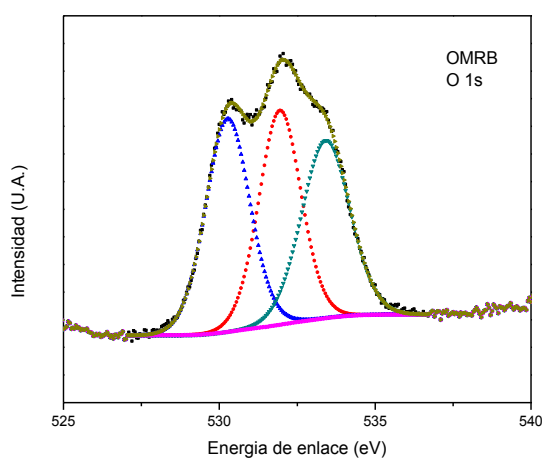

(c)

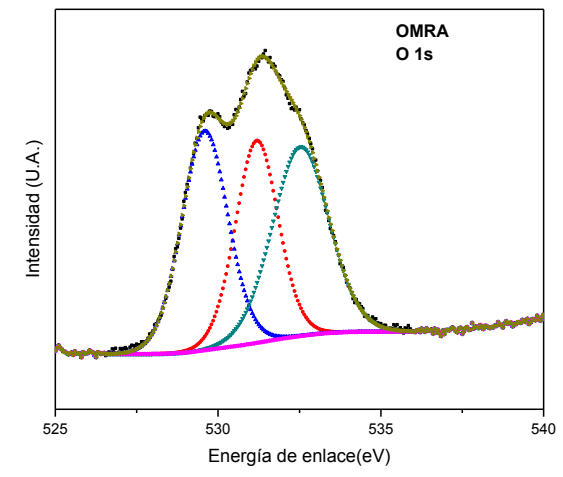

(b)

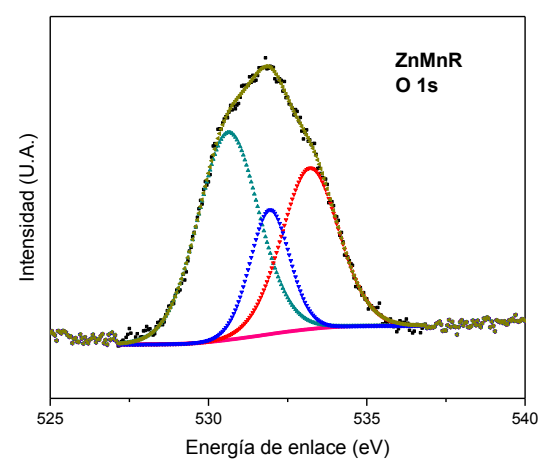

(d)

Figura 5.15. Espectros O 1s correspondientes a los sólidos recuperados:(a) OMR, (b) OMRA, (c) OMRB y (d) ZnMnR. 
Tabla 5.4. Resultados XPS de los sólidos recuperados.

\begin{tabular}{lllll}
\hline Muestras & Especie & $\mathbf{\%}$ & especie & \% \\
\hline ZnMnR & O(I) & 48 & $\mathrm{Mn}^{3+}$ & 49 \\
& O(II) & 20 & $\mathrm{Mn}^{4+}$ & 51 \\
OMR & O(III) & 32 & & \\
& O(I) & 43 & $\mathrm{Mn}^{3+}$ & 35 \\
OMRA & O(II) & 29 & $\mathrm{Mn}^{4+}$ & 65 \\
& O(III) & 28 & & \\
OMRB & O(I) & 45 & $\mathrm{Mn}^{3+}$ & 62 \\
& O(II) & 38 & $\mathrm{Mn}^{4+}$ & 38 \\
& O(III) & 16 & & \\
& O(I) & 34 & $\mathrm{Mn}^{3+}$ & 70 \\
\hline
\end{tabular}

Los espectros de $\mathrm{Zn} 2 \mathrm{p}_{3 / 2}$ de los sólidos estudiados presentan un pico centrado alrededor de 1021 eV que podría ajustarse usando una única componente, anulando la posibilidad de múltiples estados de oxidación. En los sólidos OMR y OMRB este pico aparece a menores valores de energía de enlace, con respecto a $\mathrm{ZnO}$ puro (Tabla 5.5). La disminución del valor de energía de enlace con el aumento del contenido de Mn, está de acuerdo con lo reportado en un trabajo de Gallegos y col. ${ }^{14}$ En el mismo sentido, estos autores han mostrado que la energía de enlace $\mathrm{Zn}-\mathrm{O}$ en la espinela $\mathrm{ZnMnO}_{3}$ presenta un valor menor que el $\mathrm{ZnO}$ puro, en coincidencia con los datos obtenidos en este trabajo de Tesis. Por el comportamiento del sólido OMRA, podría estar relacionado con una variación en el tamaño

\footnotetext{
${ }^{14}$ M.V. Gallegos, M. A. Peluso, H. Thomas, L. C. Damonte, J. E. Sambeth, Journal of Alloys and Compounds 689 (2016) 416-424.
} 
de partícula de acuerdo a lo señalado por Bera y col., ${ }^{15}$ tal como se observa en las imágenes TEM.

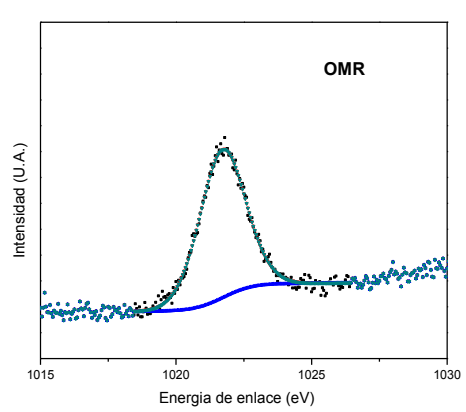

(a)

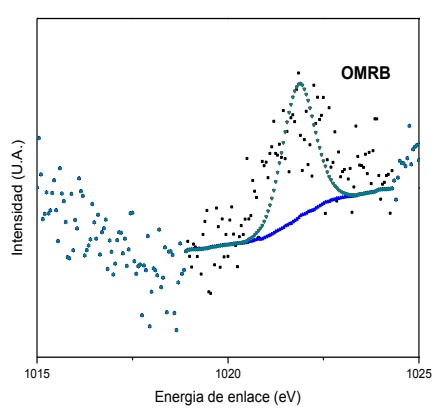

(c)

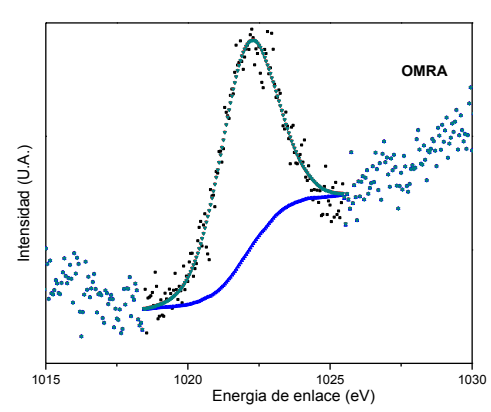

(b)

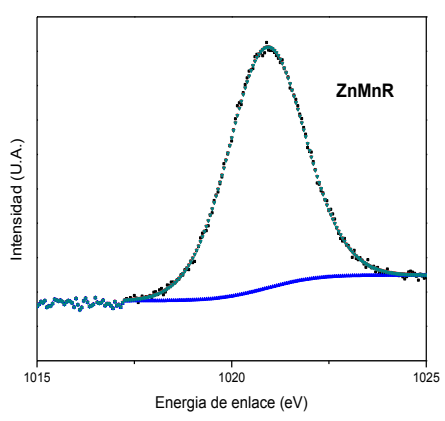

(d)

Figura 5.16. Espectros XPS de la región Zn 2p de los sólidos recuperados: (a) OMR, (b) OMRA, (c) OMRB y (d) ZnMnR.

En la Tabla 5.5 se muestra el desplazamiento del pico correspondiente a iones $\mathrm{Zn}^{2+}$ en las diferentes muestras, observándose un corrimiento hacia menores valores de energía.

15 S. Bera, S. Dhara, S. Velmurugan, A. Tyagi, International Journal of Spectroscopy 2012 (2011). 
Tabla 5.5. Desplazamiento del valor de energía de la región $\mathrm{Zn} 2 \mathrm{p}_{3 / 2}(\mathrm{eV})$.

\begin{tabular}{cc}
\hline Muestra & Energía (eV) \\
\hline ZnO & 1022,0 \\
OMR & 1021,7 \\
OMRB & 1021,8 \\
OMRA & 1022,3 \\
ZnMnR & 1020,8 \\
\hline
\end{tabular}

\subsubsection{XANES}

El espectro XANES provee información de la estructura atómica y electrónica local aún en sistemas cuyo orden sea de corto rango (fases amorfas o nanomateriales por ejemplo). Los espectros XANES en el borde $\mathrm{K}$ del Mn utilizados como caracterización en este estudio, están asociados a la transición dipolar del par electrón-hueco $1 s$ a la densidad de estados desocupados "del tipo $p$ " de los niveles del átomo absorbente de Mn. Dado que dichos estados $4 p$ están fuertemente hibridizados con los estados $\mathrm{O} 2 p$ y $\mathrm{Mn} 3 d$ de los átomos vecinos, dicha densidad $4 p$ es muy sensible a la distribución de carga y a las distorsiones locales de los enlaces $\mathrm{Mn}-\mathrm{O}$, así como también a cualquier variación en la 
hibridización de los estados $\mathrm{Mn} 3 d-\mathrm{O} 2 p$ que se consideran muy próximos al nivel de Fermi. $^{16}$

La Figura 5.17 muestra los espectros XANES en el borde K del Mn en cada una de las muestras. Los mismos fueron empleados para los análisis posteriores sobre el estado de oxidación promedio del Mn en cada caso y para determinar la naturaleza de los sitios presentes en ellas.

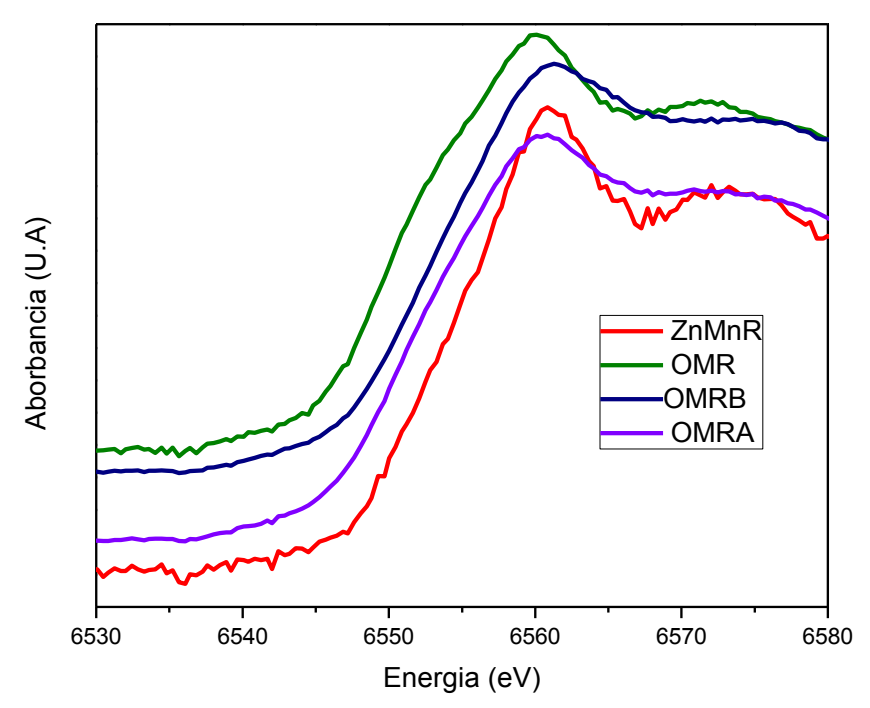

Figura 5.17. Espectros XANES de los sólidos recuperados y referencias

En general, para compuestos de Mn, un pequeño prepico en los espectros XANES cercano a los $6542 \mathrm{eV}$ da cuenta de que los átomos de $\mathrm{Mn}$ ocupan sitios sin un centro de

${ }^{16}$ F De Groot, Coordination Chemistry Reviews 249 (2005) 31-63. 
inversión. ${ }^{17}$ En nuestro caso, una simple inspección de la Figura 5.17 indica que el Mn se encuentra únicamente en sitios octaédricos ya que la intensidad de los prepicos en los espectros XANES obtenidos es muy pequeña comparada con la de aquellos sistemas con especies de $\left[\mathrm{MnO}_{4}\right]$ donde los átomos de Mn se encuentran tetraédricamente coordinados. ${ }^{18}$

Las diferentes especies químicas de Mn presentes en cada muestra contribuyen al espectro medido con el peso específico de su concentración relativa en el compuesto. Los corrimientos de energía del borde de absorción están directamente relacionados con el estado de oxidación del átomo absorbente. Más aún, la forma del espectro XANES resulta característica del tipo de simetría del entorno del Mn, lo que a su vez está determinado por su estado de oxidación.

Las características electrónicas de los átomos de Mn en cada una de las muestras, puede ser determinada mediante el análisis de los espectros XANES. En principio es posible obtener una respuesta cuantitativa promediada sobre todos los sitios de $\mathrm{Mn}^{19}$

Muchas veces resulta más sencillo analizar la estructura del espectro tomando la derivada segunda del mismo. En la Figura 5.18 puede observarse la derivada segunda de los espectros XANES correspondientes a compuestos de Mn en donde todos los átomos de Mn poseen estado de oxidación 2+, 4+ ó 3+ $\left(\mathrm{MnO}, \mathrm{MnO}_{2}\right.$ y $\left.\mathrm{Mn}_{2} \mathrm{O}_{3}\right)$.

\footnotetext{
${ }^{17}$ F. De Groot, American Chemical Society 101 (2001) 1779-1808.

${ }^{18}$ A. Bianconi, J. Garcia, M. Benfatto, A. Marcelli, C.R. Natoli y M.F. Ruiz-Lopez, Phyical Review B 43 (1991) 6885-6892.

${ }^{19}$ Q. Qian, T. Tyson, C. Kao, M. Croft, S. Cheong, G. Popov, M. Greenblatt, Physical Review B 64 (2001) 24430 .
} 
Con el propósito de efectuar una determinación cuantitativa (aunque promediada sobre todos los sitios de $\mathrm{Mn}$ ), se utilizó el método descrito por Capehart ${ }^{20}$ para determinar el estado de oxidación promedio en cada muestra.

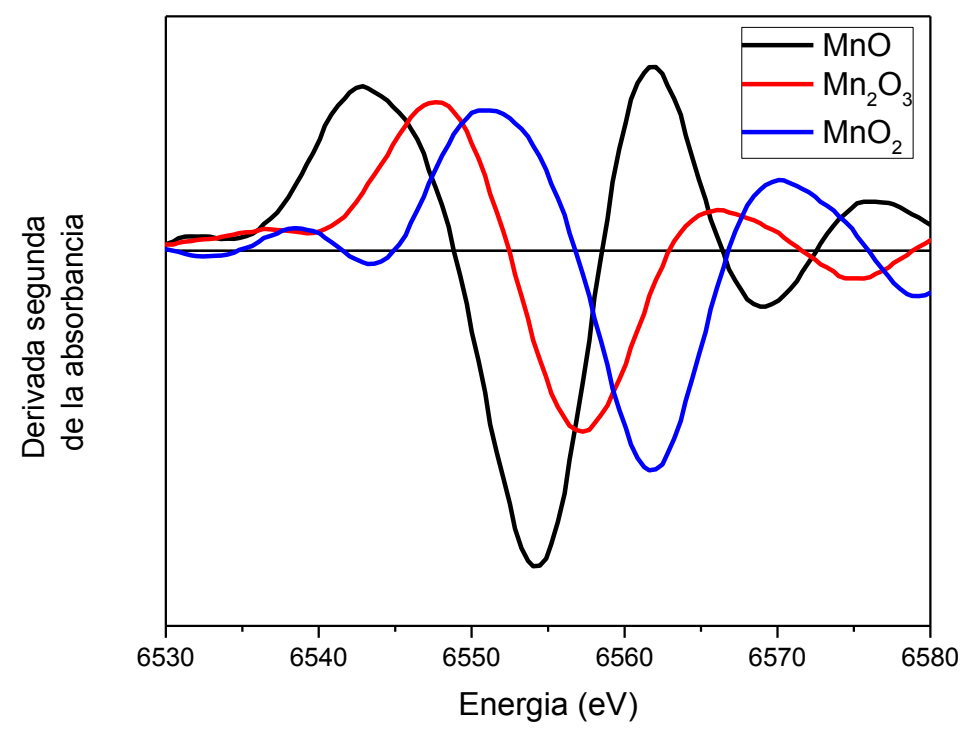

Figura 5.18. Derivada segunda de los espectros XANES en compuestos con $\mathrm{Mn}^{2+}, \mathrm{Mn}^{3+} \mathrm{y}$

$$
\mathrm{Mn}^{4+}
$$

En la Figura 5.19, se muestran las derivadas segundas de los sólidos OMR, OMRA, OMRB y ZnMnR. A partir del análisis del corrimiento con respecto al borde $\mathrm{K}$ del manganeso, es posible calcular el estado de oxidación promedio de las muestras estudiadas.

${ }^{20}$ T. Capehart, J. Herbst, F. Pinkerton, Physical Review B 52 (1995) 7907-7914. 
Se emplearon compuestos de referencia para determinar el corrimiento en energía del borde de absorción en el borde $\mathrm{K}$ del Mn correspondiente al Mn con diferentes estados de oxidación ( $\mathrm{Mn}$ metálico, $\mathrm{MnO}, \mathrm{Mn}_{2} \mathrm{O}_{3}$ y $\beta-\mathrm{MnO}_{2}$ a los cuales se le asignaron las valencias 0, 2, 3 y 4 respectivamente). Los valores obtenidos se ilustran en la Figura 5.20 y aparecen reportados en la Tabla 5.6.

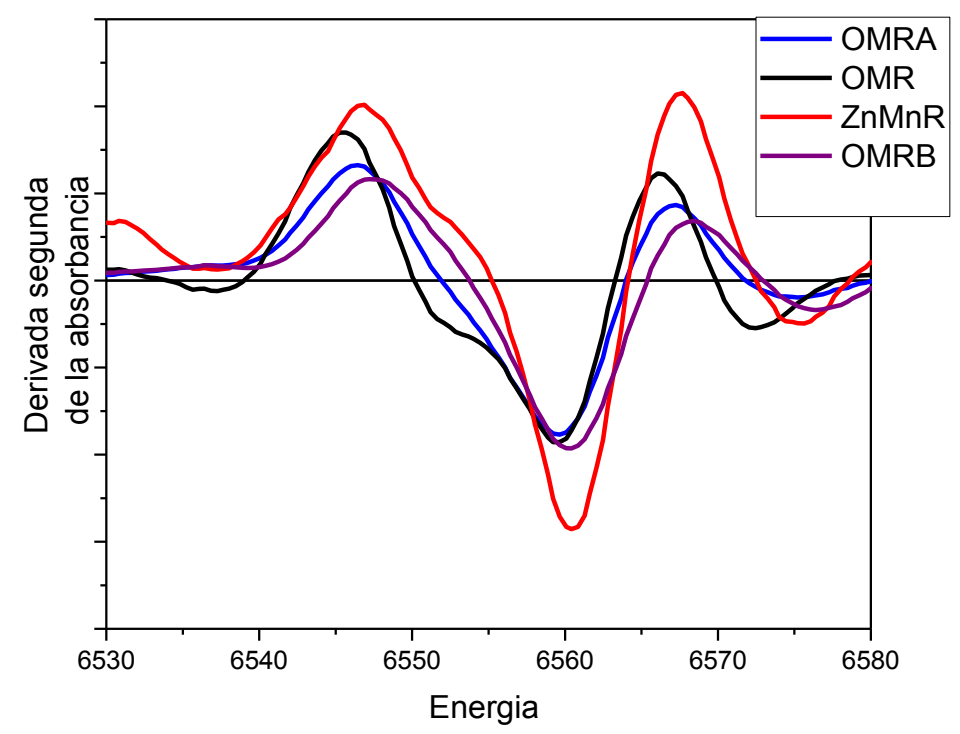

Figura 5.19. Derivada segunda de los espectros XANES en los sólidos recuperados.

El borde de absorción correspondiente al $\mathrm{Mn}^{3+}$ aparece a energías menores que el correspondiente al $\mathrm{Mn}^{4+}$. El origen de este corrimiento está dado por el diferente efecto de apantallamiento que producen electrones de valencia sobre los niveles electrónicos profundos. Cuando un electrón de valencia es eliminado, el electrón ligado al nivel profundo del átomo permanece más fuertemente ligado y de ahí la mayor energía necesaria 152 
para removerlo (en nuestro caso la mayor energía requerida para el fotón incidente en el experimento de absorción de rayos X).

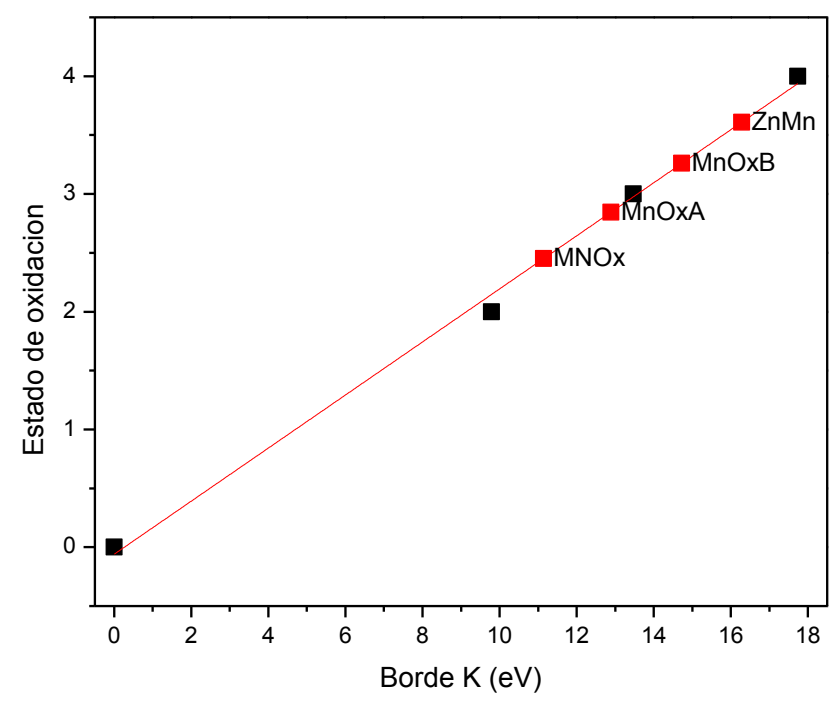

Figura 5.20. Estado de oxidación promedio del manganeso en cada uno de los óxidos.

En la Figura 5.21 se presentan los espectros XANES obtenidos en el borde K del Zn de los sólidos recuperados. Se observan bandas a 9964,9; 9668,93 y 9672,4 eV, y también se ve un hombro significativo a 9679,7 eV. Las bandas más intensas que aparecen en el borde $\mathrm{K}$ del $\mathrm{Zn}$ representan transiciones de orbitales $1 s$ a orbitales $p$ desocupados del Zn. Este 
comportamiento también se observa en una espinela del tipo $\mathrm{ZnFe}_{2} \mathrm{O}_{4}{ }^{21} \mathrm{La}$ estructura de la espinela $\left(\mathrm{AB}_{2} \mathrm{O}_{4}\right)$ se describe habitualmente como una estructura cúbica compacta $(f c c)$ de aniones $\mathrm{O}^{2-}$, donde los cationes Ay $\mathrm{B}$ ocupan los sitios intersticiales de la estructura. La espinela se llama normal cuando los cationes B ocupan la mitad de los sitios octaédricos y los cationes A ocupan una octava parte de los sitios tetraédricos. En la estructura invertida todos los cationes A y la mitad de los cationes B ocupan sitios octaédricos, mientras que los cationes B restantes ocupan sitios tetraédricos.

Tabla 5.6. Corrimiento de la energía con respecto al borde de absorción $(\Delta \mathrm{E}) \mathrm{y}$ estado de oxidación promedio (EOP).

\begin{tabular}{ccc}
\hline Muestra & $\Delta \mathbf{E}(\mathbf{e V})$ & EOP \\
\hline Mn Metálico & 0 & 0 \\
MnO & 3,79 & 2 \\
Mn2 3 & 13,47 & 3 \\
OMR & 17,74 & 4 \\
OMRA & 11,14 & 2,4 \\
OMRB & 12,89 & 2,8 \\
ZnMnR & 14,73 & 3,2 \\
\hline
\end{tabular}

21 S. Figueroa, Tesis Doctoral: "Propiedades asociadas a la estructura local en sistemas nanométricos: Estudio mediante el empleo de técnicas basadas en el uso de luz de sincrotrón" (2009) UNLP. 
Sobre espinelas de $\mathrm{ZnFe}_{2} \mathrm{O}_{4}$, Figueroa ${ }^{21}$ en su Tesis Doctoral estudió la variación de la intensidad de las bandas en el borde $\mathrm{K}$ de $\mathrm{Zn}$ de con el grado de inversión. Dichos resultados señalaron quea medida que aumenta el grado de inversión de la espinela los picos se corren a menores valores de energía, y la intensidad del segundo pico aumenta mientras que el hombro se debilita.

En la Figura 5.21 se observa un incremento en la intensidad de la banda ubicada a 9664,9, asignada a sitios $O h$ en las espinelas del tipo $\mathrm{AB}_{2} \mathrm{O}_{4}$, de acuerdo al orden: OMRA > $\mathrm{OMR}>\mathrm{OMRB}$

Por otro lado se observa una variación en la intensidad de la señal a 9674,5 eV, la cual es asignada a sitios $T d$ en una espinela normal, siguiendo el mismo orden. Esto está de acuerdo con los resultados observados por otras técnicas de caracterización, donde se determino la presencia de la fase cristalina $\mathrm{ZnMn}_{2} \mathrm{O}_{4}$ en el sólido OMRB.

Los resultados muestran una variación en el entorno del Zn que estaría relacionada con la técnica de impregnación usada. En el caso del sólido OMRA una sustitución de iones Mn por Zn en los sitios octaédricos, mientras que en el sólido OMRB además de este fenómeno se segrega la fase cristalina $\mathrm{ZnMn}_{2} \mathrm{O}_{4}$.

Por último el sólido ZnMnR presenta una banda que coincide con el $\mathrm{ZnO}$ usado como referencia, además de la asignada a iones $\mathrm{Zn}^{2+}$ con coordinación tetraédrica en una espinela 
normal. Estos resultados coinciden con los arrojados por otras técnicas de caracterización, los cuales indicaron la presencia de las fases cristalinas $\mathrm{ZnO}$ y $\mathrm{ZnMn}_{2} \mathrm{O}_{4}$.

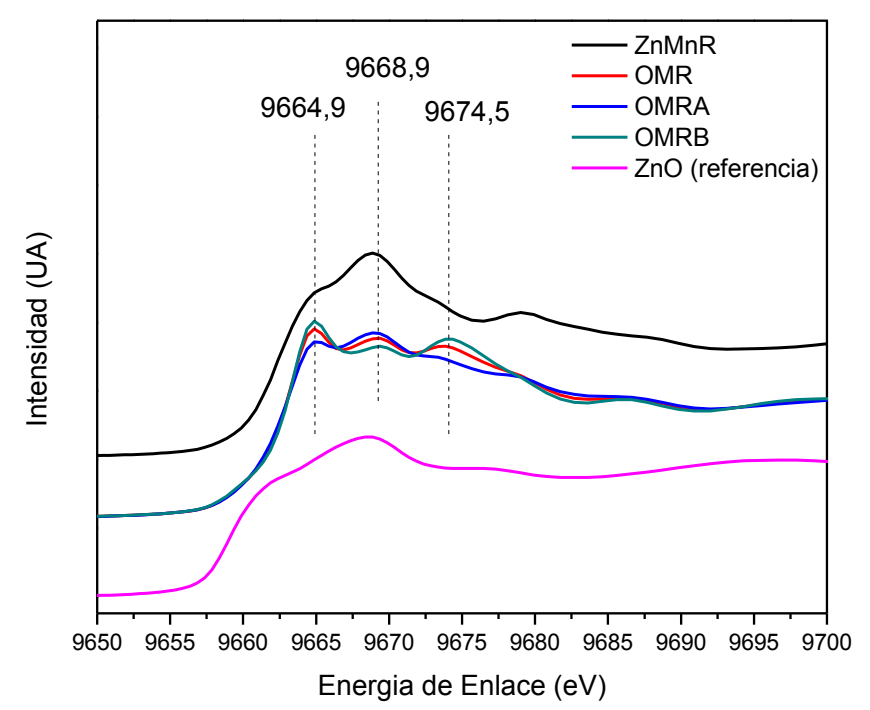

Figura 5.21. Espectros XANES normalizados borde K del Zn.

\subsubsection{Reducción Térmica Programada}

El comportamiento de reducción de los sólidos fue estudiado por RTP, donde se analiza el consumo de $\mathrm{H}_{2}$ para poder determinar el estado de oxidación de los metales presentes. En este caso se supone que el $\mathrm{MnO}$ es el estado más reducido al cual llegan los sólidos obtenidos.

En la Figura 5.22 se presentan los diagramas de RTP de los sólidos obtenidos mientras que en la Tabla 5.8 se representan las temperaturas de los máximo de reducción. En todas 
estas muestras aparece un evento de reducción presentando un diagrama de RTP similar. El pico que aparece alrededor de $400{ }^{\circ} \mathrm{C}$ corresponde a la reducción del manganeso.

Algunos autores ${ }^{22,23}$ sostienen que la reducción ocurre en dos pasos: el primer pico corresponde a la reducción de $\mathrm{MnO}_{2}$ a $\mathrm{Mn}_{2} \mathrm{O}_{3}$ y el segundo pico a la reducción de $\mathrm{Mn}_{2} \mathrm{O}_{3}$ a MnO. Otros autores ${ }^{24,25}$ describen la reducción también en dos pasos, pero sostienen que el primer pico es debido a la reducción tanto del $\mathrm{MnO}_{2}$ como del $\mathrm{Mn}_{2} \mathrm{O}_{3}$ a $\mathrm{Mn}_{3} \mathrm{O}_{4}$, y el segundo pico lo describen como la reducción de $\mathrm{Mn}_{3} \mathrm{O}_{4}$ a $\mathrm{MnO}$.

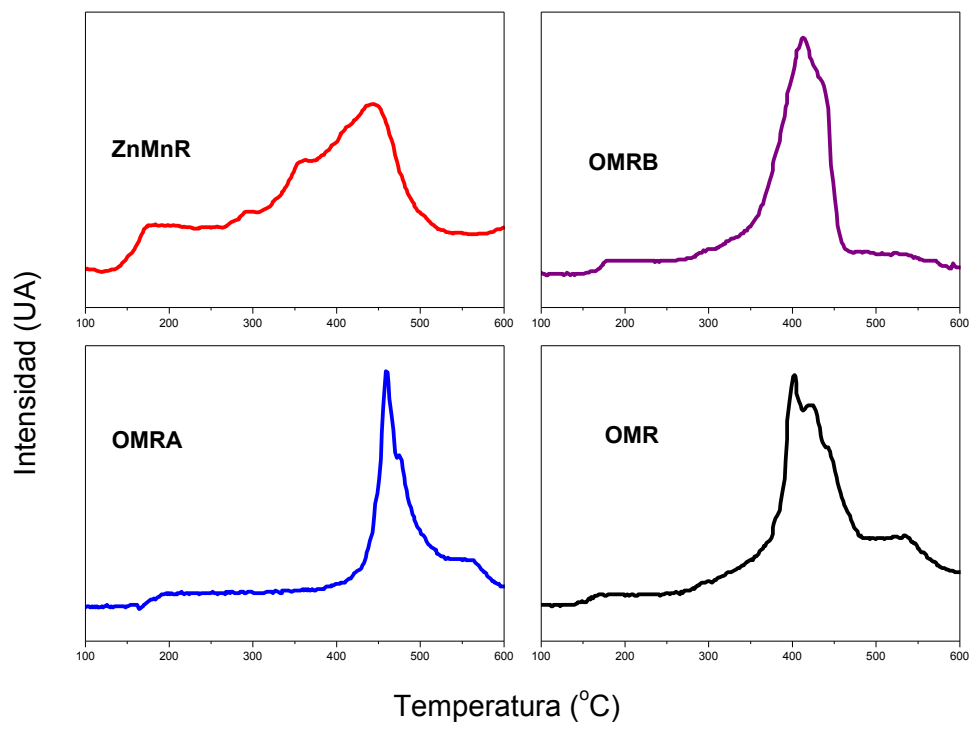

Figura 5.22. Patrones de RTP de los sólidos recuperados.

22 D. Van de Klett, Tesis Doctoral: "On the preparation and properties of manganese oxides based combustion catalysts” Universidad de Utrecht, Holanda (1994)

${ }^{23}$ T. De Brujin, Chemical Engineering Sciences 35 (1980) 1591-1600.

${ }^{24}$ M. Alvarez-Galván, B. Pawelec, V. O’Shea, J. Fierro, P. Arias, Applied Catalysis B 51 (2004) 83-91.

25 A. Gil, L. Gandía, S. Korili, Applied Catalysis A 274 (2004) 229-235. 
En los diagramas se observa una variación en la posición del máximo de la curva con la relación $\mathrm{Mn} / \mathrm{Zn}$ presente en las muestras. El sólido $\mathrm{ZnMnR}$ presenta un evento que comienza a una temperatura menor que en las demás muestras, atribuido a la reducción de la espinela presente en esta muestra.

Tabla 5.7. Temperaturas de reducción de las muestras.

\begin{tabular}{lll}
\hline Muestra & $\mathbf{T}\left({ }^{\circ} \mathbf{C}\right)$ máx. & T( $\left.{ }^{\circ} \mathbf{C}\right)$ inicio \\
& & evento \\
\hline OMR & 400 & 280 \\
OMRB & 416 & 294 \\
OMRA & 456 & 390 \\
ZnMnR & 444 & 293 \\
\hline
\end{tabular}




\subsubsection{Resumen de las caracterizaciones de óxidos de manganeso recuperados}

A continuación se presenta un breve resumen de los resultados arrojados por las diversas caracterizaciones de los sólidos recuperados de la mezcla de pilas alcalinas y de $\mathrm{Zn} / \mathrm{C}$ agotadas:

- El rendimiento de recuperación alcanzó un $95 \%$ para el Zn y un 75 \% en el caso de Mn.

Se obtuvieron dos sólidos:

OMR: por reacción entre $\mathrm{Mn}^{2+}$, presente en la solución lixiviada, y $\mathrm{KMnO}_{4}$.

ZnMnR: por adición de $\mathrm{NaOH}$ a la solución lixiviada.

El sólido OMR se impregnó por dos métodos diferentes, usando una solución de iones $\mathrm{Zn}^{2+}$ procedente de la lixiviación de pilas alcalinas. Los métodos usados fueron: a humedad incipiente y con exceso de solución. Los sólidos obtenidos se denominaron OMRA y OMRB, respectivamente.

$\checkmark$ Por DRX se observaron las siguientes fases:

OMR: $\alpha \mathrm{MnO}_{2}, \mathrm{Mn}_{2} \mathrm{O}_{3}$.

OMRA $\alpha \mathrm{MnO}_{2}$, con variaciones respecto al anterior producto de la incorporación de $\mathrm{Zn}^{2+}$ en la estructura, $\mathrm{Mn}_{2} \mathrm{O}_{3}$ y posiblemente $\mathrm{ZnMn}_{2} \mathrm{O}_{4}$.

$\mathrm{OMRB} \alpha \mathrm{MnO}_{2}$ y $\mathrm{ZnO}$ con estructura del tipo wurzita.

ZnMnR: $\mathrm{ZnO}, \mathrm{ZnMn}_{2} \mathrm{O}_{4}$ y $\mathrm{MnO}_{x}$.

$\checkmark$ La relación $\mathrm{Mn} / \mathrm{Zn}$ analizada por Absorción Atómica permitió establecer que la cantidad de Zn aumenta en el siguiente orden OMR $<$ OMRB $<$ OMRA $<$ ZnMnR. Mientras que el análisis EDS estableció que en los sólidos OMR, OMRB y ZnMnR 
la relación es similar siendo mucho mayor la concentración de Mn superficial en el sólido OMRA.

$\checkmark$ Los espectros FTIR y RAMAN de los sólidos OMR y ZnMnR, presentaron bandas corrspondientes a estiramientos $\mathrm{Mn}-\mathrm{O}$ y Mn-O-Zn respectivamente; por otro lado los sólidos OMRA y OMRB muestran bandas similares al sólido de partida OMR con variaciones como consecuencia del tratamiento con la solución de iones $\mathrm{Zn}^{2+}$.

$\checkmark$ Por XPS, se determinó en todos los casos la presencia del par $\mathrm{Mn}^{3+} / \mathrm{Mn}^{4+}$, entre los sólidos estudiados se encontraron diferencias en esta relación. Por otra parte, la relacion OII/OI presenta variaciones relacionadas con la variacion en la $\mathrm{Mn}^{3+}$ $/ \mathrm{Mn}^{4+}$.

$\checkmark$ El análisis XANES en el borde K de manganeso se observaron variaciones en los estados de oxiacion de los iones Mn en los sólidos OMR y OMRA, que podrían estar relacionados con la técnica usada. El estudio de las variaciones de las bandas observadas en el borde $\mathrm{K}$ de zinc se utilizó para analizar la coordinaciones de los iones $\mathrm{Zn}^{2+}$ en los diferentes sólidos. Se observaron diferencias en los sólidos OMRA y OMRB con respecto al sólido de partida. 


\subsubsection{Impregnación de estructuras monolíticas}

\section{Impregnación por inmersión}

Tal como se mencionó en el Capítulo 4, sección 2.1.5 se impregnó un monolito de alúmina por el método de washcoating. Se analizaron las propiedades reológicas de suspensiones 20, 30 y $40 \% \mathrm{p} / \mathrm{p}$ del sólido OMR y la influencia de la presencia de dispersante $(0,5 \% \mathrm{p} / \mathrm{p})$. De estos resultados se concluyó que la suspensión $30 \% \mathrm{p} / \mathrm{p}$ y 0.5 $\% \mathrm{p} / \mathrm{p}$ de dispersante presentaba un comportamiento de tipo pseudoplastico. Se buscó esta característica, ya que este hecho facilita el"pintado" / washcoating de la superficie.

Por otra parte, con el objetivo de encontrar el pH óptimo de trabajo, es decir aquel donde el sólido no flocula se estudió el punto isoeléctrico. En la Figura 5.23 se muestra el resultado del análisis para la suspensión $30 \%$, el valor obtenido fue de 3.6. 


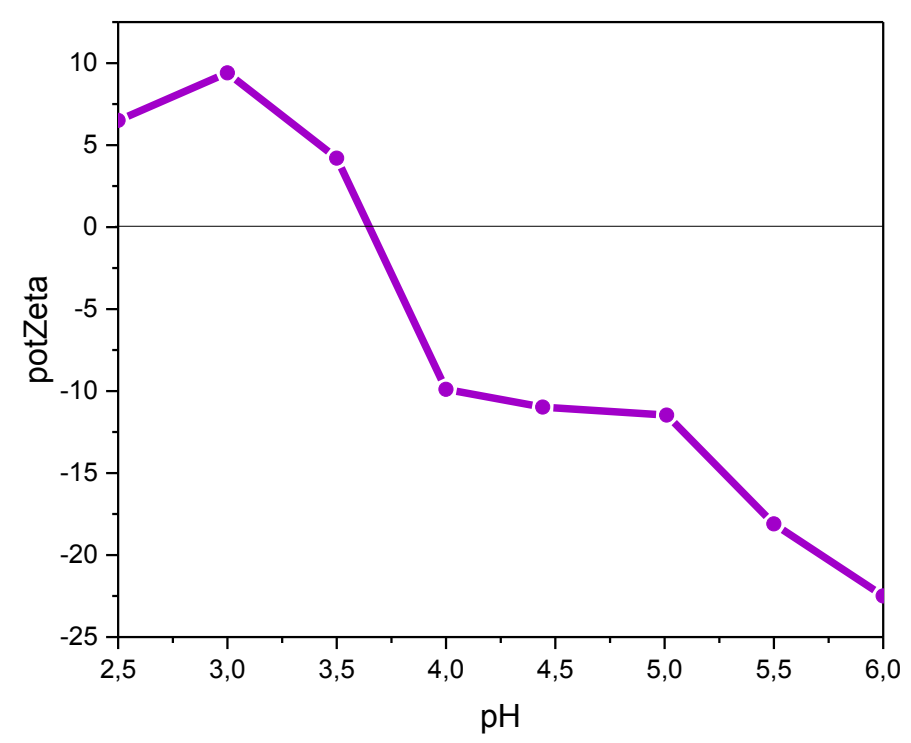

Figura 5.23. Potencial Zeta del sólido OMR.

En la Figura 5.24 se representa el incremento en la masa depositada sobre una placa de $3 \mathrm{~cm}$ x $3 \mathrm{~cm}$ en función del número de impregnaciones.

Se observa un aumento en la masa depositada con el número de impregnaciones, hasta la sexta impregnación, no hallándose un aumento significativo luego de la $6^{\text {ta }}$ impregnación. Una vez preparados los monolitos, la cantidad de óxido de manganeso se determinó por diferencia de peso antes y después de las respectivas impregnaciones. 


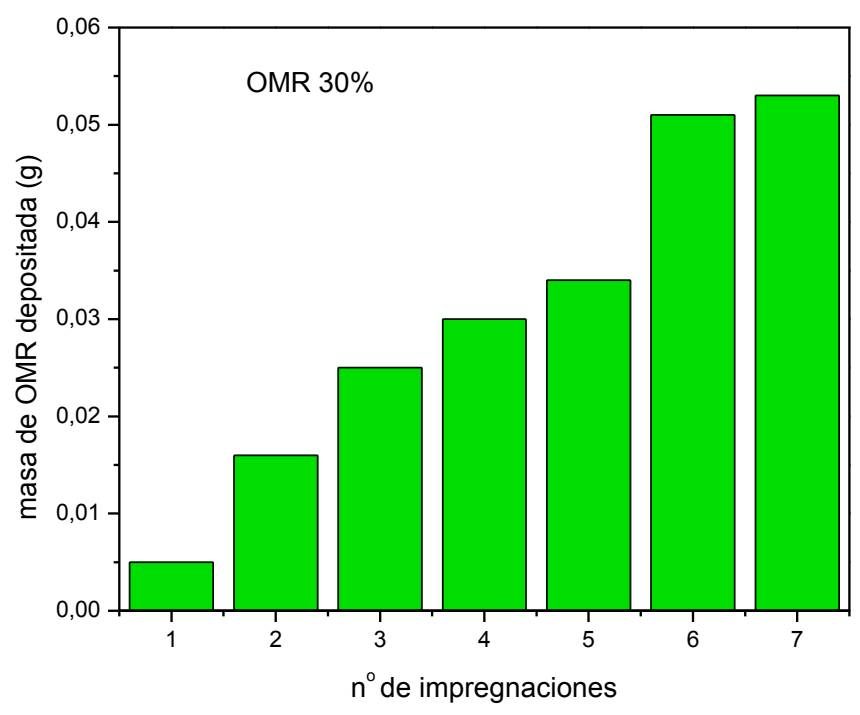

Figura 5.24. Variación de la masa con el número de impregnaciones en el monolito OMRW.

A partir de los resultados obtenidos, se concluyó que las condiciones óptimas para la impregnación fueron:

$\checkmark \mathrm{pH}$ de 6

$\checkmark$ suspensión $30 \%$ p/p

$\checkmark \quad 0,5 \% \mathrm{p} / \mathrm{p}$ de dispersante, en este caso carboximetilcelulosa.

$\checkmark 6$ impregnaciones 


\section{Resultados de la caracterización}

Los resultados del análisis mediante EDS se muestran en la Tabla 5.8. Las medidas de superficie específica arrojaron valores similares para ambos monolitos $\left(48 \mathrm{~m}^{2} \mathrm{~g}^{-1}\right)$.

Tabla 5.8. Propiedades de los monolitos.

\begin{tabular}{lcccccc}
\hline & $\mathbf{g}$ & SBET & Mn & $\mathbf{K}$ & $\mathbf{S}$ & $\mathbf{Z n}$ \\
Monolito & MnOx & $\left(\mathbf{m}^{\mathbf{2}} \mathbf{g}^{-1}\right)$ & $\mathbf{\% p} / \mathbf{p}$ & $\mathbf{\% p} / \mathbf{p}$ & $\mathbf{\% p} / \mathbf{p}$ & $\mathbf{\% p} / \mathbf{p}$ \\
\hline OMRW & 0,517 & 48,39 & 61,8 & 0,4 & 4,7 & 33,0 \\
MK & 0,638 & 47,60 & 89,6 & 7,0 & 3,2 & 0 \\
\hline
\end{tabular}

El monolito impregnado con el sólido OMR presenta un color marrón homogéneo característico de los óxidos de manganeso. Mientras que el monolito impregnado con sales de $\mathrm{Mn}$ comerciales presenta un color heterogéneo con puntos donde se acumula óxido de manganeso. Estas diferencias se observan en las fotografías de Figura 5.25

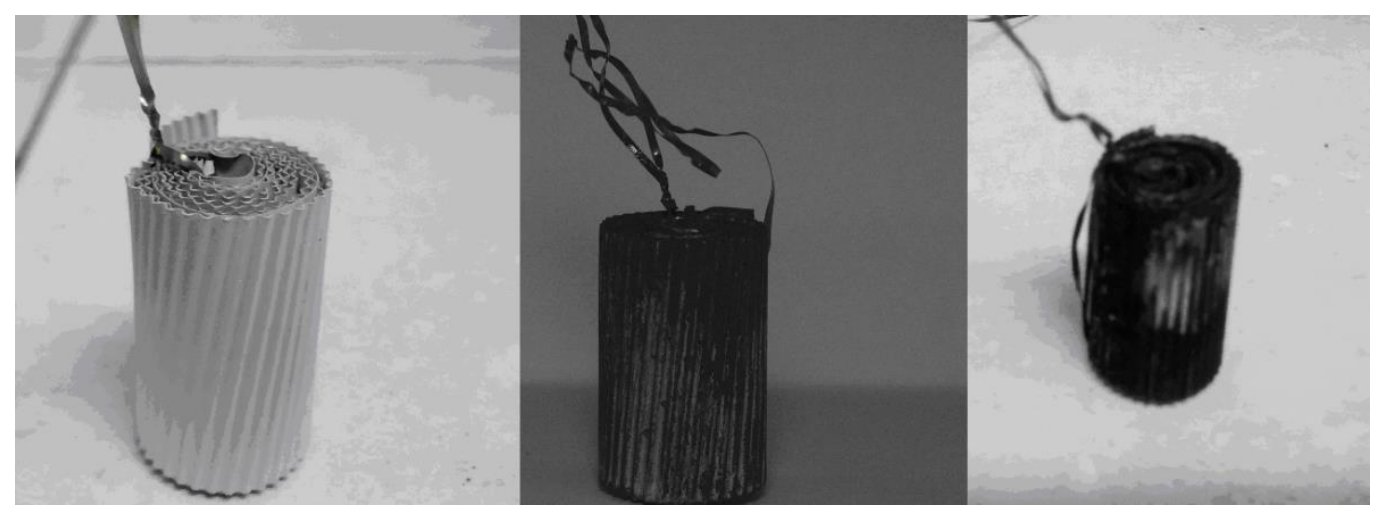


Figura 5.25. Fotografías de los monolitos anodizados e impregnados; (a) anodizado; (b) OMRW y (c) MK.

En la Figura 5.26 se muestran las micrografías obtenidas por SEM de las placas de los monolitos impregnados con óxido de manganeso junto con una placa de aluminio anodizada sin impregnar. Los resultados confirman que el monolito estructurado obtenido por washcoating posee una distribución más homogénea de fase activa sobre la superficie.

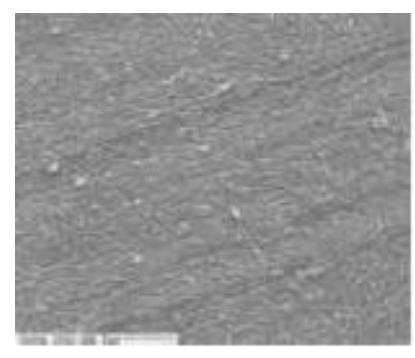

(a)

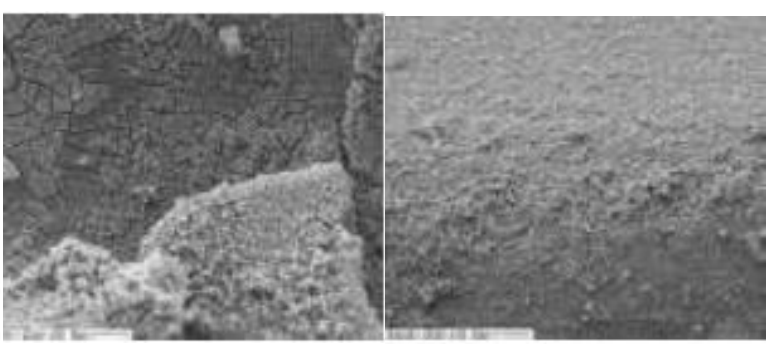

(b)

(c)

Figura 5.25. Micrografías SEM de las placas de aluminio anodizadas e impregnadas: (a)

$$
\mathrm{Al}_{2} \mathrm{O}_{3} / \mathrm{Al} \text {; (b) MK y (c) OMRW. }
$$

Los resultados del test de adherencia mostraron una mayor estabilidad del monolito MK $(88,6 \%)$ con respecto al OMRW (72,2\%). Esta diferencia puede atribuirse a las técnicas de impregnación.

En el caso de la técnia de washcoating, se ha demostrado que la adhesión del recubrimiento depende principalmente del tamaño de partícula de los polvos depositados. 
Agrafiotis y col. ${ }^{26}$ estudiaron el efecto de las características del polvo y los parámetros de procesamiento sobre las propiedades de los recubrimientos de alúmina, zirconia y titania depositados sobre soportes cerámicos. Llegaron a la conclusión de que la adhesión del recubrimiento sobre el soporte tiene lugar principalmente por un mecanismo mecánico y, en mucha menor medida, por medios químicos o de afinidad. Zamaro y col. ${ }^{27}$ [36] informaron los resultados de recubrimientos de ZSM5 sobre monolitos de cordierita, en donde observaron que el orden de estabilidad se correlaciona bien con el tamaño de los agregados de zeolita: se obtiene una mayor adhesión con tamaños más bajos. Los agregados más grandes no pueden entrar dentro de los poros de cordierita; por lo tanto, se obtiene una mala adhesión.

${ }^{26}$ C. Agrafiotis, A. Tsetsekou, A. Ekonomakau, Journal of Materials Science Letters 18 (1999) 1421-1424.

${ }^{27}$ J.M. Zamaro, M.A. Ulla, E.E. Miró, Chemical Engineering Journal 106 (2005) 25-33. 


\subsubsection{Recuperación de Zinc}

\subsubsection{Introducción}

En la síntesis de nuevos materiales es importante el análisis de sus propiedades estructurales, con el objetivo de estudiar sus posibles aplicaciones en diferentes campos. Por esta razón, la caracterización fisicoquímica de los sólidos es de fundamental importancia. En este trabajo se han empleado varias técnicas de caracterización con el objetivo de dilucidar la estructura y las propiedades ópticas y electrónicas de los sólidos.

En primer lugar, se muestra un esquema (Figura 5.26) de la recuperación de $\mathrm{Zn}^{2+}$ de pilas alcalinas agotadas. A continuación del esquema se presentan los resultados obtenidos de la caracterización fisicoquímica de los $\mathrm{ZnO}$ recuperados por diferentes técnicas como: estudio de superficie específica por adsorción de $\mathrm{N}_{2}\left(\mathrm{~S}_{\mathrm{BET}}\right)$, DRX, espectroscopía UV-vis y de aniquilación de positrones (PALS). En todos los casos, se comparó el comportamiento con un óxido de zinc tomado como referencia $(\mathrm{ZnOc})$. 


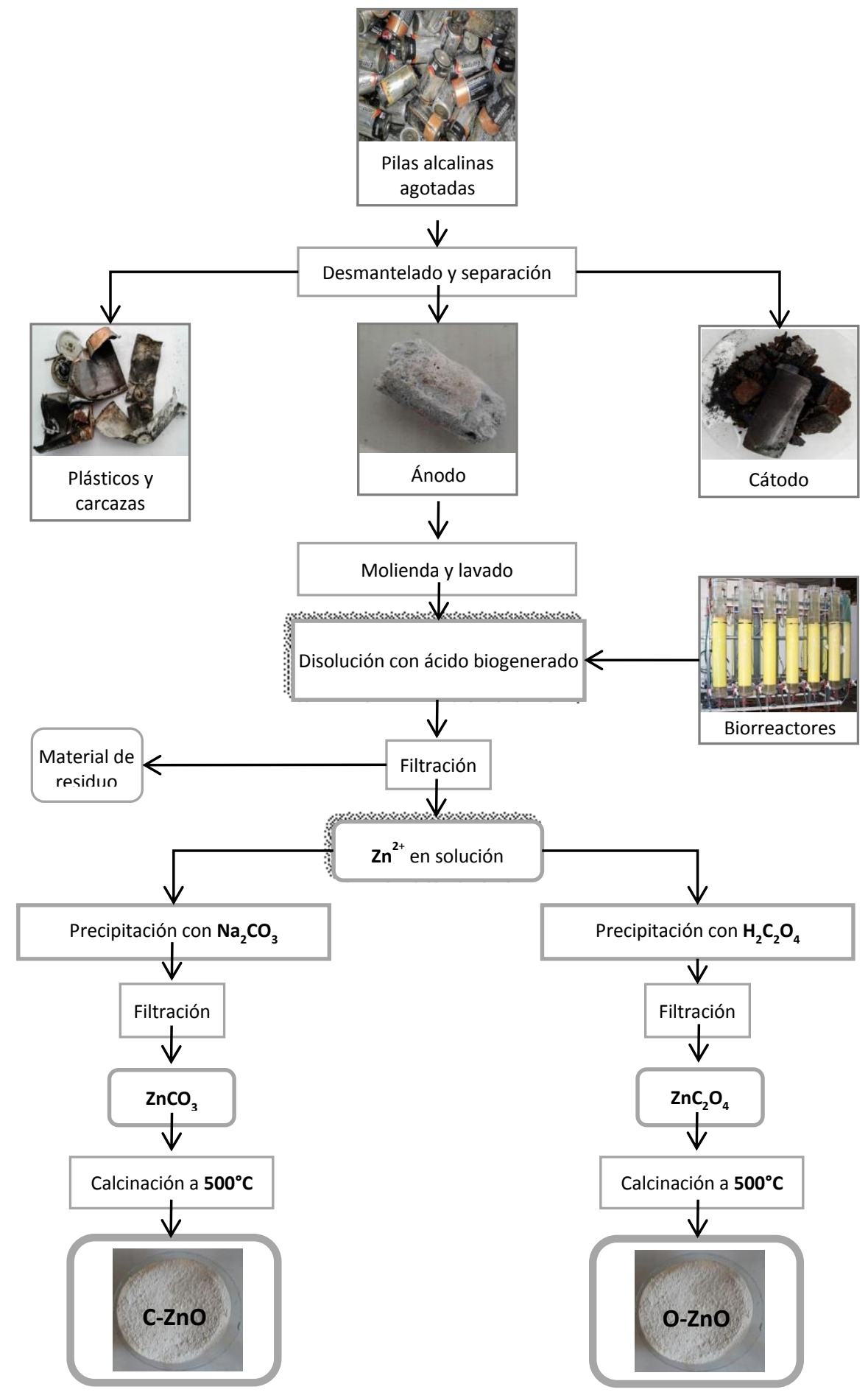

Figura 5.26. Esquema de la recuperación de $\mathrm{Zn}^{2+}$ a partir de pilas alcalinas agotadas. 


\subsubsection{Difracción de Rayos $X$}

En la Figura 5.27 se muestran los patrones de difracción de Rayos X de los sólidos estudiados. En todos los casos la única fase cristalina detectada es la Wurtzita (JCPDF \# 36-1451). Los picos característicos de mayor intensidad observados fueron los correspondientes a los planos (100), (002) y (101), los cuales presentan variaciones en la posición y ancho entre las diferentes muestras.

En este caso estudiaremos la variación de la posición y el valor del ancho a mitad de altura (FWHM) del pico correspondiente al plano (101), ubicado en $2 \theta=36^{\circ}$.

En la Tabla 5.10 se presentan los valores de $2 \theta=36^{\circ}$ correspondientes a los sólidos recuperados y al óxido de zinc comercial usado como referencia $(\mathrm{ZnOc})$. De acuerdo a Dutta y col. ${ }^{28}$ las variaciones observadas en la posición y en el ancho a mitad de pico podrían relacionarse con la cantidad e identidad de las vacancias.

Asimismo, en la Tabla 5.10 también se muestra el tamaño de cristal calculado a partir de la ecuación de Scherrer.

$$
d_{h k l}=\frac{k \lambda}{b \cos \theta_{h k l}}
$$

\footnotetext{
${ }^{28}$ S. Dutta, S. Chattopadhyay, A. Sarkar, M.Chakrabarti, D.Sanyal, D. Jana.Progress in Materials Science 54
} (2009) 89-136 


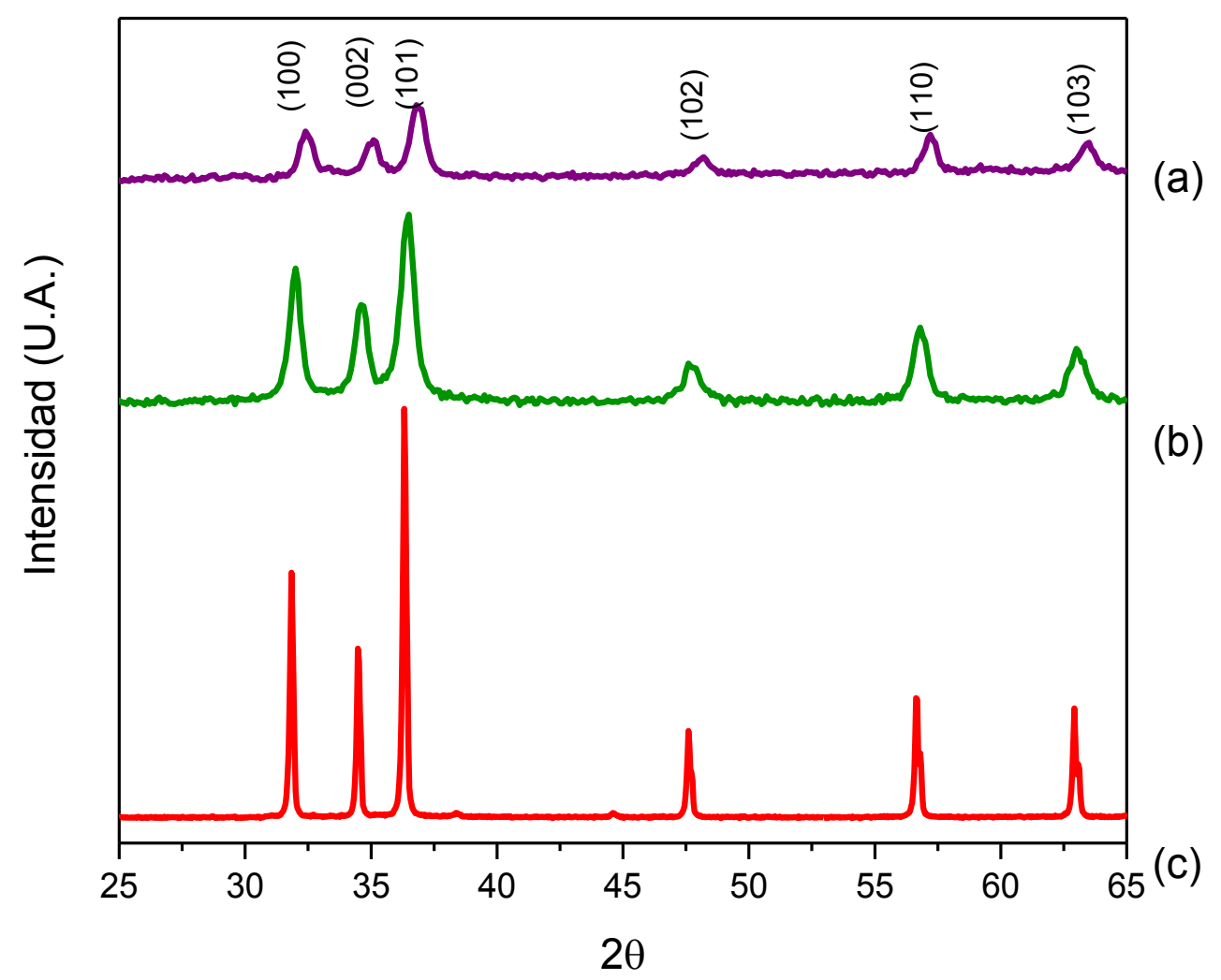

Figura 5.27. Patrones de Difracción de Rayos $X$ de los sólidos: (a) C-ZnO, (b) O-ZnO y (c) ZnOc.

Los resultados muestran que los tamaños de cristal de las muestras recuperadas presentan valores menores comparados con el correspondiente a ZnOc, esta variación en el valor D se corresponde con el corrimiento observado en los difractogramas de la Figura 5.23 y coincide con lo observado por Dutta y col. ${ }^{28}$ 
Asimismo, la variación en las posiciones de los picos en los difractogramas es producto de la aparición de defectos o dislocaciones, este hecho se traduce en un cambio en los parámetros de red. En semiconductores, los valores de los parámetros de red, normalmente dependen de los siguientes factores: i) la concentración de electrones libres en la banda de conducción, ii) la concentración de átomos “diferentes” iii) tensiones externas y iv) de la temperatura. ${ }^{29}$ Los valores calculados teórica y experimentalmente varían entre 3,2475 y 3,2501 para el parámetro a y 5,2042 a 5,2075 para el parámetro $c$. La desviación de los valores ideales depende de la estabilidad de la celda y de la carga libre en la celda producto de defectos puntuales (vacancias) o extendidos (dislocaciones). ${ }^{29}$

Usando el método de Rietveld ${ }^{30}$ se calcularon los parámetros de red que se muestran en la Tabla 5.10, donde puede observarse una disminución en el parámetro $c$ de celda, desde 5,19 a $5,15 \AA$ A. En el parámetro de celda $a$ se observa la misma tendencia, lo que implica una contracción de la celda. Li y col. ${ }^{31}$ sugieren que este hecho se debe a un aumento en las vacancias de oxígeno.

\footnotetext{
${ }^{29}$ HadisMorkoc, UmitOzgur, General properties of $\mathrm{ZnO}$, en Zinc Oxide: Fundamentals, Materials and device technology. Wiley- VCH.

${ }^{30}$ L. Lutterotti, P. Scardij. Appl. Cryst. (1990). 23, 246-252

${ }^{31}$ X. Li, Y. Wang, W. Liu, G. Jiang, C. Zhu, Materials Letters 85 (2012) 25-28.
} 
Tabla 5.10. Parámetros de red de los óxidos de zinc.

\begin{tabular}{lcccccc}
\hline Muestra & $\begin{array}{c}\text { Posición de } \\
\left.\text { picos ( }{ }^{\circ}\right)\end{array}$ & $\mathbf{D}(\mathbf{n m})$ & $\boldsymbol{\beta}$ & $\boldsymbol{a}=\boldsymbol{b}(\AA)$ & $\boldsymbol{c}(\AA)$ & $\boldsymbol{c} / \boldsymbol{a}$ \\
\hline ZnOc & 36,3 & 44 & 0,2 & 3,24 & 5,19 & 1,60 \\
OZnO & 36,4 & 15 & 0,6 & 3,20 & 5,17 & 1,61 \\
CZnO & 36,7 & 13 & 0,7 & 3,18 & 5,15 & 1,61 \\
\hline
\end{tabular}

\subsubsection{Microscopia Electrónica de Barrido (SEM) y de Transmisión (TEM)}

Se han identificado una amplia variedad de estructuras de $\mathrm{ZnO}$. Diversos autores han reportado estas estructuras como por ejemplo: agujas, hélices, anillos, ${ }^{32}$ nanoplaquetas y nanopellets. También pueden adoptar estructuras en 3 dimensiones como nanoflores o copos de nieve. ${ }^{33,34}$ Por este motivo el $\mathrm{ZnO}$ es uno de los nuevos materiales con la mayor diversidad de estructuras, este hecho permite su aplicación en diversos campos tal como se mencionó en el Capítulo 3. Catellanot y col. ${ }^{35}$ encontraron que la concentración de $\mathrm{H}_{2} \mathrm{SO}_{4}$ genera una morfología diferente a la observada para $\mathrm{ZnO}$ sintetizados a partir de $\mathrm{Zn}\left(\mathrm{NO}_{3}\right)_{2}$

\footnotetext{
${ }^{32}$ X. Kong, Y. Ding, R. Yang, Z. Wang, Science 303 (2004) 134-1351.

${ }^{33}$ W. Chiu, P. Khiew, M. Clokea, D. Isa, T. Tan, S. Radiman, R. Abd-Shukor, M. Abd-Hamid, N. Huang, H. Lim, Chemical Enineering Journal 158 (2010) 345-352.

${ }^{34}$ M. Jose-Yacaman, C. Gutierrez-Wing, M. Miki, D. Yang, K. Piyakis, E. Sacher, The Journal of Physical Chemistry B 109 (2005) 9703-9711.

${ }^{35}$ M. Castellano, E. Matijevic, Chemistry of Materials 1 (1989) 78-82.
} 
o $\mathrm{ZnCl}_{2}$ por ejemplo. Raj y col. ${ }^{36}$ observaron que la influencia del ion $\mathrm{SO}_{4}{ }^{2-}$ consistía en estabilizar al $\mathrm{ZnC}_{2} \mathrm{O}_{4}$ en estructuras en forma de plaquetas, estas luego al ser calcinadas adoptaban la forma de nanorosas. La formación de estas nanorosas cumple con los requerimientos del "Ostwald ripening", en el cual las plaquetas formadas inicialmente se ordenan para formar estas nuevas estructuras durante el proceso de calcinación.

Los sólidos estudiados en esta tesis presentan diferentes morfologías, esto se muestra en la Figura 5.28. Las imágenes SEM de los sólidos CZnO y OZnO (Figura 5.28a y Figura 5.28b) muestran una morfología en forma de "nanorosas", a diferencia de la muestra ZnOc. Esta morfología puede relacionarse con la adsorción de los iones $\mathrm{SO}_{4}^{2-}$ a la cara polar (001), como consecuencia del pH y grupos hidroxilos presentes en la superficie del sustrato. Este hecho indicaría que la morfología está relacionada con la naturaleza del contraion presente en la solución madre, en coincidencia con lo observado por Raj y col. ${ }^{36}$ Estos autores encontraron diferencias en $\mathrm{ZnO}$ sintetizados a partir de $\mathrm{Zn}\left(\mathrm{NO}_{3}\right)_{2}$ y $\mathrm{ZnCl}_{2}$ con respecto a un sólido preparado a partir de $\mathrm{ZnSO}_{4}$.

${ }^{36}$ C. J. Raj, R.K. Joshi, K.B. R. Varma, Crystal Research and Technology 46 (2011) 1181-1188. 


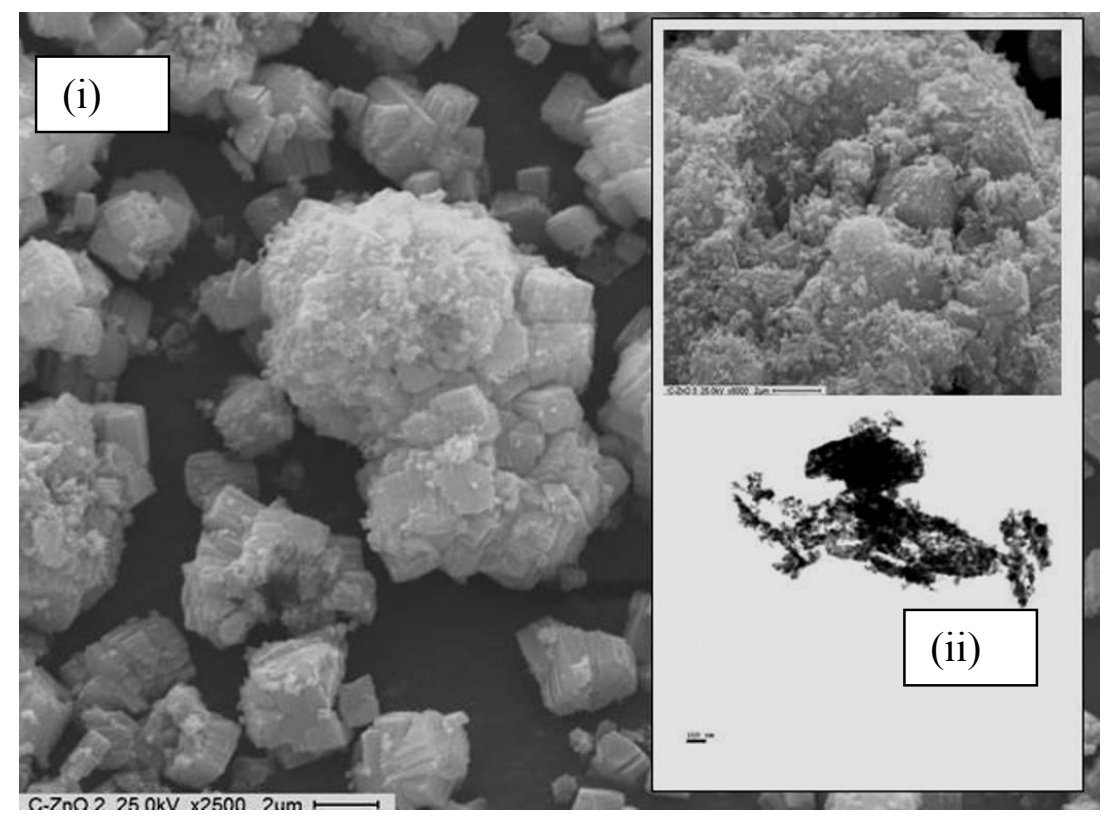

Figura 5.28 (a). Micrografias (i) SEM y (ii) TEM del sólido CZnO

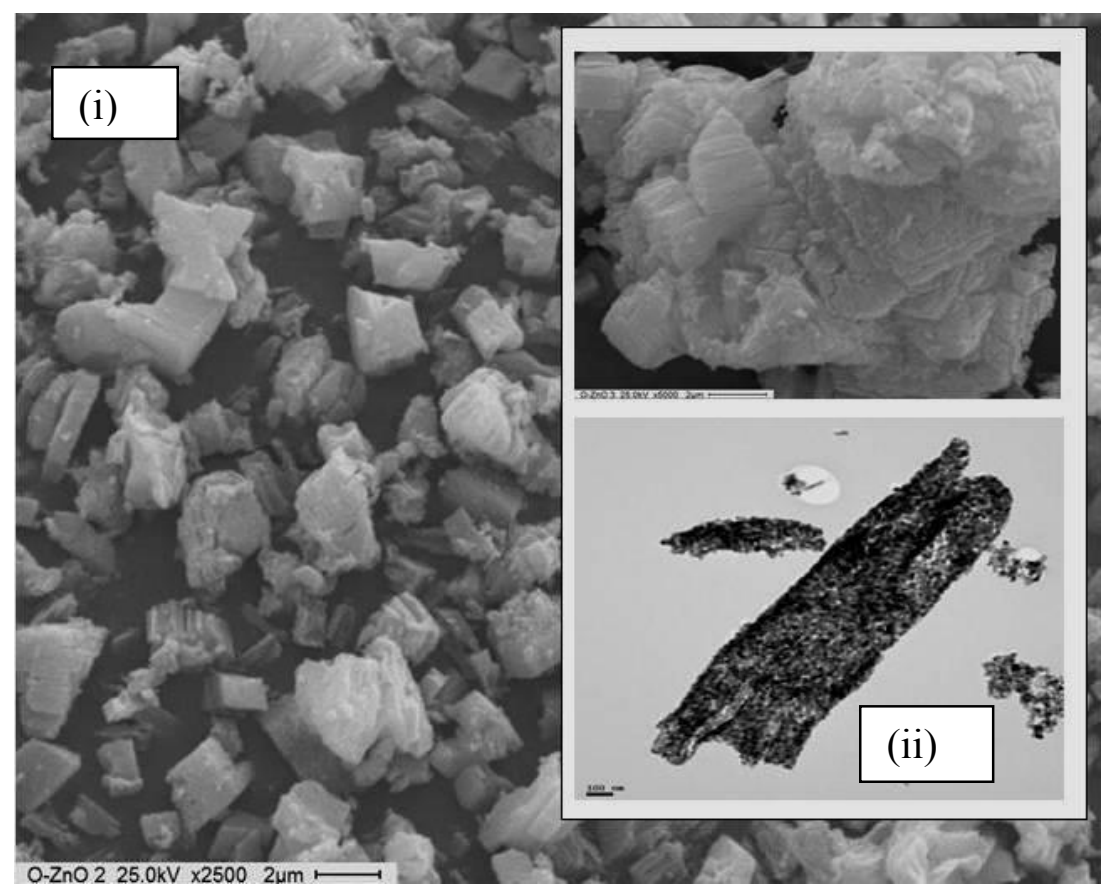

Figura 5.28 (b). Micrografias (i) SEM y (ii) TEM del sólido OZnO 


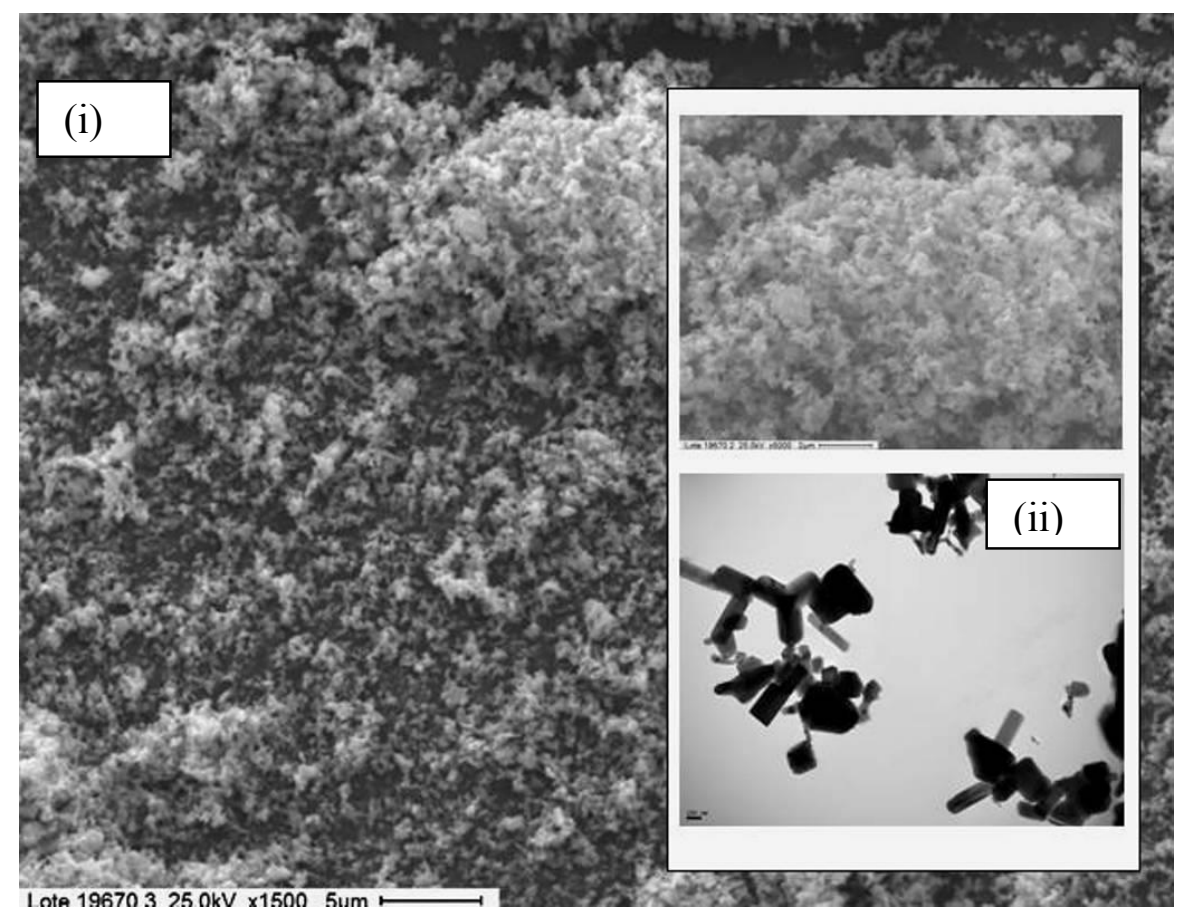

Figura 5.28 (c). Micrografias (i) SEM y (ii) TEM del sólido ZnOc.

La morfología de lo sólidos OZnO y $\mathrm{CZnO}$ es similar y como se mencionó anteriormente podría relacionarse con la presencia de iones $\mathrm{SO}_{4}{ }^{2-}$. Por otro lado el grado de aglomeración de las partículas es mayor en el sólido $\mathrm{CZnO}$ que en $\mathrm{OZnO}$, esta diferencia puede atribuirse a diferencias en el mecanismo de crecimiento. En este caso una variación en el $\mathrm{pH}$ debido a cada uno de los agentes precipitantes usados podría explicar la diferencia en el mecanismo de crecimiento, de acuerdo a bibliografía. ${ }^{37}$

37 J. Zhang, L. Sun, J. Yin, H. Su, C. Liao, C. Yan, Chemical Materials 14 (2002) 4172-4177 
En la Figura 5.28c correspondiente al óxido de zinc usado como referencia, ZnOc, se observa una clara diferencia con respecto a los sólidos recuperados. Este sólido presenta cristales aciculares.

La morfología que presentan los sólidos recuperados $(\mathrm{OZnO}$ y $\mathrm{CZnO})$ está relacionada directamente con el método de síntesis, en este caso la estructura de nanorosas se atribuye a la presencia de iones $\mathrm{SO}_{4}^{-2}$ en la solución madre a partir de la cual se obtuvieron los sólidos recuperados. En cambio, el grado de agregación de las muestras depende del mecanismo de crecimiento que sufre cada sólido y esto se relacionaría con el agente precipitante usado en cada caso.

\subsubsection{Espectroscopía UV Visible con Reflectancia Difusa}

El óxido de zinc tiene una banda de energía prohibida o band gap, Egap, que varía alrededor de 3,37 eV y una energía de enlace exitónica de $60 \mathrm{MeV}$. El exitón es una cuasipartícula que se forma a partir de la interacción entre el electrón y un hueco a través de una interacción coulombiana, siendo este valor para el $\mathrm{ZnO}$ mucho más grande que el que presentan otros semiconductores. Esto lo hace un material prometedor en la fabricación de dispositivos semiconductores de banda corto o fotoelectrónicos.

Previamente se ha reportado que el óxido de zinc presenta bandas de emisión en la zona $U^{38}$ y visible ${ }^{39,40}$ del espectro electromagnético. La banda de emisión en la zona UV se

${ }^{38}$ L. Vayssieres, K. Keis, A. Hagfeldt, S. T. Lindquist, Chemical Materials 13 (2001) 4395-4398. 
atribuye a diferentes defectos intrínsecos como vacancias de oxígeno, vacancias de zinc, oxígenos insterticiales, etc.

Según bibliografía el óxido de zinc con estructura wurtzita presenta un máximo de absorción alrededor de $390 \mathrm{~nm}$. En la Figura 5.29 se presentan los gráficos correspondientes a la absorción de los sólidos en función de la longitud de onda, en la zona entre 350 y $500 \mathrm{~nm}$. Se puede observar que los sólidos $\mathrm{OZnO}$ y $\mathrm{CZnO}$ presentan un pequeño aumento de la absorbancia hacia mayores longitudes de onda y un corrimiento hacia el rojo. Tan y col. ${ }^{41}$ sugieren que este fenómeno se debe a perturbaciones debidas al crecimiento de las vacancias de oxígeno.

De la comparación entre los dos sólidos recuperados, se observa que la muestra $\mathrm{CZnO}$ presenta una absorción mayor que $\mathrm{OZnO}$ sugiriendo una mayor presencia de vacancias de oxígeno, una consecuencia de este hecho sería un aumento en la actividad fotocatalitica. ${ }^{42}$ Los resultados observados coinciden también con los propuestos por Raj y col. ${ }^{36}$

Por otro lado, la diferencia en el número de vacancias podría relacionarse con el agente precipitante usado en cada caso. Además, este último factor genera mecanismos de crecimiento diferentes, dando lugar a variaciones en cuanto a la aglomeración de partículas en cada uno de los sólidos.

\footnotetext{
${ }^{39}$ K. Vanheusdev, W. L. Warren, C. H. Seager, D. R. Tallant, J. A. Voigt, B. E Gnade, Journal of Applied Physics 79 (1996)7983-7990.

${ }^{40}$ W. Q Peng, S. C. Qu, G. W.Cong, Z. G. Wang, Materials Science in Semiconductor Processing 9 (2006) 156-159.

${ }^{41}$ S. T. Tan, B. J. Chen, X. W. Sun, W. J. Fan ,H. S. Kwok, X. H. Zhang, S. J. Chua, Journal of Applied Physics 98 (2005) 013505.

${ }^{42}$ Y. Lv, W. Yao, X.Ma, C. Pan, R. Zong, Y.Zhu, Catalysis Science and Technology 3 (2013) 3136-3146.
} 


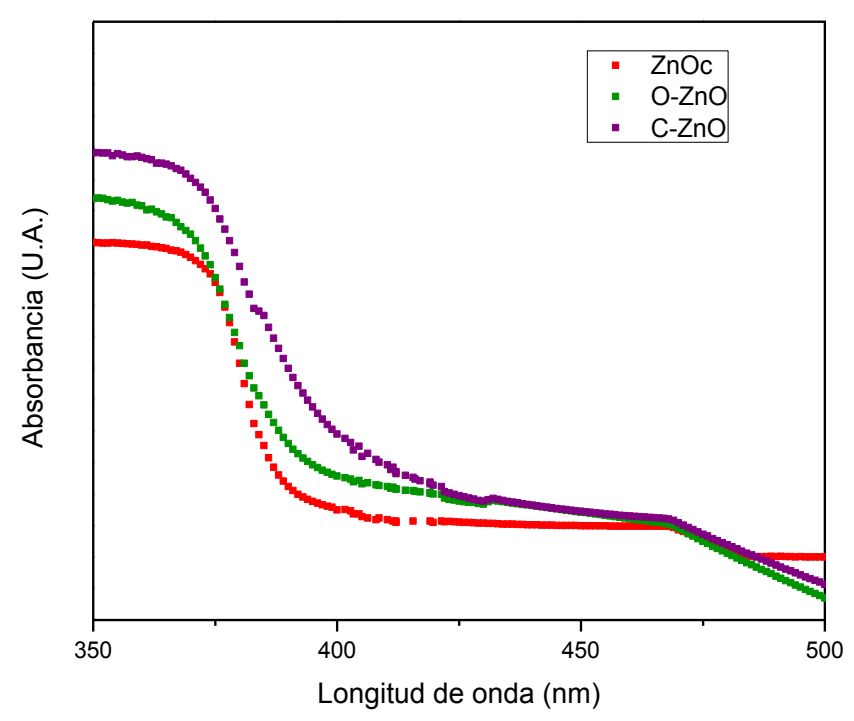

Figura 5.29. Absorbancia óptica de los sólidos.

Un modelo conocido que relaciona la absorbancia con la energía de la radiación incidente para regiones del espectro cercanas al borde de absorción, es el de Tauc-Mott ${ }^{43}$ :

$$
\left(\alpha \mathrm{E}_{\mathrm{f}}\right)^{\mathrm{n}}=\mathrm{B}\left(\mathrm{E}_{\mathrm{f}}-\mathrm{E}_{g a p}\right)
$$

donde n es un índice característico del tipo de transición electrónica (depende del material); $E_{\mathrm{f}}$ es la energía del fotón incidente; $\mathrm{B}$ es una constante de proporcionalidad asociada generalmente a las impurezas del material; Egap la energía del band gap y $\alpha$ es la absorbancia y viene dada por la siguiente ecuación:

${ }^{43}$ X. Li, H. Zhu, J. Wei, K. Wang, E. Xu, Z. Li, D. Wu, Applied Physics A 97(2009) 341-344. 


$$
\alpha=-\ln \left(\mathrm{I} / \mathrm{I}_{0}\right) 1 / \mathrm{t}
$$

donde I es la intensidad transmitida a través de la muestra, $\mathrm{I}_{0}$ la intensidad de la fuente y t el espesor de la muestra. De esta manera, midiéndose absorbancia de un semiconductor al ser irradiada con energía electromagnética en el rango de longitudes de onda correspondiente a las transiciones, se puede obtener $\mathrm{E}_{g a p}$ de acuerdo a la ecuación propuesta por Tauc.

De acuerdo al modelo de Tauc-Mott ${ }^{44}$ para transiciones indirectas permitidas $(n=2)$, se graficó $\alpha \mathrm{E}_{\mathrm{f}}$ vs. $\mathrm{E}_{\mathrm{f}}$, esto se muestra en la Figura 5.30. El régimen lineal denota el comienzo de la absorción, por lo tanto la extrapolación de este hacia el eje de las abscisas nos da la información de la energía de la banda óptica del material. Para ello se realizaron ajustes lineales de la forma $\mathrm{Y}=\mathrm{AX}+\mathrm{B}$.

Varios autores señalan que los valores de $\alpha(E)$ y $E_{\text {gap }}$ son factores importantes en el ZnO y que se ven modificados por la presencia de defectos, tamaño de grano y grado de desorden.

Entonces podemos ver que las muestras estudiadas presentan diferencias en los valores de $\alpha($ E) y Egap, como se muestran en la Figura 5.30 y en la Tabla 5.11. Estos resultados son consistentes con lo observado por DRX y en las micrografías SEM y TEM, en cuanto al valor de $\mathrm{D}$, parámetros de celda y morfología.

${ }^{44}$ E. A. Davis, N.F. Mott, Philosophical Magazine A 22 (1970) 903-922. 


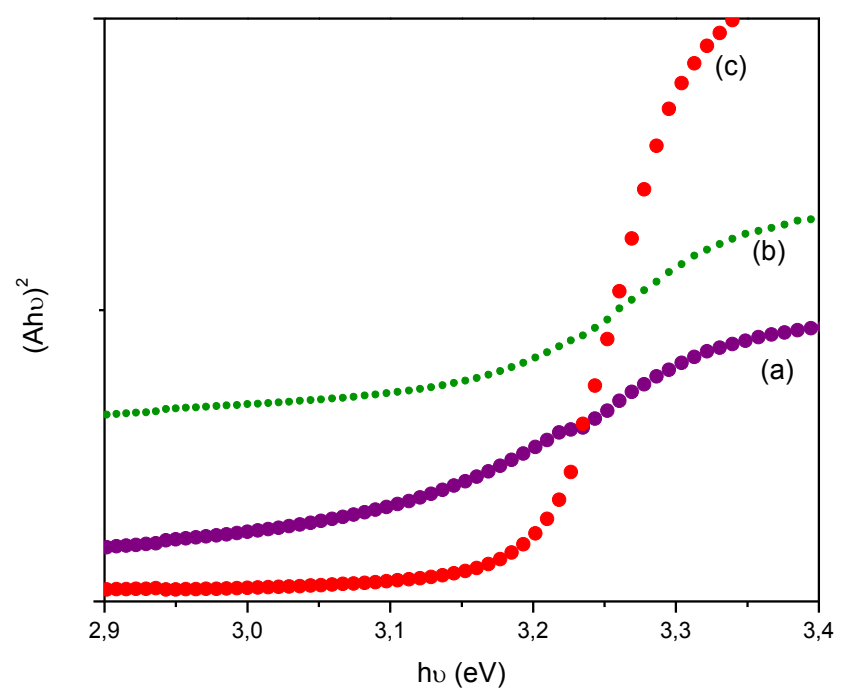

Figure 5.30. Gráficos de Tauc de los sólidos: (a) C-ZnO; (b) O-ZnO y (c) ZnOc.

Tabla 5.11. Propiedades texturales y ópticas de los sólidos.

\begin{tabular}{llll}
\hline Muestra & $\mathbf{S}_{\text {BET }}\left(\mathbf{m}^{\mathbf{2}} \mathbf{g}^{-1}\right)$ & $\mathbf{V}_{\mathbf{p}}\left(\mathbf{c m}^{\mathbf{3}} \mathbf{g}^{-\mathbf{1}}\right)$ & $\mathbf{E}_{\text {gap }}(\mathbf{e V})$ \\
\hline ZnO c & 3 & 0,014 & 3,2 \\
C-ZnO & 9 & 0.06 & 2,98 \\
O-ZnO & 31 & 0,18 & 3,05 \\
\hline
\end{tabular}

\subsubsection{Espectrocopía de Aniquilación de Positrones (PALS)}

Como se mencionó en el Capítulo 4, sección 3 la espectroscopía de aniquilación de positrones permite caracterizar los defectos presentes en un sólido. Luego de la sustracción 
del fondo y la deconvolución con la función resolución, los espectros fueron analizados con el programa POSITRONFIT. ${ }^{45,46}$ En todos los casos, se realizó una descomposición de los espectros PALS en tres decaimientos exponenciales.

Generalmente un semiconductor está caracterizado por dos vidas medias, una de ellas, la más corta se debe a aniquilaciones de positrones libres, la llamada vida media de bulk que caracteriza al material. La segunda, más larga, se debe a aniquilaciones de positrones atrapados en defectos tanto intrínsecos como extrínsecos, los que dependen básicamente del método de preparación. En el caso del $\mathrm{ZnO}$ se conoce que la vida media de bulk es de 158 ps. $^{47}$

En el presente estudio, la primera vida media $\left(\tau_{1}\right)$ resulta algo mayor a la vida media de bulk reportada para $\mathrm{ZnO}$, siendo en consecuencia, el resultado de dos contribuciones. Por un lado aniquilaciones libres en el seno del material y a la aniquilación de positrones atrapados en defectos del cristal (monovacancias) y en sistemas desordenados a sitios con baja densidad electrónica. La segunda componente, $\tau_{2}$, presenta valores mayores, las cuales podrían asociarse a positrones aniquilados en defectos de mayor tamaño (clusters de vacancias, por ejemplo). Por último, $\tau_{3}$ (con vidas medias del orden de los 2 ns e intensidades del orden del 1-2\%) se asocia a aniquilaciones espúreas en las inmediaciones de la fuente.

\footnotetext{
${ }^{45}$ P. Kirkegaard, M. Eldrup, Computer Physics Communications 3 (1972) 240-255.

${ }^{46}$ P. Kirkegaard, M. Eldrup, Computer Physics Communications 7 (1974) 401- 409.

${ }^{47}$ M. Dutta, S. Chakrabarti, D. Chattopadhyay, D. Jana, D. Sanyal, A. Sarkar, Journal of Applied Physics 98 (2005) 503-513.
} 
La Figura 5.31 muestra los parámetros de aniquilación de positrones resultantes para las muestras estudiadas.

No se observan diferencias en los valores de cada una de las componentes en los sólidos, pero si en las intensidades. Del análisis de las intensidades relativas, se puede obtener información sobre la concentración de defectos presentes. ${ }^{48,49}$

La relación $I_{1} / I_{2}$ en el sólido $\mathrm{OZnO}$ presenta un valor cercano a 0.5 , mientras que en $\mathrm{CZnO}$ aumenta a 0,8 . Esto indica un aumento en la cantidad de defectos de mayor tamaño en el sólido $\mathrm{OZnO}$.

En el sólido $\mathrm{C}-\mathrm{ZnO}$ tanto $\tau_{1}$ como su intensidad correspondiente aumentaron, con respecto a las otras muestras. Esta componente tiene un valor mayor, 199 ps, que el tiempo de vida de bulk del $\mathrm{ZnO}$ (158 ps). En materiales nanocristalinos, la presencia de monovacancias o los efectos de borde de grano con frecuencia actúan como sitios de aniquilación de positrones con valores similares a la vida de bulk. ${ }^{50}$ Estas podrían ser monovacancias de oxígeno, VO, en coincidencia con lo observado por espectroscopía UVvis.

${ }^{48}$ S. Chakraverty, S. Mitra, K. Mandal, P. Nambissan, S. Chattopadhyay, Physical Reviews B 71 (2005) 024115.

${ }^{49}$ S. Dannefer, T. Bretagnon, D.J. Kerr, Journal of Applied Physics 74 (1993) 884.

${ }^{50}$ S.Sharma, P. Pujari, K. Sudarshan, D. Dutta, M. Mahapatra, S. Godbole, Solid State Communication 149 (2009) 550-554. 

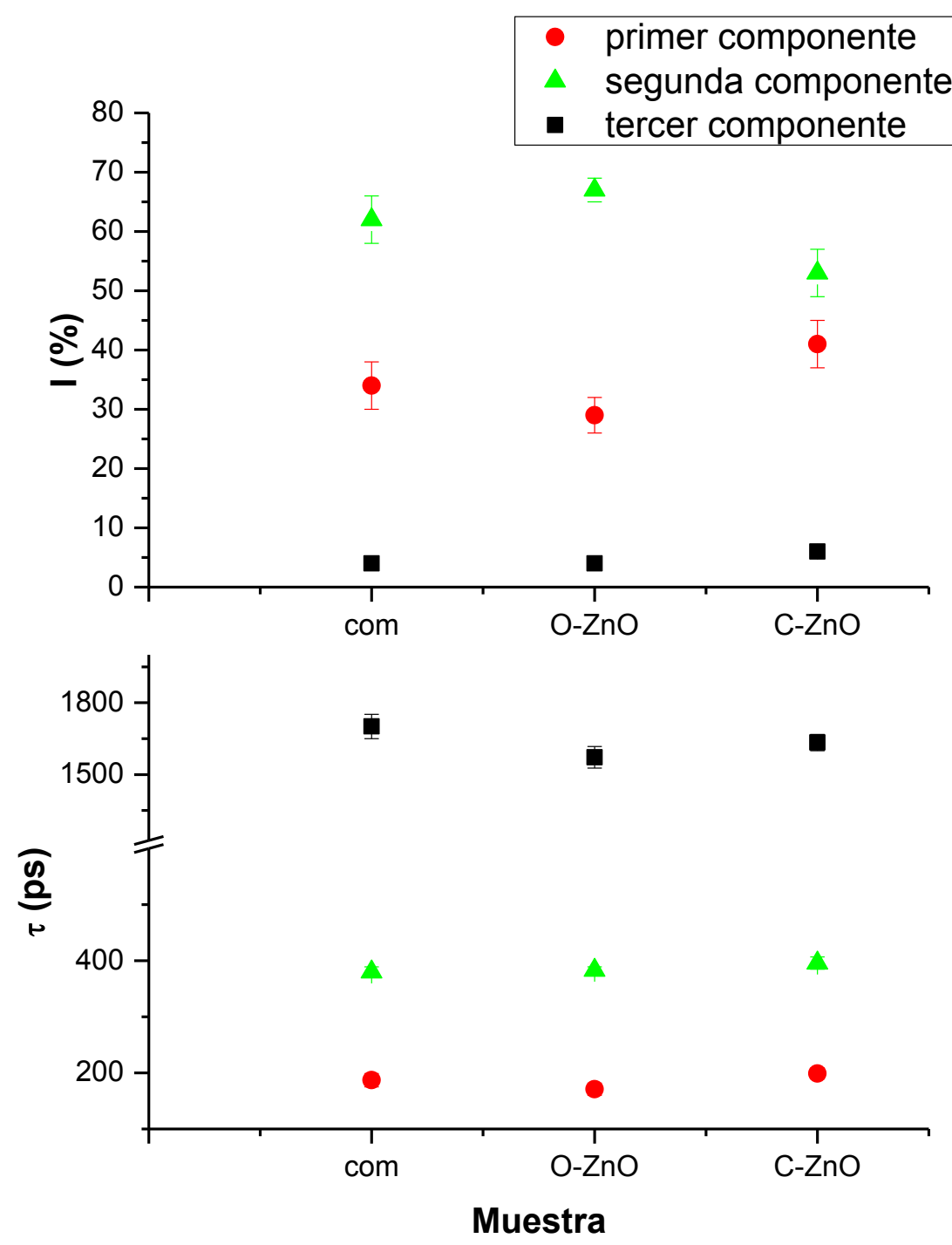

Figura 5.31. Parámetros de vidas medias de aniquilación de positrones en las muestras.

Este hecho, junto con el análisis de la relación de intensidades $I_{1} / I_{2}$, indica que este sólido presenta mayor cantidad de monovacancias y menos defectos de mayor tamaño 
(como divacancias o aglomeración de vacancias). En cambio, en los sólidos OZnO y $\mathrm{ZnOc}$, los resultados indican un aumento en la concentración de defectos de mayor tamaño superficiales. La concentración relativa de defectos de bulk y superficiales puede ser modificada variando las condiciones de síntesis, en este caso las diferencias observadas entre los sólidos $\mathrm{CZnO}$ y $\mathrm{OZnO}$ podrían relacionarse con los agentes precipitantes usados en ambos casos. Los presentes resultados coinciden con los reportados por Dutta y col. ${ }^{44}$ para nanopartículas de $\mathrm{ZnO}$ obtenidas por molienda mecánica. A fututo podrían someterse a diferentes procesos con el objetivo de mejorar sus propiedades físicas y químicas. 


\subsubsection{Resumen de las caracterizaciones de óxidos de zinc recuperados}

A continuación se muestra un breve resumen de la caracterización de los sólidos recuperados de pilas alcalinas agotadas:

$\checkmark$ La fase cristalina presente en las muestras es la wurtzita. Se observan diferencias en el ancho y posición de pico, que podrían ser consecuencia del agente precipitamte usado en la síntesis.

$\checkmark$ En los sólidos recuperados se observan diferencias en el grado de aglomeración. Esta variación en el grado de aglomeración, estaría relacionada con el mecanismo de crecimiento de los cristales.

$\checkmark$ Del análisis por DRS UV- vis se observaron variación en la absorbancia de sólidos, estas diferencias podrían estar relacionadas con la variación en la concentración de vacancias presentes.

$\checkmark$ Los valores de $E_{g a p}$, calculados a partir del método de Taucc, presentan diferencias en las muestras, siendo menores que $\mathrm{ZnOc}$ usado como referencia.

$\checkmark$ Por la espectroscopía de aniquilación de positrones (PALS) se determinó que los sólidos recuperados presentan diferencias en cuanto a la naturaleza y cantidad de defectos presentes. 


\title{
5.3 Uso de los óxidos recuperados
}

\section{como catalizadores. Estudio en}

\author{
reacción de degradación de COVs
}




\subsubsection{Problemática de COVs}

Los COVs son contaminantes primarios, es decir que por su naturaleza tienen efectos tóxicos en la salud humana y pueden afectar al medioambiente por sí mismos. Al participar en reacciones fotoquímicas atmosféricas, algunos de ellos pueden generar contaminantes secundarios como $\mathrm{O}_{3}$ y PAN (nitrato de peroxoacetilo), productos que son altamente nocivos para la salud. ${ }^{1,2}$

Existen numerosos métodos para destruir las emisiones de compuestos orgánicos volátiles, los cuales se pueden clasificar en destructivos y no destructivos. En los primeros, los COVs se transforman en compuestos inertes o de menor toxicidad, mientras que en los métodos no destructivos, los COVs son recuperados. Ejemplos de métodos destructivos son: la incineración térmica, la incineración catalítica, los procesos electroquímicos, la oxidación fotoquímica y la biodegradación, ${ }^{3}$ mientras que entre los métodos no destructivos encontramos el uso de adsorbentes, absorbentes, precipitación, condensación y tecnologías de membranas. La adopción de estos métodos depende entre otros factores de la concentración, velocidad de flujo, gasto de energía, peso molecular y presión de vapor de la sustancia, costos y factores climáticos, como humedad, lluvias o velocidad del viento tal como lo señalan Purcell y Shareef ${ }^{4}$ y Buonicore. ${ }^{5}$

En la incineración térmica los COVs son transformados en $\mathrm{CO}_{2}$ y $\mathrm{H}_{2} \mathrm{O}$ mediante un proceso de combustión completa lográndose una reducción mayor al 99 \% para

\footnotetext{
${ }^{1}$ P. Wolkoff, T. Schneider, J. Kildeso, R. Degerth, M. Jaroszewski, H. Schunk, Science of the Total Environment 215 (1998)135-156.

${ }^{2}$ G. Pappas, R. Hebert, W. Hendersson, J. Koenig, B. Stover, S. Barnhart, International Journal of the Occupational and Environmental Health 6 (2000) 1-8.

${ }^{3}$ R. Bethea, B. Murthy, D. Carey, Environmental Science \& Technology 7 (1973) 495-504.

${ }^{4}$ R. Purcell, G. Shareef, Technologies for hazardous air pollution, Editado EPA EEUU (1986).

${ }^{5}$ A. Buonicore, Air Pollution Engineering Manual, Ed. Air \& Waste Management Association (1992).
} 
concentraciones mayores a $100 \mathrm{ppm}$. Generalmente este proceso opera según las siguientes condiciones: intervalo de temperatura de 500 a $850{ }^{\circ} \mathrm{C}$, tiempos de residencia entre 0,5 y 0,75 segundos, y velocidades de flujo entre 6 y $12 \mathrm{~m} \mathrm{~s}^{-1}$. Entre las ventajas de este método se puede mencionar: la sencillez del proceso, eliminación completa de los contaminantes, no se generan residuos sólidos ni líquidos y costo inicial relativamente bajo. La principal desventaja de este tipo de proceso está centrada en el costo del combustible, aunque puede ser recuperado calor por el uso de intercambiadores. Se recomienda su uso cuando se tiene un bajo volumen de aire y una alta concentración de COVs.

Como variante de la incineración térmica se utiliza la incineración catalítica: esta consiste en oxidar los $\mathrm{COVs}$ a $\mathrm{CO}_{2}$ y $\mathrm{H}_{2} \mathrm{O}$ haciéndose pasar la corriente gaseosa a través de un catalizador. Frente a la incineración térmica, presenta varias ventajas: a) opera a menores temperaturas implicando un ahorro considerable de energía (hasta del $60 \%$ ), b) disminución de las emisiones de $\mathrm{NO}_{\mathrm{x}}$ de las fuentes de combustión. La eficiencia del método se encuentra entre el 95 y $99 \%$ para concentraciones de 3 a un centenar de ppm, teniendo el catalizador una vida promedio entre 3 y 7 años dependiendo del COVs. Otra característica de la combustión catalítica es que opera a una relación oxidante-COV menor que el límite de explosión de la mezcla, ${ }^{6}$ por lo que en la práctica se puede operar a muy bajas concentraciones de contaminantes, en las cuales la combustión térmica no es rentable. Sin embargo, presenta algunas desventajas como un alto costo de instalación inicial y la posibilidad de envenenamiento del catalizador.

La eliminación de compuestos orgánicos volátiles utilizando diferentes fases de $\mathrm{MnO}_{\mathrm{x}}$ $\left(\mathrm{Mn}_{2} \mathrm{O}_{3}\right.$ y sólidos OMS-2 por ejemplo Nsutita y Holandita) y $\mathrm{MnO}_{\mathrm{x}}$ dopados con otros

\footnotetext{
${ }^{6}$ R. Ferrauto, R. Heck, Catalysis Today 55 (2000) 179-187.
} 
metales tales como Ce, Pt, ha sido ampliamente estudiada por distintos autores tales como Sekine, ${ }^{7}$ Gandía y col., ${ }^{8}$ Gil y col., ${ }^{9}$ Paulis y col., ${ }^{10}$ Álvarez-Galván y col. ${ }^{11}$ y Spinicci y col. $^{12}$

Para este trabajo de Tesis se han seleccionado como moléculas prueba etanol y tolueno. Esta selección está basada en la amplia gama de "procesos" caseros e industriales que generan dichos contaminantes y abarcan un amplio espectro de industria y PyMES tales como: frigoríficos, restaurantes, panificadoras, pinturerías, talleres de chapa y pintura e imprentas.

\subsubsection{Procedimiento experimental}

En la Figura 5.32 se muestra el diagrama de flujo del equipo utilizado en los estudios de actividad catalítica de eliminación de COVs.

Como reactivo se utilizó aire sintético $\left(21 \% \mathrm{O}_{2}\right.$ en $\mathrm{N}_{2}$, calidad analítica). Las sustancias utilizadas como COV fueron etanol absoluto (Dorwill 99,0\%) y tolueno.

La corriente de aire seco (1) pasa a través de un controlador de flujo másico (2), para luego circular por un saturador termostatizado (3) que contiene el COV bajo estudio. La temperatura del saturador se controla mediante un baño criostático (4). De esta manera, la concentración del COV se controla con la temperatura del saturador.

\footnotetext{
${ }^{7}$ Y. Sekine, Atmospheric Environment. 36 (2002) 5543-5547.

${ }^{8}$ L. Gandía, M. Vicente, A. Gil, Applied Catalysis B 38 (2002) 295-307.

${ }^{9}$ A. Gil, L. Gandía, S. Korili, Applied Catalysis A 274 (2004) 229-235.

${ }^{10}$ M. Paulis, L. Gandia, A. Gil, J. Sambeth, J. Odriozola, M. Montes, Applied Catalysis B 26 (2000) 37-46.

${ }^{11}$ M. Alvarez-Galván, V. O`Shea, J. Fierro, P. Arias, Catalysis Communications 4 (2003) 215-223.

${ }^{12}$ R. Spinicci, M. Faticani, P. Marini, S. De Rossi, P. Porta, Journal of Molecular Cataysis A 197 (2003) $147-$ 155.
} 
Una válvula aguja (5) permite la dilución con aire de la corriente COV/aire. La corriente de aire saturada en el COV bajo estudio circula por una llave de tres vías (6) que permite el pasaje de la corriente hacia el reactor o hacia la siguiente llave (7).

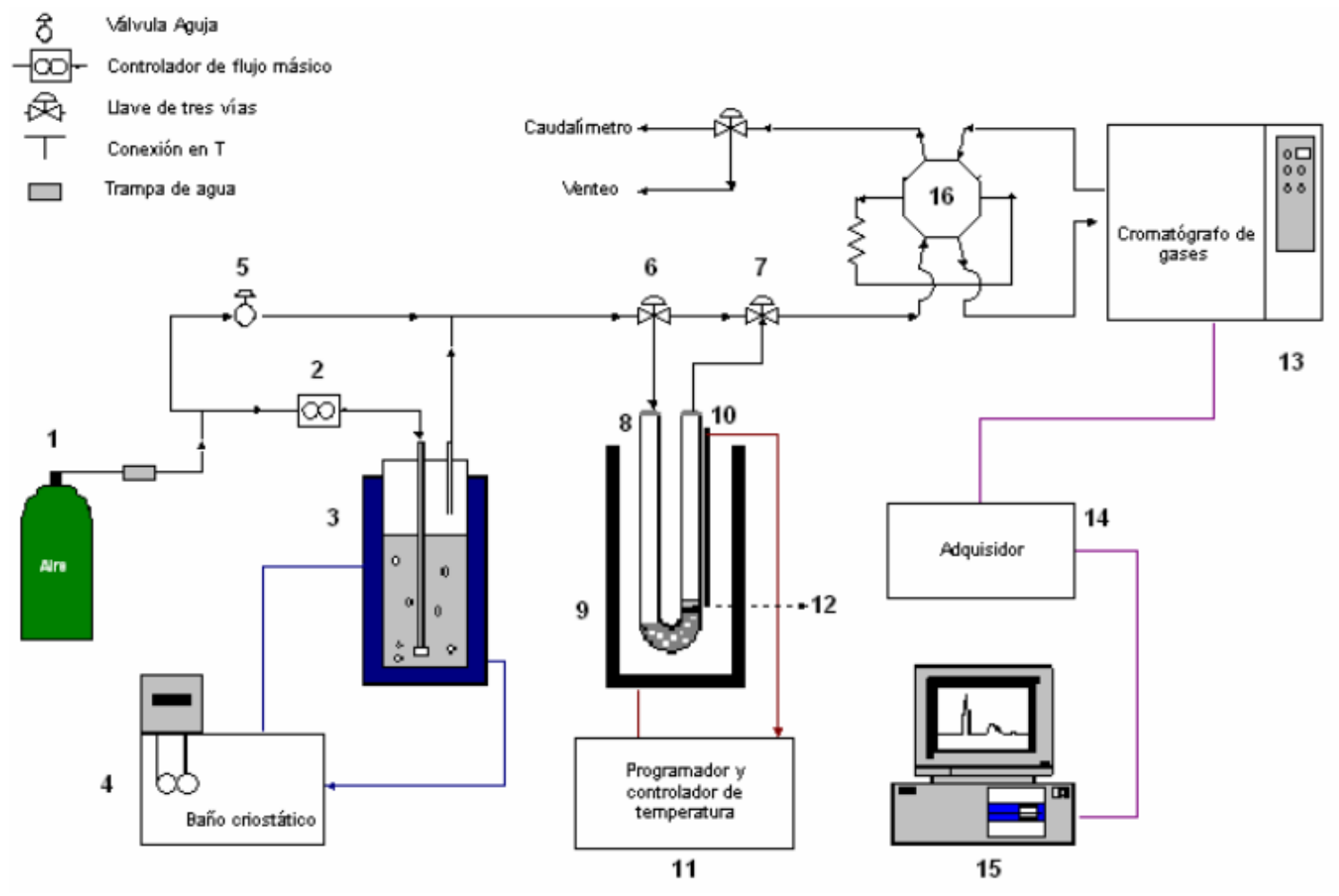

Figura 5.32. Diagrama de flujo del equipo usado en las medidas de actividad catalítica.

Se empleó un reactor en U de vidrio Pirex (8) calefaccionado por un horno eléctrico cilíndrico aislado térmicamente (9). El control de temperatura se realiza por medio de una termocupla (10) que está adosada a la parte externa del reactor a la altura del lecho catalítico. La termocupla se encuentra conectada a un programador y controlador de temperatura (11). El catalizador (12) se coloca entre dos fragmentos de lana de vidrio sobre 
partículas de cuarzo, agregadas para asegurar la premezcla y homogeneización de la mezcla COV/aire y que actúan como base del lecho catalítico.

Los análisis se llevaron a cabo en un cromatógrafo de gases Thermofinnigan Trace GC (13) equipado con una columna J\&W Scientific DB-17 y un detector de ionización de llama (FID). El cromatógrafo se encuentra conectado en serie a un adquisidor de datos (14) y éste a una computadora (15).

La toma de muestras se realizó con un sistema constituido por una válvula de seis vías (16) que posee un rulo de volumen conocido. A la válvula llega la corriente gaseosa (desde el reactor o desde el saturador) la cual llena el rulo o se ventea. La muestra gaseosa es barrida por el helio procedente del cromatógrafo de gases, y es enviada a la columna DB17.

En el caso de utilizar como catalizadores monolitos metálicos impregnados con sales de manganeso, se varía únicamente en el diámetro del reactor. Se utiliza un reactor con distintas dimensiones, especialmente diseñado para el análisis de monolitos. 


\subsubsection{Curvas de actividad catalítica}

\section{Procedimiento experimental}

La actividad catalítica de las muestra fue evaluada mediante las curvas de ignición de etanol y tolueno en aire. Se colocaron $100 \mathrm{mg}$ de catalizador, el flujo que contiene el contaminante circula con una velocidad de $100 \mathrm{~cm}^{3} \mathrm{~min}^{-1}$.

La conversión de $\mathrm{COV}(\mathrm{X})$ y el rendimiento a $\mathrm{CO}_{2}\left(\mathrm{XCO}_{2}\right)$ fueron calculados a través de las siguientes ecuaciones:

$$
\begin{gathered}
\mathrm{X}=1-\frac{\mathrm{F}_{\mathrm{COV}}}{\mathrm{F}_{\mathrm{COV}, \text { in }}} \\
\mathrm{XCO}_{2}=\frac{\mathrm{F}_{\mathrm{CO} 2}}{v \mathrm{~F}_{\mathrm{COV}}}
\end{gathered}
$$

en donde $\mathrm{F}_{\mathrm{COV}}$ es el flujo de $\mathrm{COV}$ en estado estacionario a la entrada, $\mathrm{F}_{\mathrm{COV} \text {,in }}$ es el flujo molar de $\mathrm{COV}$ a la salida, $\mathrm{FCO}_{2}$ es el flujo molar de $\mathrm{CO}_{2}$ a la salida y $v$ es el número de átomos de $\mathrm{C}$ en el contaminante (para etanol y tolueno, $v=2$ y 7 , respectivamente). En el caso de etanol, la conversión en acetaldehído (Xacetal) se calculó como:

$$
\text { Xacetal }=\frac{F_{\text {actal }}}{F_{C O V, \text { in }}}
$$

Donde $\mathrm{F}_{\text {acetal }}$ es el flujo molar de acetaldehído en estado estacionario a la salida del reactor.

Las curvas que se obtienen de estos ensayos de actividad catalítica, en los que se representa la conversión del COV frente a la temperatura, se denominan curvas de ignición. Un punto característico de estas curvas es la $\mathrm{T}_{50}$, que es la temperatura a la cual la se alcanza el $50 \%$ de conversión. También se utiliza otro punto característico que es la $\mathrm{T}_{90}$, 
temperatura a la que se alcanza el $90 \%$ de conversión, debido a que veces un proceso resulta eficiente sin llegar al 100\% de conversión.

La curva de ignición de etanol sobre los catalizadores se estudió también utilizando $\mathrm{N}_{2}$ en ausencia de aire en el mismo reactor que se describió anteriormente.

\subsubsection{Estudio de especies adsorbidas por Espectroscopia Infrarroja de Transmisión}

\section{Procedimiento experimental}

El estudio de la adsorción de los COVs se llevó a cabo en el Laboratorio de Química de Superficies y Catálisis Industrial de la Universidad de Génova, Italia, usando un espectrómetro FT- IR Nicolet 380, con las muestras puras en forma de pastillas ( $30 \mathrm{mg})$.

Los sólidos se activaron en la celda IR, esta se encuentra conectada a un equipo de manipulación de gases. La activación se realizó a $500^{\circ} \mathrm{C}$ en aire y en vacío $\left(10^{-4}\right.$ torr).

Las muestras activadas se pusieron en contacto con etanol y tolueno a temperatura ambiente, luego se aplicó una rampa de temperatura hasta $500{ }^{\circ} \mathrm{C}$. Luego se realizó la misma experiencia pero en este caso en presencia de aire.

A cada temperatura se estudiaron las especies adsorbidas en la superficie, así como también las especies presentes en la fase gaseosa. La celda IR se encontraba conectada a un aparato convencional de manipulación de gases, el cual permite la introducción de moléculas de prueba y el estudio de su evolución a medida que se aumenta la temperatura. 


\subsubsection{Resultados de la oxidación catalítica de COVs}

Los resultados de la actividad catalítica en presencia de aire se muestran en la Figura 5.34 y 5.35. Los valores de $\mathrm{T}_{50} \mathrm{y} \mathrm{T}_{90}$, para las muestras estudiadas se presentan en la Tabla 5.12.

En el estudio de la oxidación de etanol sobre los sólidos OMR y ZnMnR, los valores de $\mathrm{T}_{50}$ se encuentran dentro del intervalo de temperatura señalados por diferentes autores ${ }^{13,14,15,16,17}$ para distintas fases de $\mathrm{MnO}_{\mathrm{x}}$, se encuentran entre los 150 y $180{ }^{\circ} \mathrm{C}$ dependiendo del tipo de óxido de manganeso. Sin embargo la $\mathrm{T}_{90}$ de estos sólidos en la oxidación de etanol es superior, por ejemplo si es comparada con los resultados de Santos y col. ${ }^{17}$ que registran una $\mathrm{T}_{90}$ del orden de $\operatorname{los} 210{ }^{\circ} \mathrm{C}$. Para los sólidos impregnados ambas temperaturas fueron muy elevadas.

Tabla 5.12. Temperaturas correspondientes al 50 y $90 \%$ de conversión para etanol y tolueno.

\begin{tabular}{lcccc}
\hline Muestra & \multicolumn{2}{c}{ Etanol } & \multicolumn{2}{c}{ Tolueno } \\
\hline & T $_{\mathbf{5 0}}$ & T.90 $_{\mathbf{9 0}}$ & $\mathbf{T}_{\mathbf{5 0}}$ & $\mathbf{T}_{\mathbf{9 0}}$ \\
\hline OMR & 170 & 257 & 274 & $\mathrm{~N} / \mathrm{R}$ \\
ZnMnR & 156 & 299 & $\mathrm{~N} / \mathrm{R}$ & $\mathrm{N} / \mathrm{R}$ \\
OMRA & 192 & 281 & 300 & $\mathrm{~N} / \mathrm{R}$ \\
OMRB & 200 & 288 & $\mathrm{~N} / \mathrm{R}$ & $\mathrm{N} / \mathrm{R}$ \\
\hline
\end{tabular}

N/R No registrada

\footnotetext{
${ }^{13}$ H. Sun, Z. Liu, S. Chen, X. Quan, Chemical Engineering Journal 270(2015) 58-65.

${ }^{14}$ H. Sun, S. Chen, P. Wang, X. Quan, Chemical Engineering Journal 178 (2011)191-196.

${ }^{15}$ L. Lamaita, M. Peluso, J.E. Sambeth, H.J. Thomas, Applied Catalysis B 61(1-2) (2005) 114-119.

${ }^{16}$ V. Santos, M. Pereira, J. Orfao, J. Figueiredo, Journal of Hazardous Materials 185(2-3) (2011) 1236-40.

${ }^{17}$ V. Santos, M. Pereira, J. Orfao, J. Figueiredo, Applied Catalysis B 99 (2010) 353-363.
} 
En el caso de la oxidación de tolueno sólo fue alcanzada la conversión del 50\% en los sólidos OMR y OMRA con temperaturas también superiores a las registradas por Sun y col. ${ }^{14}$ y Santos y col. ${ }^{17}$ las cuales se ubican en 220 y $255^{\circ} \mathrm{C}$, respectivamente. En los otros dos sólidos no se alcanzó una conversión mayor al $40 \%$ en el ZnMnR y aproximadamente el $35 \%$ en el caso del sólido OMRB.
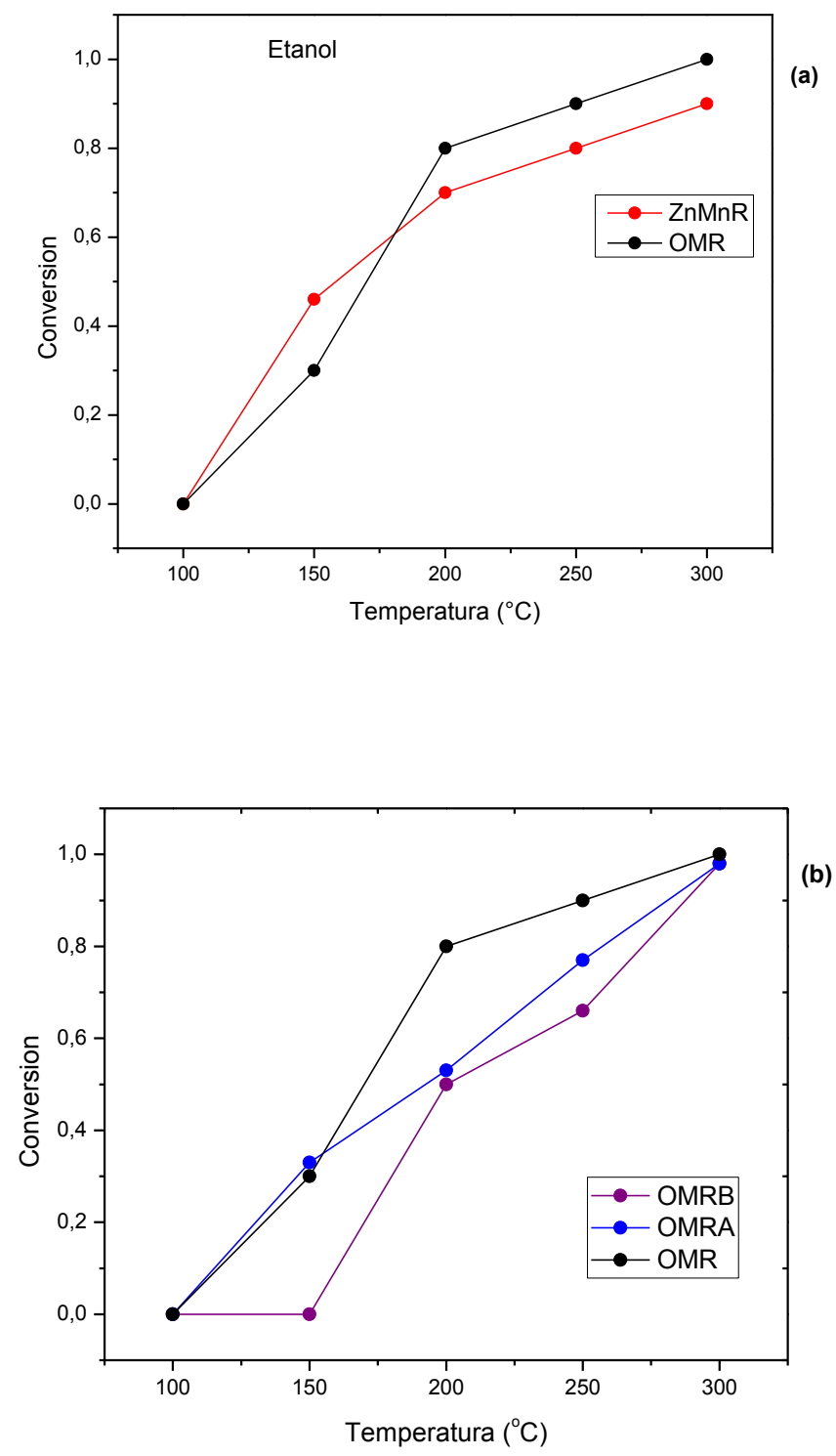

Figura 5.33. Conversión de etanol sobre los sólidos recuperados 
En todos los sólidos el producto mayoritario de la oxidación de etanol es $\mathrm{CO}_{2}$, aunque también fue detectado acetaldehído.
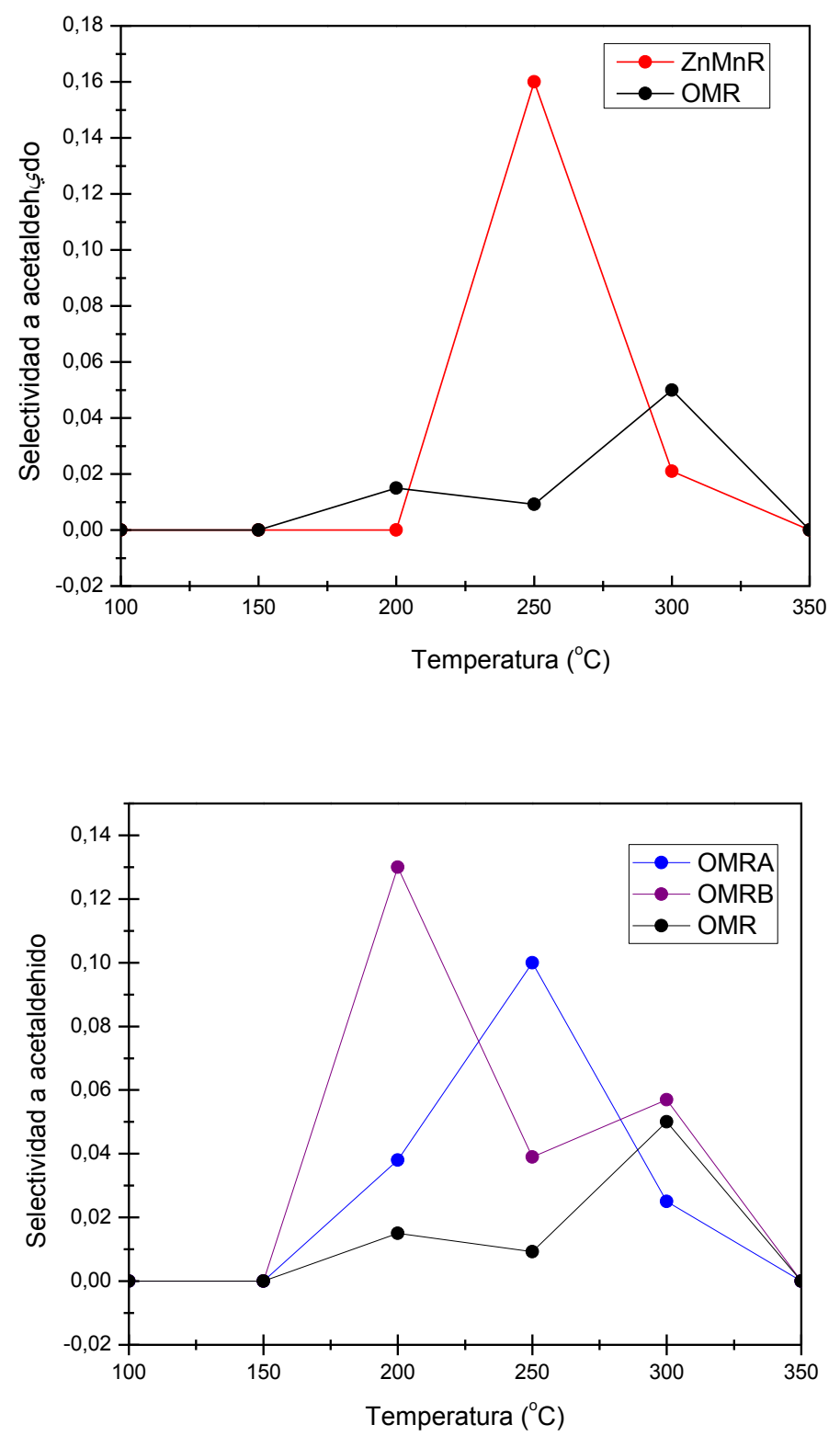

Figura 5.34. Selectividad a acetaldehído (a) OMR y ZnMnR y (b) OMR, OMRA y OMRB. 
En los sólidos más activos el proceso de adsorción-oxidación de etanol puede ser dividido en dos partes: una entre $0 \%$ y $50 \%$ de conversión y la otra entre $50 \%$ y $100 \%$. Del análisis del primer intervalo, se observa que la temperatura de oxidación de etanol es menor en el sólido ZnMnR. En esta primera zona sobre este sólido no se detecta acetaldehído, aunque si a altas temperaturas $\left(250^{\circ} \mathrm{C}\right.$ con 0,17 de selectividad). En la muestra OMR la presencia de acetaldehído se registra ya a la $\mathrm{T}_{50}$, teniendo dos máximos de selectividad a 200 y $300{ }^{\circ} \mathrm{C}$. En los otros dos sólidos, las $\mathrm{T}_{50}$ y $\mathrm{T}_{90}$ son similares, observándose en ambos catalizadores acetaldehído a temperaturas por debajo de la $\mathrm{T}_{50}$.

Peluso y col. ${ }^{18}$ señalan que el proceso de oxidación de etanol ocurre sobre dos sitios activos por medio de dos mecanismos de reacción donde el etanol en un sitio es adsorbido y oxidado a acetaldehído y posteriormente a $\mathrm{CO}_{2}$ y en otro donde el etanol es fuertemente adsorbido como etoxi oxidándose directamente a $\mathrm{CO}_{2}$ a mayor temperatura, de acuerdo a los siguientes mecanismos:

$$
\begin{gathered}
\text { Etanol } \rightarrow \text { Acetaldehído } \rightarrow \mathrm{CO}_{2} \\
\text { Etanol } \rightarrow \mathrm{CO}_{2}
\end{gathered}
$$

Dada la complejidad de la superficie podría suponer que el proceso de oxidación de etanol ocurre sobre diferentes fases que tienen en algunos casos una sinergia. La mayor selectividad en los sólidos OMRA, OMRB y ZnMnR a acetaldehído sugiere que el etanol se oxida más fácilmente a este COVs sobre la espinela $\mathrm{ZnMn}_{2} \mathrm{O}_{4}$.

Sin embargo, debe destacarse el comportamiento anómalo del $\mathrm{ZnMnR}$ respecto del menor valor de $\mathrm{T}_{50}$ comparado con los otros catalizadores. De acuerdo con Casanovas y

\footnotetext{
${ }^{18}$ M.A. Peluso, L. A. Gambaro, E. Pronsato, D. Gazzoli, H.J. Thomas, J. E. Sambeth, Catalysis Today 133135 (2008) 487-492.
} 
col. ${ }^{19}$, Llorca y col. ${ }^{20}$ y Vohs y Barteau ${ }^{21}$ el $\mathrm{ZnO}$ juega un papel importante en el reformado de etanol participando en la generación de acetaldehído a temperaturas por debajo de 200 ${ }^{\circ} \mathrm{C}$ y su posterior reformado a $\mathrm{H}_{2}$ a temperaturas por encima de $400{ }^{\circ} \mathrm{C}$. Las conclusiones de estos autores sobre los productos formados por el reformado de etanol sobre el $\mathrm{ZnO}$ y los resultados de este trabajo, permiten suponer que sobre el sólido $\mathrm{ZnMnR}$ el proceso se ve favorecido por un "ensemble" $\mathrm{ZnO}-\mathrm{MnO}_{\mathrm{x}}$ donde hay una mayor adsorción-oxidación de etanol. Asociado a esto puede decirse que el catalizador $\mathrm{ZnMnR}$ presenta una menor temperatura de inicio de la reducción lo cual se vincula con la labilidad y reactividad de los oxígenos de red.

\section{Tolueno}

En la Figura 5.35 (a) se presentan las curvas de conversión de tolueno sobre los sólidos OMR y ZnMnR, mientras que en la Figura 5.35 (b) se observan las curvas para los sólidos OMRA y OMRB. En todos los casos el único producto detectado con la técnica utilizada fue $\mathrm{CO}_{2}$. El sólido OMR es el más activo, mostrando un $70 \%$ de conversión a $350^{\circ} \mathrm{C}$, mientras que sobre el sólido ZnMnR la conversión alcanzo el 40\%.

\footnotetext{
19 A. Casanovas, M. Roig, C. De Leitenburg, A. Trovarelli, J. Llorca, International Journal of Hydrogen Energy 35 (2010) $7690-7698$

${ }^{20}$ J. Llorca, N. Homs, P. Ramirez de la Piscina, Journal of Catalysis 227(2) (2004) 556-560.

${ }^{21}$ J. M. Vohs, M. A. Barteau, Surface Science 221 (1989) 590-608.
} 

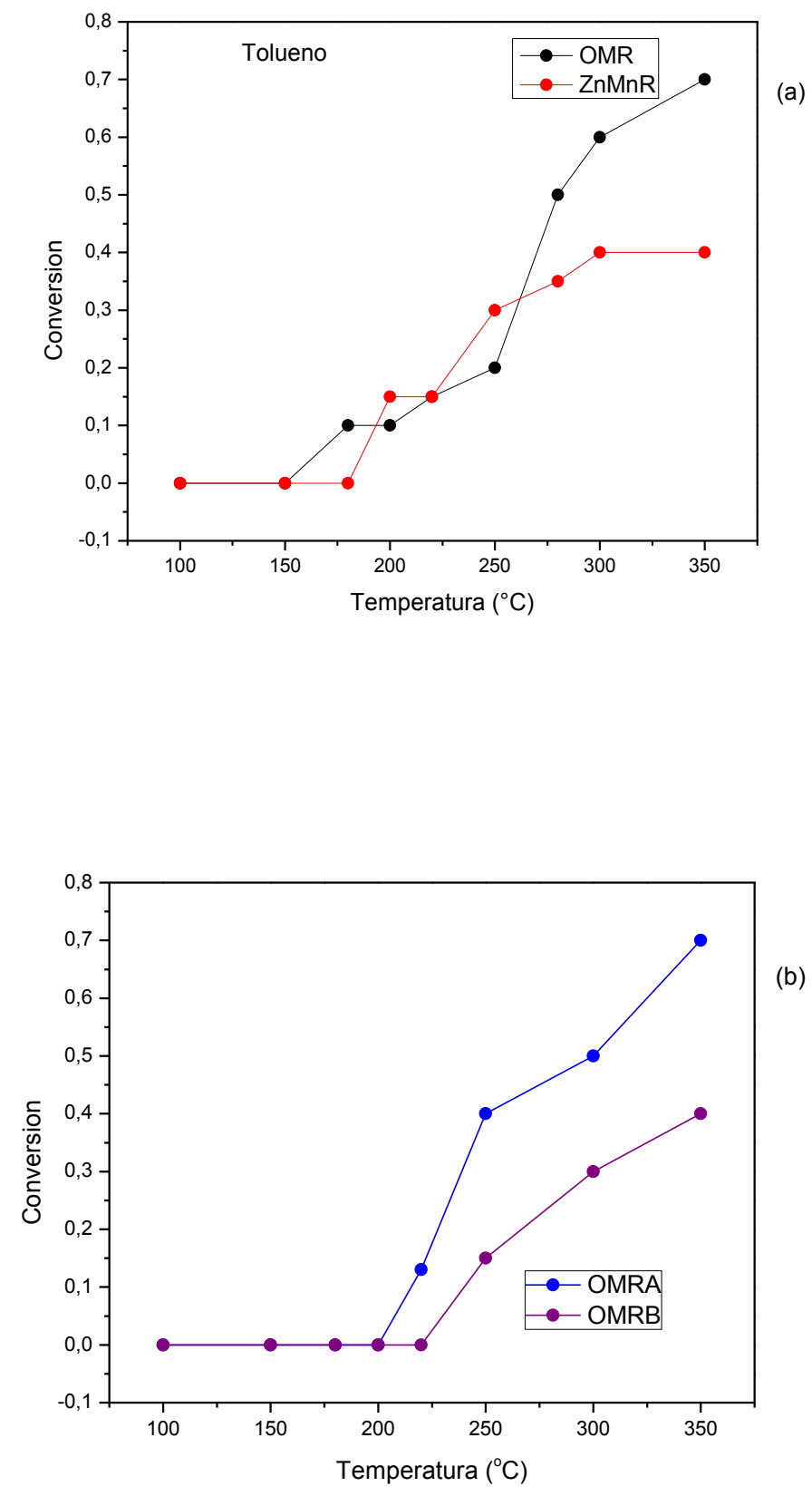

(b)

Figura 5.35. Conversión de tolueno sobre los sólidos

(a) OMR y ZnMnR y (b) OMRA y OMRB

Cuando el tolueno se adsorbe sobre el sólido OMR, el anillo aromático se vuelve inestable, esto conduce a la oxidación total a $\mathrm{CO}_{2}$. Santos y col., ${ }^{17}$ mostraron que sobre 
óxidos de manganeso con estructura de tipo holandita el tolueno adsorbido afecta la movilidad de los oxígenos de red, haciéndolos menos reactivos produciendo una fuerte adsorción de tolueno. Como señalan Lüth y col. ${ }^{22}$ los COVs oxigenados (O-COVs) se adsorben sobre la superficie del óxido mediante la coordinación de los pares de electrones no enlazantes del oxígeno con una fuerte interacción con el metal del óxido, siendo la energía de activación para la combustión de O-COVs más baja que para compuestos aromáticos y por lo tanto, la combustión ocurre a menor temperatura ( $\mathrm{T}_{50} \mathrm{OMR}$-etanol 170 ${ }^{\circ} \mathrm{C}$; OMR-Tolueno $274{ }^{\circ} \mathrm{C}$ ).

Los resultados obtenidos en esta Tesis indican que la interacción COVs-ZnO podría ser el principal responsable de las diferencias en la actividad catalítica en los sólidos.

\subsubsection{Estudio FTIR In Situ de la Combustión de Etanol}

El estudio de la reacción química por FTIR se realizó un equipo Nicolet 380 y fueron realizados en la Facultad de Ingeniería Química de la Universidad de Génova. Los sólidos OMR y $\mathrm{ZnMnR}$ fueron prensados con $\mathrm{KBr}$ para generar pastillas de $30 \mathrm{mg}$, las cuales fueron colocadas en una celda de IR que permite la incorporación y evacuación de gas. Las muestras fueron actividades a $500{ }^{\circ} \mathrm{C}$ en aire y bajo vacío $\left(10^{-4}\right.$ torr). Posterior a la activación se realizó un espectro del sólido activado y luego se incorporaron los COVs (etanol o tolueno) a temperatura ambiente $\left(25^{\circ} \mathrm{C}\right)$. El estudio de la reacción se realizó desde r.t. hasta $\operatorname{los} 500^{\circ} \mathrm{C}$, evaluándose la reacción en presencia y en ausencia de aire. Se tomaron espectros tanto de la superficie como la fase gaseosa con el objetivo de determinar los productos de reacción y las especies intermedias formadas.

${ }^{22}$ H. Lüth, G.W. Rubloff, W.D. Grobman, Surface Science 74 (1978) 365-372. 
En la Figura 5.36 se observan los resultados sobre la muestra de OMR en ausencia de aire.

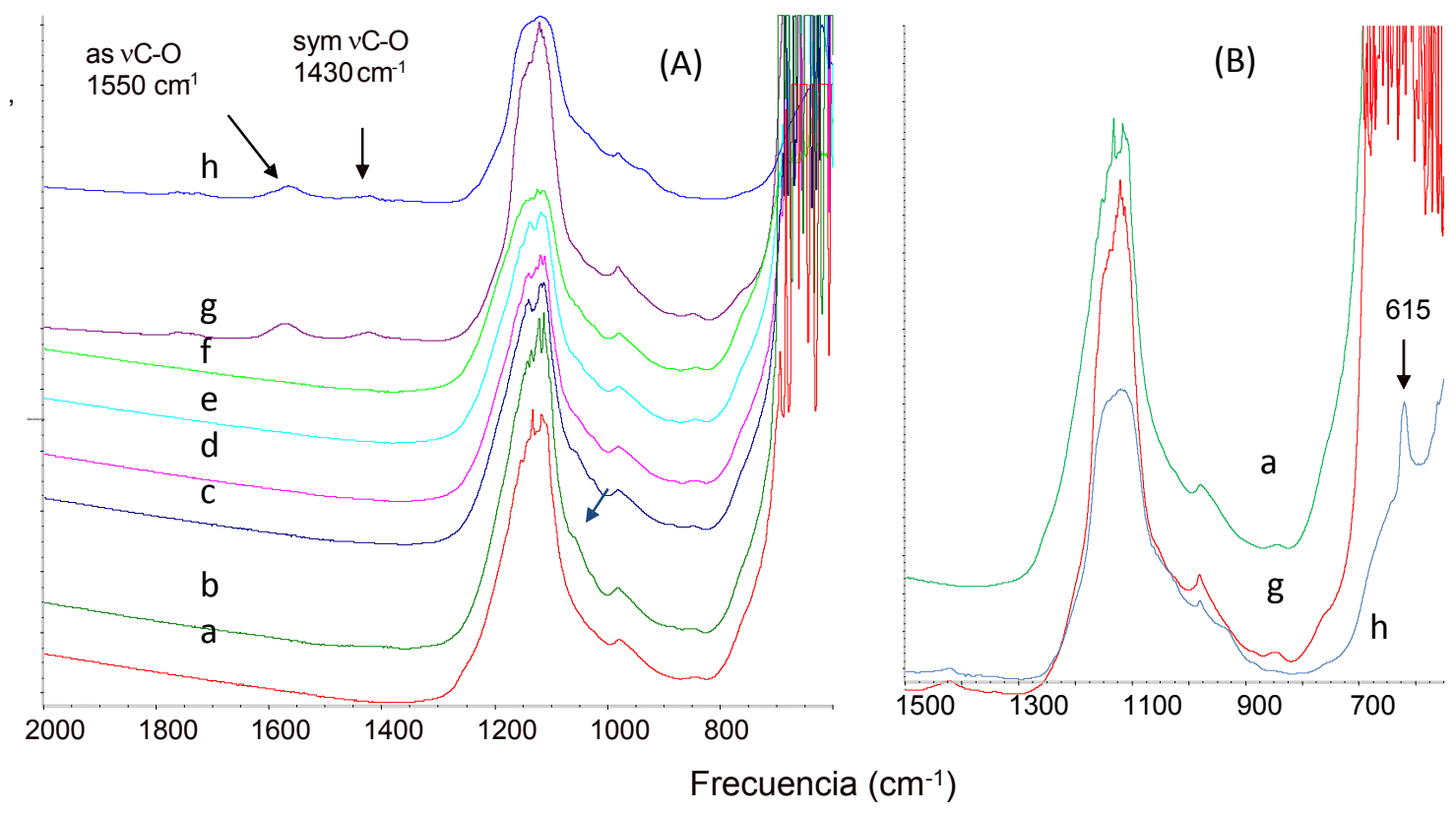

Figura 5.36. Espectros FT IR de especies superficiales derivadas de la adsorción y conversión de etanol sobre catalizador OMR ( $\sin$ aire) (A): en (a) superficie desgasificada a $500{ }^{\circ} \mathrm{C}$, (b) después de la adsorción de etanol a $25^{\circ} \mathrm{C}$, (c) a $100^{\circ} \mathrm{C}$, (d) a $150{ }^{\circ} \mathrm{C}$, (e) a 200

${ }^{\circ} \mathrm{C}$, (f) $250{ }^{\circ} \mathrm{C}$, (g) $340{ }^{\circ} \mathrm{C}$ y (h) a $380{ }^{\circ} \mathrm{C}$. (B) Detalle de la región de baja frecuencia: modos de estiramiento $\mathrm{Mn}-\mathrm{O}$.

En primer lugar debe mencionarse que la banda centrada en los $1170 \mathrm{~cm}^{-1}$ se corresponde con los grupos sulfatos, que se hallan presentes en los sólidos debido al tratamiento de recuperación de las pilas. 
Después de la adsorción de etanol a temperatura ambiente, se observa un hombro cerca de $1030 \mathrm{~cm}^{-1}$ (Fig. 5.36 a), solapada en la banda de sulfatos, que puede ser asignada a un estiramiento $\mathrm{CO} / \mathrm{CC}$ de grupos etoxi superficiales. Este desaparece por encima de $250{ }^{\circ} \mathrm{C}$, coincidiendo con la aparición de dos bandas a 1550 y $1430 \mathrm{~cm}^{-1}$ que se atribuyen a especies acetatos superficiales $\left(v_{\mathrm{COO}}\right)$ en sus modos asimétrico y simétrico, respectivamente.

Los espectros del sólido (Figura 5.36 b espectro h) también sufren modificaciones en la zona de bajas frecuencias. Como puede verse se detecta la aparición de una banda a 615 $\mathrm{cm}^{-1}$ asignada a la espinela de $\mathrm{Mn}_{3} \mathrm{O}_{4}$.

Con el fin de evidenciar las especies adsorbidas recientemente formadas, en la Fig. 5.37se aprecian los espectros de sustracción. Estos espectros se obtienen al sustraer el espectro de la superficie de OMR desgasificada a alta temperatura del espectro de la superficie en presencia de etanol a la temperatura indicada. 


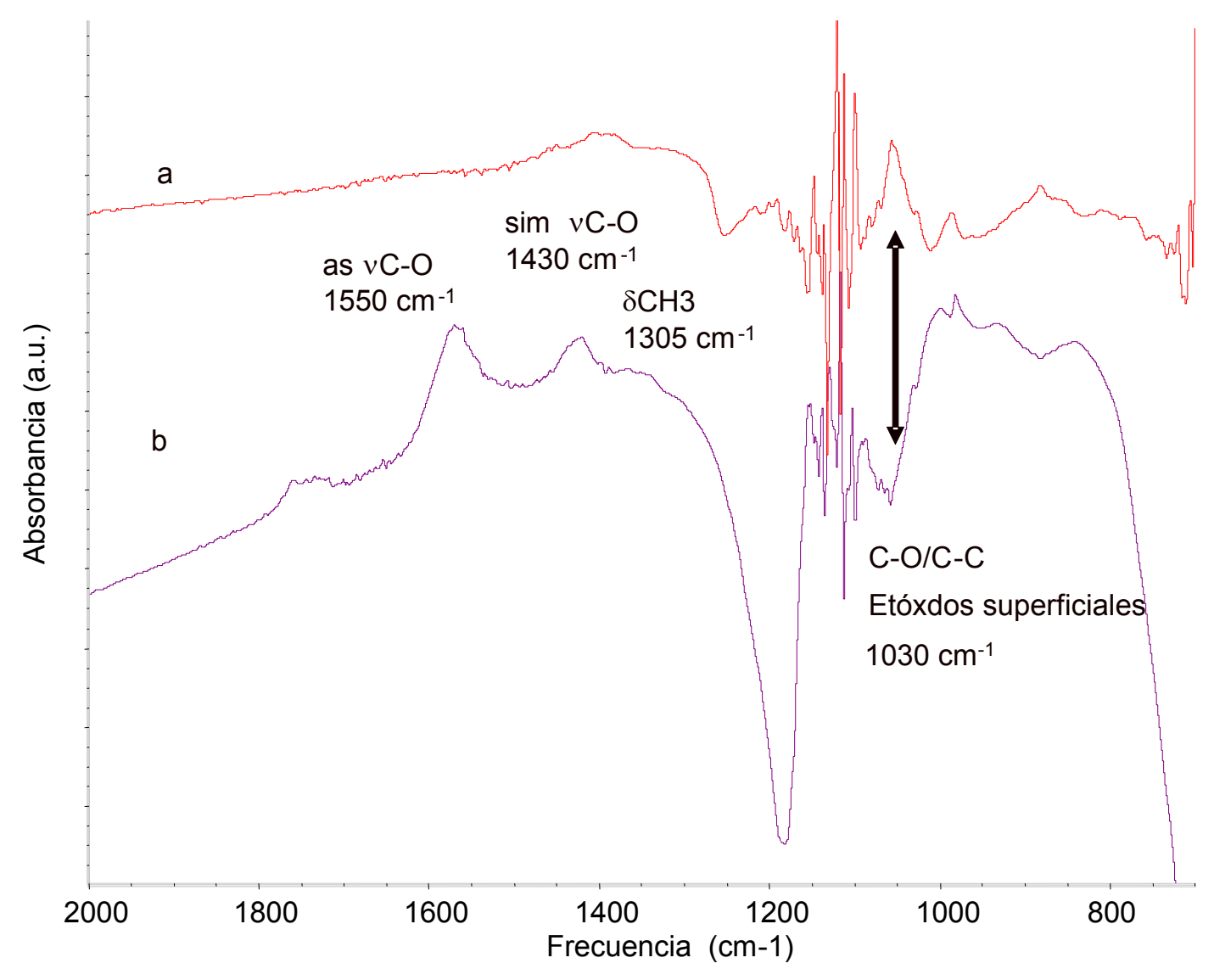

Figura 5.37. Espectros de sustracción IR FT de las especies superficiales derivadas de la adsorción de etanol sobre el catalizador OMR a $25^{\circ} \mathrm{C}$ (a) y a $380^{\circ} \mathrm{C}$ (b). La superficie activada ha sido restada.

El análisis espectral confirma que los grupos etoxi se forman tras la absorción de etanol (banda positiva en el espectro 5.37 a) y desaparecen cuando se forman especies de acetato de superficie y acetaldehído (banda negativa de grupos etoxi y banda positiva de especies de acetato en el espectro 5.37 b). La secuencia de los espectros sugiere que los grupos etoxi son precursores de la formación de acetaldehído mientras que las especies de acetato no lo 
son, siendo estables a $380^{\circ} \mathrm{C}$. Los espectros de sustracción también muestran que las especies de sulfato sufren algunos cambios ligeros, con la desaparición de una banda a $1250 \mathrm{~cm}^{-1}$ tras la adsorción de etanol. Esto indica que parte de la banda de sulfato se debe a especies de sulfato superficiales, que se caracteriza por el estiramiento $\mathrm{S}=\mathrm{O}$ en el lado de frecuencia más alta. Esta banda es sensible a la superficie y se desplaza a frecuencias más bajas (similares a las de los sulfatos a granel) tras la adsorción de etanol. Por lo tanto, las especies de sulfato de superficie pueden estar implicadas en la adsorción y conversión de etanol.

Correspondientemente, en los espectros de fase gaseosa (Fig. 5.38), además de las bandas que caracterizan vapor de etanol a $3600 \mathrm{~cm}^{-1}$ (modo de estiramiento $\mathrm{OH}$ ), 3000$2800 \mathrm{~cm}^{-1}$ (modos de estiramiento $\mathrm{CH}$ ) y $1100-1000 \mathrm{~cm}^{-1}$ (CC / Modos de estiramiento $\mathrm{CO}$ ), se detectan nuevas bandas, correspondientes a la formación de productos de reacción. En estas condiciones, la oxidación del etanol comienza a $250{ }^{\circ} \mathrm{C}$ con la formación de acetaldehído (bandas a $1700 \mathrm{~cm}^{-1}$, modo de estiramiento $\mathrm{C}=\mathrm{O}$, y a $2700 \mathrm{~cm}^{-1}$, estiramiento de $\mathrm{CH}$ con banda de resonancia de Fermi). Por otro lado, todavía se detectan bandas debido al etanol residual sin reaccionar. 


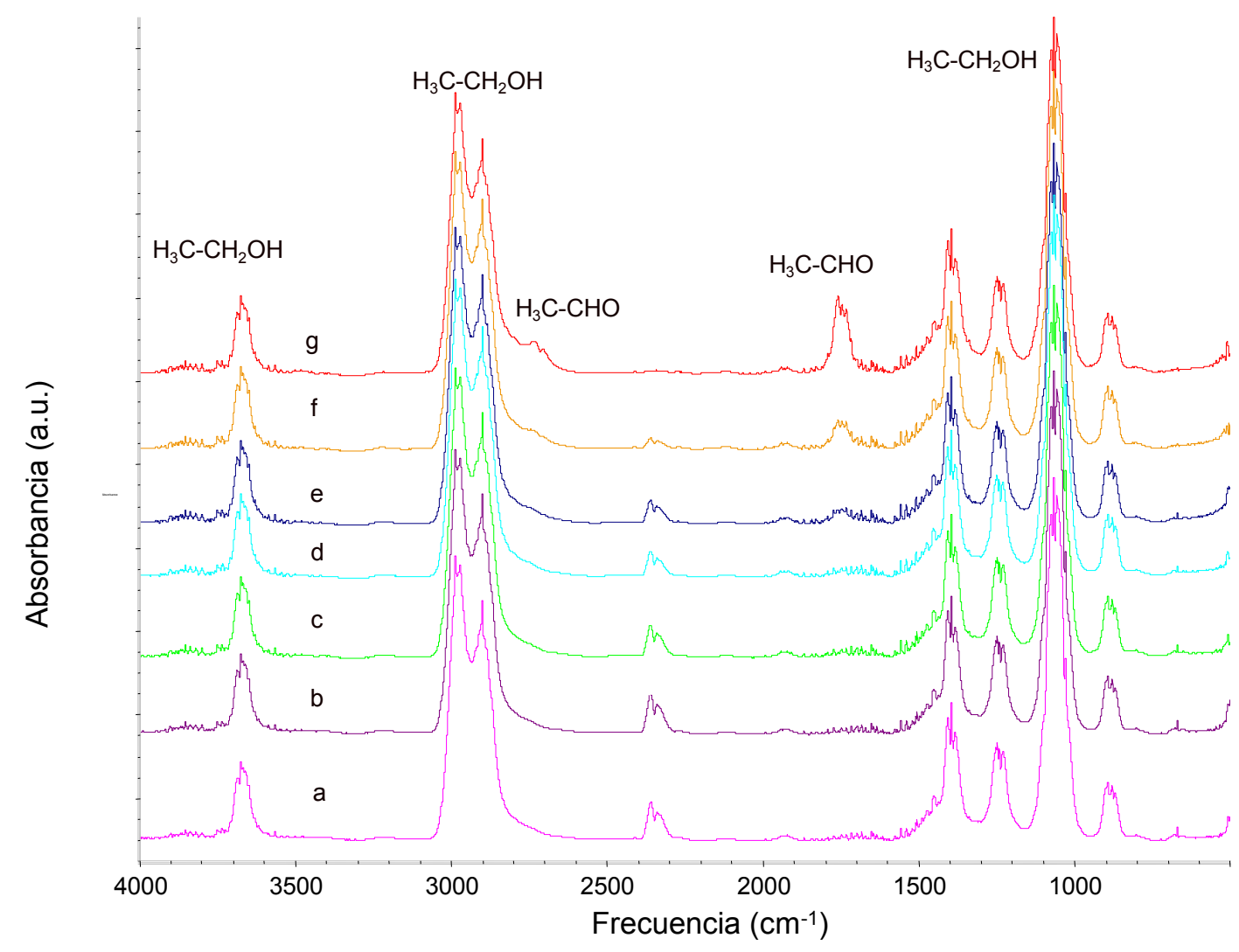

Figura 5.38. Espectro FT IR de las especies en fase gaseosa derivadas de la conversión de etanol sobre el catalizador OMR (sin aire) a (a) $25^{\circ} \mathrm{C}$, (b) $100^{\circ} \mathrm{C}$, (c) $150^{\circ} \mathrm{C}$, (d) $200^{\circ} \mathrm{C}$, (e) $250{ }^{\circ} \mathrm{C}$, (f) $300{ }^{\circ} \mathrm{C} \mathrm{y} \mathrm{(g)} 380{ }^{\circ} \mathrm{C}$.

En el experimento realizado en la célula IR con oxígeno en la celda, el acetaldehído se forma en la misma región de temperatura que en el experimento realizado sin oxígeno gaseoso (Fig. 5.39), mostrando que el oxígeno reticular, por el conocido mecanismo de Mars-van Krevelen, está implicado en la deshidrogenación oxidativa del etanol. A $400{ }^{\circ} \mathrm{C}$ se detecta la formación de $\mathrm{CO}_{2}$, aunque también se observan $\mathrm{CO}$ y $\mathrm{CH}_{4}$. Probablemente, en las condiciones estáticas, algunos subproductos tales como $\mathrm{CO}$ y metano se forman debido a la alta relación $\mathrm{VOC} / \mathrm{O}_{2}$, y posiblemente surgen de una fracción limitada de moléculas de acetaldehído que experimentan una ruta de conversión paralela. 


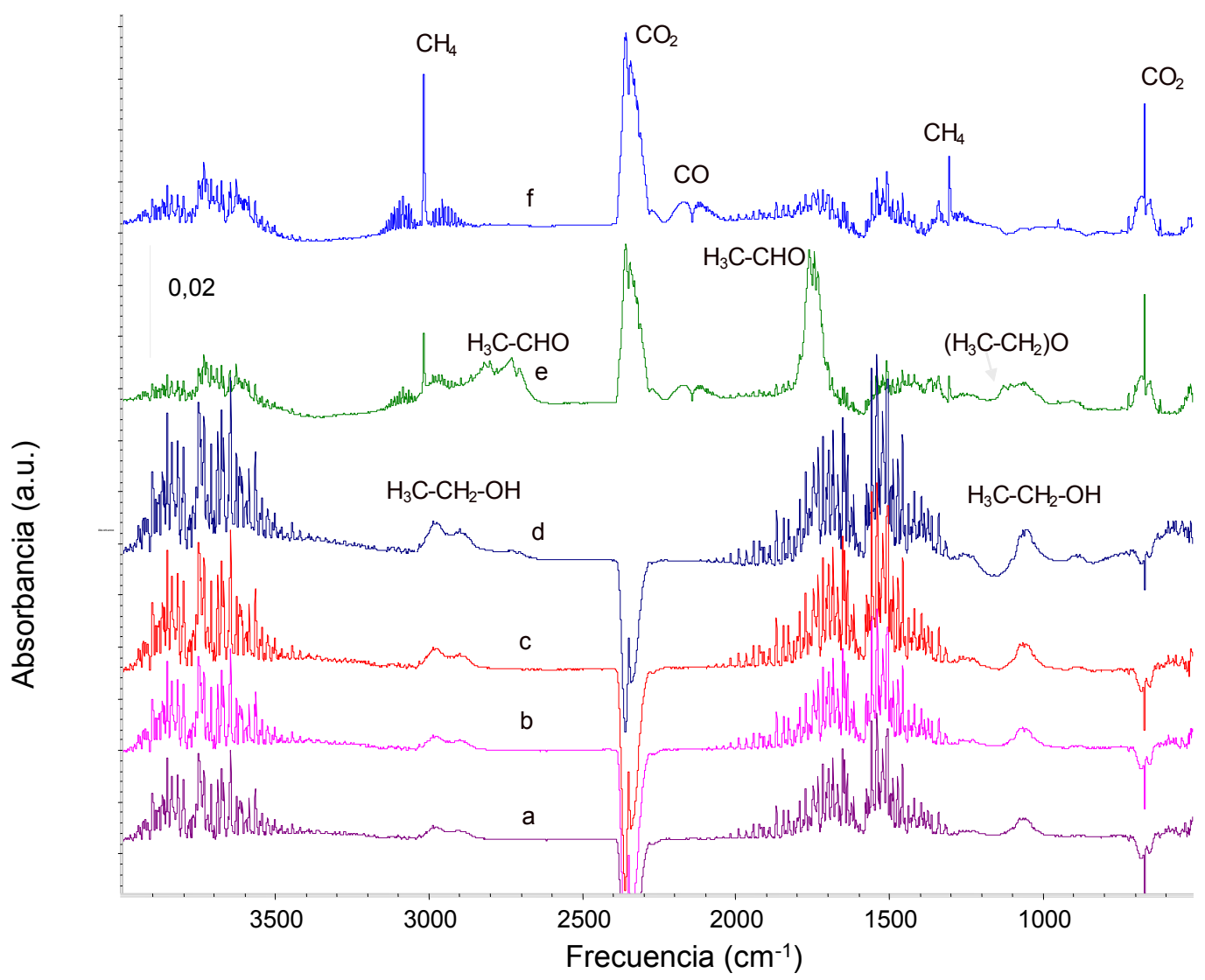

Figura 5.39. Espectro FT IR de las especies en fase gaseosa derivadas de la conversión de etanol sobre OMR (en presencia de aire) a (a) $25^{\circ} \mathrm{C}$, (b) $100{ }^{\circ} \mathrm{C}$, (c) $200{ }^{\circ} \mathrm{C}$, (d) $300{ }^{\circ} \mathrm{C}$, (e) $400{ }^{\circ} \mathrm{C}$ y (f) $500{ }^{\circ} \mathrm{C}$.

Los espectros de las especies adsorbidas muestran nuevamente la formación de grupos etoxi a baja temperatura y de especies de acetato a temperatura más alta (Figura 5.40). Además, en este caso, la banda asociada con los modos de Mn-O (banda 610-630 $\mathrm{cm}^{-1}$ ) se reduce ligeramente sólo a alta temperatura. 


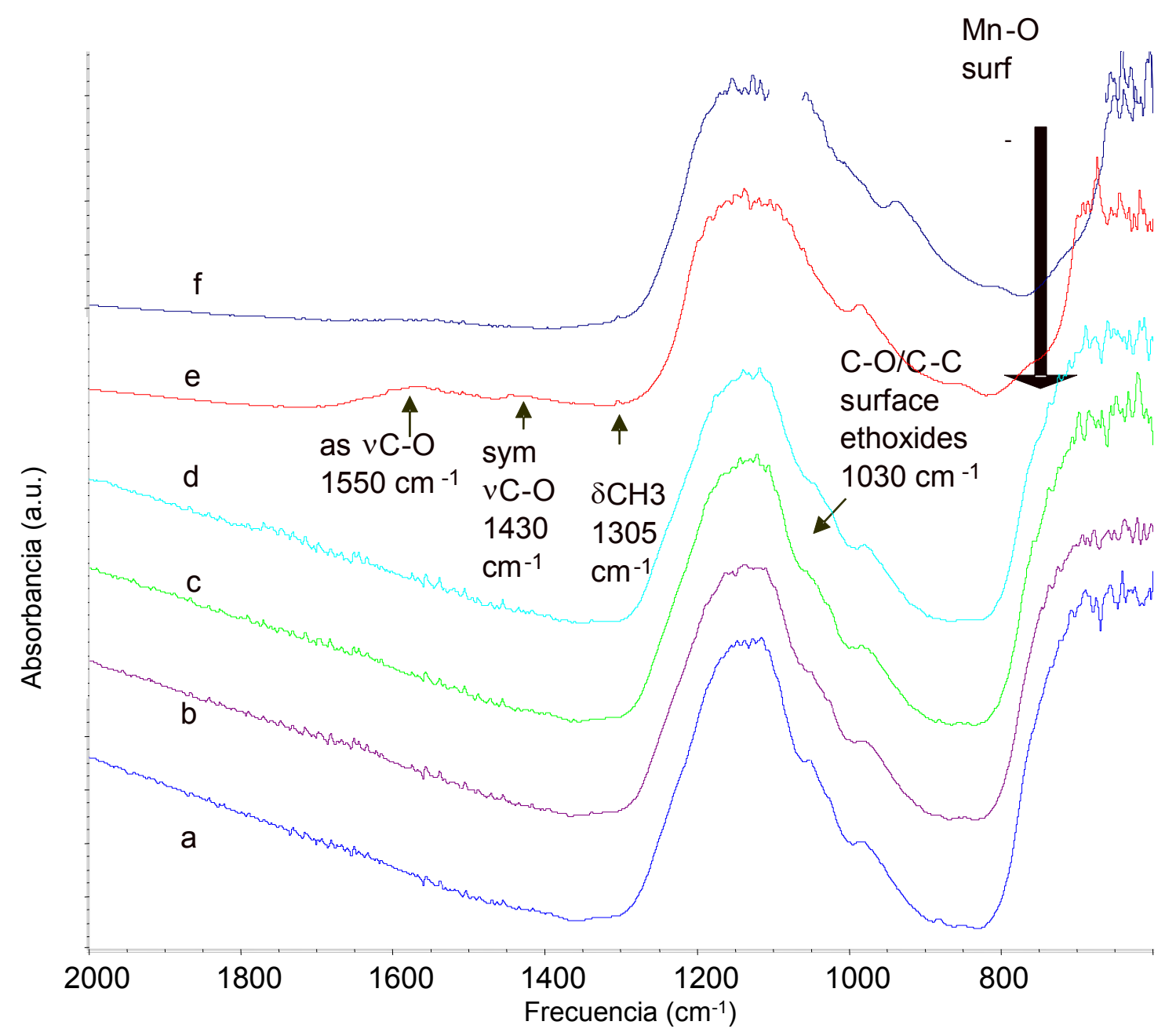

Figura 5.40. Espectros FT IR de especies superficiales derivadas de la adsorción y conversión de etanol sobre catalizador OMR (en presencia de aire) en: (a) $25{ }^{\circ} \mathrm{C}$, (b) 100 ${ }^{\circ} \mathrm{C}$, (c) $200{ }^{\circ} \mathrm{C}$, (d) $300{ }^{\circ} \mathrm{C}$, (e) $400{ }^{\circ} \mathrm{C}$ y (f) $500{ }^{\circ} \mathrm{C}$.

El análisis de la reacción por FTIR puede ser comparada con los resultados de la conversión catalítica de etanol, mostrándose que el etanol puede quemarse de forma 
eficiente sobre este catalizador, pero la reacción debe realizarse a una temperatura mínima de $300{ }^{\circ} \mathrm{C}$ para evitar la formación de acetaldehído, un subproducto VOC no deseado.

Los experimentos de oxidación de etanol llevados a cabo en condiciones estáticas en la celda IR sobre la muestra de $\mathrm{ZnMnR}$, en general, los resultados son similares a los de OMR. Como comparación, puede verse la Figura 5.41 donde se muestran los espectros en fase gaseosa de la oxidación de etanol en ausencia de aire.

Como en la muestra OMR, las bandas a $3600 \mathrm{~cm}^{-1}, 3000-2800 \mathrm{~cm}^{-1} \mathrm{y} 1100-1000 \mathrm{~cm}^{-1}$ son características del vapor de etanol, que corresponden a los modos de estiramiento $\mathrm{OH}$, CH y CC / CO, respectivamente. La formación de acetaldehído $\left(1700 \mathrm{~cm}^{-1}\right.$ y $\left.2700 \mathrm{~cm}^{-1}\right)$ comienza alrededor de $\operatorname{los} 250^{\circ} \mathrm{C}$ en estas condiciones, es decir, unos $50{ }^{\circ} \mathrm{C}$ por encima de la temperatura a la que comienza en la muestra de OMR.

Los resultados señalan que la oxidación de etanol en el aire sobre un óxido de manganeso se produce por la adsorción de etanol y la oxidación a acetaldehído o $\mathrm{CO}_{2}$ en función de la temperatura. Las especies de acetato adsorbido también pueden comportarse como intermedias de reacción y oxidarse directamente a $\mathrm{CO}_{2}$ a alta temperatura. 


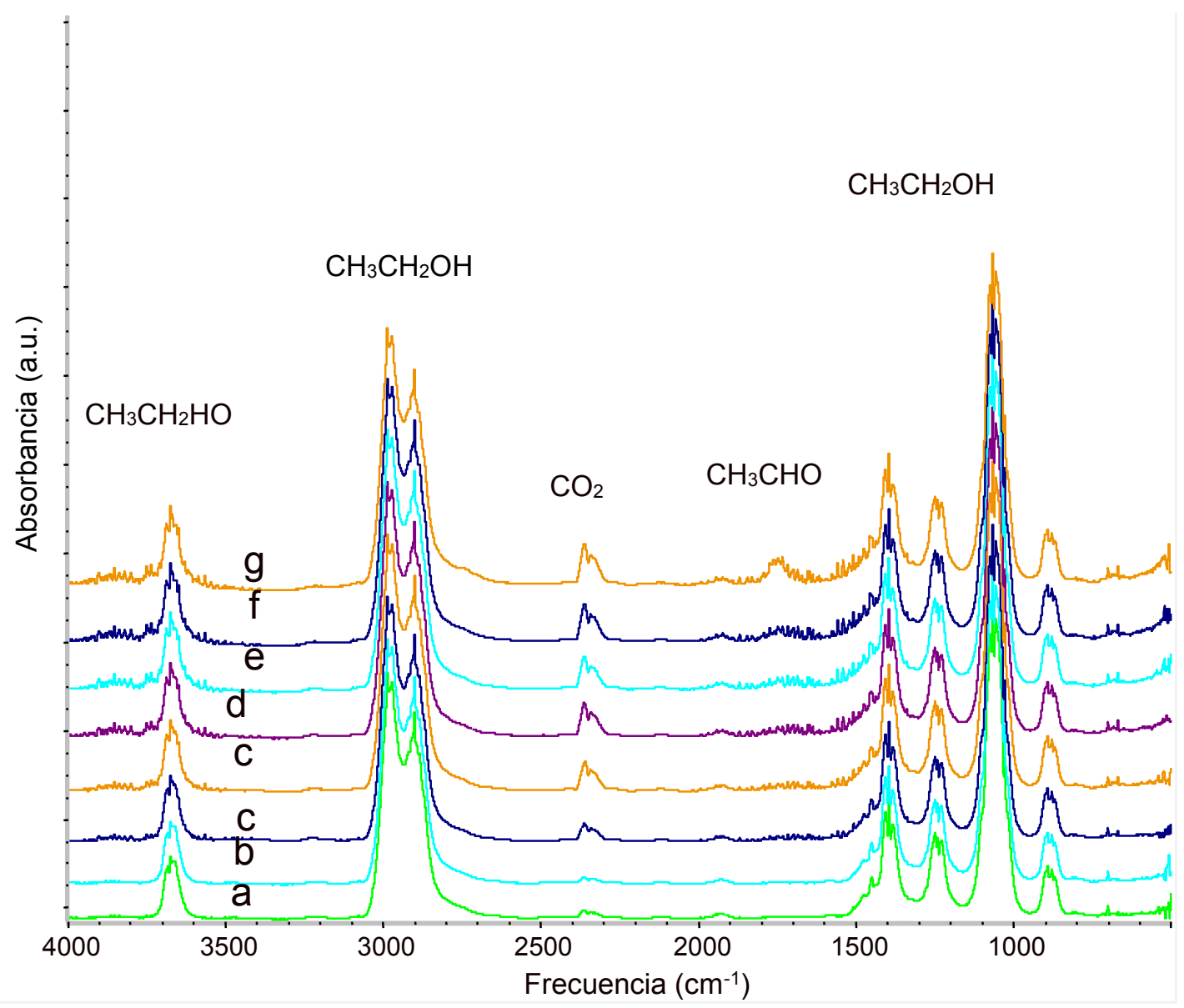

Figura 5.41. Espectros de FT IR de especies en fase gaseosa derivadas de la conversión de etanol sobre catalizador de $\mathrm{ZnMnO}$ (sin aire) a (a) $25^{\circ} \mathrm{C}$, (b) $100^{\circ} \mathrm{C}$, (c) $150{ }^{\circ} \mathrm{C}$, (d) 200 ${ }^{\circ} \mathrm{C}$, (e) $250{ }^{\circ} \mathrm{C}$, (f) $300{ }^{\circ} \mathrm{C}$ y (g) $380{ }^{\circ} \mathrm{C}$. 
A modo de conclusión para la oxidación de etanol en aire sobre estos sólidos puede decirse que los resultados de las pruebas catalíticas y de la espectroscopia IR permiten postular un probable mecanismo de combustión, tal como el que se muestra en el esquema:

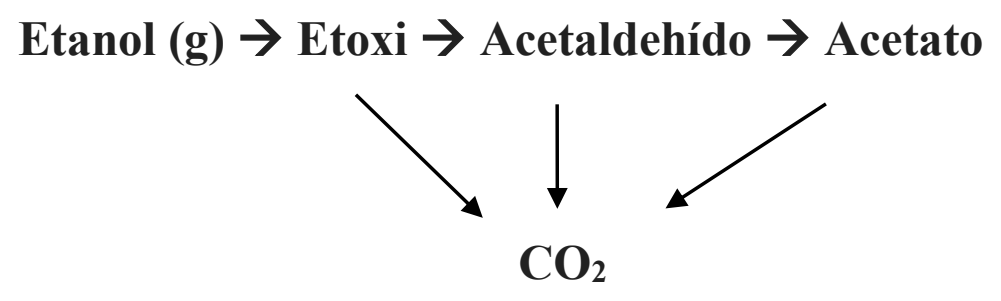

\subsubsection{Estudio FTIR In Situ de la Combustión de Tolueno}

En forma similar se analizó la oxidación de tolueno sobre estos dos sólidos. En la Figura 5.43, se aprecia el espectro IR de la superficie de reacción del catalizador OMR en presencia de aire. Los espectros correspondientes a especies en fase gaseosa se muestran en la Figura 5.44. 


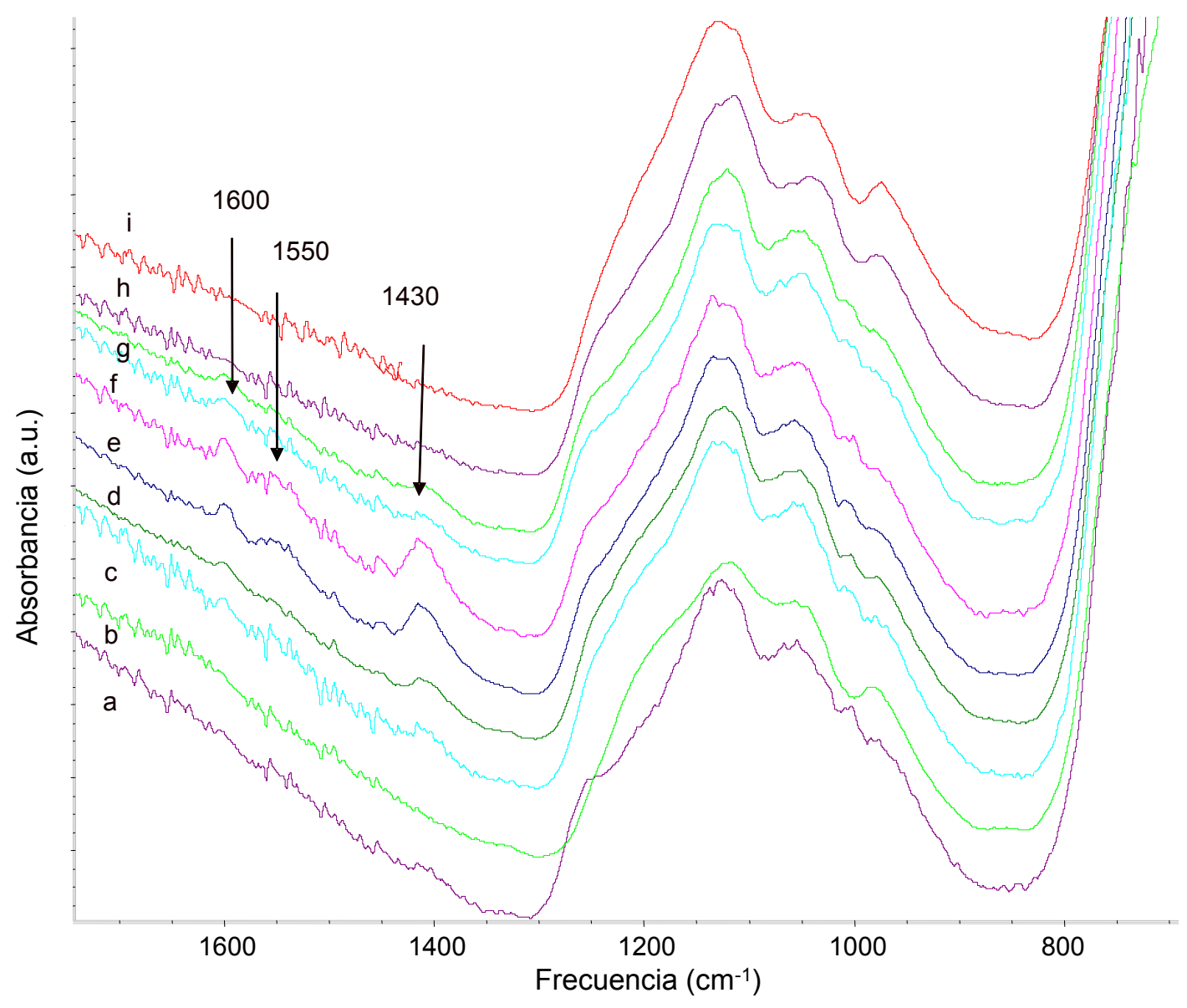

Figura 5.42. Espectro IR FT de las especies superficiales derivadas de la adsorción y conversión de tolueno sobre el catalizador OMR (en presencia de aire): (a) superficie activada, (b) $25^{\circ} \mathrm{C}$, (c) $100^{\circ} \mathrm{C}$, (d) $150{ }^{\circ} \mathrm{C}$, (e) $200{ }^{\circ} \mathrm{C}$, (f) $250^{\circ} \mathrm{C}$, (g) $300{ }^{\circ} \mathrm{C}$, (h) $350^{\circ} \mathrm{C}$, (i) $400{ }^{\circ} \mathrm{C}$ y (j) $500{ }^{\circ} \mathrm{C}$. 


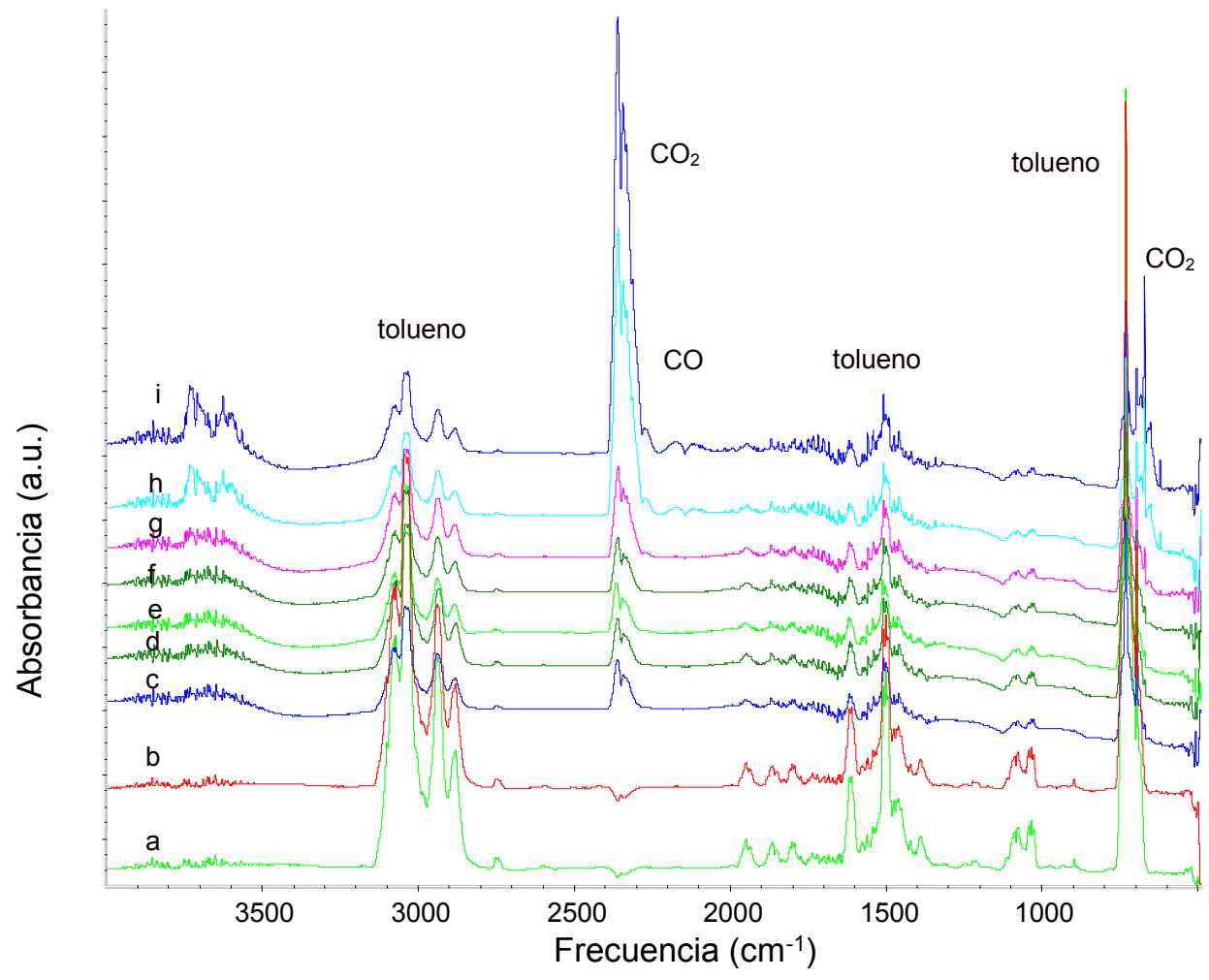

Figura 5.43. Espectros FT IR de especies en fase gaseosa derivadas de la conversión de tolueno sobre OMR (en presencia de aire) a: (a) $25^{\circ} \mathrm{C}$, (b) $100^{\circ} \mathrm{C}$, (c) $150{ }^{\circ} \mathrm{C}$, (d) $200{ }^{\circ} \mathrm{C}$, (e) $250{ }^{\circ} \mathrm{C}$, (f) $300{ }^{\circ} \mathrm{C}$, (g) $350{ }^{\circ} \mathrm{C}$, (h) $400{ }^{\circ} \mathrm{C}$, (i) $500{ }^{\circ} \mathrm{C}$.

En esta figura, la molécula de tolueno se caracteriza por dos grupos de bandas de estiramiento de $\mathrm{CH}$, por encima y por debajo de $3000 \mathrm{~cm}^{-1}$, correspondientes a los modos de estiramiento $\mathrm{CH}$ de $\mathrm{CH}$ aromático y alifático grupos, respectivamente. ${ }^{23}$ Otro grupo de bandas más agudas y más débiles se detectan entre 1450 y $1600 \mathrm{~cm}^{-1}$, debido a los modos vibratorios del anillo. La banda fuerte alrededor de $750 \mathrm{~cm}^{-1}$ es típica del anillo aromático monosustituido. Estas bandas disminuyen ligeramente en intensidad por encima de $250{ }^{\circ} \mathrm{C}$.

23 D. Lin-Vien, N.B. Colthup, W.G. Fateley, J.G. Grasselli, The Handbook of Infrared and Raman Characteristic Frequencies of Organic Molecules, Elsevier (1991) 
El tolueno comienza a convertirse significativamente en $\mathrm{CO}_{2}$ a $300{ }^{\circ} \mathrm{C}$, cuando la banda de $\mathrm{CO}_{2}\left(2350 \mathrm{~cm}^{-1}\right)$ comienza a crecer en los espectros de fase gaseosa. A $400{ }^{\circ} \mathrm{C}$, también se observa CO (banda a $2150 \mathrm{~cm}^{-1}$ ), pero su formación debe estar relacionada con las condiciones de reacción en la celda IR (es decir, alto contenido de COV). No se observan otras especies en la fase gaseosa. Al observar las especies de superficie, las bandas a 1600, 1550 y $1430 \mathrm{~cm}^{-1}$ ya se observan a $150{ }^{\circ} \mathrm{C}$, y su intensidad disminuye progresivamente a partir de $300{ }^{\circ} \mathrm{C}$ (Figura 5.43, g). Estas bandas podrían asignarse a especies de carboxilato (probablemente benzoato ${ }^{24}$, sugiriendo que la conversión de tolueno ocurre primero a través de la oxidación en el grupo metilo, lo que resulta en una fuerte adsorción en el catalizador, seguido por la ruptura del anillo por la combustión a temperaturas más altas (superior a $\left.200{ }^{\circ} \mathrm{C}\right) \mathrm{a} \mathrm{CO}_{2}$ y CO . No se pudo detectar ninguna especie intermedia con menor grado de oxidación, como alcóxidos o aldehídos. Es probable que estas especies se formen, pero a una temperatura a la que se produce inmediatamente una mayor oxidación, como ya se informó en algunos trabajos iniciales sobre la combustión de COV. ${ }^{25}$

La oxidación de tolueno sobre el catalizador ZnMnR se representa en la Figura 5.44. En los espectros de fase gaseosa, aparte de algo de tolueno residual, $\mathrm{CO}_{2}$ y trazas de $\mathrm{CO}$ a las temperaturas más altas, no se detectan otras especies. Aparentemente, sobre este catalizador se forman $\mathrm{CO}_{2}$ y $\mathrm{CO}$ en menor cantidad en comparación con el catalizador OMR (ver Figura 5.43), de acuerdo con pruebas de actividad que evidencian la actividad notablemente más alta de OMR en la oxidación de tolueno.

${ }^{24}$ C.-J. Li, G.-R. Xu, Materials Science and Engineering B 176 (2011) 552-558

${ }^{25}$ E. Finocchio, G. Busca, V. Lorenzelli, R.J. Willey, Journal of Catalysis 151 (1995) 204-215 


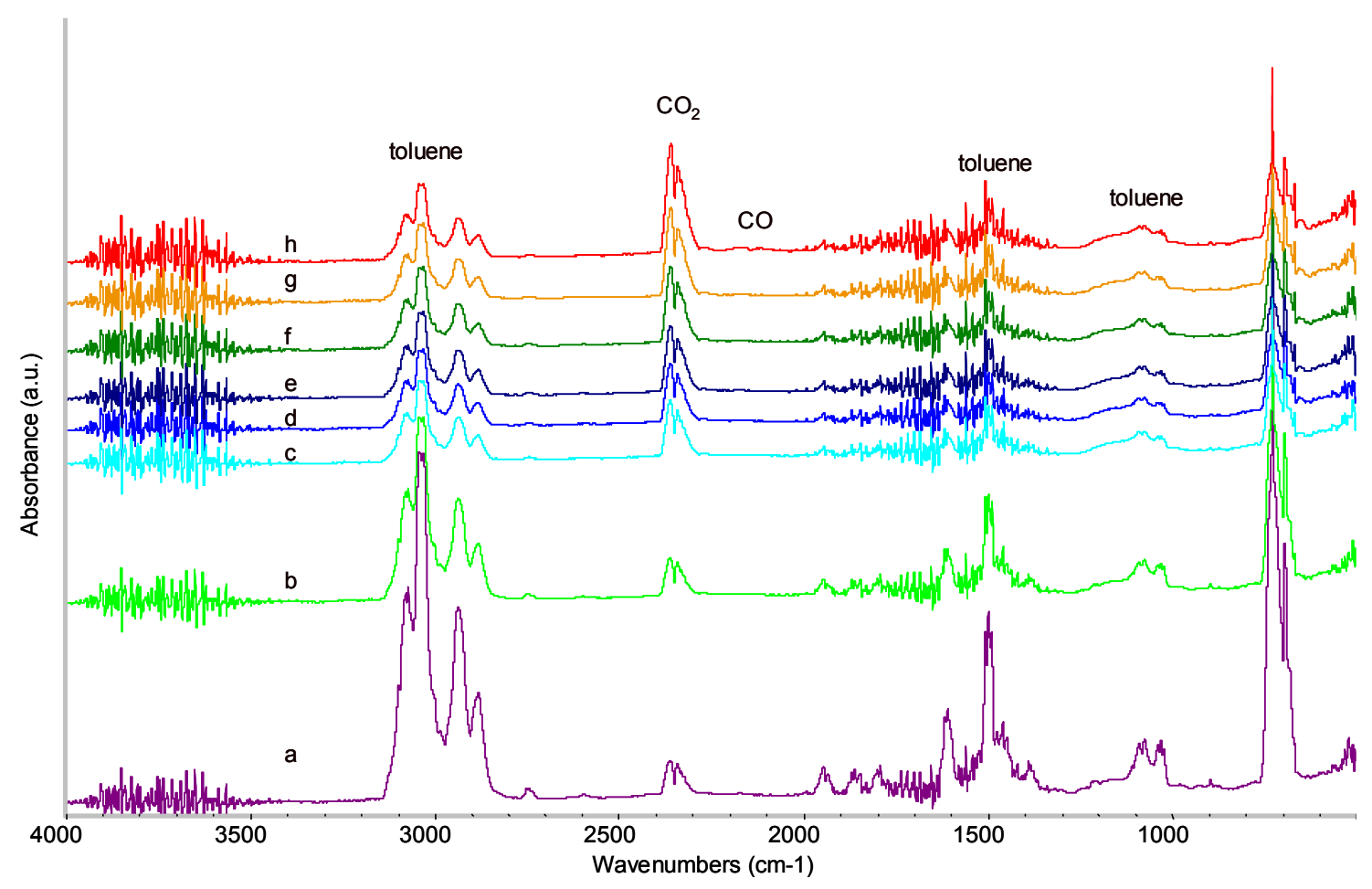

Figura 5.44. Espectro FT IR de las especies en fase gaseosa derivadas de la conversión de tolueno sobre $\mathrm{ZnMnR}$ (en presencia de aire) a: (a) $25^{\circ} \mathrm{C}$, (b) $100{ }^{\circ} \mathrm{C}$, (c) $150{ }^{\circ} \mathrm{C}$, (d) $200^{\circ} \mathrm{C}$, (e) $250{ }^{\circ} \mathrm{C}$, (f) $350{ }^{\circ} \mathrm{C}$, (g) $400{ }^{\circ} \mathrm{C}$ y (h) $500{ }^{\circ} \mathrm{C}$.

Estos resultados están de acuerdo con la conclusión de Sun y col. ${ }^{26}$, que han propuesto que el tolueno se adsorbe como especies de benzoato, tal como se muestra en el esquema siguiente:

${ }^{26}$ H. Sun, Z. Liu, S. Chen, X. Quan, Chemical Engineering Journal 270 (2015) 58-65. 


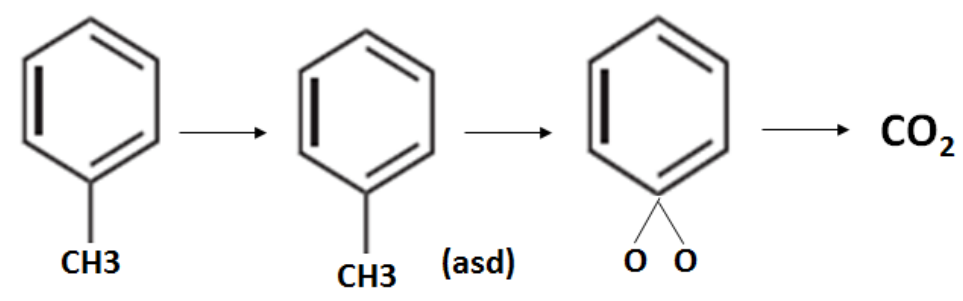

Diferentes autores ${ }^{27,28}$ han demostrado que el tolueno es estable en la superficie de los óxidos de manganeso y la oxidación total se alcanza entre 240 y $300{ }^{\circ} \mathrm{C}$. El catalizador OMR sintetizado en este trabajo, que es un sólido reciclado, alcanza la oxidación completa de tolueno a $250{ }^{\circ} \mathrm{C}$ sin formación de productos de oxidación parcial. Sin embargo debe mencionarse que esta temperatura es un sistema estanco, mientras que los resultados en flujo muestran que a esa temperatura no se llegó al valor del 50\% de conversión.

\subsubsection{Oxidación catalítica de COVs sobre estructuras monolíticas}

\section{Procedimiento experimental.}

La actividad catalítica de los óxidos se midió en la reacción de combustión de tolueno, en exceso de oxígeno. En la Figura 5.45 se representa un esquema del dispositivo utilizado. Se empleó un reactor tubular de acero inoxidable. La parte inferior del reactor se llenó con carborundo para precalentar la mezcla de gases y como soporte para el monolito, el cual queda en el medio del reactor.

${ }^{27}$ H. Sun, S. Chen, P. Wang, X. Quan, Chemical Engineering Journal 178 (2011) 191-196.

${ }^{28}$ S. Bastos, S. Carabineiro, J. Orfao, M. Pereira, J. Delgado, J. Figueiredo, CatalysisToday 180 (2012) 148154. 


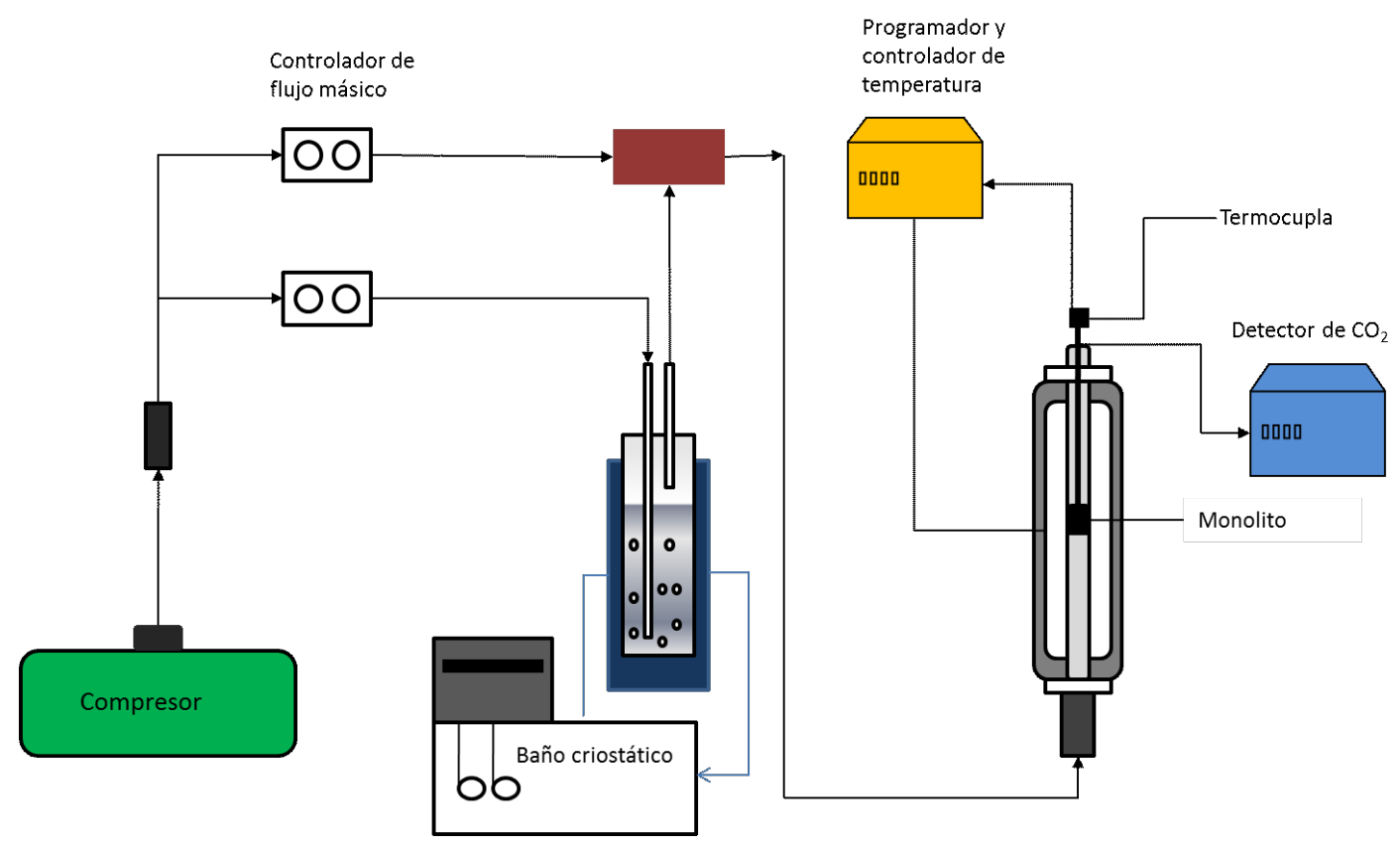

Figura 5.45. Diagrama de flujo del reactor empleado en las medidas de actividad catalítica de los monolitos.

La temperatura dentro del reactor se midió con una termocupla interna en contacto con el monolito. La corriente de alimentación contenía una concentración de $1000 \mathrm{mgC} \mathrm{m}^{-3} \mathrm{de}$ tolueno en aire. Se trabajó en el intervalo de temperatura de 100 a $500{ }^{\circ} \mathrm{C}$, a presión atmosférica y a un caudal de la corriente de tolueno/aire de $1000 \mathrm{~cm}^{3} \mathrm{~min}^{-1}$. Previo a la reacción, se realizó un pretratamiento con aire a $400{ }^{\circ} \mathrm{C}$ durante 1 hora. Durante la reacción se sigue la señal de $\mathrm{CO}_{2}$ monitorizando en continuo la señal de un medidor de $\mathrm{CO}_{2}$ (Telaire T6613) ubicado a la salida del reactor. La conversión $\left(\mathrm{XCO}_{2}\right)$ fue calculada como la relación entre el valor de la concentración de $\mathrm{CO}_{2}$ divido su valor cuando se alcanzó la conversión completa a altas temperaturas. No se encontraron productos de oxidación parcial. 


\section{Curvas de actividad catalítica}

Como se mencionó anteriormente el monolito preparado a partir del sólido reciclado OMR fue comparado con un monolito preparado a partir de sales de $\mathrm{Mn}$ comerciales (Monolito llamado MK).

Los resultados de la actividad catalítica se presentan en la Figura 5.46, observándose una mejor conversión a $\mathrm{CO}_{2}$ en el monolito $\mathrm{MK}$.

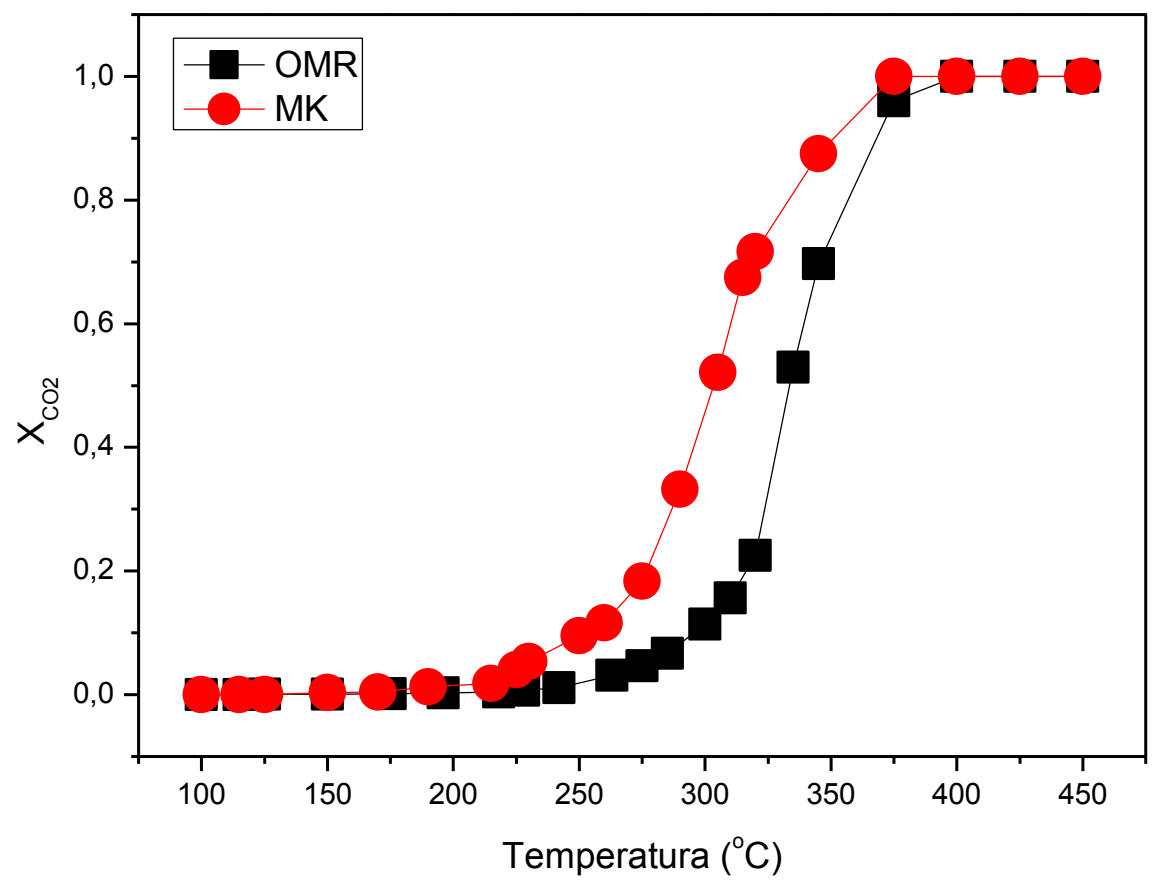

Figura 5.46. Curvas de selectividad a $\mathrm{CO}_{2}$ en la combustión de tolueno.

Estos resultados pueden atribuirse a un aumento en la carga de manganeso del MK respecto del OMR, pero los resultados de la caracterización permiten decir que la presencia de zinc el sólido OMR modifica las propiedades físicoquímicas del sólido, lo cual está asociado a la actividad catalítica. 
A manera de conclusión del estudio de la actividad catalítica puede decirse que los resultados son interesantes desde tanto desde el punto de vista tecnológico como de la valorización de residuos. Las baterías son un desecho peligroso para el medio ambiente y como se ha mostrado por medio de un adecuado reciclado pueden obtenerse materias primas para preparar diferentes óxidos de manganeso, los cuales pueden usarse como catalizadores para la oxidación total de las emisiones de compuestos orgánicos volátiles, logrando de esta forma cerrar el ciclo de vida de los residuos provenientes de pilas alcalinas. 


\section{Capítulo 6}

\section{Modelado Computacional}




\subsection{Métodos Computacionales}

Desde el punto de vista del desarrollo de nuevos materiales catalíticos o de la introducción de mejoras en aleaciones ya existentes, el método usual se basa en un extensivo y costoso trabajo experimental de "prueba y error". Sin embargo, en los últimos años se ha prestado mayor atención al modelado computacional con modernos métodos teóricos.

En principio, el punto de partida de estos métodos son los elementos intervinientes y una razonable información estructural. Se puede así predecir y orientar el diseño de materiales con la asistencia computacional. Existen distintos métodos computacionales con los cuales se pueden simular diferentes sistemas. Estos métodos se pueden dividir en dos grandes grupos:

-Mecánica Molecular: Aplica las leyes de la física clásica al núcleo molecular sin considerar explícitamente a los electrones.

-Mecánica Cuántica: Resuelve la ecuación de Schrödinger para describir una molécula o un sólido con un tratamiento directo de la estructura electrónica. A su vez se subdivide según el tratamiento realizado, en dos clases:

-métodos semi-empíricos, que se basan en formalismos de Hartree-Fock (H-F). Estos cálculos utilizan muchas aproximaciones y parámetros, algunos delos cuales se consideran a partir de resultados experimentales;

-métodos ab-initio ("a primeros principios"), son métodos que no requieren ningún parámetro empírico o semi-empírico para la resolución de las ecuaciones. En este caso, la solución a la ecuación de Schrödinger es una solución aproximada.

No hay un método que sea el mejor para todos los sistemas a estudiar; sin embargo, para una aplicación determinada, cada método posee ventajas y desventajas que son 
necesarias conocer. La elección del método lleva a la evaluación de una serie de factores tales como: naturaleza del sólido que se pretende estudiar, tipo de información que se desea obtener, disponibilidad para poder aplicar parámetros experimentales determinados (ya que algunos de los métodos así lo requieren) y recursos computacionales.

Para los cálculos se utilizó el programa $\mathrm{VASP}^{1}$, el cual permite encontrar de manera autoconsistente la densidad electrónica del sistema en estudio. Además, posibilita optimizar la estructura geométrica del sistema; en otros términos, se puede obtener la "estructura relajada" del mismo

En este capítulo se presentan y discuten los resultados obtenidos mediante cálculos computacionales basados en la teoría del funcional de la densidad:

- $\mathrm{ZnO}$ perfecto y con defectos tipo-vacancia de Oxígeno $\left(\mathrm{V}_{\mathrm{O}}\right)$ con estado de carga $q(q=0,+2)$.

- $\mathrm{MnO}_{2}, \mathrm{KMnO}_{2}$ (tipo holandita) y $\mathrm{KMnO}_{2}+\mathrm{Zn}$, donde el $\mathrm{Zn}$ reemplaza a $\mathrm{Mn}$.

En todos los sistemas estudiados, se calcularon:

- Parámetros de red y distancia de enlace atómicas.

- Curvas de densidad totales (TDOS) y proyectadas (PDOS).

- Transferencia electrónica entre los átomos,

- Energía del Band gap ( $\left.\mathrm{E}_{g a p}\right)$.

- Corrimiento del nivel de Fermi respecto de la bandas de valencia (BV) y conducción $(\mathrm{BC})$.

- Momento magnético.

\footnotetext{
${ }^{1}$ G. Kresse, D. Joubert. Physical Review B 59 (1999) 1758
} 


\subsection{Detalles de Cálculo para $\mathrm{ZnO}$}

Basados en resultados experimentales ${ }^{2}$ se consideró una relajación total de la estructura $\mathrm{ZnO}$, es decir todos los grados de libertad de la celda fueron dejados libres, incluyendo un posible cambio de volumen y forma de la misma. Para las relajaciones se usó el algoritmo de gradiente conjugado hasta que la fuerza Hellman-Feynman sobre cada uno de los átomos relajados fuese menor a $0.01 \mathrm{eV} / \AA$. El criterio de convergencia usado para los cálculos de los sistemas, tanto para la estructura estática como la relajada, consistió en considerar que entre pasos consecutivos la diferencia en energía superase los $10^{-4} \mathrm{eV}$. Se utilizó la corrección DFT+U solamente para los átomos de $\mathrm{Zn}$ con el método propuesto por Dudarev et al. ${ }^{3}$ Utilizando valores de convergencia $\mathrm{U}=6 \mathrm{y}$ $\mathbf{J}=0$. Para describir los elementos que conforman el óxido de zinc se recurrió al uso del pseudo-potencial PAW con las siguientes configuraciones electrónicas:

- $\mathrm{Zn}: d^{10} p^{2}$

- $\mathrm{O}: s^{2} p^{4}$

Para modelar la estructura de $\mathrm{ZnO}$ perfecto y con vacancias se utilizó una súpercelda con los siguientes parámetros de red, $a=b=10.05 \AA, c=5.22$ y $\beta=120^{\circ}$, basados en datos de literatura ${ }^{4}$. La súper-celda se construyó con 36 átomos, es decir $\mathrm{Zn}_{18} \mathrm{O}_{18}$, tal como se muestra en la Figura 6.1. La vacancia de oxígeno $\left(\mathrm{V}_{\mathrm{O}}\right)$ se generó removiendo un átomo de oxígeno del centro de la celda, de esta manera se asegura que no interactúe con su imagen periódica, colocando el estado de carga en el lugar de la vacancia.

2 Zinc Oxide: Fundamentals, Materials and Device Technology. HadisMorkoç and ÜmitÖzg€ur Copyright_2009 WILEY-VCH Verlag GmbH \& Co. KGaA, Weinheim

3 S.L. Dudarev, G.A. Botton, S.Y. Savrasov, C.J. Humphreys, A.P. Sutton, Physical Review B 57(1998) 1505. 


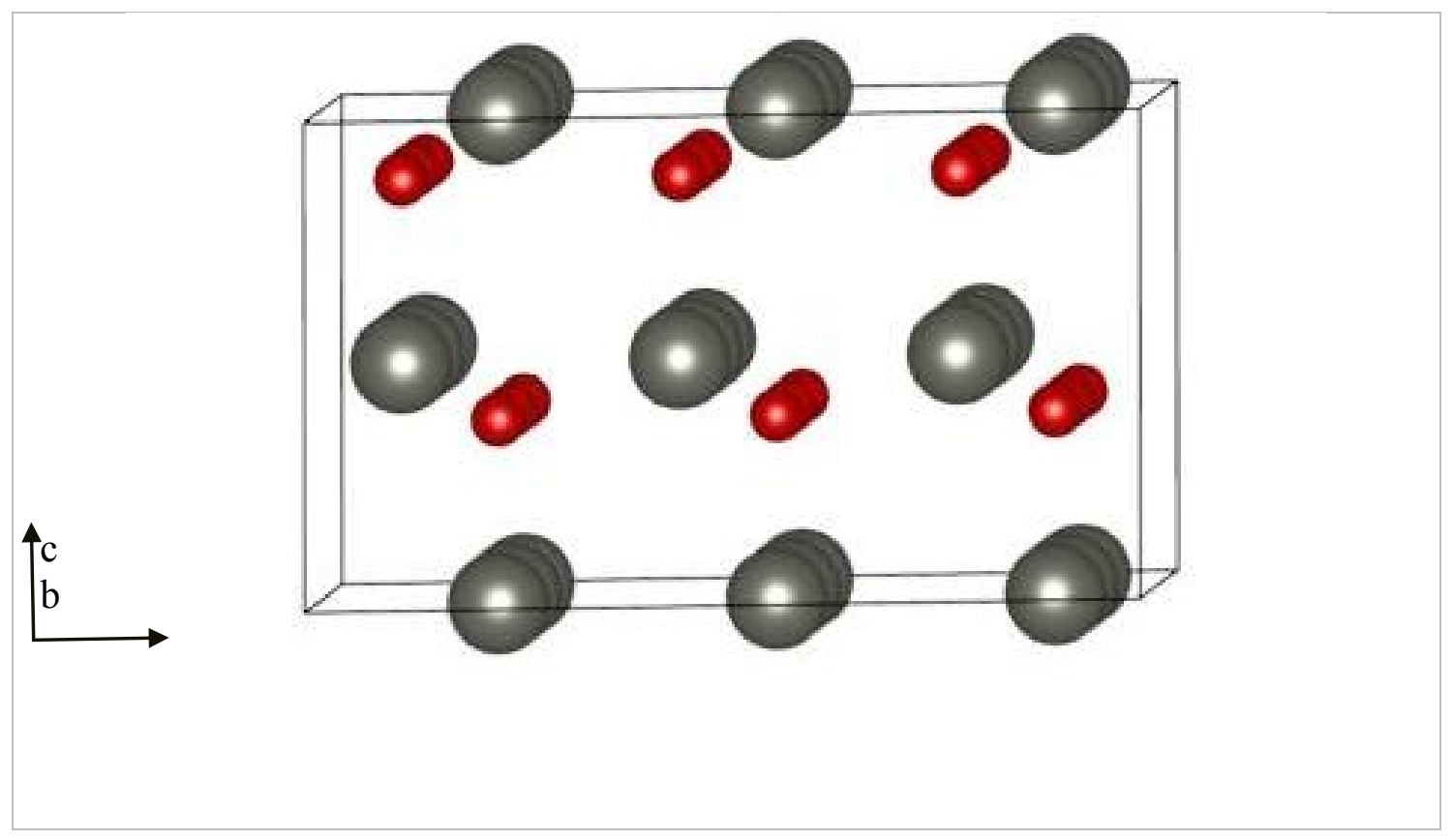

Figura 6.1. Súper-celda con los siguientes parámetros de red: $a=b=10.05 \AA, c=5.22 \mathrm{y}$

$$
\beta=120^{\circ}
$$

\subsection{Resultados}

\subsection{1 $\mathrm{ZnO}$ perfecto}

En la Tabla 6.1 se reportan los resultados obtenidos junto a los hallados en bibliografía de los parámetros de red, momento magnético $(\mu)$, Energía del band gap $\left(\mathrm{E}_{g a p}\right)$, distancia del nivel de Fermi respecto a la banda de valencia y conducción, $\Delta \mathrm{BV}$ y $\triangle \mathrm{BC}$.

Los resultados obtenidos muestran un buen acuerdo con los reportados, tanto teóricos como experimentales. Los parámetros de red muestran una pequeña subestimación respecto a resultados experimentales y teóricos reportados por otros autores. 
Tabla 6.1. Parámetros de red, momento magnético $(\mu)$, band gap $\left(E_{g a p}\right)$, distancia del nivel de Fermi respecto al banda de valencia y conducción, $\Delta \mathrm{VB}$ y $\Delta \mathrm{CB}$ respectivamente para bulk $\mathrm{ZnO}$.

\section{ZnOperfecto}

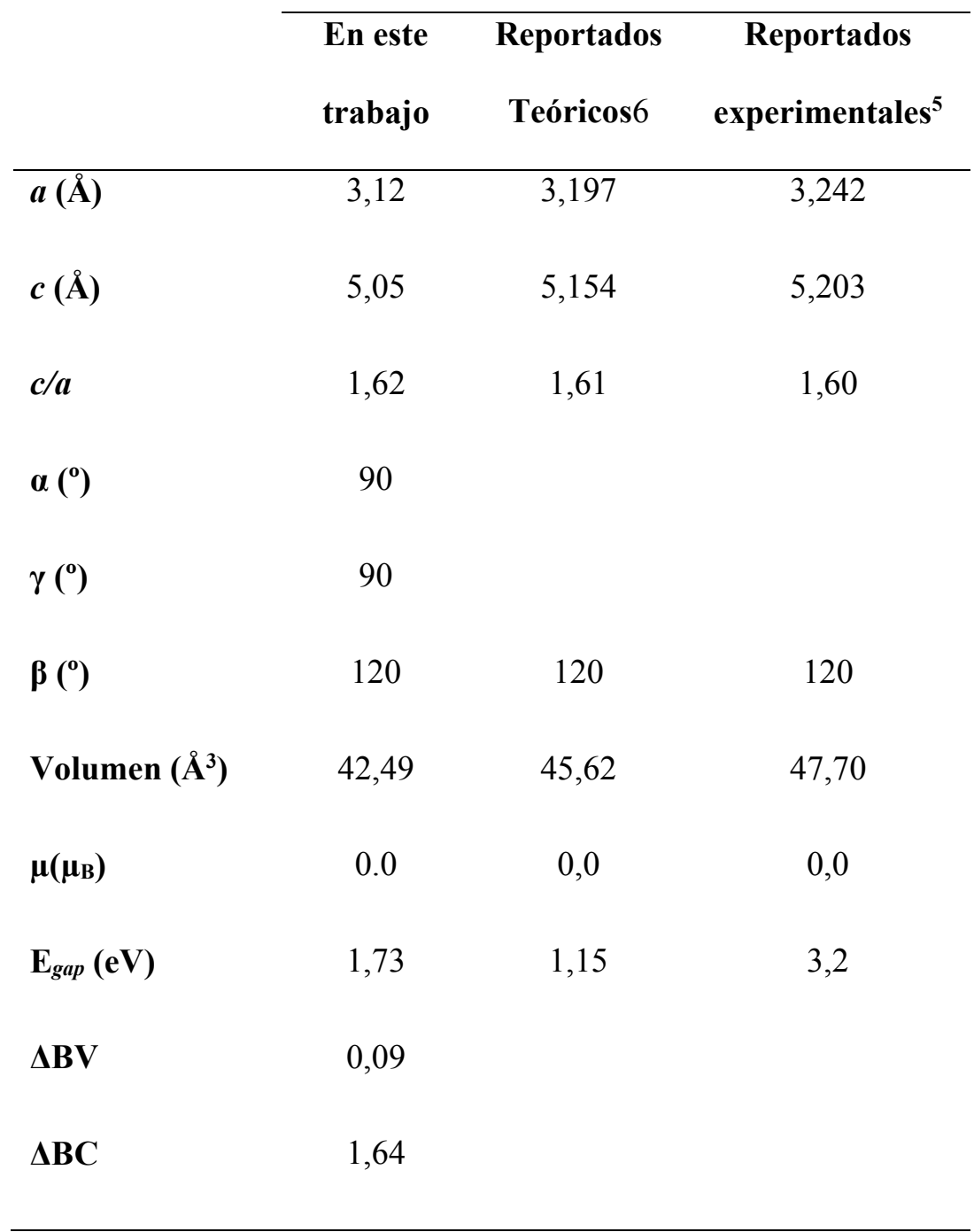

El valor de banda prohibida que se obtuvo $\left(\mathrm{E}_{\text {gap }}\right)$ es un $45 \%$ menor respecto al obtenido en un trabajo previo ${ }^{5}$, pero más cercano al experimental si se compara con otros resultados teóricos los cuales muestran una diferencia del $64 \%{ }^{6}$ Esta

\footnotetext{
${ }^{5}$ M. Gallegos, M. Peluso, H. Thomas, J. Sambeth, L. Damonte, Journal of Alloys and Compounds 689 (2016) 416- 424

${ }^{6}$ M.K. Yaakob, N.H. Hussin, M.F.M. Tab, T.I. Kudin, O.H. Hasson, A.M. Ali, M.Z. Yahya, Integrated Ferroelectrics 155(2014) 15-22.
} 
subestimación en $\mathrm{E}_{g a p}$ se debe a que la banda prohibida que se calcula desde el formalismo Kohn-Sham implementada con DFT en general subestima los band gaps de algunos aislantes y semiconductores. ${ }^{7}$

En la Figura 6.2 se muestra la estructura optimizada de $\mathrm{ZnO}$. Se puede notar que las distancias de enlaces Zn-O, Zn-Zn y O-O son 1,91; 3,11 y 3,10 Å respectivamente.

De acuerdo al análisis de carga los átomos de Zn quedan con carga positiva, mientras que los oxígenos presentan estado de carga negativa. De aquí se desprende el hecho de que se estudie una vacancia de oxígeno positiva, y no con estado de carga negativa.

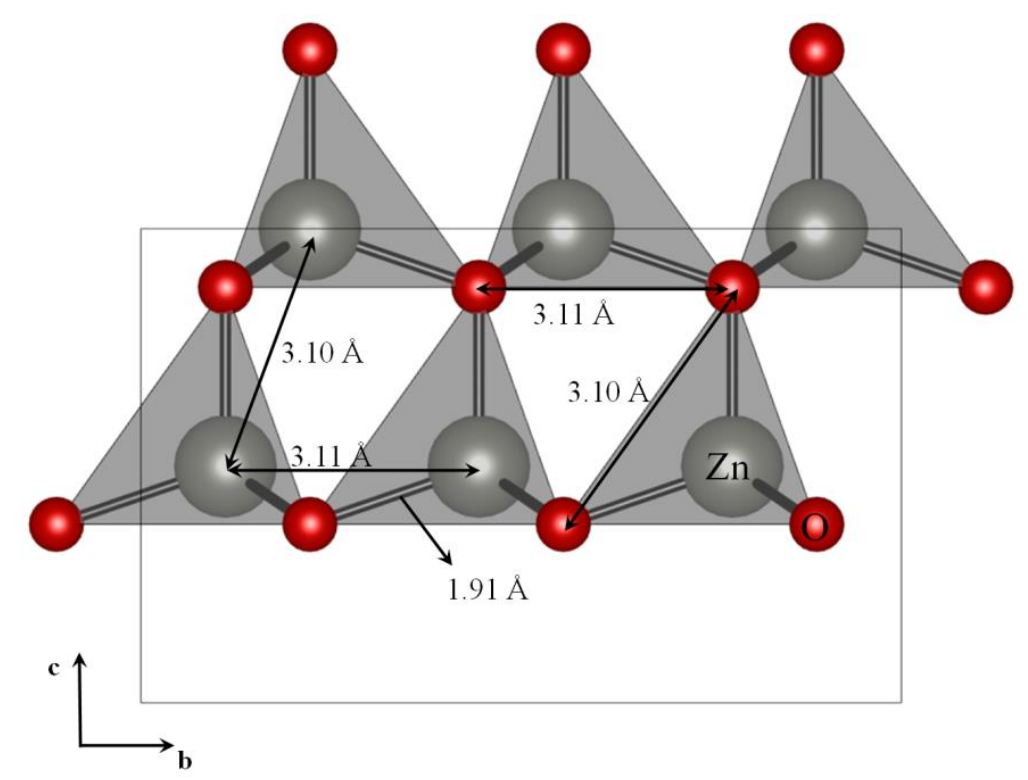

Figura 6.2. Estructura optimizada de $\mathrm{ZnO}$.

En la Figura 6.3 se presentan las curvas DOS totales y proyectadas del sistema $\mathrm{ZnO}$. En estas curvas, el oxígeno participa con sus electrones tipo $p$, mientras que el Zn lo hace con los electrones $d$ principalmente. En este grafico se observa un comportamiento típico de un semiconductor $p$, debido a que el nivel de Fermi se

${ }^{7}$ P.J. Hasnip, K. Refson, M.I. Probert, J.R. Yates, S.J. Clark, C.J. Pickard, Philosophical Transactions of The Royal Society A 372 (2014) 1-26 
encuentra cercano a la banda de valencia. El comportamiento de la densidad de estados total es consistente con lo reportado por Yaakob y col. ${ }^{6}$ La simetría entre los contribuciones espín "up" y “down” de la TDOS es consistente con el momento magnético nulo obtenido.

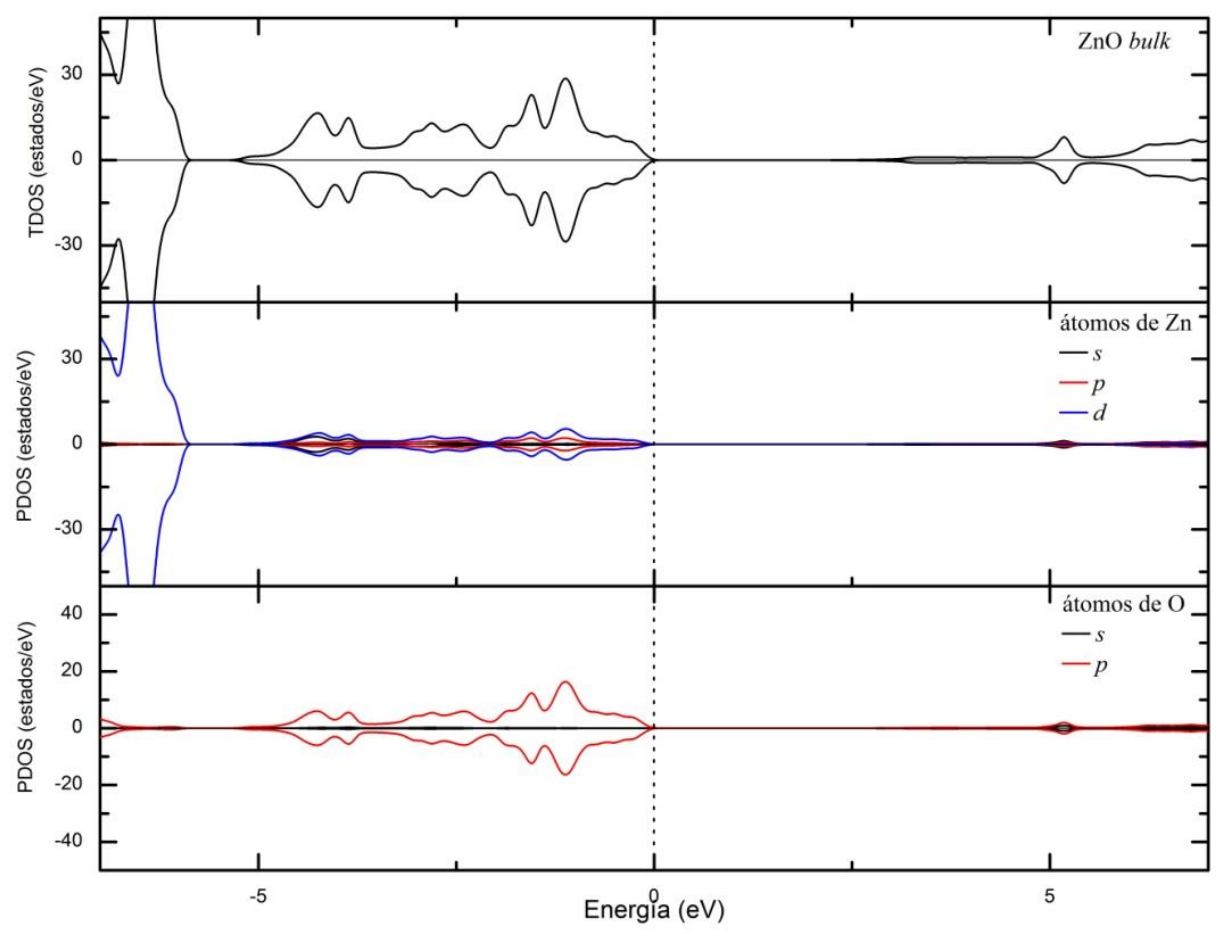

Figura 6.3. Densidad de estados total (TDOS) para ZnO perfecto. Densidad de estados proyectada (PDOS) para los átomos de Zn y O. La línea punteada corresponde al nivel de Fermi.

\subsubsection{Vacancia de $\mathrm{O}$ en $\mathrm{ZnO}$}

Cuando se estudió la vacancia de oxígeno $\left(\mathrm{V}_{\mathrm{O}}\right)$ se consideraron dos tipos de carga $q 0,+2$. La energía de formación $\left(\mathrm{E}_{\text {form}}\right)$ de una vacancia con estado de carga $\mathrm{q}$, se calculó de acuerdo a la siguiente ecuación.

$$
E_{\text {form }}=E\left(V_{O^{q}}^{q}\right)-E_{\text {sist }}+\sum n_{i}\left(\mu+E_{\text {refi }}\right)+q\left(E_{f}+E_{v}+\Delta V\right)
$$


Donde $\mathrm{E}\left(\mathrm{V}_{\mathrm{O}}{ }^{\mathrm{q}}\right)$ es la energía del sistema con la vacancia, $\mathrm{E}_{\text {sist }}$ es la energía del sistema perfecto, $\mathrm{n}_{\mathrm{i}}$ es el número de átomos removidos, $\mu$ el potencial químico, $\mathrm{E}_{\mathrm{f}}$ es el nivel de Fermi referido a la última capa de la banda de valencia (Ev) y $\Delta \mathrm{V}$ es la corrección con de Ev con respecto a un estado ideal.

En la Figura 6.4 se muestra la energía de formación $\left(E_{\text {form }}\right)$ en función del nivel de Fermi $\left(\mathrm{E}_{\mathrm{f}}\right)$ en la región del "band gap". El límite inferior corresponde $\left(\mathrm{E}_{\mathrm{f}}=0\right)$ al último estado ocupado de la banda de valencia, mientras que el límite superior está asociado al primer estado desocupado de la banda de conducción. En primer lugar, observamos que la energía de formación del $\mathrm{V}_{\mathrm{O}}{ }^{0}$ es bastante alta, $3.08 \mathrm{eV}$, mientras que en el caso $\mathrm{deV}_{\mathrm{O}}{ }^{2+}$ es $2.14 \mathrm{eV}$. Los valores anteriores se calcularon en el nivel de Fermi intrínseco $(1.5 \mathrm{eV})$, lo que indica que la concentración de $\mathrm{V}_{\mathrm{O}}{ }^{0}$ siempre será baja bajo condiciones de equilibrio. La Figura 6.4 muestra que el nivel de transición 2+/0 se produce a $1 \mathrm{eV}$ por debajo de la banda de conducción.

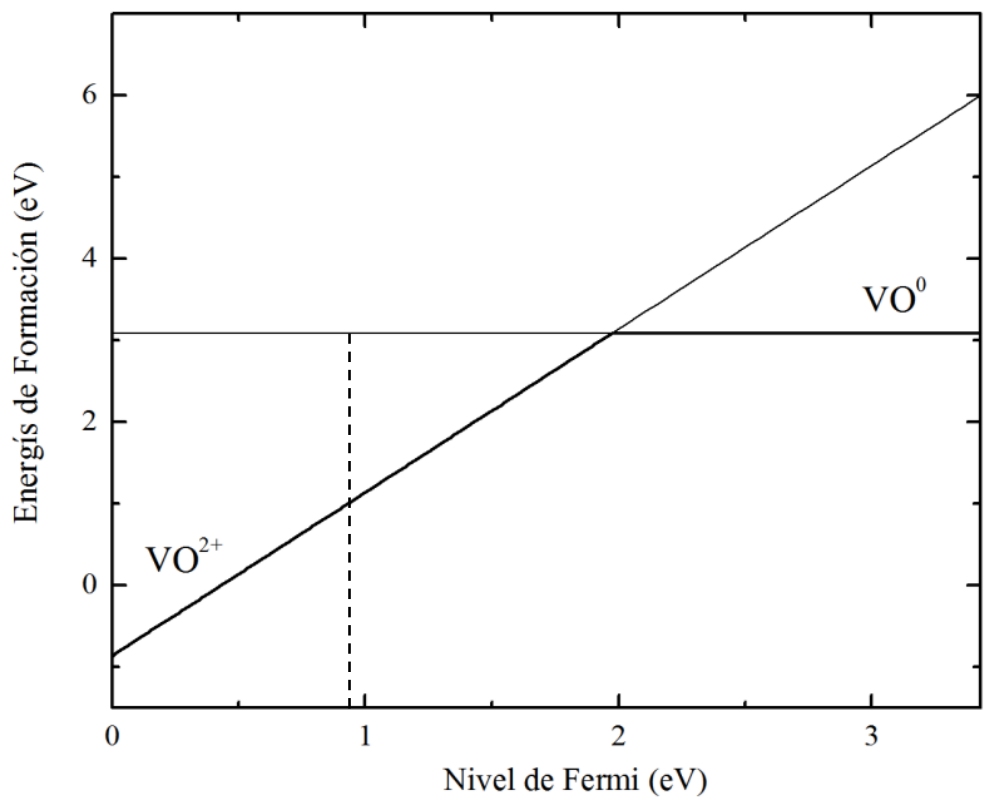

Figura 6.4. Energía de Formación en función del nivel de Fermi. 
En la Figura 6.5 se muestran las estructuras cristalinas de $\mathrm{ZnO}$ perfecto y con vacancias. Los resultados indican que los cambios en la red cristalina dependen de la carga de la vacancia generada. En el caso de $\mathrm{V}_{\mathrm{O}}{ }^{0}$ se produce un desplazamiento hacia el interior de los átomos de $\mathrm{Zn}$, mientras que cuando se trata de una vacancia doblemente cargada es hacia el exterior.
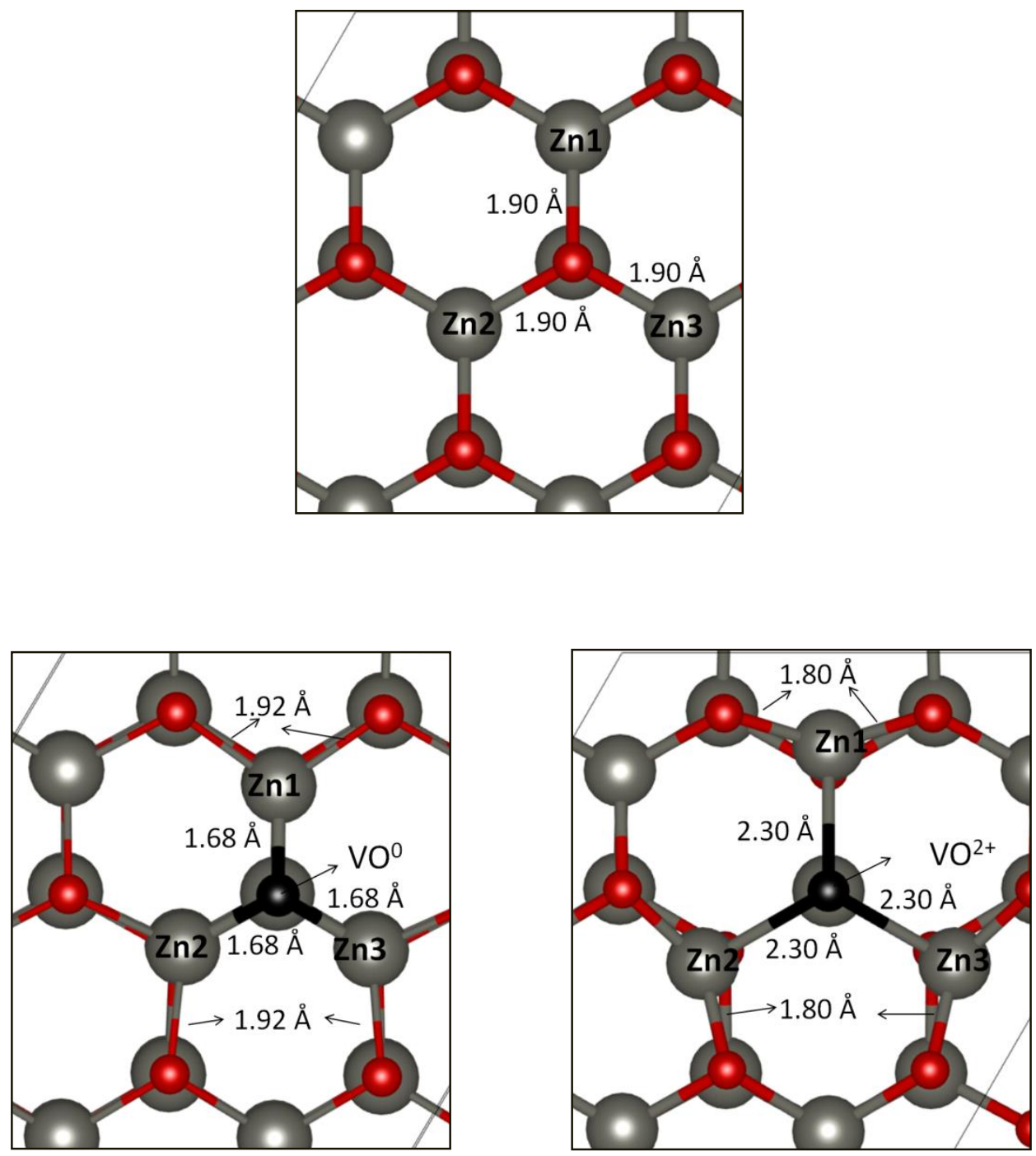

Figura 6.5. Estructura cristalina de $\mathrm{ZnO}$ : (a) sin vacancias, (b) $\mathrm{VO}^{0}$ y (c) $\mathrm{VO}^{2+}$ 
En la Tabla 6.2 se muestran los parámetros calculados para el $\mathrm{ZnO}$ perfecto y con vacancias de oxigeno $\left(\mathrm{V}_{\mathrm{O}}{ }^{0} \mathrm{y} \mathrm{VO}^{2+}\right)$.

Tabla 6.2. Parámetros de red en las celdas con vacancia de oxígeno.

\begin{tabular}{|c|c|c|c|}
\hline \multirow{2}{*}{ parámetro } & \multicolumn{3}{|c|}{ Sistema } \\
\hline & bulk & $\mathrm{V}_{\mathrm{O}}{ }^{0}$ & $\mathrm{~V}_{\mathrm{O}}^{2+}$ \\
\hline$a(\AA)$ & 3,12 & 3,10 & 3,10 \\
\hline$c(\AA)$ & 5,05 & 4,99 & 5,00 \\
\hline$c / a$ & 1,62 & 1,61 & 1,61 \\
\hline$\alpha\left(^{\circ}\right)$ & 90 & 90 & 90 \\
\hline$\beta\left(^{\circ}\right)$ & 90 & 90 & 90 \\
\hline$\gamma\left({ }^{\circ}\right)$ & 120 & 120 & 120 \\
\hline Volumen $\left(\AA^{3}\right)$ & 42,49 & 41,52 & 41,64 \\
\hline$\mu\left(\mu_{\mathrm{B}}\right)$ & 0,0 & 0,0 & 0,0 \\
\hline $\begin{array}{l}\mathrm{E}_{g a p 1} / \mathrm{E}_{\text {gap } 2} \\
(\mathrm{eV})\end{array}$ & 1,73 & $0,46 / 2,35$ & 1,20 \\
\hline$\Delta \mathrm{BV}$ & 0,09 & 0,00 & 0,09 \\
\hline$\triangle \mathrm{BC}$ & 1,64 & 2,35 & 1,11 \\
\hline
\end{tabular}

Los resultados muestran que la presencia de vacancias de oxigeno conduce a una disminución en los parámetros de red de la celda. Esta tendencia es consistente con los resultados mostrados en el Capítulo 5, sección 2 (Tabla 6). El sólido OZnO (CZnO) presenta una reducción de $1.23 \%$ (1.8\%) para el parámetro de celda $a$ y $0.4 \%(0.8 \%)$ para el $c$ con respecto a $\mathrm{ZnOc}$, el cual fue considerado como referencia. 
A partir de lo anterior podría suponerse una diferencia en la concentración de vacancias presentes en los sólidos recuperados de pilas alcalinas agotadas (OZnO y $\mathrm{CZnO})$.

Respecto al valor de $\mathrm{E}_{\text {gap }}$, se observan variaciones que dependen del estado de carga de la vacancia. La presencia de $\mathrm{V}_{\mathrm{O}}{ }^{2+}$ provoca una disminución en $\mathrm{E}_{\text {gap }}$, mientras que $\mathrm{V}_{\mathrm{O}}{ }^{0}$ genera un aumento de dicho valor, estos resultados teóricos coinciden con los encontrados en el Capítulo 5, Sección 2. El análisis de DRS UV-Vis para los sólidos recuperados $(\mathrm{OZnO}$ y $\mathrm{CZnO})$, presenta un aumento a longitudes de onda mayores con respecto a ZnOc indicando una disminución de Egap (Figura 5.26 y Tabla 7).

En la Figura 6.6 se muestran las densidades de estado total (TDOS) para el sistema con vacancias, neutra $\left(\mathrm{V}_{\mathrm{O}}{ }^{0}\right)$ y positiva $\left(\mathrm{V}_{\mathrm{O}}{ }^{2+}\right)$. No se presentan los estados s del oxígeno y $s$ y $p$ del Zn, debido a su baja contribución a la densidad de estados total. La interacción entre $\mathrm{Zn}$ y O se produce a través de electrones tipo $d$ y $p$ respectivamente, de la misma manera que ocurre en el cristal perfecto. Si se compara con la densidad de estados total del sistema perfecto (Figura 6.2) se observa que la incorporación de vacancias genera estados en la región del "band gap". Para el caso neutro puede verse la aparición de pequeños estados trampa entre la banda de valencia y el nivel de Fermi.

En ambos casos se observa una simetría entre las contribuciones espín "up" y "down" de las curvas indicando que este defecto no induce momento magnético al sistema. 


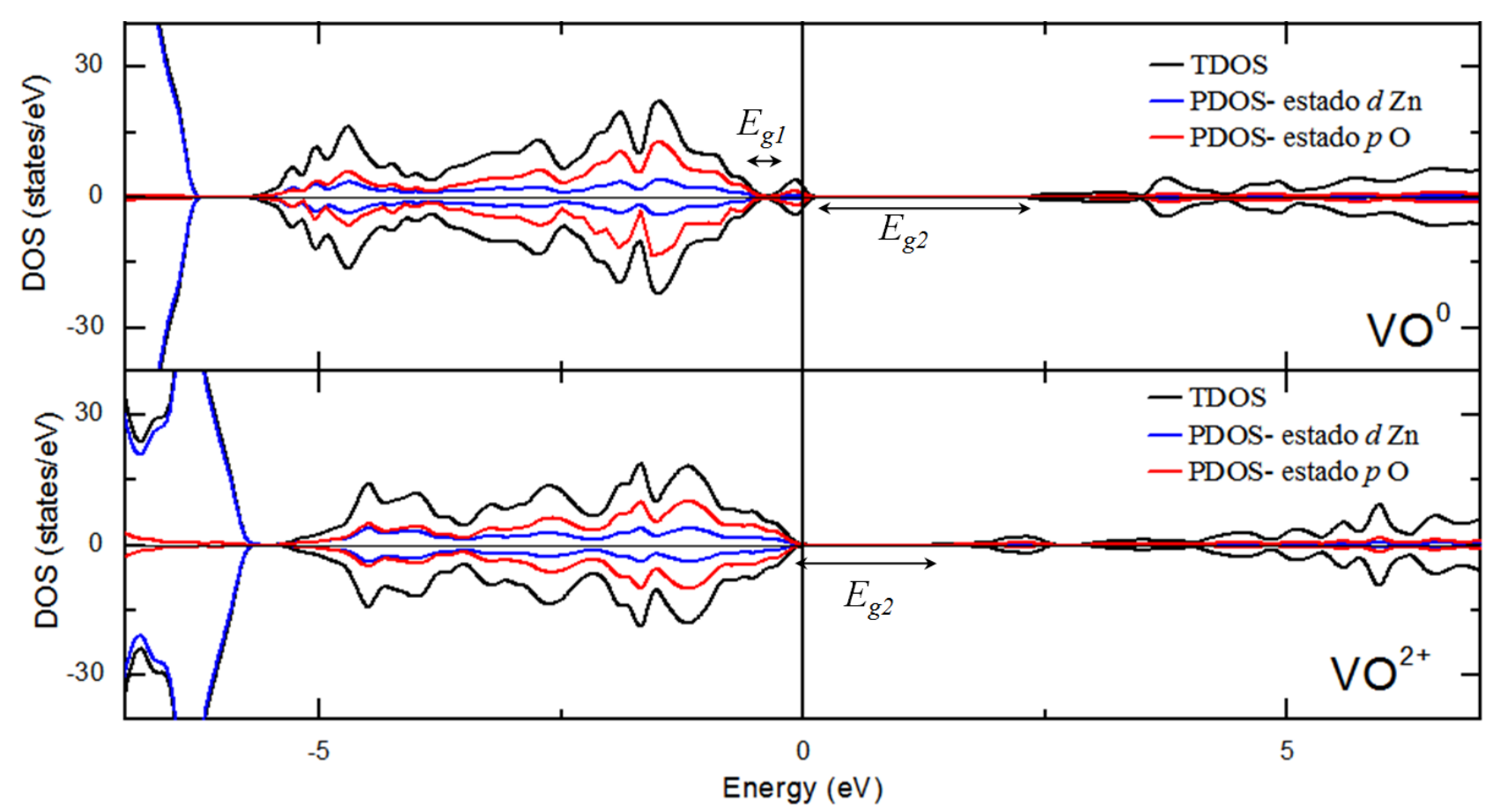

Figura 6.6. DOS total (TDOS) para $\mathrm{ZnO}$ con vacancias neutra $\left(\mathrm{V}_{\mathrm{O}}{ }^{0}\right)$ y positiva $\left(\mathrm{V}_{\mathrm{O}^{2+}}\right)$ 


\subsection{Cálculos DFT en sistemas Mn-O. Estudio de parámetros de red, densidad de estados y magnetismo del sistema perfecto y con Zn sustitucional}

\subsubsection{Modelado de óxidos de manganeso}

Como primer paso se optimizó la geometría de la estructura $\alpha \mathrm{MnO}_{2}$ monoclínica. En el Capítulo 5, sección 2 se analizaron los diagramas de difracción de Rayos X del sólido OMR, encontrándose picos correspondientes a $\alpha \mathrm{MnO}_{2}$ (holandita), esta estructura se denominó KMnO. Experimentalmente se observó la presencia de Zn en el sólido OMR, en una relación $\mathrm{Mn} / \mathrm{Zn}$ 2,5. Con el objetivo de determinar los sitios que ocupa este ion en la estructura cristalina se analizó el espectro XANES en el borde K del $\mathrm{Zn}$, este análisis sugirió que probablemente se encuentran coordinados octaédricamente. A partir de estos resultados se reemplazaron átomos de Mn por Zn, en una relación similar a la experimental $(\mathrm{KMnZnO})$.

Se recurrió al uso del pseudo-potencial PAW con las siguientes configuraciones para los electrones de valencia:

- $\mathrm{Zn}: d^{10} p^{2}$

- $\mathrm{Mn}: d^{5} s^{2}$

- $\mathrm{K}: s^{1}$

- $\mathrm{O}: s^{2} p^{4}$

Basados en resultados experimentales se consideró una relajación total de las estructuras, es decir todos los grados de libertad de la celda fueron dejados libres, incluyendo un posible cambio de volumen y forma de la misma. Para las relajaciones se usó el algoritmo de gradiente conjugado hasta que la fuerza Hellman-Feynman sobre 
cada uno de los átomos relajados fuese menor a $0,01 \mathrm{eV} / \AA$. El criterio de convergencia usado para los cálculos de los sistemas, tanto para la estructura estática como la relajada, consistió en considerar que entre pasos consecutivos la diferencia en energía superase los $10^{-4} \mathrm{eV}$. Debido a que el ion $\mathrm{Mn}^{4+}$ presenta propiedades magnéticas, es crucial incluir estos efectos en estudios de estructura electrónica de óxidos de manganeso. Para poder tener en cuenta este hecho se usó la aproximación DFT + U, donde los valores de $\mathrm{U}$ y $\mathrm{J}$ fueron 2,8 y 1,2 , respectivamente.

\subsection{Resultados}

Los parámetros de red obtenidos se muestran en la Tabla 6.3; se observa que la presencia de iones $\mathrm{K}$ y $\mathrm{Zn}$ conduce a cambios geométricos. En todos los sistemas estudiados se observó un aumento en los paramentos $b, c$ y $\beta$, mientras que $a$ disminuye su valor con la incorporación de $\mathrm{K}$ y aumenta en presencia de $\mathrm{Zn}$. Los resultados obtenidos son comparables con los reportados por Espinal y col, $a=9,8394 ; b=2,856$; $c=9,790^{8}$, para una estructura de la siguiente composición $\mathrm{K}_{0.09} \mathrm{MnO}_{2}\left(\mathrm{H}_{2} \mathrm{O}\right)_{0.08}$.

\footnotetext{
${ }^{8}$ L. Espinal, W. Wong-Ng, J. A. Kaduk, A. J. Allen, C. R. Snyder, C. Chiu, D. W. Siderius, L. Li, E. Cockayne, A. E. Espinal, S. L. Suib, Journal of the American Chemical Society 134 (2012) 7944-7951
} 
Tabla 6.3. Parámetros de red optimizados

\begin{tabular}{lccc}
\hline Sistema & $\mathbf{M n O}_{2}$ & KMnO & KMnZnO \\
& & & \\
\hline $\mathbf{a}(\AA)$ & 9,99 & 9,951 & 10,048 \\
$\mathbf{b}(\AA)$ & 2,87 & 2,892 & 2,909 \\
$\mathbf{c}(\AA)$ & 9,66 & 9,693 & 9,936 \\
Beta ( $\left.{ }^{(}\right)$ & 90,97 & 90,94 & 96,6 \\
& & & \\
Eup & 0,99 & 0,80 & 0,70 \\
& & & 1,70 \\
Edown & 1,90 & 2,20 & 8,33 \\
& & & \\
\hline
\end{tabular}

Las tres estructuras optimizadas se muestran en la Figura 6.7, se observan modificaciones producto de la incorporación de $\mathrm{K}$ y Zn en la red cristalina.

En la estructura $\alpha \mathrm{MnO}_{2}$ las longitudes de enlace $\mathrm{Mn}-\mathrm{O}$ presentan valores cercanos a $\sim 1,90 \AA$ Å, tal como se muestra en la Figura 6.7.a. Del análisis de la estructura KMnO se observa que las distancias K-Mn y K-O son $3,55 \AA$ y $2,87 \AA$, respectivamente siendo estos resultados coincidentes con lo observados por Cockayne y Li. ${ }^{9}$

En la Figura 6.7.b se muestra el sistema optimizado luego de la incorporación de K en los túneles formados por los octaedros $\mathrm{MnO}_{6}$. La distancia $\mathrm{Mn}-\mathrm{O}$ se ve afectada, los enlaces dejan de ser similares y sus valores oscilan entre 1,89 y $1,95 \AA$.

\footnotetext{
${ }^{9}$ E. Cockayne, L. Li, Chemical Physics Letters544 (2012) 53-58
} 
Por último, como se presenta en la Figura 6.7.c la presencia de Zn, reemplazando a Mn provoca un aumento en las distancias Mn-O y K-O. Este resultado está de acuerdo con los observados en el análisis de reducción a temperatura programada (RTP Capítulo 5, sección 2) donde con el aumento de Zn la reducción del sólido se produce a temperaturas menores. La distancia $\mathrm{Zn}-\mathrm{O}$ es aproximadamente 2,02 $\AA$, este valor calculado es similar al obtenido del análisis EXAFS en el borde $\mathrm{K}$ de absorción de Zn (Capítulo 5, sección 2), estos resultados teóricos-experimentales señalan que los iones $\mathrm{Zn}^{2+}$ presentes en el sólido se encuentran coordinados octaédricamente.

El $\alpha \mathrm{MnO}_{2}$ en estado fundamental es antiferromagnético debido a la simetría de los enlaces Mn-O-Mn, sin embargo las interacciones entre los octaedros vecinos son débilmente ferromagnéticas, en este caso el valor es cercano a $4 \mu \mathrm{B}$. La presencia de potasio, en el caso del sistema $\mathrm{KMnO}$, provoca la reducción de $\mathrm{Mn}^{4+}$ a $\mathrm{Mn}^{3+}$ y la consecuente modificación de la estructura cristalina, como se discutió anteriormente. Luo y col. ${ }^{10}$ atribuyen a este hecho el comportamiento ferromagnético, relacionándolo con el efecto Janh-Teller como consecuencia de la existencia de iones $\mathrm{Mn}^{3+}$.A pesar de esto, no hay evidencia experimental sobre esta hipótesis.

${ }^{10}$ J. Luo, H. T. Zhu, F. Zhang, J. K. Liang, G. H. Rao, J. B. Li, Z. M. Du, Journal of Applied Physics 105, 093925 (2009) 

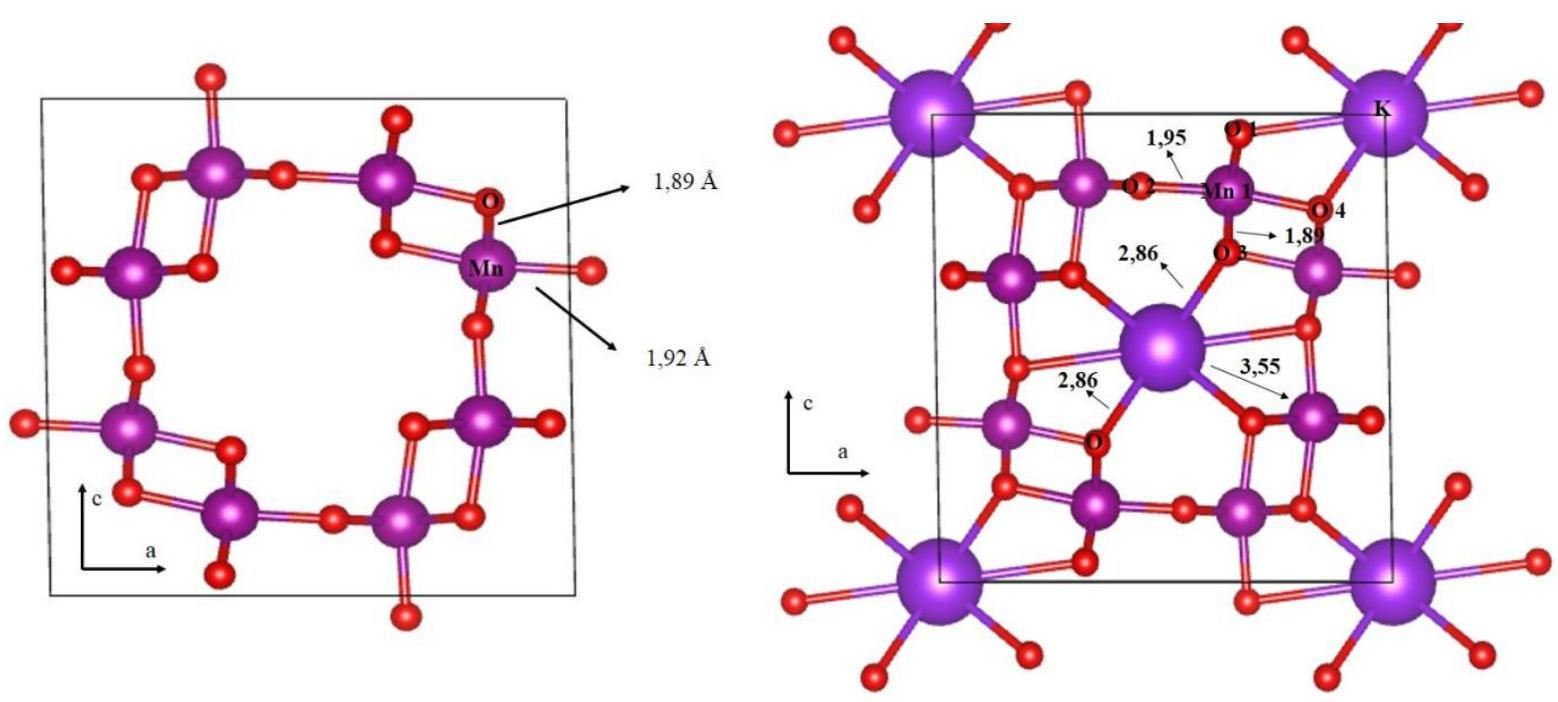

(a)

(b)

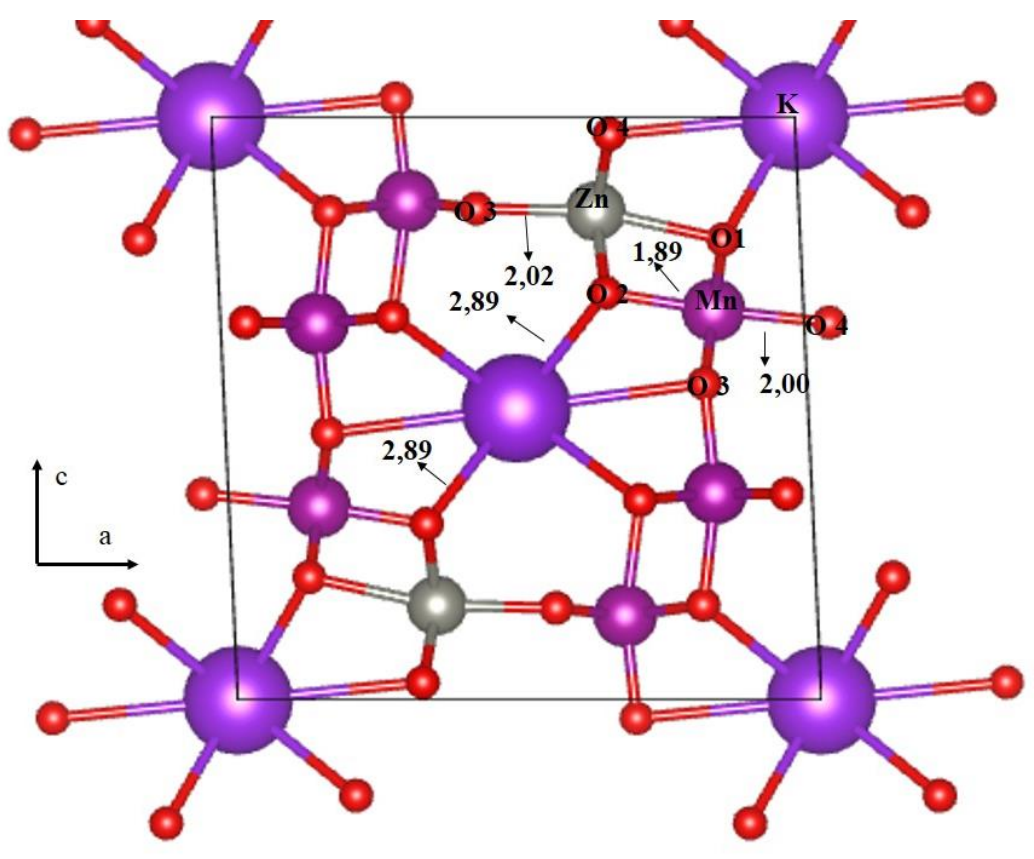

(c)

Figura 6.7. Estructuras optimizadas de: (a) $\mathrm{MnO}_{2}$, (b) $\mathrm{KMnO}_{2}$ y (c) $\mathrm{KMnZnO}_{\text {. }}$ 
En la Figura 6.8 se muestra la localización topológica de los momentos magnéticos en los sistemas estudiados. El sistema $\mathrm{KMnO}$ presenta un aumento en el momento magnético total $\left(4 \mu_{\mathrm{B}}\right)$ y de los iones Mn, alrededor del $8 \%$. Los iones Mn1, Mn2, Mn7 y Mn8 presentan un aumento levemente superior de este valor con respecto a los demás iones manganeso presentes (Figura 6.7 b).

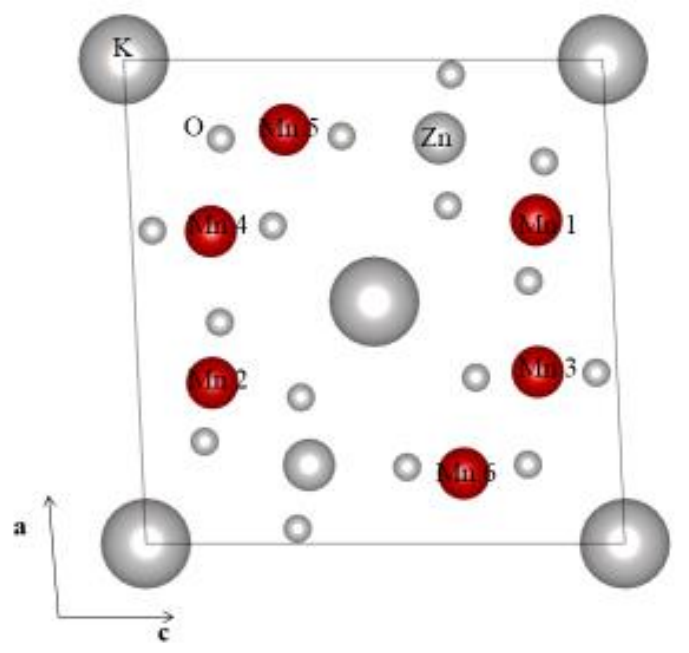

(a)

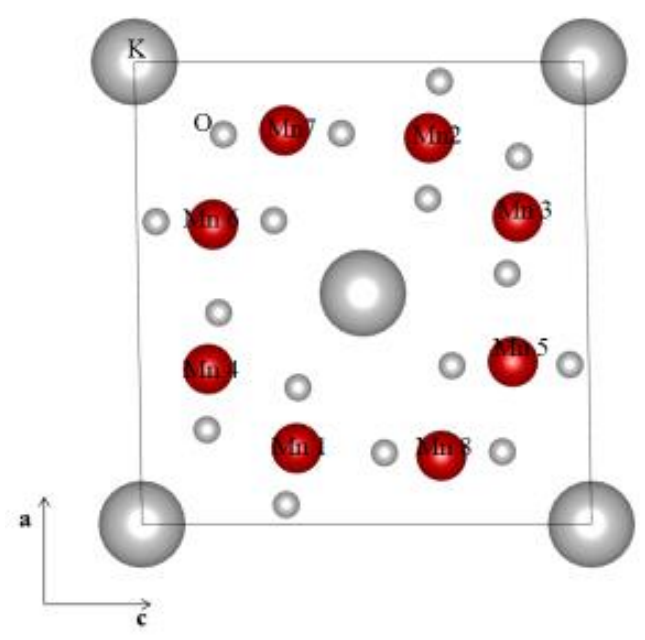

(b)

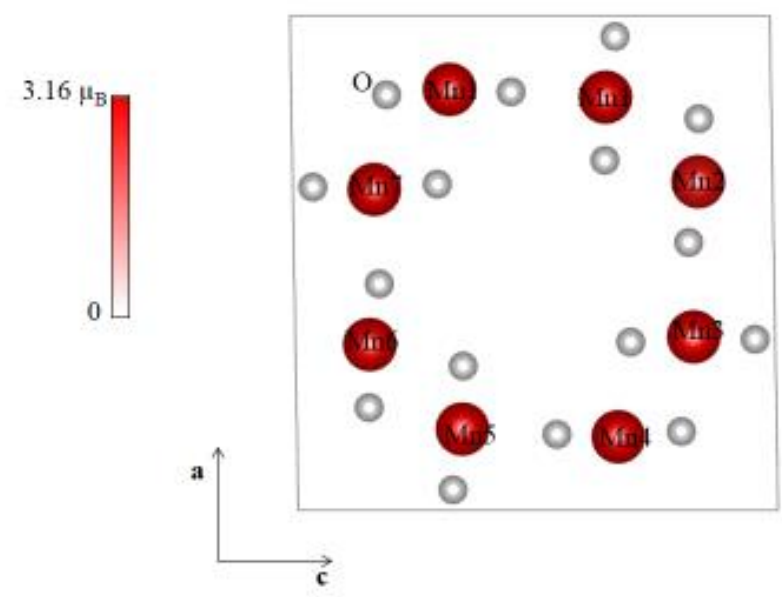

(c)

Figura 6.8. Localización topológica de los momentos magnéticos en los sistemas: (a) $\alpha \mathrm{MnO}_{2}$, (b) $\mathrm{KMnO}$ y (c) $\mathrm{KMnZnO}$. 
Cuando se estudió la influencia del Zn en las propiedades magnéticas, se observó una disminución del $\mu_{\text {tot }}\left(4.33 \mu_{\mathrm{B}}\right)$ y $\mu / \mathrm{Mn}$. En los iones Mn1 y Mn2, y Mn3 y Mn4 la disminución es cercana al 3\%; mientras que en el Mn5 y Mn6 es del 6\%.

En la Figura 6.9 se muestran la densidad de estados total (TDOS) y las densidades de estados proyectadas para los átomospresentes en los sistemas estudiados.

En la Figura 6.9.a se presentan la densidad de estados total (TDOS) y proyectada por átomo (PDOS) para el sistema $\alpha_{M_{n}}$. En la TDOS se observa que el nivel de Fermi está cercano a la banda de valencia, indicando que se trata de un semiconductor de tipo p. También resulta clara que la interacción se produce entre los electrones $d$ del $\mathrm{Mn}, p$ del $\mathrm{O}$ y $p$ de $\mathrm{K}$. Los resultados obtenidos en los cálculos coinciden con los reportados por Tseng y col. ${ }^{11}$ La baja simetría entre las contribuciones up y down en la PDOS para Mn indica que estos átomos son los responsables del magnetismo del sistema, en concordancia con lo discutido anteriormente (Figura 6.7.b).

Los cálculos obtenidos sugieren una transferencia de carga entre los átomos presentes, dando como resultado una densidad positiva sobre K y Mn y negativa sobre O. Esa transferencia de carga provoca un desplazamiento del nivel de Fermi a la banda de conducción, tal como se muestra en la TDOS (Figura 6.8.b). Los resultados obtenidos en este trabajo de tesis indican una disminución del valor de $\mathrm{E}_{\text {gap }} u p$, como consecuencia de la transferencia de carga de los iones $\mathrm{K}$ al sistema $\alpha \mathrm{MnO}_{2}$. Este hecho coincide con lo reportado por Cockayne y $\mathrm{Li}^{9}{ }^{9}$ quienes estudiaron la modificación que sufre la estructura $\alpha \mathrm{MnO}_{2}$ frente a distintas concentraciones de iones K. En la Figura 6.8.c se presentan las densidades de estados total (TDOS) y proyectadas para átomos de

\footnotetext{
${ }^{11}$ L. Tseng, Y. Lu, H. Fan, Y. Wang, X. Luo, T. Liu, P. Munroe, S. Li, J. Yi, Scientific Reports 5 (2015)
} 9094. 
Mn, O, K y Zn, en este caso también se observa una disminución del valor de $\mathrm{E}_{\text {gap }}$ up. Además se observa que el nivel de Fermi se encuentra dentro de la banda de valencia (BV), siendo un semiconductor de tipo $p$, en este caso la conducción se lleva a cabo a través de huecos. Este resultado permite determinar que la presencia de iones $\mathrm{Zn}^{2+}$ dentro de la estructura cristalina (OMR), conduce a una mejora en la actividad catalítica. 
(a)

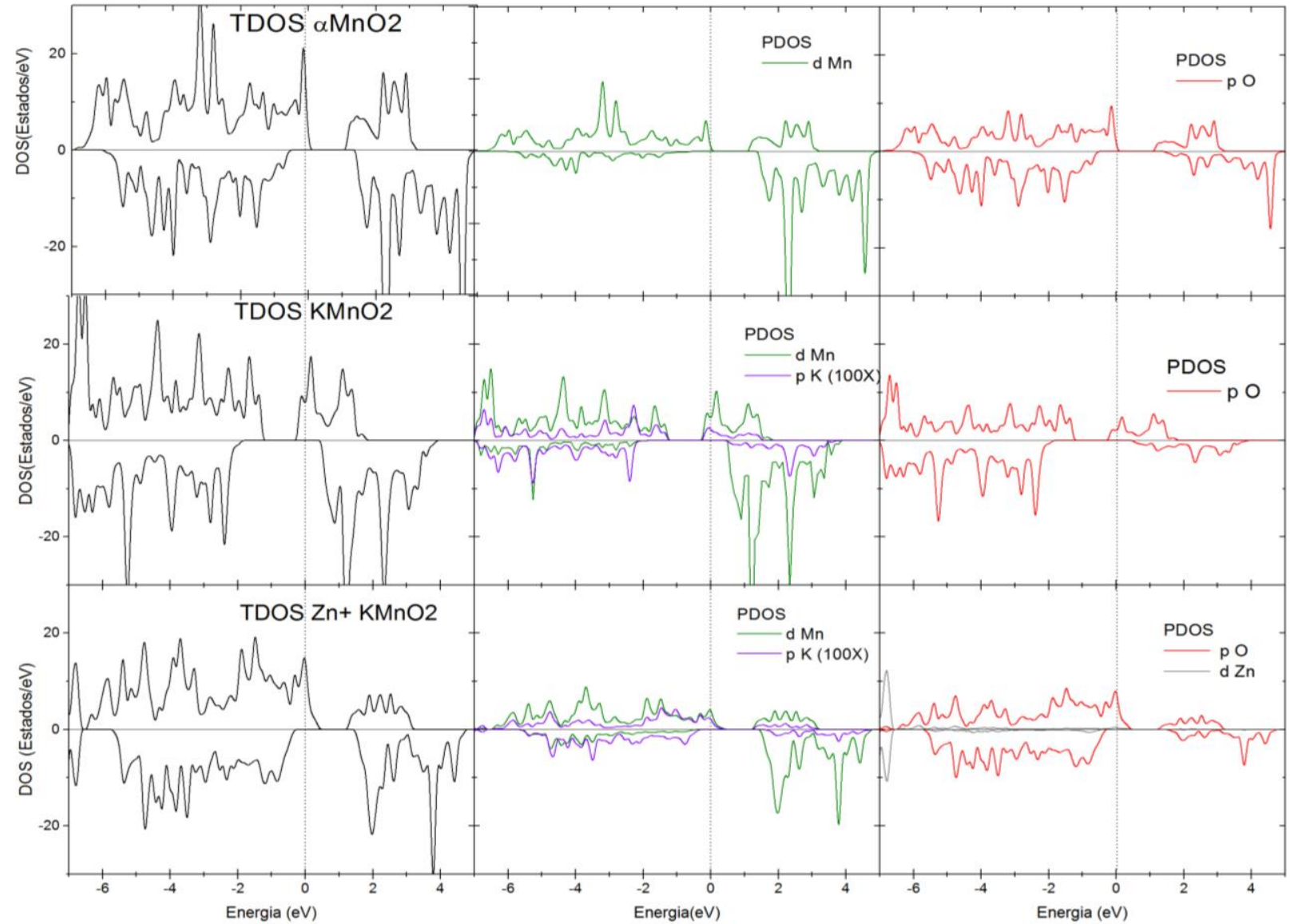

Figura 6.9. Densidad de estados total (TDOS) y proyectadas por átomo: (a) $\alpha \mathrm{MnO}_{2}$, (b) $\mathrm{KMnO}_{2}$ y (c) $\mathrm{Zn}+\mathrm{KMnO}_{2}$ 
Anexo: Otras aplicaciones de los

\section{sólidos recuperados}


Los óxidos recuperados a partir de pilas tienen un potencial uso para distintas aplicaciones, además de las comentadas en el Capítulo anterior.

Los óxidos de manganeso y de zinc pueden ser empleados en reacciones de síntesis orgánica, tales como: (1) hidrogenación, (2) animación, (3) adición aldólica, (4) reacción de adición tipo Michael, (5) adición conjugada de alcoholes, (6) reacción de Tishchenk, (7) síntesis selectiva de 1,4-dihidropiridina o 2-fenilpiridina: Reacción de Hantzsch. ${ }^{1}$ En este trabajo de Tesis se estudiara el uso de solidos recuperados de pilas como catalizadores en la reacción de Hantzsch.

Por otro lado, tal como se mencionó en el Capitulo 3, es conocido el empleo de $\mathrm{ZnO}$ como fotocatalizador en la degradación de colorantes en agua. Usando como colorante modelo azul de metileno, se estudiara el uso de los $\mathrm{ZnO}$ recuperados como fotocatalizador.

Por último, en el Capítulo 2 se mencionó el uso de los óxidos de manganeso como adsorbentes de metales pesados, debido a las propiedades que le confiere la estructura en forma de túneles. El óxido de manganeso recuperado, OMR, se estudiado en la adosrcion de iones $\mathrm{Pb} 2+$ y $\mathrm{Cu} 2+$ en solución acuosa

\section{A.1 Uso de óxidos de Mn-Zn en la síntesis selectiva de 1,4-dihidropiridina o 2- fenilpiridina: Reacción de Hantzsch}

Debido a sus propiedades ácido-base, redox y su fácil separación del medio de reacción los óxidos de metales de transición, se han comenzado a usar en diferentes reacciones de síntesis orgánica para cumplir con los Principios de la Química Verde. Los objetivos de la

\footnotetext{
${ }^{1}$ H. Hattori. Applied Catalysis A: General 2 22 (2001) 247-259
} 
Química Verde son: evitar el uso de ácidos fuertes, mejorar la selectividad de las reacciones evitando la generación de subproductos y evitar procesos de purificación.

Por otro lado, las reacciones multicomponentes (MCR) están en auge ya que involucran varios reactivos y los productos finales retienen gran parte de las moléculas de partida, esto es economía atómica. Además, se realizan en ausencia de solvente, siendo de esta forma amigables con el ambiente.

\section{Procedimiento experimental}

En esta reacción se estudiaron los sólidos OMR y ZnMnR y CZnO. Se mezclaron $50 \mathrm{mg}$ de catalizador con $1 \mathrm{mmol}$ de benzaldehído, $2 \mathrm{mmol}$ de acetoacetato de metilo y 1,3 mmol de acetato de amonio, con agitación continua, a 18 y $80{ }^{\circ} \mathrm{C}$, respectivamente. Todos los experimentos se realizaron tres veces. Se tomaron muestras de la mezcla de reacción durante la reacción a intervalos de tiempo. El análisis se realizó en un cromatógrafo de gases Shimadzu 2014 equipado con una columna capilar SPB-1 de $30 \mathrm{~mm}$ x 0,32 mm. Se estudió el reúso de los sólidos como catalizadores, realizando para ellos sucesivas reacciones. Previamente mediante el uso de indicadores de Hammet, se determinó la fuerza básica de los sólidos usados En un procedimiento típico, se mezclaron $1 \mathrm{ml}$ de solución indicador Hammett diluida en $10 \mathrm{ml}$ de metanol, con $10 \mathrm{mg}$ de catalizador, durante $2 \mathrm{~h}$.

\section{Resultados}

Como se observa en la Figura A.1, en general la reacción de Hantzsch produce la correspondiente 1,4 dihidropiridina $(\mathbf{H})$ como el producto principal en presencia de catalizador, temperatura y solvente. Esta reacción ocurre por una adición 1,4 (tipo Michael), formando el compuesto más favorable termodinámicamente. Por otro lado, a 
temperatura ambiente, en ausencia de solvente y catalizador y en un período de tiempo de $72 \mathrm{~h}$, puede obtenerse como producto principal la 2- fenillpiridina (T).

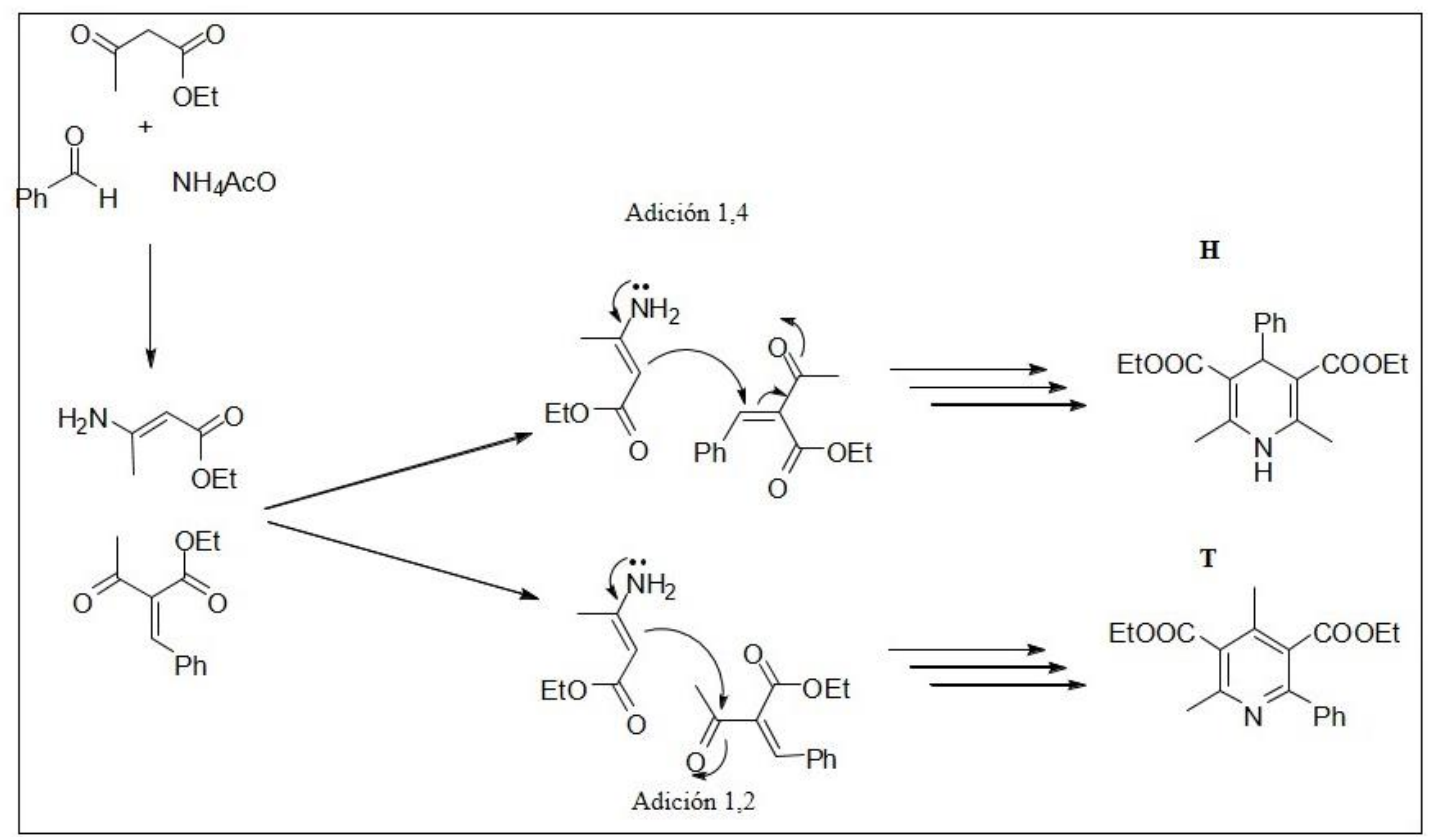

Figura A.1. Esquema de la reacción de síntesis de 1,4- dihidropiridina (H) o 2 fenilpiridina $(\mathbf{T})$.

Los resultados de la selectividad hacia los productos $\mathbf{T}$ o $\mathbf{H}$ a $18{ }^{\circ} \mathrm{C}$ se presentan en la Tabla A.1. En todos los catalizadores estudiados, la conversión de benzaldehído fue del $100 \%$ al cabo de $6 \mathrm{~h}$, un tiempo bastante menor que el necesario en ausencia de catalizador $(60 \mathrm{~h})$ en las mismas condiciones de reacción. Para todos los óxidos, el producto principal obtenido fue la 2- fenilpiridina, con muy buenos rendimientos. Sobre $\mathrm{ZnMnR}$ y C-ZnO, la selectividad para la 2-fenilpiridina (T) (95 y 94\%, respectivamente) fue mayor que la de OMR (85\%).

ZnMnR y C-ZnO son excelentes catalizadores para la síntesis de 2-fenilpiridina (T) mediante la reacción de Hantzsch a $18^{\circ} \mathrm{C}$. 
Utilizando óxidos de manganeso y de cerio a $25{ }^{\circ} \mathrm{C}$, D`Alessandro y col. ${ }^{2}$ obtuvieron selectividades hacia $\mathbf{T}$ del 92 y $97 \%$, respectivamente. Estos valores de selectividad son similares a los obtenidos en este trabajo utilizando óxidos de manganeso y de zinc recuperados de pilas alcalinas y $\mathrm{Zn} / \mathrm{C}$ agotadas.

Tabla A.1. Selectividad hacia los productos $\mathbf{T}$ o $\mathbf{H}$ sobre los sólidos usados a $18{ }^{\circ} \mathrm{C}$.

\begin{tabular}{cccc}
\hline Muestra & $\begin{array}{c}\text { Tiempo } \\
(\mathrm{min})\end{array}$ & $\begin{array}{c}\text { Selectividad } \\
\text { T (\%) }\end{array}$ & $\begin{array}{c}\text { Selectividad } \\
\text { H (\%) }\end{array}$ \\
\hline Blanco & 60 & 87 & 13 \\
OMR & 6 & 85 & 15 \\
ZnMnR & 6 & 95 & 5 \\
C-ZnO & 6 & 94 & 6 \\
\hline
\end{tabular}

En la Tabla A.2 se muestran los resultados de la selectividad hacia los productos $\mathbf{T}$ o $\mathbf{H}$ a $80{ }^{\circ} \mathrm{C}$. En este caso, sólo es necesaria una hora para lograr una conversión del $100 \%$. Además, se observa un cambio en la selectividad de la producción en comparación con los experimentos realizados a una temperatura más baja. En este caso, la reacción procede por adición 1,4 (tipo Michael) y adición 1,2. En ambos óxidos conteniendo manganeso, OMR y ZnMnR, la selectividad es casi del 50\% para ambos productos, $\mathbf{H}$ y $\mathbf{T}$.

${ }^{1}$ O. D'Alessandro, A. Sathicq, J. Sambeth, H. Thomas, G. Romanelli, Catalysis Communication 60 (2015) 65-69. 
Tabla A.2. Selectividad hacia los productos T o $\mathbf{H}$ sobre los sólidos usados a $80{ }^{\circ} \mathrm{C}$.

\begin{tabular}{cccc}
\hline Muestra & Tiempo & Selectividad & Selectividad \\
& $(\mathrm{min})$ & $\mathbf{T}(\%)$ & $\mathbf{H}(\%)$ \\
\hline Blanco & 12 & 70 & 30 \\
OMR & 1 & 50 & 50 \\
ZnMnR & 1 & 54 & 46 \\
C-ZnO & 1 & 30 & 70 \\
\hline
\end{tabular}

Los valores de la fuerza básica de los óxidos fueron obtenidos por el método de Hammet. El intervalo de $\mathrm{pH}$ de los óxidos recuperados fue: $\mathrm{ZnO}, 8<\mathrm{pH}<11$; $\mathrm{ZnMnR}, 7<$ $\mathrm{pH}<8$; OMR, $5<\mathrm{pH}<6$. Se observa un aumento en el valor de la fuerza básica a medida que aumenta el contenido de $\mathrm{Zn}$ en las muestras.

La selectividad hacia $\mathbf{H}$ a $80{ }^{\circ} \mathrm{C}$ de los óxidos que contienen manganeso utilizados en este trabajo (OMR y ZnMn) fue ligeramente mayor que la de un óxido de manganeso preparado a partir de sales comerciales ${ }^{1}$. La alta selectividad para $\mathbf{H}$ obtenida con el C-ZnO reciclado a $80{ }^{\circ} \mathrm{C}$ fue similar a la de $\mathrm{CeO}_{2}$ preparado por D'Alessandro y col. ${ }^{1}$ Dicho óxido de cerio posee un área específica mayor que la del C-ZnO reciclado. Sin embargo, el valor de fuerza básica fue similar, con lo cual la formación del producto $\mathbf{H}$ a $80{ }^{\circ} \mathrm{C}$ podría estar favorecida por una elevada fuerza básica.

Luego de completarse la reacción a $18{ }^{\circ} \mathrm{C}$ usando como catalizador ZnMnR, se agregó a la mezcla de reacción acetato de etilo $(3 \times 1 \mathrm{~mL})$. El sólido usado se recuperó y secó en vacío a $25{ }^{\circ} \mathrm{C}$ para analizar su reúso en tres ciclos. Los rendimientos de 2-arilpiridina para la primera, segunda y tercera reutilización fueron 95, 93 y 92\% respectivamente. 


\section{A.2 OMR como adsorbente de metales pesados}

La contaminación del agua representa un gran problema ya que es un elemento esencial para el desarrollo de la vida. A lo largo de la historia se han identificado innumerables inconvenientes tanto en la salud humana como en los ecosistemas que habitan aguas contaminadas ya sea por fuentes naturales o humanas.

Los metales pesados son uno de los contaminantes más dañinos en los ecosistemas acuáticos debido a que aun en muy bajas concentraciones tienen una alta toxicidad para los seres vivos. Estos elementos forman parte de un grupo cercano a 40 elementos de la tabla periódico con valores de densidad mayores a $5 \mathrm{~g} \mathrm{~cm}^{-3} \cdot 3$ El rasgo distintivo de la fisiología de los metales pesados, es que aun cuando muchos de ellos son esenciales para el crecimiento como el $\mathrm{Na}, \mathrm{K}, \mathrm{Mg}, \mathrm{Ca}, \mathrm{V}, \mathrm{Mn}, \mathrm{Fe}, \mathrm{Co}, \mathrm{Ni}, \mathrm{Cu}, \mathrm{Zn}$ y $\mathrm{Mo}$, se ha reportado que también tienen efectos tóxicos sobre las células, principalmente como resultado de su capacidad para alterar o desnaturalizar las proteínas. ${ }^{4}$ Una vez en el agua los metales pesados pueden ser incorporados a las células vivas y sufrir procesos de bioconcentración, bioacumulación y biomagnificación a través de las cadenas alimentarias. ${ }^{5}$ Debido a su movilidad en los ecosistemas acuáticos naturales y a su toxicidad para las formas superiores de vida, los iones de metales pesados presentes en los abastecimientos de aguas superficiales y subterráneos, se les ha dado prioridad como los contaminantes inorgánicos más importantes en el ambiente. Aun cuando se encuentren presentes en cantidades bajas e indetectables, la recalcitrancia y consiguiente persistencia de los metales pesados en cuerpos de agua, implica que a través de procesos naturales como la biomagnificación, su concentración puede llegar a ser tan elevada que empiece a ser tóxica. Los metales pesados

\footnotetext{
${ }^{3}$ H. Passow, T. Clarkson, Pharmacological Reviews 13 (1961) 185-224.

${ }^{4}$ R. Cañizares-Villanueva, Revista Latinoamericana de Microbiología 42 (2000) 131-143.

${ }^{5}$ G. Ponce-Velez, A. Botello, Hidrobiologica 1 (1992) 1-10.
} 
pueden ser detectados ya sea en su estado elemental, lo que implica que no sufren modificaciones, o enlazados en varios complejos con sales. ${ }^{6}$ La adsorción sobre diferentes materiales es una técnica que está tomando protagonismo en cuanto a la eliminación de metales pesados disueltos en agua, debido a su bajo costo y fácil aplicación. ${ }^{7}$ Como se mencionó anteriormente en el Capítulo 2.1, los óxidos de manganeso con estructura de túneles son prometedores como materiales adsorbentes. Por esta razón se estudió la adsorción de dos metales $(\mathrm{Pb}$ y $\mathrm{Cu})$ sobre el sólido denominado OMR.

\section{Procedimiento experimental}

Isotermas de adsorción de $\mathrm{Pb}$ y $\mathrm{Cu}$.

Para la obtención de las isotermas de absorción de $\mathrm{Cu}$ y $\mathrm{Pb}$ se prepararon inicialmente dos soluciones madre como se detalla a continuación:

- Solución 1000 mg $\mathbf{L}^{-1}$ en Pb: Se disolvieron 1,831 g de $\mathrm{Pb}\left(\mathrm{CH}_{3} \mathrm{COO}\right)_{2} \times 3 \mathrm{H}_{2} \mathrm{O}$ (BioPack puro) y $1 \mathrm{ml}$ de $\mathrm{HNO}_{3} 65 \% \mathrm{v} / \mathrm{v}$ en agua destilada y se lo llevo a $1 \mathrm{~L}$ en matraz aforado.

- Solución 1000mg $\mathbf{L}^{-1}$ en $\mathbf{C u}$ : Se disolvieron 3,936 g de $\mathrm{CuSO}_{4} \times 5 \mathrm{H}_{2} \mathrm{O}$ (Cicarelli, puro) en agua destilada y se lo llevo a $1 \mathrm{~L}$ en matraz aforado.

De las soluciones madre se realizaron diluciones sucesivas con pipetas doble aforo y matraces aforados, para obtener concentraciones de 25, 50, 100 y $200 \mathrm{mg} \mathrm{L}^{-1}$ en $\mathrm{Cu}$ y $\mathrm{Pb}$ respectivamente.

Luego se procedió a realizar el ensayo de contacto, adsorbente-solución. Se tomaron 0,04 g del sólido OMR y se le adicionaron $40 \mathrm{ml}$ de las distintas soluciones por separado,

\footnotetext{
${ }^{6}$ B. Atkinson, F. Bux, H. Kasan, Water SA 24 (1998) 129-144.

${ }^{7}$ B. Pan, B. Pan, W. Zhang, L. Lv, Q. Zhang, S. Zheng, Chemical Engineering Journal 151(2009) 19-29.
} 
en tubos falcon de $50 \mathrm{ml}$. Los tubos fueron llevados a agitación continua orbital por $2 \mathrm{hs}$. Los ensayos fueron realizados a $25{ }^{\circ} \mathrm{C}$ y a un $\mathrm{pH}$ inicial de 5 . Se tomaron muestras a distintos intervalos de tiempo $(5,10,20,30,60$ y 120 min) y se midió la concentración del metal por absorción atómica.

La capacidad de adsorción $\mathrm{q}_{\mathrm{e}}\left(\mathrm{mg}^{-1}\right)$ después del equilibrio fue calculada de la siguiente manera:

$$
\mathrm{q}_{\mathrm{e}}=\left(\mathrm{C}_{0}-\mathrm{C}_{\mathrm{i}}\right) . \mathrm{V} / \mathrm{W}
$$

donde $\mathrm{C}_{0}$ es la concentración inicial de metal; $\mathrm{C}_{\mathrm{i}}$ es la concentración final de metal; $\mathrm{V}$ es el volumen de solución (L) y W la masa de adsorbente (g).

\section{Resultados}

Las concentraciones reales de $\mathrm{Pb}$ y $\mathrm{Cu}$, medida con absorción atómica, se muestran en la Tabla A.3. Estos valores difieren de los valores nominales por errores típicos de los instrumentos utilizados en la preparación de las disoluciones.

Tabla A.3. Concentración nominal y concentración real de $\mathrm{Pb}^{2+} \mathrm{y} \mathrm{Cu}^{2+}$ en solución.

\begin{tabular}{ccc}
$\begin{array}{c}\text { Concentración nominal } \\
\left(\mathrm{mg} \mathrm{L}^{-1}\right)\end{array}$ & $\begin{array}{c}\text { Concentración real } \mathrm{Pb}^{*} \\
\left(\mathrm{mg} \mathrm{L}^{-1}\right)\end{array}$ & $\begin{array}{c}\text { Concentración real } \mathrm{Cu}^{*} \\
\left(\mathrm{mg} \mathrm{L}^{-1}\right)\end{array}$ \\
\hline 25 & 23,0 & 26,9 \\
50 & 49,6 & 49,7 \\
100 & 105,3 & 101,1 \\
200 & 185,6 & 188,2 \\
\hline
\end{tabular}

*Medida por AA. 
A partir de las medidas realizadas sobre las soluciones conteniendo $100 \mathrm{mg} \mathrm{L}^{-1}$ de metales, luego del contacto adsorbato-solución se obtuvieron las curvas que se muestran en la Figura A.2, en donde se grafica capacidad de adsorción versus tiempo.

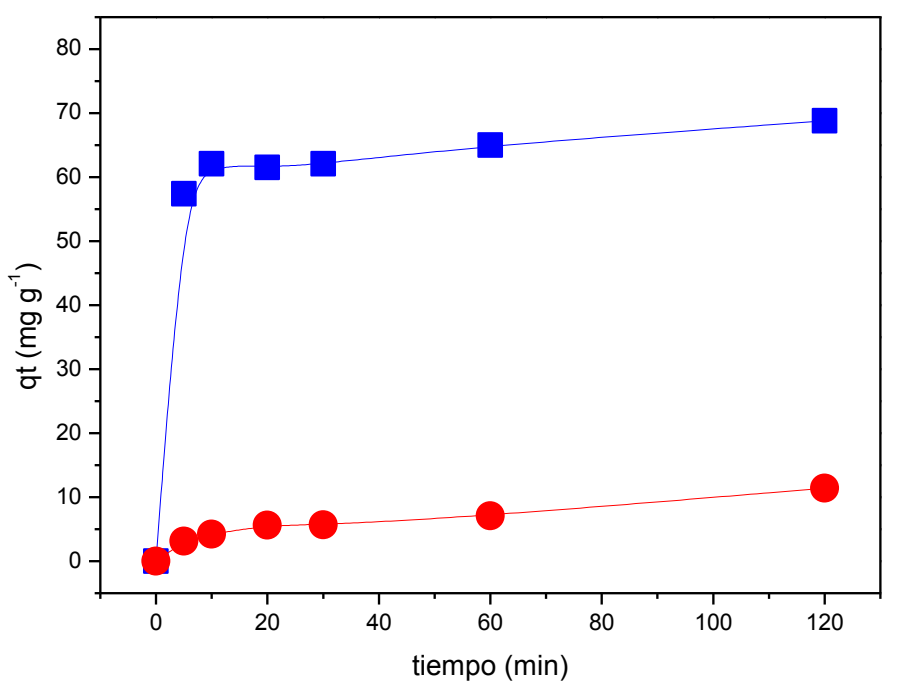

Figura A.2. Adsorción de $\bigcirc \mathrm{Cu}^{2+}$ y $\square \mathrm{Pb}^{2+}$ sobre OMR.

En general, la adsorción de los metales aumenta con el tiempo hasta alcanzar el equilibrio. La adsorción de $\mathrm{Pb}^{2+}$ es mayor que la correspondiente a $\mathrm{Cu}^{2+}$, resultado coincidente con lo reportado por Lee y col. ${ }^{8} \mathrm{La}$ adsorción de $\mathrm{Pb}^{2+}$ y $\mathrm{Cu}^{2+}$ ocurre en dos etapas: una fase inicial rápida donde la adsorción ocurre rápidamente y una segunda fase lenta, como es observado en la mayoría de los estudios de adsorción de metales pesados.

\footnotetext{
${ }^{8}$ M. Lee, J. Park, J. Chung, C. Lee, S. Kang, Journal of Industrial and Engineering Chemistry 21 (2015) 470475.
} 
A pesar de la baja superficie específica del solido OMR se logró una alta adsorción. Este resultado indica que las cargas superficiales en el óxido usado son un factor a tener en cuenta en la adsorción de metales pesados, tal como señalan Peluso y col. ${ }^{9}$

En la Figura A.3 se representa el valor de la capacidad de adsorción $\mathrm{q}_{\mathrm{e}}$ después del equilibrio, para diferentes concentraciones iniciales de metales. En todas las concentraciones estudiadas, la capacidad de adsorción de $\mathrm{Pb}$ fue mayor que la de $\mathrm{Cu}$.

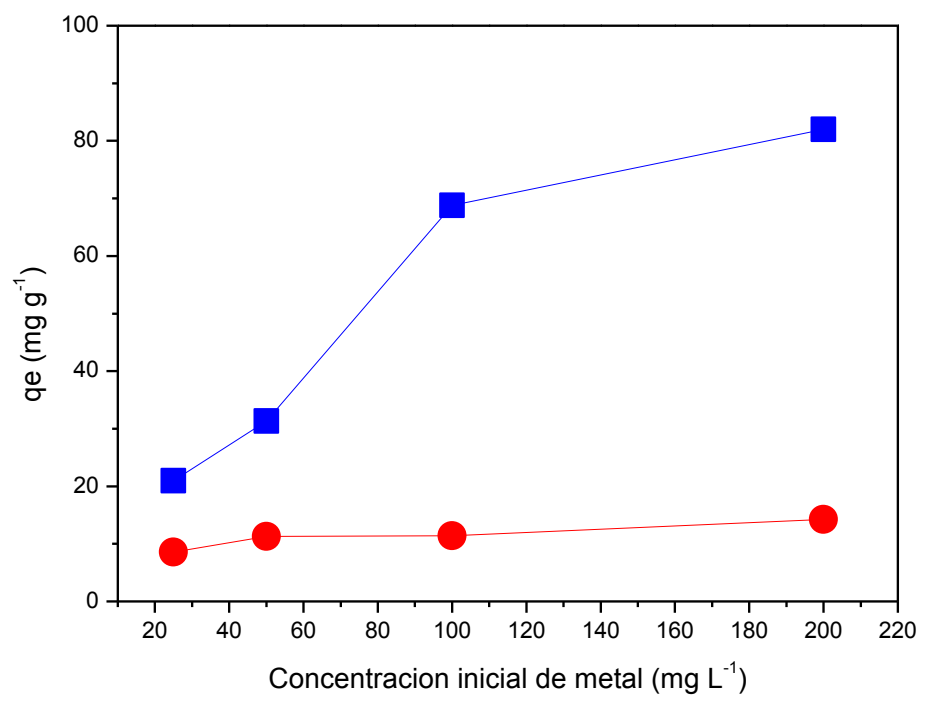

Figura A.3. Capacidad de adsorción después del equilibrio para $\mathrm{OCu}^{2+}$ y $\square \mathrm{Pb}^{2+}$ sobre OMR a diferentes concentraciones iniciales de metales.

\section{Cinética de adsorción}

Los datos obtenidos se pueden analizar bajo cuatro modelos de adsorción: modelo cinético de pseudo primer orden, modelo cinético de pseudo-segundo orden, difusión intrapartícula y modelo de Elovich.

\footnotetext{
${ }^{9}$ M. A. Peluso, L. A. Gambaro, E. Pronsato, D. Gazzoli, H. J. Thomas, J. E. Sambeth. Catalysis Today 133 (2008) 487-492.
} 
El modelo cinético de pseudo-primer orden asume que un ion $(\mathrm{Pb}$ o $\mathrm{Cu})$ es adsorbido en un sitio activo de óxido de manganeso:

$$
\begin{aligned}
& \mathrm{A}_{(\mathrm{s})}+\mathrm{Cu}^{2+}{ }_{(\mathrm{ac})} \stackrel{k 1 C u}{\longrightarrow} \mathrm{ACu}_{(\mathrm{s})} \\
& \mathrm{A}_{(\mathrm{s})}+\mathrm{Pb}^{2+}{ }_{(\mathrm{ac})} \stackrel{k 1 P b}{\longrightarrow} \mathrm{APb}_{(\mathrm{s})}
\end{aligned}
$$

Donde A es el sitio del adsorbente y $k 1$ y $k 2$ corresponden a los valores de constantes de velocidad para una cinética de pseudo primer orden. ${ }^{10}$

La ecuación de Lagergren describe este mecanismo:

$$
\ln \left(q_{e}-q_{t}\right)=\ln q_{e}-k 1 t
$$

$\mathrm{Q}_{\mathrm{e}}$ and $\mathrm{q}_{\mathrm{t}}\left(\mathrm{mg} \mathrm{g}^{-1}\right)$ corresponden a los valores de capacidad de adsorción en el equilibrio y a un tiempo t, respectivamente.

El modelo que describe una cinética de pseudo segundo orden asume que el ion se adsorbe en dos sitios activos:

$$
\begin{aligned}
& 2 \mathrm{~A}_{(\mathrm{s})}+\mathrm{Cu}^{2+}{ }_{(\mathrm{ac})} \stackrel{k 2 \mathrm{Cu}}{\longrightarrow} \mathrm{A}_{2} \mathrm{Cu}_{(\mathrm{s})} \\
& 2 \mathrm{~A}_{(\mathrm{s})}+\mathrm{Pb}^{2+}{ }_{(\mathrm{ac})} \stackrel{k 2 P b}{\longrightarrow} \mathrm{A}_{2} \mathrm{~Pb}_{(\mathrm{s})}
\end{aligned}
$$

La ecuación que describe este modelo se muestra a continuación:

$$
\frac{t}{q t}=\frac{1}{k 2 q_{e}^{2}}+\frac{t}{q_{e}}
$$

Aquí, $k_{2}$ indica el valor de la constante de velocidad para una cinética de pseudo segundo orden. ${ }^{11}$

${ }^{10}$ H. Boparai, M. Joseph, D. O’Carroll, Journal of Hazardous Materials 186 (2011) 458-465.

${ }^{11}$ D. Kavitha, C. Namasivayam, Bioresource Technology 98 (2007) 14-21. 
El modelo de difusión intrapartícula establece una relación lineal entre la raíz cuadrada del tiempo y la capacidad de adsorción ${ }^{12}$

$$
q t=k_{d} t^{1 / 2}+C
$$

$K_{d}$ representa la constante de velocidad.

Por último, el modelo de Elovich se describe mediante la siguiente ecuación:

$$
q_{t}=\frac{\ln (\alpha \beta)}{\beta}+\frac{\ln (t)}{\beta}
$$

Donde $\alpha$ es la velocidad inicial de adsorción y el parámetro $\beta$ se relaciona con la habilidad para cubrirse de la superficie y la energía de activación del proceso de quimisorción. ${ }^{13}$

En el caso de $\mathrm{Pb}$ y $\mathrm{Cu}$, se observa un buen ajuste entre los datos experimentales con valores teóricos de cinética de pseudo-segundo orden, obteniéndose un mejor ajuste para el caso de $\mathrm{Pb}$ (Figura A.4.b). Para los otros modelos probados, los ajustes para ambos casos son pobres.

\footnotetext{
${ }^{12}$ M. Sathishkumar, A. Binupriya, D. Kavitha, S. Yun, Bioresource Technology 98 (2007) 866-873.

${ }^{13}$ C. Cheung, J. Porter, G. Mckay. Separation and Purification Technology 19 (2000) 55-64.
} 

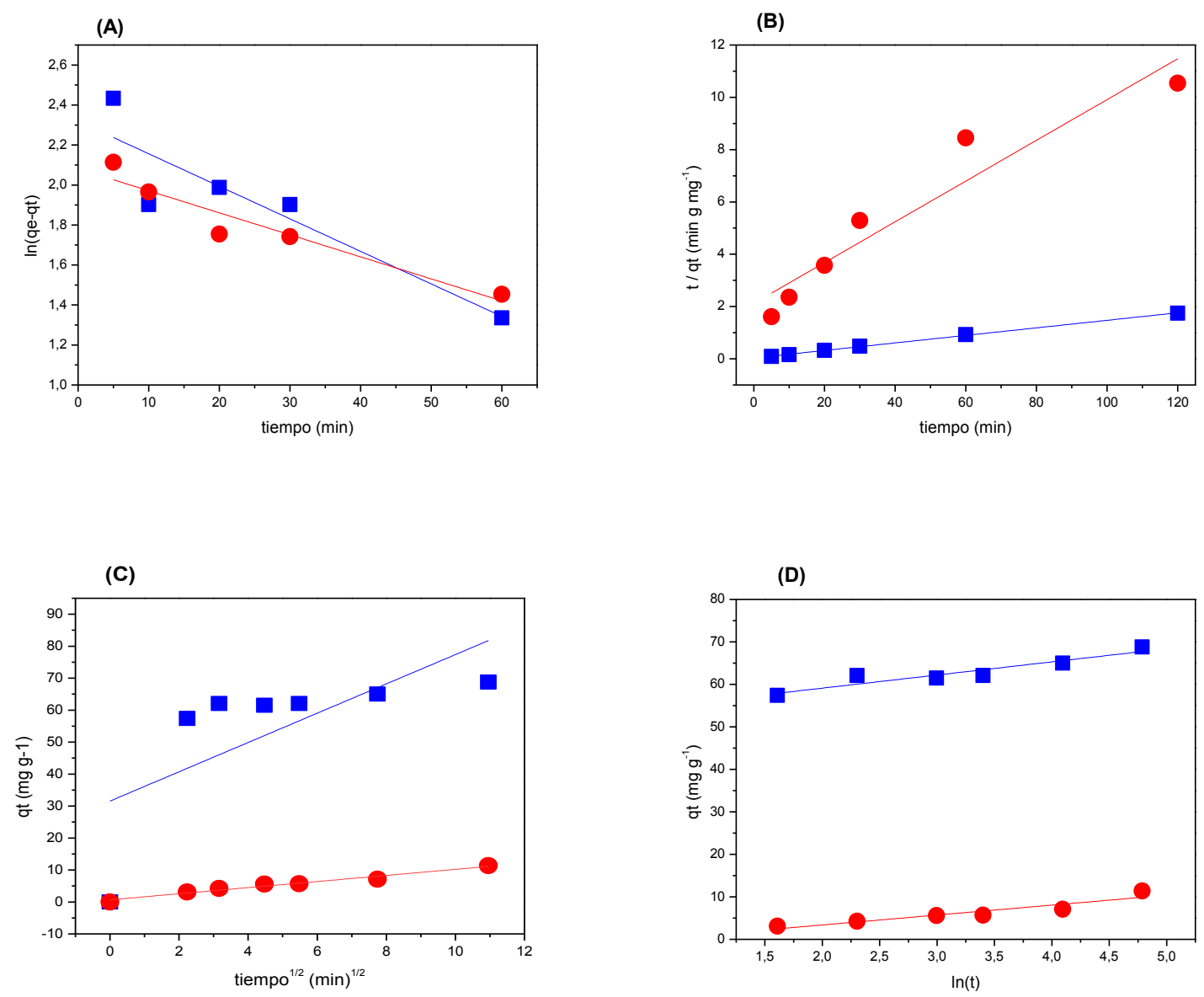

Figura A.4. Modelo de: (A) pseudo-primer-orden, (B) pseudo-segundo-orden, (C) difusión intrapartícula y (D) Elovich, para $100 \mathrm{mg} \mathrm{L}^{-1}$ de $\quad \mathrm{Cu}^{2+}$ y $\quad \mathrm{Pb}^{2+}$ sobre OMR.

La Tabla A.4 muestra los parámetros cinéticos para la adsorción de $100 \mathrm{mg} \mathrm{L}^{-1}$ de $\mathrm{Cu}^{2+}$ y $\mathrm{Pb}^{2+}$ sobre OMR. Para la cinética de pseudo-segundo orden se obtienen los mejores valores de $\mathrm{R}^{2}$, 0,999 para $\mathrm{Pb}$ y 0,892-0,934 para $\mathrm{Cu}$ y las capacidades de adsorción teóricas predichas por este modelo son muy similares a las obtenidas experimentalmente. Para la cinética de primer orden, los valores obtenidos para $\mathrm{Pb}$ y Cu están entre 0,7 y 0,9; Y para Elovich y modelos de difusión intrapartícula, el $\mathrm{R}^{2}$ obtenido es inferior a 0,850 , no mostrando una buena correlación. 
Tabla A.4. Parámetros cinéticos

\begin{tabular}{llcc}
\hline & & $\mathrm{Pb}$ & $\mathrm{Cu}$ \\
\hline Cinética de pseudo-primer orden & $\mathbf{K}_{\mathbf{1}}$ & 0,053 & 0,011 \\
& $\mathbf{R}^{2}$ & 0,722 & 0,892 \\
& $\mathbf{q}$ & 7,2 & 8,0 \\
& $\mathbf{q e}$ exp. & 68,1 & 11,4 \\
\hline
\end{tabular}

\begin{tabular}{llcc}
\hline Cinética de pseudo-segundo orden & $\mathbf{K}_{2}$ & 0,006 & 0,003 \\
& $\mathbf{R}^{\mathbf{2}}$ & 0,999 & 0,892 \\
& $\mathbf{q}$ & 69,4 & 12,8 \\
\hline
\end{tabular}

\begin{tabular}{llrr}
\hline Difusión Intra-particula & $\mathbf{K}_{\mathbf{d}}$ & 1,667 & 5,153 \\
& $\mathbf{R}^{\mathbf{2}}$ & 0,793 & 0,230
\end{tabular}

\begin{tabular}{cccc}
\hline Elovich & $\boldsymbol{\alpha}$ & $1,2 \times 10^{22}$ & 0,94 \\
$\boldsymbol{\beta}$ & 0,65 & 0,23 \\
$\mathbf{R}^{2}$ & 0,603 & 0,746 \\
\hline
\end{tabular}

Sobre la base de los modelos cinéticos estudiados, el mejor ajuste a los datos experimentales es el modelo de pseudo segundo orden; Por lo tanto, esto sugiere que el paso limitante de la adsorción es la adsorción química. ${ }^{14,15}$

\footnotetext{
${ }^{14}$ L. Puppa, M. Komárek, F. Bordas, J. Bollinger, E. Joussein, Journal of Colloid and Interface Science 399
} (2013) 99-106. 


\section{Parámetros termodinámicos}

Con el objetivo de investigar las isotermas de adsorción de $\mathrm{Pb}^{2+} \mathrm{y} \mathrm{Cu}^{2+}$, se usaron los modelos de Langmuir y Freundlich. El modelo de Langmuir es usado en el caso de adsorción en monocapa, es expresado en la siguiente forma linearizada:

$$
\frac{C_{e}}{q_{e}}=\frac{1}{Q^{o} b}+\frac{C_{e}}{Q^{o}}
$$

en donde $\mathrm{C}_{\mathrm{e}}$ es la concentración de equilibrio de la solución $\left(\mathrm{mg} \mathrm{L}^{-1}\right), \mathrm{Q}^{0}$ es la capacidad de adsorción de la monocapa $\left(\mathrm{mg} \mathrm{g}^{-1}\right)$ y b es una constante relacionada con la energía libre o entalpía de adsorción. ${ }^{16}$

El modelo de Freundlich es derivado de la adsorción en multicapas y de la adsorción sobre superficies heterogéneas. La ecuación linearizada de este modelo tiene la expresión:

$$
\log \left(q_{e}\right)=\log \left(K_{f}\right)+\log \left(C_{e}\right) \frac{1}{n}
$$

Donde $\mathrm{K}_{\mathrm{f}}$ es la capacidad de adsorción relativa del adsorbente y $1 / n$ es la intensidad de la adsorción.

Las formas linealizadas de las isotermas de adsorción de Langmuir y Freundlich, así como sus parámetros, se representan en la Figura A.5 y la Tabla A.5.

Para el caso de $\mathrm{Cu}$, el modelo de Langmuir se adapta mejor que el de Freundlich, sin embargo se obtienen valores de $\mathrm{R}^{2}$ inferiores a 0,99 , lo que indicaría que este modelo no describe perfectamente la adsorción de $\mathrm{Cu}^{2+}$. En el caso de la adsorción de $\mathrm{Pb}$, el modelo de Freundlich se adapta mejor que el de Langmuir. Sin embargo, nuevamente el valor de $\mathrm{R}^{2}$ es

15 S. Wang, W. Gong, X. Liu, Y. Yao, B. Gao, Q. Yue, Separation and Purification Technology 58 (2007) 17-23.

${ }^{16}$ A. Ghosh, M. Pala, K. Biswas, U. Ghosh, B. Manna, Journal of Water Process Engineering 7 (2015) 176186. 
inferior a 0,99. Para el caso de adsorción de $\mathrm{Pb}$, se obtienen valores de $\mathrm{Q}_{0}$ (capacidad de adsorción máxima) muy superiores a los reportados en la literatura, lo que podría ser debido a que para $\mathrm{Pb}^{2+}$ este modelo no se adapta a los datos experimentales.
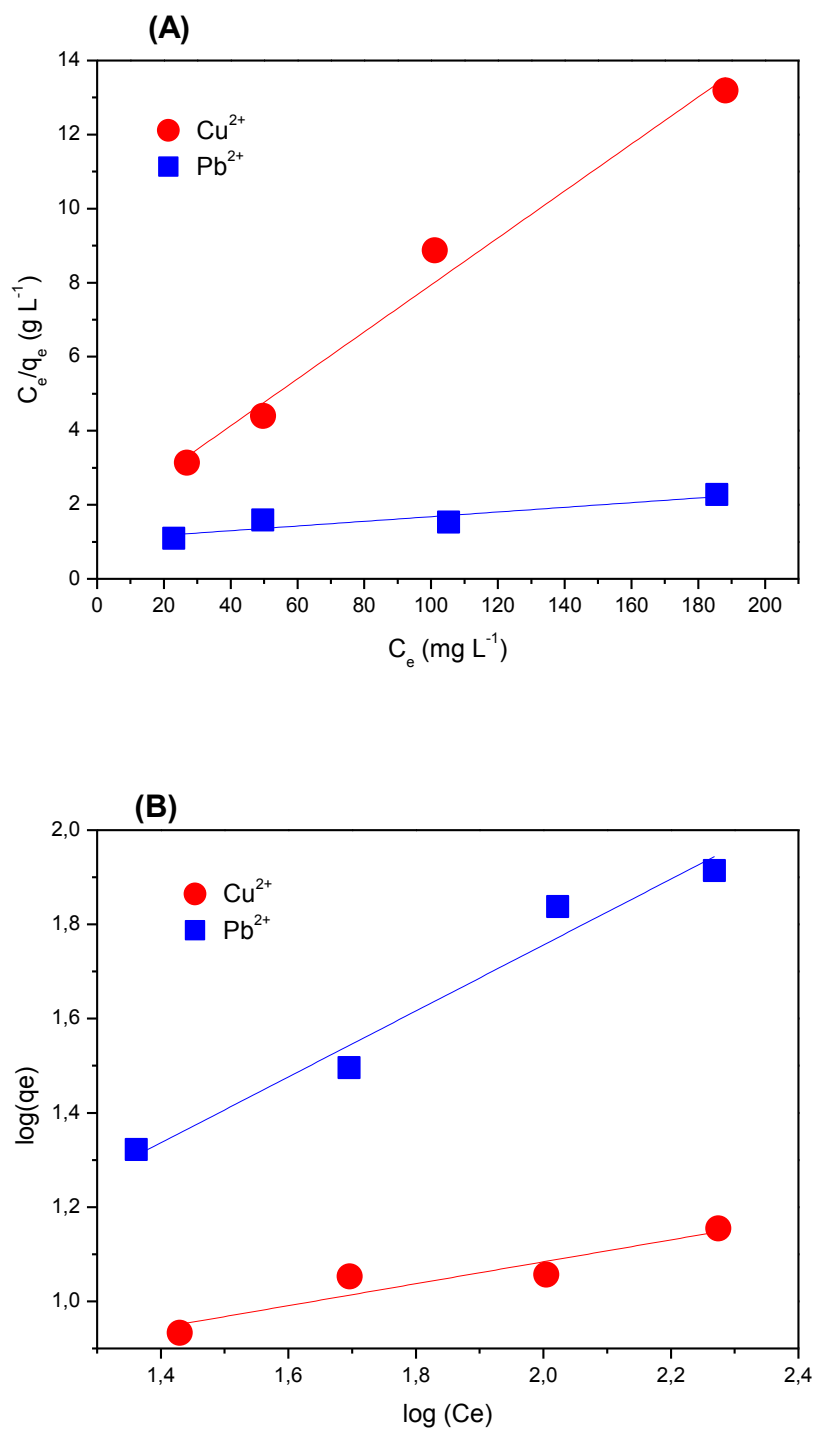

Figura A.5. Isotermas de adsorción de $\mathrm{Pb}^{2+} \mathrm{y} \mathrm{Cu}^{2+}$ sobre OMR: (A) Modelo de Langmuir y (B) Modelo de Freundlich. 
En el caso de la adsorción de $\mathrm{Cu}^{2+}$, los valores de $\mathrm{Q}_{0}$ se encuentran dentro de los valores reportados en la bibliografía, 8,20 para $\mathrm{MnO}_{2}$ soportado sobre zeolitas ${ }^{17}$ y 37,04 para $\mathrm{Mn}_{3} \mathrm{O}_{4}$ soportado sobre carbono. ${ }^{7}$ Por otro lado, la constante de Freundlich $n$ es mayor que 1 para la adsorción de $\mathrm{Pb}^{2+}$, lo que indica que los iones metálicos están adsorbidos favorablemente sobre la superficie de los óxidos de manganeso utilizados en este trabajo. ${ }^{18}$

TABLA A.5. Parámetros de las Isotermas de adsorción de $\mathrm{Pb}^{2+} \mathrm{y} \mathrm{Cu}^{2+}$ sobre OMR.

\begin{tabular}{ccccccc}
\hline & \multicolumn{3}{c}{ Langmuir } & \multicolumn{3}{c}{ Freundlich } \\
\cline { 2 - 7 } Metal & $\mathbf{Q}^{\mathbf{0}}$ & $\mathbf{b}$ & $\mathbf{R}^{\mathbf{2}}$ & $\mathbf{K}_{\boldsymbol{f}}$ & $\boldsymbol{n}$ & $\mathbf{R}^{\mathbf{2}}$ \\
\hline $\mathrm{Pb}$ & 735 & $1,1 \times 10^{-3}$ & 0,799 & 1,19 & 1,12 & 0,950 \\
$\mathrm{Cu}$ & 16 & 0,039 & 0,976 & 4,14 & 4,30 & 0,832 \\
\hline
\end{tabular}

Los resultados de las isotermas muestran que los óxidos de manganeso recuperados de pilas agotadas podrían ser usados como materiales adsorbentes prometedores para la eliminación de metales pesados de efluentes acuosos.

\section{A.3 Uso de ZnO recuperados como catalizadores en la glicólisis de PET}

El Polietilentereftalato (PET) es un polímero termoplástico lineal, pertenece a la familia de los poliésteres y por su naturaleza semicristalina se hace apto para la fabricación de fibras, películas, botellas y entre otros. ${ }^{19}$ Debido a la creciente tendencia del empleo tanto en botellas y envases, el reciclado de este tipo de plástico se ha convertido en un tema de gran importancia, sumado a que su materia prima es un recurso no renovable y no son

\footnotetext{
${ }^{17}$ W. Zou, R. Han, Z. Chen, Z. Jinghua, J. Shi, Colloids and Surfaces A: Physicochemical and Engineering Aspects 279 (2006) 238-246.

${ }^{18}$ Z. Aksu. Process Biochemistry 38 (2002) 89-99.

${ }^{19}$ N. Singh, D. Hui, R. Singh, I. P. S. Ahuja, L. Feo, F. Fraternali, Composites Part B: Engineering. 115 (2017) 409-422.
} 
biodegradables. Existen distintos procesos de despolimerización química del PET: la degradación hidrolítica en condiciones ácidas o básicas ${ }^{20}$, la metanólisis, donde reacciona con metanol líquido o gaseoso para dar dimetiltereftalato $(\mathrm{DMT})^{21}$ y la glicólisis, que involucra la inserción de un diol, como etilenglicol (EG), mediante reacciones de transesterificación entre el diol y los grupos éster del PET para producir oligómeros y/o monómeros. Uno de los productos principales es el monómero bis-(2-hidroxietil) tereftalato (BHET) que puede ser fácilmente utilizado en la producción de PET virgen, mientras que los oligómeros pueden emplearse como bloques de construcción en la síntesis de otros polímeros de alto valor económico, como espumas de poliuretano, copoliesteres, entre otros. ${ }^{22}$ La glicólisis se lleva a cabo en un rango de temperatura comprendido entre 180-240 ${ }^{\circ} \mathrm{C}$ y en presencia de un exceso del glicol. ${ }^{23}$ Diferentes autores ${ }^{24,25}$ han reportado uso de acetatos de metales como zinc, manganeso, cobalto como catalizadores para la glicólisis obteniendo conversiones de hasta el $98 \%$ con rendimientos al BHET cercanos al $80 \%$. La presencia del metal en el catalizador es de suma importancia ya que es el responsable de activar al grupo carbonilo del éster de la cadena de PET para que se lleve a cabo la despolimerización. ${ }^{25}$

En función de los Principios de la Química Verde, se propone como objetivo de este trabajo estudio del uso de los óxidos provenientes de las pilas como catalizadores en la glicólisis de PET.

\footnotetext{
${ }^{20}$ G. Karayannidis, A. Nikolaidis, D. Achilias, Macromolecular Materials and Engineering 291 (2006) 13381347.

${ }^{21}$ N. Ikladious. Journal of Elastomers and Plastics 32(2000) 140-151.

${ }^{22}$ U. R. Vaidya, V. M. Nadkarni. Journal of Applied Polymer Science 38 (1989) 1179-1190.

${ }^{23}$ M. Y. Abdelaal, T. R. Sobahi, M. S. I. Makki. Construction and Building Materials 25 (2011) 3267-3271.

${ }^{24}$ M. Imran, D. Kim, W. A. Al-Masry, S. Haider, S. M. Ramay. Polymimer Degradation and Stability 98 (2013) 904-915.

${ }^{25}$ L. Bartolome, M. Imran, B. G. Cho, D. H. Kim, Material Recycling Trends and Perspectives- Recent Developments in the Chemical Recycling of PET (2012) 65-84.
} 


\section{Procedimiento experimental}

La reacción de glicolisis de PET con etilenglicol (Sigma Aldrich; denominado EG) se llevó a cabo en un reactor de vidrio de tres bocas operando a reflujo bajo presión atmosférica y temperatura controlada de $196^{\circ} \mathrm{C}$ y velocidad de agitación de 200-350 rpm. En todas las reacciones se utilizaron $2 \mathrm{~g}$ de PET y relaciones PET/CATALIZADOR y PET/EG de 100:1 y 1:8, respectivamente. Se definió a la producción de BHET de acuerdo a la masa de BHET producido respecto de la masa de PET empleada:

$$
\% B H E T=\frac{m o P E T-m f P E T}{m o P E T}=\frac{m B H E T}{m o P E T} \frac{P M P E T}{P M B H E T}
$$

Dónde: mo PET es la masa de PET empleada para la reacción (2 g); mfPET es la masa de PET al final de la reacción ( no determinada experimentalmente); mBHET es la masa de BHET producida; PMPET y PMBHET son, respectivamente, pesos moleculares de PET ( su unidad repetitiva $\left.192 \mathrm{~g} \mathrm{~mol}^{-1}\right)$ y BHET $\left(254 \mathrm{~g} \mathrm{~mol}^{-1}\right)$

Finalizado el tiempo de reacción se dejó enfriar el reactor hasta temperatura ambiente y se agregaron $60 \mathrm{ml}$ de agua destilada hirviendo manteniendo la temperatura a $90{ }^{\circ} \mathrm{C}$ y agitación durante 60 min para disolver el monómero en la fase acuosa. A continuación, se agregaron $40 \mathrm{ml}$ de agua destilada hirviendo y para la extracción del monómero se realizaron 2 filtraciones sucesivas en caliente (Munkutell, filtro de microfibra de vidrio MG-C $1.2 \mu \mathrm{m}$ y $0,7 \mu \mathrm{m})$. El filtrado final que contiene producto, EG y catalizador, fue almacenado a $4{ }^{\circ} \mathrm{C}$ en la heladera durante 16 hs con el objetivo de cristalizar el monómero. Después de filtrarlo, el mismo fue lavado con agua destilada fría y secado a $60^{\circ} \mathrm{C}$ hasta 
alcanzar un peso constante. El monómero purificado fue caracterizado por FTIR, SEMEDS y RMN de $1 \mathrm{H}$ y $13 \mathrm{C}$.

\section{Resultados}

Los resultados de la producción de BHET se observan en la Figura A.6. Se observa que los sólidos reciclados poseen la mayor producción del monómero. Los resultados indican que la estructura morfológica del PET, fibra o botella, tiene un efecto en la disponibilidad de los grupos carbonilos del polímero para interaccionar con los cationes metálicos del catalizador. Además, se concluye que una mejor actividad catalítica estaría relacionada con una menor $\mathrm{E}_{g a p}$ de los sólidos recuperados, lo cual está asociado a la presencia de vacancias de oxígeno.

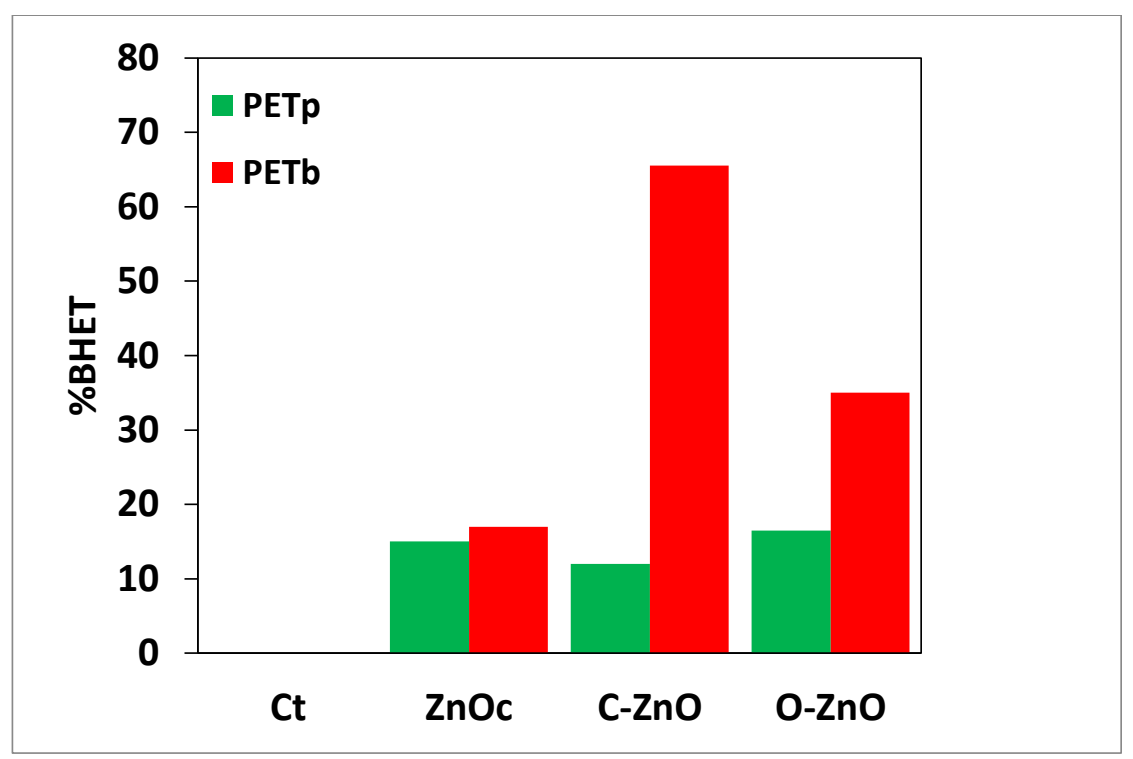

Figura A.6. Producción de BHET sobre los sólidos recuperados. 
En la Figura A.7 se observan los espectros de IR de los monómeros purificados para cada PET. En general, se detectan la presencia de bandas similares en ambos tipos de plásticos, correspondientes a la banda del grupo $-\mathrm{OH}$ a $3450 \mathrm{~cm}^{-1}$ y $1135 \mathrm{~cm}^{-1} \mathrm{C}-\mathrm{O}$ del éster, estiramiento $\mathrm{C}=\mathrm{O}$ a $1715 \mathrm{~cm}^{-1}, \mathrm{C}-\mathrm{H}$ alquílico a $2879 \mathrm{~cm}^{-1}$ y $2954 \mathrm{~cm}^{-1}$ y $\mathrm{C}-\mathrm{H}$ aromáticos a 1411-1504 $\mathrm{cm}^{-1}$. Estos resultados indican la presencia del grupo éster y el anillo aromático en la estructura del producto.

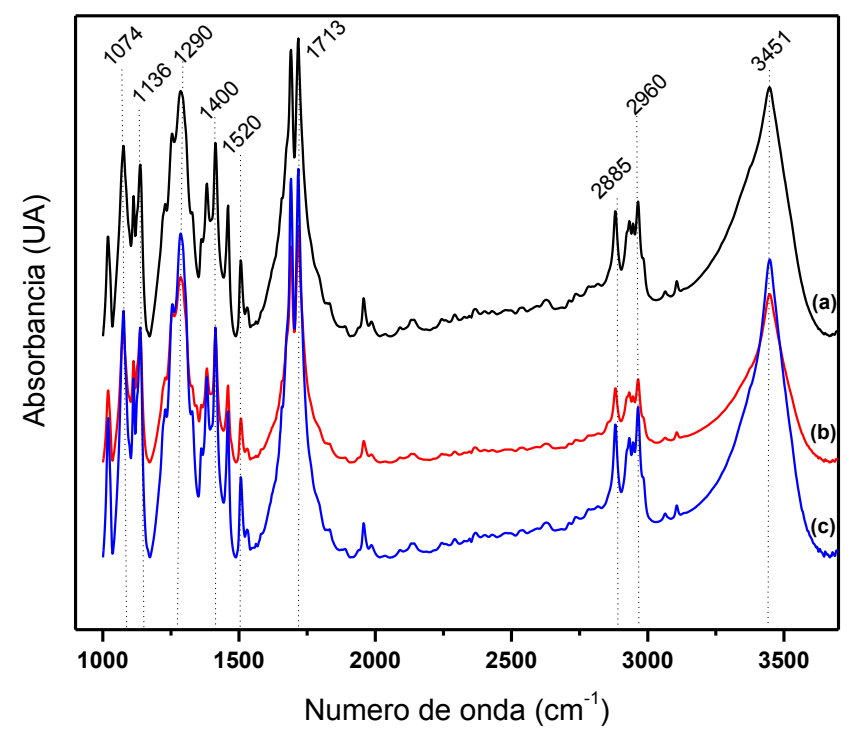

Figura A.7. FITR de los monómeros producto de la glicólisis de PETp con: (a) OZnO, (b) $\mathrm{ZnOc}$ y (c) $\mathrm{CZnO}$.

\section{A.4 Estudio de la actividad fotocatalítica de $\mathrm{ZnO}$ recuperados. Degradación de azul de metileno (AM)}

La fotocatálisis usando metales semiconductores ha surgido como una ruta atractiva hacia la mitigación de la contaminación del medio ambiente debido a su alta eficacia para degradar una amplia gama de compuestos orgánicos, inorgánicos, medicamentos y 
contaminantes microbianos. El $\mathrm{TiO}_{2}$ es el fotocatalizador más utilizado usando radiación UV, sin embargo este oxido presenta una baja actividad cuando se lo irradia con luz visible, por esta razón se busca reemplazarlo por algún solido que presente alta eficiencia en esta zona del espectro. Como se mencionó en el Capítulo 3, las propiedades del $\mathrm{ZnO}$ lo convierten en un material prometedor en la fotocatálisis, debido a sus propiedades ópticas y electrónicas. Debido a la necesidad de una mayor eficiencia fotocatalítica se dopan los cristales de $\mathrm{ZnO}$ con nitrógeno, manganeso, vanadio, etc. El área y los defectos superficiales juegan un papel importante en la actividad fotocatalitica, por esta razón se busca modificar los sólidos. ${ }^{26}$

\section{Procedimiento experimental}

El objetivo de este ensayo fue probar la actividad fotocatalítica los óxidos de zinc recuperados de pilas alcalinas agotadas. Como contaminante modelo se usó azul de metileno. La actividad fotocatalítica fue comparada con la de un $\mathrm{TiO}_{2}$, ya que este es el fotocatalizador por excelencia.

Para evaluar la actividad fotocatalítica, se irradiaron soluciones de azul de metileno, AM, (5 ppm, $200 \mathrm{~mL}$ ) con radiación de $\lambda=350 \mathrm{~nm}$ (Rayonet con 8 lámparas RPR- 3500). Se determinó la concentración remanente de AM mediante espectroscopía UV-Vis $\left(\lambda_{\text {máx }}=\right.$ $665 \mathrm{~nm}$ ). En todos los casos se utilizó una concentración de $100 \mathrm{mg} \mathrm{L}^{-1}$ de fotocatalizador. Se realizaron además dos ensayos control: (1) en oscuridad; y (2) fotólisis directa del colorante (en ausencia del catalizador.

\footnotetext{
${ }^{26}$ K. Rekha, M. Nirmala, M. Nair, A. Anukalianin. Physica B 405 (2010) 3180-3185
} 


\section{Resultados}

Las curvas de degradación de azul de metileno en función del tiempo sobre los óxidos de zinc recuperados se muestran en la Figura A.8 (A). En ausencia de fotocatalizador, AM presenta una pobre degradación, lo que refleja la alta estabilidad de AM bajo irradiación UV. En presencia de $\mathrm{OZnO}$, se observó aproximadamente un 70\% de degradación de AM a los 90 minutos, mientras que en el caso de $\mathrm{CZnO}$, al mismo tiempo, se observó una degradación del $50 \%$ de MB.

Además, también se investigó la cinética de degradación de la solución de AM, y los resultados se muestran en la Figura A.8 (B). Las tasas de degradación de la solución de AM se corresponden bien con la reacción de pseudo primer orden según el modelo simplificado de Langmuir-Hinshelwood:

$$
\ln \left(C / C_{0}\right)=-k t
$$

donde k es la constante de velocidad de reacción $\left(\mathrm{min}^{-1}\right)$ y $C_{0}$ y $C$ son la concentración inicial y real de $\mathrm{AM}$ en el tiempo $t$, respectivamente. $\mathrm{OZnO}$ muestra la actividad fotocatalítica más alta con una constante de velocidad de $0.0061 \mathrm{~min}^{-1}$, siendo mayor que la de $\mathrm{CZnO}\left(0.0036 \mathrm{~min}^{-1}\right)$. 


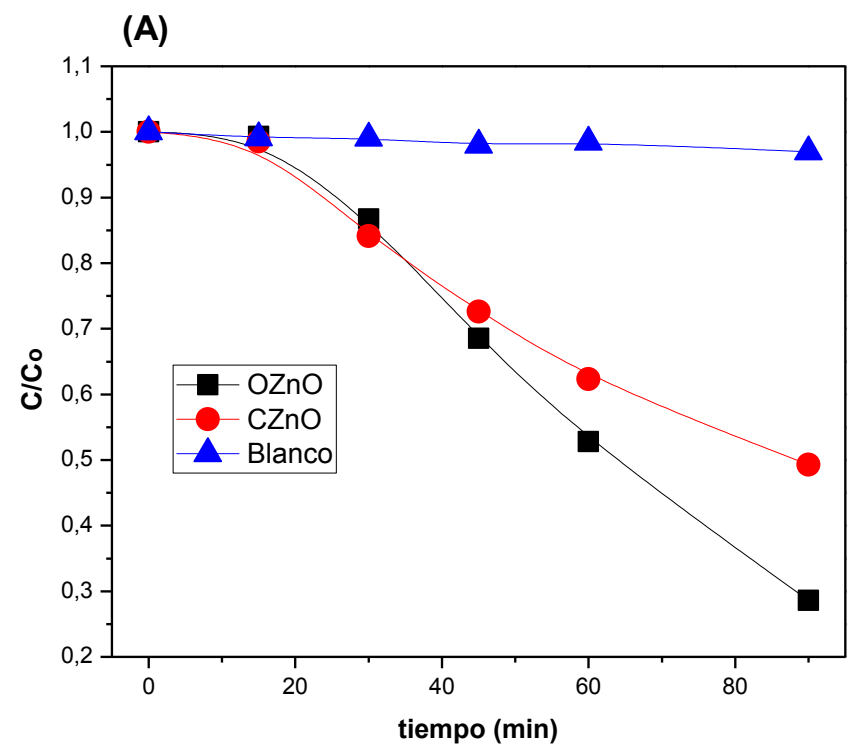

(B)

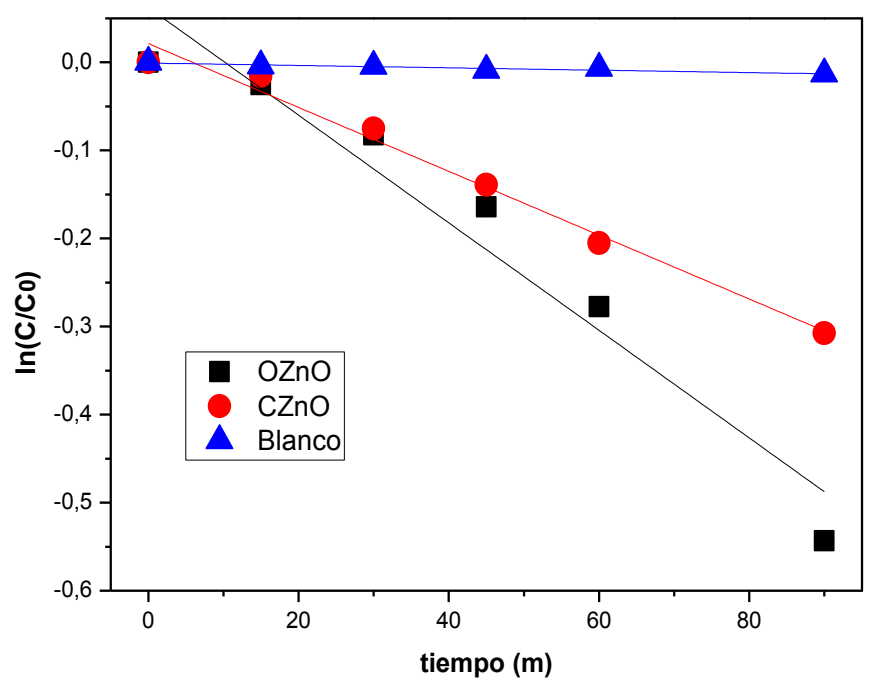

Figura A.8. (A) Degradación de AM y (B) cinética de degradación de AM en función del tiempo sobre los óxidos de zinc recuperados. 
El estudio de Rekha y col. ${ }^{27}$ sobre la actividad fotocatalítica de $\mathrm{ZnO}$ y $\mathrm{ZnO}$ dopado con diferentes cantidades de manganeso han demostrado que la capacidad fotocatalítica disminuye cuando el valor de $\mathrm{E}_{\text {gap }}$ es menor. Los resultados obtenidos con los óxidos de zinc recuperados de pilas en este trabajo en la reacción de degradación de AM coinciden con lo reportado por Rekha y col. ${ }^{26}$ Los óxidos de zinc recuperados (OZnO y CZnO) presentan valores de $\mathrm{E}_{\text {gap }}$ menores que el $\mathrm{ZnOc}$, el cual fue usado como referencia. Este último sólido a los 30 min de reacción presentó una conversión del 70\%, mientras que los sólidos $\mathrm{OZnO}$ y $\mathrm{CZnO}$ alcanzan ese valor de conversión a los $100 \mathrm{~min}$.

Por otro lado, la diferencia de actividad en la degradación de $\mathrm{MB}$ sobre $\mathrm{OZnO}$ y $\mathrm{CZnO}$ podría relacionarse con la variación en la relación $\mathrm{Cdb} / \mathrm{Cds}$, la cual se estudió mediante espectroscopía de aniquilación de positrones (PALS), tal como se muestra en el Capítulo 5, sección 2.

Se acepta que la actividad fotocatalítica aumenta cuando mayor la es separación electrón-huecos $(e-h)$. Diferentes autores han informado que disminución en la relación $\mathrm{Cdb} / \mathrm{Cds}$ conduce a un aumento en la eficiencia de separación $e-h .^{28,29}$ En coincidencia con esto, el sólido $\mathrm{OZnO}$ presenta un valor menor de $\mathrm{Cdb} / \mathrm{Cds}$ en comparación con $\mathrm{CZnO}$, indicando una mayor concentración de defectos superficiales. La consecuencia de esta diferencia en la cantidad de defectos se traduce en un aumento en la actividad foto catalítica en el sólido $\mathrm{OZnO}$, frente al $\mathrm{CZnO}$.

${ }^{27}$ K. Rekha, M. Nirmala, M. Nair, A. Anukalianin. Physica B: Physics of Condensed Matter 405 (2010) 3180-3185.

${ }^{28}$ M. Kong, Y. Li, X. Chen, T. Tian, P. Fang, F. Zheng, X. Zhao, Journal of the American Chemical Society 133 (2011) 16414-16417

${ }^{29}$ Y. Zheng, C. Chen, Y. Zhan, X. Lin, Q. Zheng, K. Wei, J. Zhu, Y. Zhu, Inorganic Chemistry 46 (2007) 6675-6682. 


\section{A.5 CONCLUSIONES ANEXO}

Los resultados de las experiencias realizadas señalan que los óxidos obtenidos de pilas agotadas podrían ser utilizados en diversas aplicaciones tecnológicas.

Tal como se observa en el caso de las reacciones multicomponentes y de despolimerización de PET, los sólidos podrían usarse sin mayores modificaciones. En el caso de la degradación fotocatalítica de $\mathrm{MB}$ en $\mathrm{ZnOc}$ presenta mayor conversión que los óxidos recuperados $(\mathrm{OZnO}$ y $\mathrm{CZnO})$, por esta razón se presenta el desafío de modificar las propiedades ópticas de los mismos. 


\section{CONCLUSIONES GENERALES}


Las baterías alcalinas y de $\mathrm{Zn} / \mathrm{C}$ agotadas son dañinas como residuo para el medio ambiente, razón por la cual su reciclaje tiene dos ventajas comparativas. La primera de ella, es disminuir el impacto ambiental y la segunda ser una potencial fuente de materias primas para el desarrollo de nuevos materiales con el consiguiente beneficio económico.

Con esta premisa, en este Trabajo de Tesis Doctoral se ha optimizado una ruta biohidrometalúrgica para separar el zinc y el manganeso de las pilas alcalinas y $\mathrm{Zn} / \mathrm{C}$ agotadas y por otro lado, se analizaron posibles aplicaciones tecnológicas de los sólidos recuperados.

En un trabajo doctoral previo se evaluó el uso de ácido sulfúrico biogenerado como lixiviante de los residuos de pilas. Como se mencionó más arriba en este trabajo de Tesis se analizaron diferentes variables operativas tales como temperatura, adición de agentes reductores, relación sólido/líquido $(S / L)$ para mejorar el rendimiento de la lixiviación.

Las conclusiones a las que se han arribado en este sentido fueron:

- El rendimiento de la lixiviación de zinc y manganeso se mejora, alcanzando valores cercanos al $100 \%$ en una sola etapa, con el uso del ácido sulfúrico biogenerado con una relación $S / L$ de $0,04 \mathrm{~g} \mathrm{~mL}^{-1}$, en un tiempo de 120 minutos, a $30^{\circ} \mathrm{C}$ y el agregado de $\mathrm{H}_{2} \mathrm{O}_{2}$ ó $\mathrm{Na}_{2} \mathrm{SO}_{3}$ como agentes reductores en una concentración de $5 \% \mathrm{v} / \mathrm{v}$ ó del $1 \%$ p/v, respectivamente. En función de estos resultados se propone que el agente reductor sea $\mathrm{H}_{2} \mathrm{O}_{2}$ dado que su producto de reacción es $\mathrm{H}_{2} \mathrm{O}$ la cual es desde la Química Verde considerada inocua al medio ambiente.

Posterior a la lixiviación cationes zinc y manganeso en solución, se prepararon dos sólidos por precipitación utilizando como agentes $\mathrm{KMnO}_{4} \mathrm{e} \mathrm{NaOH}$. 
- El rendimiento de recuperación alcanzó un $95 \%$ para el Zn y un $75 \%$ en el caso de Mn. Se obtuvieron dos sólidos uno llamado OMR y otro denominado ZnMnR. El primero se obtuvo por la reacción redox entre $\mathrm{Mn}^{2+}$ y $\mathrm{KMnO}_{4}$ obteniéndose un sólido cuya fase se corresponde principalmente con la fase Holandita $\left(\alpha \mathrm{MnO}_{2}\right)$. En el caso de la muestra ZnMnR, obtenida por el agregado de $\mathrm{NaOH}$ a la solución, se separó un sólido formado por $\mathrm{ZnO}, \mathrm{ZnMn}_{2} \mathrm{O}_{4}$ y $\mathrm{MnO}_{\mathrm{x}}$.

A partir del sólido OMR se prepararon dos catalizadores, OMRA y OMRB, los cuales se obtuvieron a partir de la impregnación con una solución de $\mathrm{Zn}^{2+}$ procedente de la lixiviación de pilas alcalinas. Se usaron dos métodos diferentes de impregnación; a humedad incipiente y con exceso de solución.

- En el sólido OMRA se detectó la fase $\alpha \mathrm{MnO}_{2}$ con cambios en la intensidad y amplitud de los picos debido a la incorporación de iones $\mathrm{Zn}$ en los canales del óxido. En el otro óxido (OMRB) se observó la formación de $\mathrm{\alpha MnO}_{2}$ y picos correspondientes a $\mathrm{ZnO}$ con estructura del tipo wurzita.

- La relación Mn/Zn analizada por Absorción Atómica permitió establecer que la cantidad de $\mathrm{Zn}$ aumenta en el siguiente orden OMR $<$ OMRB $<$ OMRA $<$ ZnMnR. Mientras que el análisis EDS estableció que en los sólidos OMR, OMRB y ZnMnR la relación es similar siendo mucho mayor la concentración de Mn superficial en el sólido OMRA.

Los sólidos preparados fueron caracterizados por diversas técnicas que permiten señalar que:

- El análisis XPS determinó que los iones Mn en la superficie de los sólidos (OMR, OMRA, OMRB y ZnMnR) tiene estados de oxidación 3+ y 4+, resultado que coincide por 
el estudio XANES en las muestras OMR y ZnMnR. Sin embargo, el análisis XANES en las muestras OMR y OMRA permitió calcular un estado de oxidación promedio $2+$ y 3+, siendo esta diferencia atribuida a la técnica de análisis. Del análisis del borde $\mathrm{K}$ del Zn en estos óxidos, se observan diferencias en la posición y la intensidad de los picos atribuido a que el Zn ocupa sitios octaédricos o tetraédricos.

- El estudio por Reducción Térmica Programada permitió determinar que la temperatura inicial de comienzo del proceso reducción está asociada a la relación $\mathrm{Mn} / \mathrm{Zn}$ en las muestras

La actividad catalítica de estos sólidos en la oxidación de etanol y tolueno fue estudiada en un reactor de flujo convencional analizándose la conversión y selectividad por CG y por medio de FTIR en flujo estanco se evaluó la formación de especies superficiales y gaseosas durante la oxidación.

- El sólido OMR fue el que presentó la mejor perfomance con un resultado similar a un oxido de manganeso sintetizado a partir de la sal de nitrato. Estos resultados permiten decir que, teniendo en cuenta que se trata de óxidos recuperados de pilas agotadas, pueden ser usados como catalizadores en la destrucción de COVs. En los sólidos OMRA, OMRB y ZnMnR el comportamiento observado está relacionado con la cantidad de zinc presente, siendo la actividad menor cuando este valor aumenta.

- Cuando se comparan los sólidos OMRA y OMRB los resultados observados están relacionados con las diferencias en el método de impregnación, siendo menor la actividad en el sólido OMRB. Este último fue impregnado con exceso de una solución ácida de iones 
$\mathrm{Zn}^{2+}$, esto podría provocar la lixiviación del manganeso presente en el sólido de partida (OMR).

- Las experiencias por FTIR "in situ” permiten concluir que:

$\checkmark$ En todos los sólidos el etanol se adsorbe en forma de etóxido, observándose que estas especies se oxidan a $\mathrm{CO}_{2}$ a altas temperaturas. Asimismo en la superficie se detectaron especies carboxilato (acetatos) que podrían comportarse como intermediarios de reacción. A temperaturas intermedias los grupos etóxidos conducen a la formación de acetaldehído, el cual es detectado en fase gaseosa. También en la atmósfera de reacción se detectó CO. $\checkmark$ Cuando se estudió la oxidación de tolueno, como producto de reacción se detectaron $\mathrm{CO}_{2}$ y $\mathrm{CO}$ en fase gaseosa. El estudio del mecanismo de reacción superficial permite proponer que la oxidación del tolueno se produce en primer lugar por la interacción con la superficie de la molécula por el grupo metilo, seguido de la formación de un grupo benzoato y finalmente la oxidación a $\mathrm{CO}_{2}$.

Por otro lado, con el objetivo de obtener $\mathrm{ZnO}$, se separaron en cátodo y ánodo de las pilas alcalinas, el cual se trató con ácido sulfúrico biogenerado. A partir de esta solución se sintetizaron diferentes $\mathrm{ZnO}$ usando la técnica de precipitación. Como agentes precipitantes se usaron $\mathrm{Na}_{2} \mathrm{CO}_{3}$ y $\mathrm{H}_{2} \mathrm{C}_{2} \mathrm{O}_{4}$, denominándose a los sólidos $\mathrm{CZnO}$ y OZnO.

El estudio de la caracterización permitió determinar que:

- La fase cristalina presente en ambas muestras es la wurtzita, encontrándose diferencias en la intensidad y ancho de pico. Dichas diferencias están relacionadas con defectos y dislocaciones presentes en las estructuras. El estudio por el método de Rietveld permitió 
determinar que hay una contracción en el parámetro c de la celda asociada a un aumento de vacancias de oxígeno.

- Los resultados de las diferentes técnicas de caracterización sugieren que los agentes precipitantes así como el contraion $\left(\mathrm{SO}_{4}{ }^{2-}\right)$ presente conducen a la formación de partículas con distintas morfologías.

- Los valores de $\mathrm{E}_{\text {gap }}$, calculados a partir del método de Taucc, muestran diferencias en los sólidos. Se observa que los sólidos $\mathrm{OZnO}$ y $\mathrm{CZnO}$ tienen menores valores que el $\mathrm{ZnO}$ comercial el cual fue usado como patrón, lo cual indica un aumento en la cantidad de vacancias en los sólidos recuperados.

- De la espectroscopía de aniquilación de positrones (PALS) se observan diferencias en los valores de vidas medias promedio. El mayor valor de intensidad $\left(I_{1}\right)$ en el sólido $\mathrm{CZnO}$ indica que posee un mayor número de vacancias de oxígeno, mientras que el $\mathrm{OZnO}$ con un $\mathrm{I}_{2}$ mayor y una mayor $\mathrm{S}_{\mathrm{BET}}$ indican mayor tamaño de defectos.

Por su parte los estudios teóricos corroboran los resultados experimentales, demostrando que:

- En el sistema $\mathrm{ZnO}$ se observa que se generan vacancias de oxígeno en la red que dan lugar a una disminución en el valor de $\mathrm{E}_{g a p}$.

- El estudio teórico del sistema ZnMn donde se reemplazó Mn por Zn en la red, muestran que ocurre un aumento en las distancias Mn-O, lo que genera una mayor labilidad de los oxígenos de red. Este resultado está de acuerdo con los datos del análisis RTP donde se determinó que el aumento de $\mathrm{Zn}$ produce la reducción del sólido a menores temperaturas. 
- La distancia teórica Zn-O, en estos óxidos ZnMn es aproximadamente 2,02 Å. Este valor calculado es similar al obtenido del análisis EXAFS, lo que permite confirmar que los iones $\mathrm{Zn}^{2+}$ presentes en el sólido se encuentran coordinados octaédricamente.

- Finalmente, se observa que el nivel de Fermi, al reemplazar Mn por Zn en la estructura, se encuentra dentro de zona de la banda de valencia (BV). Este resultado permite determinar que la presencia de iones $\mathrm{Zn}^{2+}$ dentro de la estructura cristalina (OMR) en posición octaédrica favorece la actividad catalítica en concordancia con los postulados de Volkstein y la Teoría Electrónica de la Catálisis.

En la última parte de esta Tesis se analizaron otros posibles usos tecnológicos de los sólidos preparados como catalizadores en reacciones multicomponentes, la despolimerización de PET, como fotocatalizador en la destrucción de un colorante en agua y como adsorbente de metales pesados en agua. Los resultados permiten concluir que,

- Los sólidos $\mathrm{CZnO}$ y OZnO, tanto para la reacción de despolimerización de PET como en la degradación fotocatalítica de azul de metileno son activos catalizadores, con interesantes resultados.

- El estudio de los sólidos OMR y ZnMnR como catalizadores multicomponentes en ausencia de solvente, en la llamada Reacción de Hantzsch, muestra diferencias en los resultados asociados con la cantidad de zinc presente. El aumento de la cantidad de zinc, aumenta la fuerza básica y esto conduce a una mejora en la conversión a baja temperatura de uno de los productos $(\mathrm{T})$. 
- Como adsorbente de $\mathrm{Pb}^{2+}$ y $\mathrm{Cu}^{2+}$ se evaluó el sólido OMR obteniéndose valores de adsorción mayores para $\mathrm{Pb}^{2+}$, lo cual estaría asociado a suponer que la adsorción se relaciona con las cargas superficiales presentes en el sólido.

Como conclusión final de este trabajo de Tesis Doctoral puede decirse que la recuperación de metales provenientes de pilas agotadas en forma de óxidos puede ser una alternativa en diferentes procesos tecnológicos como catálisis, fotocatálisis, adsorción y fabricación de celdas solares, reduciéndose así el impacto ambiental y obteniendo un beneficio económico importante ya que se usan residuos como materia prima de nuevos materiales con un importante valor agregado, cumpliendo así los Principios de la Química Verde en cuanto a la reducción y reutilización de residuos cerrando así el ciclo de vida de la cuna a la tumba. 
Se plantea continuar con producir $\mathrm{ZnO}$ provenientes de otras cadenas de residuos, tanto puros como dopados, y analizar sus propiedades. En particular se propone;

$\checkmark$ Utilizar los metales recuperados de residuos industriales, pilas y baterías ión-Li a fin de obtener óxidos de Zinc que serán dopados con Manganeso y Cobalto mediante la utilización de la molienda mecánica.

$\checkmark$ Analizar las propiedades estructurales, ópticas y de transporte de los óxidos obtenidos.

$\checkmark$ Preparar nanoestructuras (nanohilos, nanoláminas, etc) por deposición por transporte de vapor (DTV) con la intención de utilizar los sistemas obtenidos para la fabricación de dispositivos optoeletrónicos, en particular celdas solares. 
De este trabajo de Tesis Doctoral se han publicado los siguientes trabajos:

\section{REVISTAS}

\section{PUBLICADOS}

Recovery of manganese oxides from spent alkaline and zinc-carbon batteries. An application as catalysts for VOCs elimination.

María V. Gallegos, Lorena R. Falco, Miguel A. Peluso, Jorge E. Sambeth, Horacio J.

Thomas. Waste Management 33 (2013) 1483-1490.

Structural and optical properties of $\mathrm{ZnO}$ and manganese-doped $\mathrm{ZnO}$

María V. Gallegos, Miguel A. Peluso, Horacio Thomas, Laura C. Damonte, Jorge E. Sambeth. Journal of Alloys and Compounds 689 (2016) 416- 424.

Removal of VOCs by catalytic process. A study of $\mathrm{MnZnO}$ composites synthesized from waste alkaline and $\mathrm{Zn} / \mathrm{C}$ batteries.

María V. Gallegos, Miguel A. Peluso, Elisabetta Finocchio, Horacio J. Thomas, Guido Busca, Jorge E. Sambeth. Chemical Engineering Journal 313 (2017) 1099-1111.

Structural, optical and photocatalytic properties of zinc oxides obtained from spent alkaline batteries.

María V. Gallegos, Francisca Aparicio, Miguel A. Peluso, Laura C. Damonte, Jorge E. Sambeth. Materials Research Bulletin https://doi.org/10.1016/j.materresbull.2018.03.022 


\section{ENVIADOS}

Eco-friendly recycling of $\mathrm{Mn}$ and $\mathrm{Zn}$ oxides from spent alkaline and $\mathrm{Zn} / \mathrm{C}$ batteries and their use in multicomponent organic reaction.

María V. Gallegos, Miguel A. Peluso, Gabriel Sathicq, Horacio Thomas, Jorge E.

Sambeth. Enviado Noviembre 2017 a Journal of Cleaner Production.

\section{CONGRESOS}

María V. Gallegos, Miguel A. Peluso, Jorge E. Sambeth, Horacio Thomas.

"Comparación de $\mathrm{MnOx}$ soportados sobre reactores estructurados para la combustión de compuestos orgánicos volátiles". Córdoba, Argentina. XX CAC 2017. Congreso Argentino de Catálisis.

Cynthia Fuentes, María Victoria Gallegoos, Darío Moyano, Andrés Peluso, Susana Cortizo y Jorge Sambeth.

"Glicólisis de PET usando como catalizadores sólidos recuperados de pilas" ". Córdoba, Argentina. XX CAC 2017. Congreso Argentino de Catálisis.

María V. Gallegos, Miguel A. Peluso, Elisabetta Finocchio, Horacio Thomas, Guido Busca, Jorge E. Sambeth.

"Estudio por FTIR de la adsorción y reacción de Cloroformo sobre Óxidos de Mn-Zn". Córdoba, Argentina. XX CAC 2017. Congreso Argentino de Catálisis. 
María V. Gallegos, Francisca Aparicio, Luciano Carlos, Daniel Martire, Andrés Peluso, Horacio Thomas, Jorge Sambeth.

"Estudio de la actividad fotocatalítica de $\mathrm{ZnO}$ recuperados de pilas agotadas"

Argentina. Córdoba. 2016. Libro. Resumen. Congreso Internacional de Metalurgia y Materiales 16o SAM-CONAMET.

María V. Gallegos, Andrés Peluso, Horacio Thomas, Jorge Sambeth, Laura Damonte "Estudio de las propiedades optoelectrónicas de $\mathrm{ZnO}$ recuperados de pilas alcalinas agotadas" Argentina. Córdoba. 2016. Libro. Resumen. Congreso. Congreso Internacional de Metalurgia y Materiales $16^{\circ}$ SAM-CONAMET.

"Estudio por FTIR de la oxidación de etanol y tolueno sobre óxidos de $\mathrm{ZnMnO}$ recuperados de pilas alcalinas" M.V. Gallegos, M.A. Peluso, E. Finocchio, G. Busca, H. Thomas, J. Sambeth. XIX Congreso Argentino de Catálisis VIII Congreso de Catálisis del Mercosur, Bahía Blanca, Argentina, 2015.

"Metal recovery from spent Li-ion and alkaline and Zn/C batteries" C.G. Marcoccia, M.V.Gallegos, M.A. Peluso, J. Sambeth, H. Thomas. 6th International Conference on Science and Technology of Composite Materiasl (COMAT 2015), Argentina, 2015.

C.G. Marcoccia, M.V. Gallegos, M.A. Peluso, J. Sambeth, H. Thomas. "Synthesis of oxides from spent alkaline and Li-ion batteries. Application as catalyst for VOC oxidation" XII Europacat, Rusia, 2015. 
Carla Marcoccia, María V. Gallegos, Andrés Peluso, Jorge Sambeth, Horacio Thomas

"Metal recovery from spent Li-ion and alkaline and $\mathrm{Zn} / \mathrm{C}$ batteries".

Argentina. Buenos Aires. 2015. Libro. Artículo Completo. Congreso. 6th International Conference on Science and Technology of Composite Materials (COMAT 2015). COMAT.

María V. Gallegos, Andrés Peluso, Luis Gambaro, Jorge Sambeth, Horacio Thomas.

"Desarrollo de catalizadores a partir de metales recuperados de pilas. Relación entre la técnica de recuperación y la actividad catalítica". Colombia. Medellín. 2014. Libro. Artículo Completo. Congreso. XXIV Congreso Iberoamericano de Catálisis.

Carla Marcoccia, María V. Gallegos, Andrés Peluso, Jorge Sambeth, Horacio Thomas. "Recuperación de metales a partir de pilas y baterías agotadas". Argentina. Buenos Aires. 2014. Revista. Artículo Breve. Congreso. 30 Congreso Argentino de Quimica.

María V. Gallegos, Andrés Peluso, Jorge Sambeth, Horacio Thomas.

"Recuperación de Zn y Mn de pilas agotadas a través de un proceso hiohidrometalurgico". Argentina. Córdoba. 2014. Libro. Artículo Breve. Congreso. III Reunión Interdisciplinaria de Tecnología y Procesos Químicos. 


\section{Apéndice 1}

\section{A.I Cálculo del tamaño de partícula mediante DRX}

El tamaño de partícula de un cristal, d,se puede estimar aplicando la ecuación de Scherrer:

$$
\mathrm{d}=\mathrm{k} \lambda / \mathrm{b} \cos \theta_{\mathrm{hk}}
$$

$\lambda=$ longitud de onda de la radiación de rayos $\mathrm{X}$ empleada. En este trabajo se empleó la radiación $\mathrm{CuK} \alpha, \lambda=1.540589 \AA$.

$\mathrm{k}=$ constante que depende de cómo se ha medido el ensanchamiento de la línea de difracción. El valor de $\mathrm{k}$ puede variar desde 0,9 hasta 1,2, por lo que se probó con tres valores, $0,9,1,0$ y 1,2 .

$\theta$ = ángulo de Bragg para la línea de difracción elegida.

$\mathrm{b}=$ ensanchamiento del pico debido al tamaño del cristal

$\mathrm{B}=$ ensanchamiento del pico hallado experimentalmente.

$\beta=$ ensanchamiento del pico debido al instrumento. En nuestro caso el valor utilizado fue de $0,1^{\circ}$.

El ensanchamiento de pico hallado experimentalmente es una contribución debida al tamaño de partícula y al ensanchamiento producido debido al instrumento de medida. 


$$
\mathrm{B}^{2}=\beta^{2}+\mathrm{b}^{2}
$$

Por lo tanto, el ensanchamiento debido solo al tamaño de la partícula se obtiene despejando la ecuación anterior:

$$
\begin{gathered}
b^{2}=B^{2}-\beta^{2} \\
b=\left(B^{2}-\beta^{2}\right)^{0,5}
\end{gathered}
$$




\section{Apéndice 2}

A.II.1 Condiciones de trabajo empleadas en el análisis de $\mathrm{Pb}$ y $\mathrm{Cu}$ por Absorción Atómica

Las condiciones empleadas en el análisis de $\mathrm{Pb}$ y $\mathrm{Cu}$ en solución mediante la técnica de Absorción Atómica se muestran en la Tabla A.II.1.

TABLA A.II.1. Condiciones de trabajo para el análisis por absorción atómica.

\begin{tabular}{|c|c|c|c|c|}
\hline Metal & $\begin{array}{l}\text { Longitud de } \\
\text { onda (nm) }\end{array}$ & $\begin{array}{c}\text { Ancho de } \\
\text { rendija }(\mathrm{mm})\end{array}$ & $\begin{array}{c}\text { Rango óptimo } \\
\text { de trabajo } \\
\left(\mathrm{mg} \mathrm{L}^{-1}\right)\end{array}$ & $\begin{array}{c}\text { Corriente de } \\
\text { la lámpara } \\
(\mathbf{m A})\end{array}$ \\
\hline $\mathrm{Pb}$ & 261,4 & 0,5 & $5-800$ & 5 \\
\hline $\mathrm{Cu}$ & 222,6 & 0,2 & $1-280$ & 4 \\
\hline
\end{tabular}

Curvas de calibración de metales para Absorción Atómica (AA)

Las curvas de calibración de AA para plomo y cobre en las condiciones de trabajo se muestran en la Figura A.II.1, observándose una correlación lineal en el intervalo de concentraciones estudiadas. 

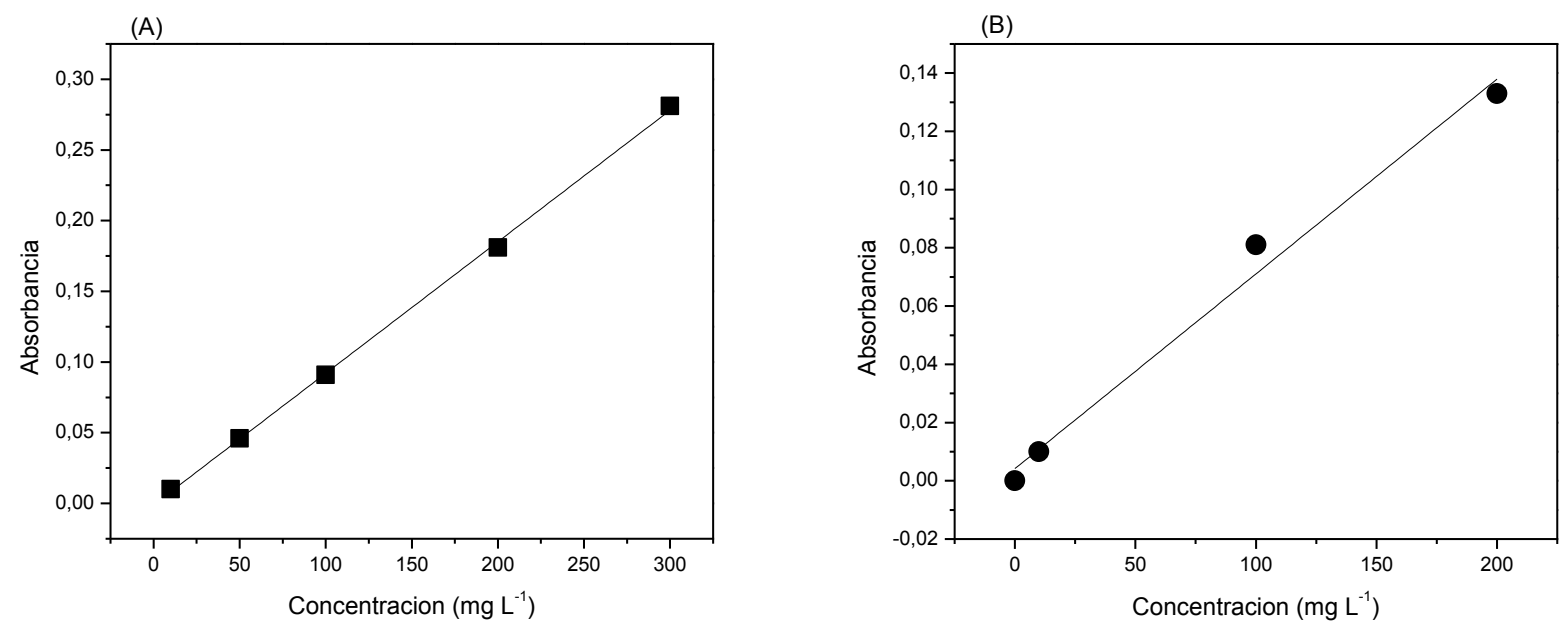

Figura A.II.1. Curva de calibración de: (A) plomo y (B) cobre. 